Paula Fernanda da Silva Farina

\title{
EFEITO DAS ADIÇÕES DE TRATAMENTOS CRIOGÊNICOS E DE ALÍVIO DE TENSÕES NO CICLO TÉRMICO DO AÇO FERRAMENTA AISI D2
}

Tese apresentada à Escola

Politécnica da Universidade de São

Paulo para obtenção do título de Doutor em Engenharia.

São Paulo 
Paula Fernanda da Silva Farina

\section{EFEITO DAS ADIÇÕES DE TRATAMENTOS CRIOGÊNICOS E DE ALÍVIO DE TENSÕES NO CICLO TÉRMICO DO AÇO FERRAMENTA AISI D2}

Tese apresentada à Escola

Politécnica da Universidade de São

Paulo para obtenção do título de Doutor em Engenharia.

Área de concentração:

Engenharia Metalúrgica e de

Materiais

Orientador: Prof. Dr.

Hélio Goldenstein

São Paulo 
Este exemplar foi revisado e alterado em relação à versão original, sob responsabilidade única do autor e com a anuência de seu orientador.

São Paulo, 30 de maio de 2011.

Assinatura do autor

Assinatura do orientador

FICHA CATALOGRÁFICA

Farina, Paula Fernanda da Silva

Efeito das adições de tratamentos criogênicos e de alívio de tensões no ciclo térmico do aço ferramenta AISI D2 / P.F.S.

Farina. -- São Paulo, 2011.

$122 \mathrm{p}$.

Tese (Doutorado) - Escola Politécnica da Universidade de São Paulo. Departamento de Engenharia Metalúrgica e de Materiais.

1. Tratamento térmico 2. Alívio de tensões 3. Carbono 4. Aço ferramenta 5. Baixa temperatura (Tratamento) I. Universidade de São Paulo. Escola Politécnica. Departamento de Engenharia Metalúrgica e de Materiais II. t. 


\section{DEDICATÓRIA}

Ao meu marido Alexandre.

Aos meus pais Elvio (em memória) e Rosa.

Às minhas sobrinhas e sobrinho: Rafaella, Giovanna, Eduarda, Arthur e Flora. 


\section{AGRADECIMENTOS}

Ao meu orientador, e hoje também amigo, Prof. Hélio Goldenstein, pelas valiosas discussões técnicas e, mais valiosas ainda, discussões sobre a vida.

Ao meu marido, companheiro de vida e de trabalho, Alexandre Bellegard Farina (M. Eng.), pela valiosa contribuição técnica ao trabalho e companheirismo inestimável em todos os momentos.

Ao Eng. Celso Antonio Barbosa, gerente de Pesquisa e Desenvolvimento da Villares Metals S.A., pela excelente oportunidade de trabalho em conjunto com o desenvolvimento desta tese.

À minha família: mãe, sogra, irmãs, cunhados, sobrinhas e sobrinho, pela alegre e harmoniosa convivência, fundamentais para o meu bem estar e equilíbrio.

Aos colegas do Laboratório de Transformações de Fases: Arthur, Diego, Edgar, Eduardo, Isaac, Kaio, Mário, Paulo e Viviam pelos momentos de ciência e de descontração vivenciados.

Ao Prof. Michel Perez e ao Prof. Xavier Kleber do Laboratório Mateis (Materiaux: Ingénierie et Science) do INSA-Lyon (Institut National des Sciences Appliquées de Lyon), ao primeiro por ter me recebido e aos dois pelo total apoio na execução dos ensaios de potencial termo-elétrico.

Ao Dr. Rafael Mesquita pelo apoio nas etapas iniciais deste trabalho.

Ao M. Eng. Marcelo Ferreira, do Instituto de Pesquisas Tecnológicas do Estado de São Paulo, pelas análises em MEV-FEG.

Ao Dr. Ramon Valls Martin, do Instituto de Pesquisas Tecnológicas do Estado de São Paulo, pela realização dos ensaios de saturação magnética.

Ao Prof. Linilson do laboratório Ladin - PME - EPUSP, pelo uso do equipamento BarkTech para execução dos ensaios de medida magnética de ruído de Barkhausen.

Ao Prof. Julio Capo, Facultad de Ciencias Naturales, Universidad de Oriente Cuba, pelo total apoio para execução dos ensaios de Barkhausen.

Ao Laboratório Nacional de Luz Síncroton, na pessoa do Dr. Eduardo Granado, pela realização dos ensaios de difração de raios-X na linha D10B-XPD.

Ao Prof. Marcos Flávio de Campos, pelos ensaios de difração de raios-X realizados na Universidade Federal Fluminense. 
À empresa Villares Metals S.A, pelo apoio financeiro para execução deste trabalho.

À Coordenação de Aperfeiçoamento de Pessoal de Nível Superior (CAPES) pela bolsa de doutorado concedida.

Por fim, agradeço a Deus, por ser minha força nos momentos de fraqueza; por me dar perseverança nos momentos de inconstância; e por me fornecer (alguma) sabedoria para a execução deste trabalho. 


\section{SUMÁRIO}

\section{LISTA DE FIGURAS}

LISTA DE TABELAS

LISTA DE SÍMBOLOS

RESUMO

ABSTRACT

1 MOTIVAÇÃO

2 REVISÃO BIBLIOGRÁFICA 2

2.1 Aço Ferramenta para Trabalho a Frio - AISI D2 2

2.2 Tratamento Criogênico 5

2.2.1 Nomenclaturas para o tratamento criogênico 6

2.2.2 Reivindicações da literatura para o aço AISI D2 6

2.2.3 Mecanismos Propostos 7

2.2.3.1 Transformação da austenita retida em martensita $\quad 7$

2.2.3.2 Precipitação de carbonetos eta $(\eta) \quad 8$

2.2.4 Alívio de Tensões 12

$\begin{array}{lll}2.2 .5 & \text { Revenimento } & 13\end{array}$

2.2.6 Resumo do Ciclo Térmico do Aço AISI D2 com TC 18

$\begin{array}{lll}2.3 & \text { Martensita } & 20\end{array}$

2.4 Martensita Isotérmica 22

2.5 Envelhecimento (Condicionamento) da Martensita Virgem 23

2.6 Estabilização da Austenita Retida 26

2.7 Precipitação de Carbonetos Secundários 33

$\begin{array}{lll}3 & \text { OBJETIVOS } & 36\end{array}$

$4 \quad$ MATERIAIS E MÉTODOS

$\begin{array}{lll}4.1 & \text { Material } & 37\end{array}$

4.2 Ciclos Térmicos e Identificação das Amostras 38

$\begin{array}{lll}\text { 4.2.1 Primeira Série de Experimentos } & 38\end{array}$ 
4.2.2 Segunda Série de Experimentos 39

4.2.3 Terceira Série de Experimentos 41

4.3 Caracterização Metalográfica dos Corpos de Prova $\quad 41$

4.4 Difração de Raios-X utilizando Radiação Síncroton 43

4.5 Ensaios de Potencial Termo-Elétrico (TEP) 43

4.5.1 Interpretação dos resultados $\quad 45$

$5 \quad$ RESULTADOS $\quad 47$

5.1 Primeira Série de Experimentos 47

$5.2 \quad$ Segunda Série de Experimentos 53

$\begin{array}{lll}5.3 & \text { Terceira Série de Experimentos } & 67\end{array}$

$6 \quad$ DISCUSSÕES 71

6.1 Primeira Série de Experimentos $\quad 71$

6.2 Segunda Série de Experimentos 71

6.3 Terceira série de experimentos 76

$\begin{array}{lll}\text { 6.3.1 Proposição de mecanismos } & 78\end{array}$

6.4 Discussão Geral 81

$7 \quad$ CONCLUSÕES $\quad 84$

$8 \quad$ TRABALHOS FUTUROS 86

APÊNDICE A - TRABALHOS PUBLICADOS 87

$\begin{array}{ll}\text { REFERÊNCIAS } & 118\end{array}$ 


\section{LISTA DE FIGURAS}

Figura 1 Curva temperatura-tempo-transformação para decomposição da austenita em um aço AISI D2. Adaptado da referência [1].

Figura 2 Fração volumétrica de austenita retida em função da temperatura de tratamento criogênico. As amostras foram submetidas a uma etapa de envelhecimento intermediária entre a têmpera e o tratamento criogênico a $60^{\circ} \mathrm{C}$. Adaptado da referência [6].

Figura 3 Distribuição dos carbonetos secundários pequenos (CSP) apresentados sem $(T+R)$ e com $(T+T C+R)$ o tratamento criogênico. Adaptado da referência [24].

Figura 4 Microestrutura inicial do aço AISI D2 estudado por Das et al. ${ }^{[25]}$. CSs: Carbonetos Secundários; CPs: Carbonetos Primários. Adaptados da referência [25].

Figura 5 Micrografias apresentadas por Das et al. ${ }^{[25]}$ como representativas de (a) tratamento térmico convencional; (b) subzero a $-75^{\circ} \mathrm{C}$; (c) subzero a $-125^{\circ} \mathrm{C}$; e (d) criogênico a $-196^{\circ} \mathrm{C}$. Todas austenitizadas a $1020^{\circ} \mathrm{C}$ e revenidas a $210^{\circ} \mathrm{C}$ por duas horas (TC entre têmpera e revenimento). CSGs: Carbonetos Secundários Grandes; CSPs: Carbonetos Secundários Pequenos. Adaptado da referência [25].

Figura 6 Curva de revenimento do aço AISI D2. Tratamento convencional $\left(20^{\circ} \mathrm{C}\right)$ : têmpera $\left(1075^{\circ} \mathrm{C}\right)+$ revenimento duplo por duas horas. ($\left.196^{\circ} \mathrm{C}\right)$ : têmpera $\left(1075^{\circ} \mathrm{C}\right)+\mathrm{TC}\left(-196^{\circ} \mathrm{C} / 15 \mathrm{~min}\right)+$ revenimento único por duas horas. Adaptado da referência [9].

Figura 7 Curva de revenimento para amostras de um aço AISI D2 austenitizadas a 1010 e $1040^{\circ} \mathrm{C}$, temperadas em óleo, com etapa de alívio de tensões $\left(130^{\circ} \mathrm{C} / 90\right.$ minutos) para as amostras com TC/15 minutos. BT - bruta de têmpera; $\mathrm{R}$ - revenimento; TC tratada criogenicamente. Desvio de 0,2 HRC [27].

Figura 8 Curvas de revenimento para amostras com tratamento térmico convencional e com tratamento criogênico para o aço AISI D2.

(a) Temperatura de austenitização de $980^{\circ} \mathrm{C}$; (b) Temperatura de austenitização de $1080^{\circ} \mathrm{C}$. Adaptado da referência [7]. 
Figura 9 Curva de revenimento para o aço AISI D2 com e sem tratamento criogênico. As amostras foram austenitizadas a $980^{\circ} \mathrm{C}$ e submetidas a um único revenimento de 1 hora. Adaptado da referência [17].

Figura 10 Curvas de revenimento para o aço AISI D2. As amostras foram austenitizadas sob vácuo por 30 minutos e temperadas em óleo, os revenimentos duplos foram realizados por 2 horas cada [28].

Figura 11 Estrutura martensítica de aços temperados. (a) 0,2\%C; martensita na forma de ripas - a $\alpha^{\prime}$ contem um grande número de discordâncias. (b) 0,8\%C; martensita na forma de ripas e de placas - a a' contem discordâncias e maclas internas. (c) $1,4 \% \mathrm{C}$, martensita na forma de placas - a $\alpha^{\prime}$ contem muitas maclas internas. Adaptado da referência [33] apud Inoue e Matsuda.

Figura 12 Curva TTT para a formação de martensita em uma liga Fe-Ni-Mn. Adaptado da referência [34].

Figura 13 Resumo esquemático das mudanças estruturais que ocorrem na martensita virgem (liga Fe-Ni-C) durante o envelhecimento da mesma. Adaptado da referência [35].

Figura 14 Representação esquemática da decomposição espinodal. (la): diagrama de equilíbrio com um "gap" de miscibilidade; (lb): curva de energia livre correspondente ao digrama acima; (II): representação esquemática dos perfis de composição para tempos crescentes em uma liga temperada dentro da região espinodal ( $\mathrm{X}_{0}$ em (la)). Adaptado da referência [36].

Figura 15 Atraso na transformação martensítica em função do tempo de permanência a $60^{\circ} \mathrm{C}$, em um aço contendo 1,1\%C-0,2\%Si0,3\%Mn. Adaptado da referência [41].

Figura 16 Evolução do RMB em função do tempo de permanência a temperatura de envelhecimento. Amostra do aço AISI D2 austenitizado a $1040^{\circ} \mathrm{C} / 40 \mathrm{~min}$ e temperado em óleo. T condição como temperada ${ }^{[42]}$. 
Figura 17 Evolução do parâmetro c/a da martensita em função do tempo de permanência a temperatura de envelhecimento para o aço AISI D2 austenitizado a $1040^{\circ} \mathrm{C} / 40$ min e temperado em óleo. T condição como temperado ${ }^{[42]}$.

Figura 18 Diminuição da temperatura Mi da austenita retida devido ao envelhecimento (Fe-1,63\%Cr-1,06\%C). Adaptado da referência [33].

Figura 19 Derivada da curva de dilatometria de um aço FeCMnAl, mostrando 5 eventos sendo 1 de pré-precipitação e 4 de revenimento. Adaptado da referência [44].

Figura 20 Composições locais calculadas da ferrita e da austenita tendo atividades de $\mathrm{C}$ iguais em temperaturas entre 200 e $600^{\circ} \mathrm{C}$ para uma liga Fe-C. Adaptado da referência [43].

Figura 21 Microestrutura do aço AISI D2. Estado inicial na condição recozida. Microscopia ótica. Ataque: Villela.

Figura 22 Representação esquemática dos ciclos térmicos da primeira série de experimentos, contendo diversas combinações de ciclo. Aço AISI D2.

Figura 23 Criostato disponível no Laboratório de Transformações de Fases da EPUSP.

Figura 24 Representação esquemática dos ciclos térmicos da segunda série de experimentos, contendo diversas combinações de ciclo. Aço AISI D2.

Figura 25 Representação esquemática dos ciclos térmicos da terceira série de experimentos. (a) ciclos 1 e 4; (b) ciclos 2 e 3 . Aço AISI D2.

Figura 26 Sequência utilizada para determinação da fração volumétrica de carbonetos com o uso do programa Image J. (a) microestrutura original - elétrons retro-espalhados; (b) imagem binária; (c) mácara mostrando os carbonetos maiores que $5 \mu \mathrm{m}$; (d) máscara

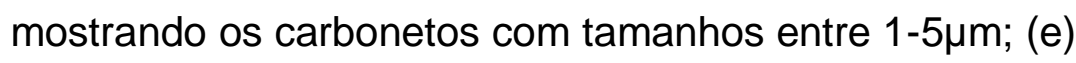
máscara mostrando os carbonetos com tamanhos entre 0,1-1 $\mu \mathrm{m}$; (f) máscara mostrando os carbonetos menores que $0,1 \mu \mathrm{m}$ (podendo ser somente artefato/ruído). 
Figura 27 (a) vista geral do equipamento utilizado para determinação do TEP, ou coeficiente de Seebeck. (b) representação esquemática da amostra (A) e dos blocos de cobre (B), com as respectivas diferenças de temperatura que causam uma diferença de potencial $\Delta \mathrm{V}$. Adaptado da referência [50].

Figura 28 Curvas típicas do TEP em função da temperatura. (a) Cinética da segregação de $\mathrm{C}$ e $\mathrm{N}$ nas discordâncias de aços ultra baixo carbono altamente deformados. (b) Cinética de precipitação do cobre no ferro. Adaptado da referência [50].

Figura 29 Microestrutura das amostras (a) TR210, (b) T-196/36hR, (c) T125/10minR e (d) T-75/10minR. Não atacadas. MEV - elétrons retro-espalhados.

Figura 30 Fração volumétrica dos diferentes tamanhos de carbonetos das amostras T1020, TR210, T-196/36hR, T-125/10minR e T75/10minR. Variação para um intervalo de confiança de $95 \%$.

Figura 31 Microestrutura das amostras (a) TR210, (b) T-196/36hR, (c) T125/10minR e (d) T-75/10minR, mostrando: (a) austenita retida; (a), (b), (c) e (d) - carbonetos eutéticos e nanométricos de revenido. Ataque: Villela/10s. MEV - elétrons secundários.

Figura 32 Detalhe da microestrutura da amostra T-125/10minR, mostrando os carbonetos de revenido nanométricos, os quais delineiam a estrutura martensítica. Ataque: Villela/10s. MEV - elétrons secundários.

Figura 33 Detalhe da microestrutura da amostra TR210, mostrando a austenita retida (blocos), os carbonetos eutéticos e os carbonetos de revenido nanométricos, os quais delineiam a estrutura martensítica. Ataque: Villela/10s. MEV - elétrons secundários.

Figura 34 Detalhe da microestrutura da amostra T-196/36hR, mostrando a austenita retida (blocos) e carbonetos secundários. Ataque: Villela/10s. MEV-FEG - elétrons secundários.

Figura 35 Detalhe da microestrutura da amostra TR210, mostrando a austenita retida (blocos) e carbonetos secundários. Ataque: Villela/10s. MEV-FEG - elétrons secundários. 
Figura 36 Microestrutura da amostra T (S21), somente temperada, mostrando a presença de carbonetos eutéticos e secundários e de martensita e austenita retida. Ataque: Villela/10s. MEV elétrons secundários.

Figura 37 Microestruturas das amostras após duplo revenimento (S16, S17, S18 e S19) mostrando a presença dos carbonetos nanométricos de revenido (marcações com linha cheia), além de carbonetos eutéticos e secundários e possível austenita retida (marcação com linha tracejada). Ataque: Villela/10s. MEV - elétrons secundários.

Figura 38 Detalhe da figura 37(a), microestrutura da amostra S16 ( $T+A T+T C / 30+2 R)$ mostrando a distribuição dos carbonetos de revenido nanométricos, os quais delineiam a estrutura martensítica e carbonetos secundários (micrométricos). Ataque: Villela/10s. MEV - elétrons secundários.

Figura 39 Detalhe da figura 37(b), microestrutura da amostra S17 $(T+T C / 30+2 R)$ mostrando a distribuição dos carbonetos de revenido nanométricos, os quais delineiam a estrutura martensítica e carbonetos secundários (micrométricos). Ataque: Villela/10s. MEV - elétrons secundários.

Figura 40 Detalhe da figura 37(c), microestrutura da amostra S18 ( $T+A T+2 R)$ mostrando a distribuição dos carbonetos de revenido nanométricos, os quais delineiam a estrutura martensítica e carbonetos secundários (micrométricos). Ataque: Villela/10s. MEV - elétrons secundários.

Figura 41 Detalhe da figura 37(d), microestrutura da amostra S19 $(T+2 R)$ mostrando a distribuição dos carbonetos de revenido nanométricos, os quais delineiam a estrutura martensítica e carbonetos secundários (micrométricos). Ataque: Villela/10s. MEV - elétrons secundários. 
Figura 42 Microestrutura da amostra S17 $(\mathrm{T}+\mathrm{TCP} / 30 \mathrm{~h}+2 \mathrm{R})$ - figuras $37(\mathrm{~b})$ e 39 - mostrando a distribuição dos carbonetos de revenido nanométricos, os quais delineiam a estrutura martensítica e carbonetos secundários (micrométricos). Ataque: Villela/10s. MEV/FEG - elétrons secundários.

Figura 43 Microestrutura da amostra S19 (T+2R) - figuras 37(d) e 41 mostrando a distribuição dos carbonetos de revenido nanométricos, os quais delineiam a estrutura martensítica e carbonetos secundários (micrométricos). Ataque: Villela/10s. MEV/FEG - elétrons secundários.

Figura 44 Difratogramas obtidos por difração de raios-X utilizando luz síncroton.

Figura 45 Difratogramas calculados utilizando refinemento por Rietveld.

Figura 46 Difratogramas calculados apresentando as fases presentes na matriz.

Figura 47 Difratogramas calculados para os carbonetos identificados.

Figura 48 Evolução do TEP em função do tempo de permanência à $130^{\circ} \mathrm{C}$.

(a) curvas completas; (b) destaque para os tempos iniciais. Ciclo 1: T + Tisotérmico; Ciclo 2: T + TC/2h + Tisotérmico; Ciclo 3: T + TC/24h + Tisotérmico; Ciclo 4: T + AT + TC/24h + Tisotérmico. Aço AISI D2.

Figura 49 Evolução do TEP em função do tempo de permanência à $210^{\circ} \mathrm{C}$. (a) curvas completas; (b) destaque para os tempos iniciais. Ciclo 1: T + Tisotérmico; Ciclo 2: T + TC/2h + Tisotérmico; Ciclo 3: T + TC/24h + Tisotérmico; Ciclo 4: T + AT + TC/24h + Tisotérmico. Aço AISI D2.

Figura 50 Evolução do TEP em função do tempo de permanência à $350^{\circ} \mathrm{C}$. (a) curvas completas (tempo final diferente entre ciclos); (b) destaque para os tempos iniciais. Ciclo 1: $T+$ Tisotérmico; Ciclo 2: $\mathrm{T}+\mathrm{TC} / 2 \mathrm{~h}+$ Tisotérmico; Ciclo 3: $\mathrm{T}+\mathrm{TC} / 24 \mathrm{~h}+$ Tisotérmico; Ciclo 4: T + AT + TC/24h + Tisotérmico. Aço AISI D2. 
Figura 51 Evolução do TEP em função do tempo de permanência à $450^{\circ} \mathrm{C}$. (a) curvas completas (tempo final diferente entre os ciclos); (b) curvas mostrando patamar no valor do TEP (com leve aumento com o tempo); e (c) destaque para os tempos iniciais. Ciclo 1: $T+$ Tisotérmico; Ciclo 2: $\mathrm{T}+\mathrm{TC} / 2 \mathrm{~h}+$ Tisotérmico; Ciclo 3: $\mathrm{T}+$ TC/24h + Tisotérmico; Ciclo 4: T + AT + TC/24h + Tisotérmico. Aço AISI D2.

Figura 53 Evolução do TEP em função do tempo de permanência à $520^{\circ} \mathrm{C}$. (a) curvas completas; (b) destaque para os tempos iniciais; (c) detalhe para as diferentes inclinações com o aumento do tempo de permanência à $520^{\circ} \mathrm{C}$; e (d) curvas com o tempo em escala logarítmica, mostrando a característica sigmoidal das mesmas. Ciclo 1: T + Tisotérmico; Ciclo 2: T + TC/2h + Tisotérmico; Ciclo 3: $\mathrm{T}+\mathrm{TC} / 24 \mathrm{~h}+$ Tisotérmico; Ciclo 4: $\mathrm{T}+\mathrm{AT}+\mathrm{TC} / 24 \mathrm{~h}+$ Tisotérmico. Aço AISI D2.

Figura 53 Porcentagem de carbono na austenita para as amostras T (S21), $T+A T$ (S12) e $T+A T+R$ (S18). Calculados com a equação: $a_{y}=$ $3,564+0,044 \times \%$.

Figura 54 Evolução do $\Delta$ TEP em função do parâmetro de Hollomon-Jaffe. (a) curvas completas; (b) destaque para os tempos iniciais; (c) destaque para os tempos intermediários; e (d) destaque para os tempos finais. Ciclo 1: $\mathrm{T}+$ Tisotérmico; Ciclo 2: $\mathrm{T}+\mathrm{TC} / 2 \mathrm{~h}+$ Tisotérmico; Ciclo 3: T + TC/24h + Tisotérmico; Ciclo 4: T + AT + TC/24h + Tisotérmico. Aço AISI D2.

Figura 55 Representação esquemática da estrutura do material na condição inicial. (a) grão com placas de martensita e blocos de austenita retida; interfaces $\alpha^{\prime} / \gamma_{R}$ e $\alpha^{\prime} / \alpha^{\prime}$. (b) maclas internas na placa de martensita. (c) estrutura modulada da martensita devido ao envelhecimento; interfaces $\alpha^{\prime}$ enriquecida em $\mathrm{C} / \alpha^{\prime}$ empobrecida em C.

Figura 56 Representação esquemática dos mecanismos propostos para a evolução do $\triangle$ TEP em função do tempo e da temperatura. 


\section{LISTA DE TABELAS}

Tabela 1 Nomenclaturas apresentadas na literatura para 0 tratamento criogênico.

Tabela 2 Temperatura de revenimento em função do tempo para precipitação de $5 \%$ de carbonetos $\eta^{[30]}$.

Tabela 3 Composição química do aço AISI D2 em \% peso, Fe - balanço. 37

Tabela $4 \quad$ Identificações das amostras da primeira série de experimentos. 38

Tabela 5 Identificações das amostras da segunda série de experimentos. 40

Tabela 6 Identificações dos ciclos térmicos da terceira série de experimentos.

Tabela 7 Valores dos parâmetros a e c da martensita e a da austenita e frações volumétricas presentes destas fases. Para a amostra $\mathrm{S} 20$, os valores na coluna da martensita correspondem à fase ferrita.

Tabela 8 Valores dos parâmetros a, b e c do carboneto $\mathrm{M}_{7} \mathrm{C}_{3}$ e a e c do carboneto $\mathrm{M}_{2} \mathrm{C}$, e frações volumétricas dos carbonetos.

Tabela 9 Análise qualitativa das figuras de 37 a 41 , ranqueando as amostras quanto ao refinamento e a fração volumétrica dos carbonetos nanométricos observados. Os sinais (++++) indicam os maiores refinamento e fração volumétrica enquanto $(+)$ indica o menores refinamento e fração volumétrica.

Tabela 10 Valores das frações volumétricas dos carbonetos $\mathrm{M}_{7} \mathrm{C}_{3}$ e $\mathrm{M}_{2} \mathrm{C}$.

Tabela 11 Relação c/a dos parâmetros de rede da martensita, parâmetro a da austenita e respectivas frações volumétricas. 


\section{LISTA DE SÍMBOLOS}

$\begin{array}{ll}\alpha^{\prime} & \text { Martensita } \\ \text { AT } & \text { Alívio de tensões } \\ \varepsilon & \text { Carboneto épsilon } \\ Y & \text { Austenita } \\ \text { YR } & \text { Austenita retida } \\ \eta & \text { Carboneto eta } \\ \theta & \text { Cementita } \\ \text { Mi } & \text { Temperatura de início da transformação martensítica } \\ \text { Mf } & \text { Temperatura final da transformação martensítica } \\ \text { TC } & \text { Tratamento criogênico } \\ \text { TSZ } & \text { Tratamento subzero } \\ \text { Vv } & \text { Fração volumétrica }\end{array}$




\section{RESUMO}

Foram estudados os efeitos da introdução de etapas de tratamento criogênico e do alívio de tensões no ciclo térmico do aço ferramenta para trabalho a frio AISI D2. Variaram-se as temperaturas de tratamento criogênico, sendo elas principalmente: criogênica $\left(-196^{\circ} \mathrm{C}\right)$ e subzero $\left(-80^{\circ} \mathrm{C}\right)$. Foram variados os tempos de permanência às temperaturas criogênicas: 2, 3, 10, 24 e 30 e 36 horas. Verificou-se o efeito da adição da etapa $\left(130^{\circ} \mathrm{C} / 90\right.$ minutos) de alívio de tensões previamente ao tratamento criogênico. As amostras com diferentes ciclos térmicos foram submetidas à caracterização metalográfica, difração de raios-X e ensaios de potencial termoelétrico. Na caracterização metalográfica as amostras foram analisadas por MEV (microscopia eletrônica de varredura) e MEV-FEG (MEV com canhão com emissão por efeito de campo). Os carbonetos secundários (micrométricos) não apresentaram variação. Os carbonetos secundários de revenido (nanométricos) apresentaram-se mais finamente dispersos na matriz nas amostras com tratamento criogênico e sem alívio de tensões. A difração de Raios- $X$ foi realizada no Laboratório Nacional de Luz Síncroton, a luz síncroton foi essencial para detectar as variações pequenas e em escala nanométrica que ocorreram devido às inserções dos tratamentos criogênicos e de alívio de tensões. Foram verificados: i) menor fração volumétrica de austenita retida nas amostras tratadas em temperatura subzero quando comparadas às amostras tratadas em temperaturas criogênicas, indicando um comportamento cinético em $C$ da curva de transformação; ii) diminuição da relação c/a dos parâmetros do reticulado cristalino da martensita e aumento do parâmetro a da austenita (devido à partição de carbono da martensita supersaturada em carbono para a austenita) causando estabilização da austenita com a inserção da etapa de alívio de tensões; iii) aumento no parâmetro a da austenita retida residual após revenimentos, com consequente aumento no teor de carbono da mesma, devido à partição de carbono; iv) maior fração volumétrica de carbonetos de revenido $\left(\mathrm{M}_{7} \mathrm{C}_{3} \mathrm{e}\right.$ $\mathrm{M}_{2} \mathrm{C}$ ) nas amostras com tratamento criogênico logo após a têmpera, seguido da amostra com tratamento criogênico + alívio de tensões, seguidos da amostra somente temperada e revenida e por fim da amostra com alívio de tensões e sem tratamento criogênico. Os ensaios de potencial termo-elétrico (realizados no INSALyon) foram utilizados para verificar o comportamento das amostras nas temperaturas de revenimento. Foram realizados tratamentos isotérmicos $\left(130^{\circ} \mathrm{C}\right.$, 
$210^{\circ} \mathrm{C}, 350^{\circ} \mathrm{C}, 450^{\circ} \mathrm{C}$ e $520^{\circ} \mathrm{C}$ ) cumulativos com tempos de 1 minuto ate 130 horas. Verificou-se que: i) nos primeiros estágios do revenimento a cinética é favorecida pelo tratamento criogênico (precipitação de carbonetos $\eta$ ou $\varepsilon$ ); ii) o alívio de tensões atrasa os dois primeiros estágios do revenimento; iii) há maior crescimento dos carbonetos de liga nas amostras sem tratamento criogênico. $O$ refinamento dos carbonetos secundários de revenimento foi atribuído a uma sequência de precipitações de carbonetos de revenido in situ: $\eta \rightarrow \theta \rightarrow M_{7} C_{3}$ e $M_{2} C$. 


\section{ABSTRACT}

The effects of cryogenic treatments and of stress relief treatment introduced in the thermal cycle of the cold work tool steel AISI D2 were studied. The cryogenic temperatures were varied: cryogenic $\left(-196^{\circ} \mathrm{C}\right)$ and subzero $\left(-80^{\circ} \mathrm{C}\right)$. It was also varied the holding times at cryogenic temperatures: $2,3,10,24,30$ and 36 hours. The effect of including a stress relief heat treatment previously to the cryogenic treatment was also verified. Samples submitted to different thermal cycles were studied using metallographic characterization, X-ray diffraction and electric power measurements. The metallographic characterization used SEM (scanning electron microscopy) and SEM-FEG (SEM with field emission gun), besides OM (optical microscopy). It was not found any variation in the secondary carbides (micrometrics) precipitation. The temper secondary carbides (nanometrics) showed to be more finely dispersed in the matrix of the samples with cryogenic treatment and without stress relief. The X-ray diffractions were carried out at the Brazilian Synchrotron Light Laboratory; synchrotron light was essential to detect small and nano sized variations occurring due to the addition of the cryogenics and stress relief treatments. It was verified: i) lower austenite volumetric fraction in the samples with subzero treatment if compared to the cryogenic treated samples, an indication of a $\mathrm{C}$ curve kinetic behavior of the transformation; ii) the stress relief treatment produced an decrease in the c/a relationship of the martensite lattice parameters and an increase in the austenite a parameter (explained by carbon atoms partition from the supersatured martensite to the retained austenite); iii) after double tempering occurred an increase in the a parameter of the remaining austenite lattice, indicating an increase in the carbon content of the residual retained austenite, due to carbon partition; iv) higher volumetric fraction of temper carbides $\left(\mathrm{M}_{7} \mathrm{C}_{3}\right.$ and $\left.\mathrm{M}_{2} \mathrm{C}\right)$ if the samples were cryogenic treated just after quench (to room temperature), followed by the sample with cryogenic treatment + stress relief, after the sample just quenched and tempered and finally by the samples with stress relief without cryogenic treatment. Thermo-electric power measurements (carried out at INSA-Lyon) characterized the samples behavior after tempering at different temperatures. Cumulative isothermal treatments $\left(130^{\circ} \mathrm{C}\right.$, $210^{\circ} \mathrm{C}, 350^{\circ} \mathrm{C}, 450^{\circ} \mathrm{C}$ e $520^{\circ} \mathrm{C}$ ) with increasing times (from 1 minute to 130 hours) were used. It was verified that: i) the kinetic is favoured by the cryogenic treatment in the first temper stage ( $\eta$ or $\varepsilon$ carbide precipitation); ii) the stress relief delayed the first 
and second temper stage; iii) the samples without cryogenic treatment showed to have a bigger growing for the alloys carbides in the last stage of temper. The refinement of the temper secondary carbides was attributed to an in situ carbide precipitation during tempering: $\eta \rightarrow \theta \rightarrow \mathrm{M}_{7} \mathrm{C}_{3}$ e $\mathrm{M}_{2} \mathrm{C}$. 


\section{MOTIVAÇÃO}

Ao longo dos últimos anos, atividades sistemáticas na área de aços ferramenta tem sido desenvolvidas pelo Laboratório de Transformações de Fases do Departamento de Engenharia Metalúrgica e de Materiais da Escola Politécnica da Universidade de São Paulo, coordenado pelo Professor Titular Dr. Hélio Goldenstein. Os temas incluindo i) aços ferramentas para trabalho a frio - AISI D2; ii) aço matriz; e iii) aço matriz do aço AISI D2 deram origem a teses, dissertações e patentes.

A doutoranda e Mestre em Eng. Paula Fernanda da Silva Farina desenvolveu o projeto de pesquisa do seu mestrado em aços rápidos - uma categoria de aços ferramenta, no Instituto de Pesquisas Tecnológicas do Estado de São Paulo, sob a orientação do pesquisador Dr. Mário Boccalini Jr., utilizando o conceito de aço matriz com adição controlada de carbonetos de alta dureza tipo NbC (Projeto FAPESP de auxílio à pesquisa $\mathrm{n}^{\circ}$ 04/05960-3).

O presente trabalho foi realizado em cooperação com a empresa Villares Metals S.A.(VMSA), sob a supervisão do Eng. Celso Antonio Barbosa. A parceria para o presente trabalho surgiu de uma necessidade da empresa VMSA, que atualmente possui um novo negócio que é o fornecimento de tratamento térmico a seus clientes.

A motivação para este trabalho decorreu do forte apelo por melhorias nas propriedades dos aços ferramenta com a inserção da etapa de tratamento criogênico no ciclo térmico dos mesmos. Para tanto, foram definidas duas premissas principais: i) o tratamento criogênico apresenta aumento na resistência ao desgaste quando comparado com ciclos térmicos tradicionais ou com tratamento subzero; ii) há um problema prático no tratamento criogênico que é o trincamento de peças durante o resfriamento devido aos gradientes térmicos; e uma pergunta: haveria modificação na sequência de precipitação dos carbonetos de revenido devido à inserção da etapa criogênica? 


\section{REVISÃO BIBLIOGRÁFICA}

$\mathrm{Na}$ revisão bibliográfica serão apresentadas as principais reinvindicações encontradas na literatura para o tratamento criogênico do aço ferramenta para trabalho a frio AISI D2.

São apresentados também os principais mecanismos de transformações de fases que podem estar relacionados com o ciclo térmico envolvendo o tratamento criogênico e a etapa de alívio de tensões destes aços.

\subsection{Aço Ferramenta para Trabalho a Frio - AISI D2}

Os aços ferramenta para trabalho a frio estão entre os mais importantes na classificação de aços ferramenta devido a sua aplicabilidade em diversos tipos de ferramentas e matrizes. Os aços para trabalho a frio com alto carbono e alto cromo, entre eles o aço AISI D2, foram desenvolvidos originalmente como possíveis substitutos para os aços rápido, no entanto, não apresentaram dureza a quente suficiente ao mesmo tempo que apresentaram-se muito frágeis para este propósito. No entanto, devido à alta resistência ao desgaste promovida pela presença de carbonetos eutéticos de cromo e a sua alta resistência ao impacto mostraram-se promissores para a fabricação de matrizes ${ }^{[1]}$.

A estrutura bruta de fundição destes aços possui dendritas que compõem os grãos e possuem teores de cromo e carbono inferiores às regiões interdendríticas. Nos contornos de dendrita há uma mistura eutética de austenita + carbonetos, a qual lembra, de certa forma, a estrutura dos aços rápido ${ }^{[1]}$. A sequência de solidificação do aço AISI D2 inicia-se com a formação da austenita primária seguida pela reação eutética: $L \rightarrow Y+M_{7} C_{3}$, a qual caracteriza o aço como hipo-eutético (neste trabalho será utilizada a nomenclatura de carbonetos apresentada por Boccalini e Goldenstein ${ }^{[2]}$, na qual os carbonetos primários precipitam diretamente do líquido e os carbonetos eutéticos precipitam a partir de uma reação eutética; a fase primária é a primeira a precipitar a partir do líquido e não participando de uma reação eutética) com a presença de células eutéticas de carbonetos $\mathrm{M}_{7} \mathrm{C}_{3}$ na microestrutura bruta de fundição. A deformação a quente dos lingotes quebra a estrutura eutética de

carbonetos com intensidade proporcional ao grau de deformação ${ }^{[3]}$. Quando o forjamento/laminação é suficiente para quebrar esta estrutura celular, os carbonetos 
eutéticos passam a estar distribuídos de forma orientada na direção de deformação. O forjamento nestes aços tende a eliminar parcialmente a estrutura celular formando uma estrutura bandeada de carbonetos, resultando em uma distribuição mais homogênea dos constituintes duros. A deformação deste aço é realizada à quente $\mathrm{e}$, devido a eliminação da estrutura celular, os carbonetos esferoidizados que precipitam em solução sólida dentro dos grãos da matriz (que estarão mais refinados) durante o resfriamento estarão distribuídos de forma mais uniforme. $\mathrm{Da}$ mesma forma, durante os tratamentos térmicos subsequentes a precipitação de carbonetos será mais uniforme dentro da matriz ${ }^{[1]}$.

A condição inicial da matriz para o tratamento térmico é, em geral, a condição recozida, com a matriz composta de ferrita com carbonetos globulares. Durante a austenitização no campo $\mathrm{y}+$ carbonetos os carbonetos secundários que precipitaram durante $o$ resfriamento do lingote e durante 0 recozimento são parcialmente dissolvidos, e ao mesmo tempo os carbonetos maiores sofrem esferoidização e engrossamento devido à maturação de Ostwald (Ostwald ripening processo no qual as partículas menores são dissolvidas ao passo que as partículas maiores crescem ${ }^{[4]}$ ).

A figura 1 (Payson e Klein apud Roberts e Cary ${ }^{[1]}$ ) apresenta o diagrama de transformação isotérmica para a decomposição da austenita no aço AISI D2. Este diagrama apresenta uma baía entre duas regiões na qual a austenita não se transforma, indicando uma alta estabilidade da austenita. A temperatura Mi (início da transformação martensítica) é função do tempo e temperatura de austenitização (esta curva é apresentada de forma simplificada, sem a precipitação de carbonetos na parte superior). 


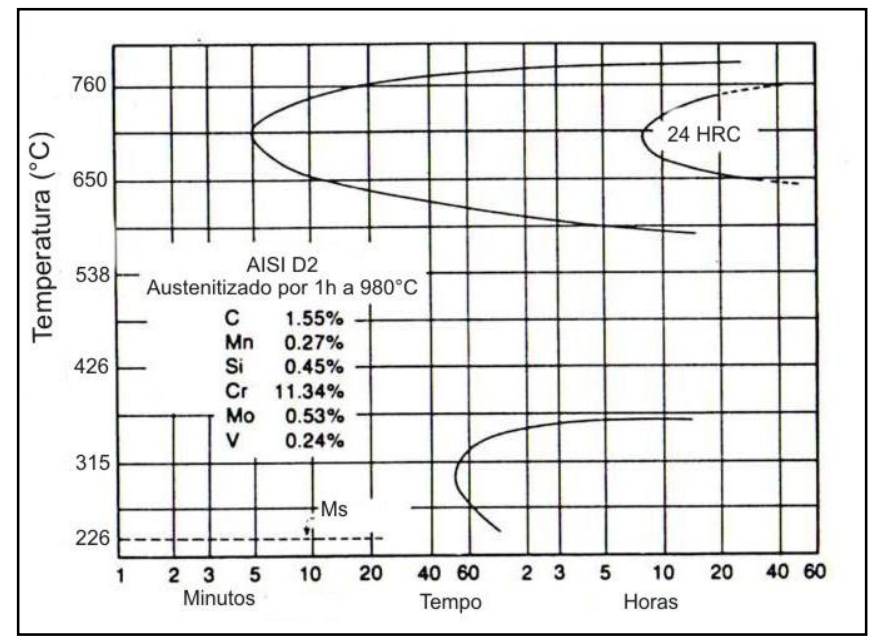

Figura 1 - Curva temperatura-tempo-transformação para decomposição da austenita em um aço AISI D2. Adaptado da referência [1].

O estágio final no processamento dos aços ferramenta para moldes e matrizes consiste de um tratamento térmico de têmpera e revenimento para produzir uma combinação ótima de alta dureza, boa resistência ao desgaste e resistência à fratura ou tenacidade suficiente para uma dada aplicação. Em geral, a alta dureza ocorre devido à transformação da austenita em martensita e a tenacidade é controlada pelo revenimento da martensita. A microestrutura final será composta de uma mistura de martensita, austenita retida e carbonetos ${ }^{[5]}$.

Adicionalmente ao processo convencional de tratamento térmico do aço ferramenta podem ser realizados tratamentos de resfriamento a temperaturas abaixo da temperatura ambiente. A literatura recente tem apresentado diversos artigos sobre os efeitos destes tratamentos, denominados de tratamentos subzero ou criogênicos. A maioria deles apresenta melhorias na resistência ao desgaste, supostamente devido a modificações microestruturais que ocorrem em temperaturas criogênicas. Supõe-se que o tratamento criogênico modifica a forma de precipitação dos carbonetos secundários de revenimento no aquecimento subsequente (até a temperatura ambiente - autorrevenido - ou no revenimento), obtendo uma distribuição mais fina e mais homogênea dos mesmos ${ }^{[6,7]}$. Entretanto, os mecanismos propostos para explicar os fenômenos que ocorrem durante o tempo de permanência a temperatura criogênica e no aquecimento subsequente (temperatura ambiente ou acima) ainda não estão claros. 


\subsection{Tratamento Criogênico}

O tratamento criogênico vem sendo apresentado como um tratamento térmico com grandes efeitos nas propriedades dos aços tratados termicamente, especialmente em aços ferramenta. A ele são atribuídas melhoras na resistência ao desgaste e na tenacidade dos aços ferramenta. No entanto, os micromecanismos propostos para explicar os fenômenos que ocorrem na microestrutura durante a permanência em temperaturas criogênicas e no aquecimento subsequente (até a temperatura ambiente ou revenimento) não estão estabelecidos de forma clara.

Os principais mecanismos propostos estão relacionados com a: (a) transformação martensítica, sendo eles: i) transformação da austenita retida $\left(\mathrm{Y}_{\mathrm{R}}\right)$ em martensita $\left(\alpha^{\prime}\right)^{[8,9,10]}$ ii) decomposição e condicionamento da martensita ${ }^{[10,11,12]}$; iii) transformação isotérmica da martensita ${ }^{[7]}$; ou com (b) a precipitação ${ }^{[10,6]}$ ou aumento da fração volumétrica ${ }^{[11,12]}$ de carbonetos $\eta$ (eta). Estes mecanismos, no entanto, estão diretamente relacionados, como será observado no desenvolvimento da revisão bibliográfica.

Além das dúvidas em relação aos micromecanismos envolvidos no processo de tratamento criogênico, a literatura apresenta diversas nomenclaturas (as quais dificultam para o leitor leigo entender de que processo se trata) e são propostos diversos ciclos térmicos, contendo: i) diferentes temperaturas criogênicas; ii) diferentes tempos de permanência à temperatura criogênica; iii) diferentes posições do revenimento no ciclo térmico (antes ou após o tratamento criogênico); iv) variação no número de revenimentos; v) inserção ou não de etapa de alívio de tensões antes do tratamento criogênico.

A inserção da etapa de alívio de tensões, apesar de não ser tratada isoladamente pela literatura sobre tratamentos criogênicos, aparece em alguns trabalhos, inclusive no trabalho de Meng et al. ${ }^{[6]}$ que vem sendo o trabalho mais citado nesta área. A etapa de alívio de tensões é importante no procedimento industrial para evitar que matrizes com geometrias complexas, onde o custo da usinagem muitas vezes sobressai ao custo do material, trinquem devido a gradientes térmicos durante o tratamento térmico. 


\subsubsection{Nomenclaturas para o tratamento criogênico}

O dicionário Larousse da Língua Portuguesa ${ }^{[13]}$ define: i) criogenia como: "Parte da física que se dedica à produção e manutenção de baixas temperaturas e ao estudo das propriedades da matéria e dos sistemas a elas submetidos."; e ii) criotemperatura como: "Temperatura baixa, inferior, por convenção, a 120K" (120K = $\left.-153^{\circ} \mathrm{C}\right)$.

A tabela 1 apresenta as principais (e mais citadas) nomenclaturas apresentadas pela literatura para o tratamento criogênico.

Tabela 1 - Nomenclaturas apresentadas na literatura para o tratamento criogênico.

\begin{tabular}{ccc}
\hline-60 a $-80^{\circ} \mathrm{C}$ & -125 a $-196^{\circ} \mathrm{C}$ & Referência \\
\hline Tratamento Criogênico & Tratamento Criogênico & {$[8]$} \\
Tratamento a Frio & Tratamento Criogênico Profundo - TCP & {$[14]$} \\
(Cold Treatment) & (Deep Cryogenic Treatment - DCT) & {$[15]$} \\
Tratamento Subzero & Tratamento Criogênico Profundo - TCP & {$[15]$} \\
\hline $\begin{array}{c}\text { Tratamento Criogênico Raso - TCR } \\
\text { (Shallow Cryogenic Treatment - SCT) }\end{array}$ & Tratamento Criogênico Profundo - TCP & {$[16]$} \\
\hline
\end{tabular}

Este trabalho, buscando ser fiel à língua portuguesa e à literatura técnica, utilizará os termos: i) tratamento subzero (TSZ) quando tratar de temperaturas em torno de $-80^{\circ} \mathrm{C}$ (193K - temperatura do gelo seco); e ii) tratamento criogênico (TC) quando tratar de temperaturas em torno de $-196^{\circ} \mathrm{C}$ ( $77 \mathrm{~K}$ - nitrogênio líquido). Quando for tratar de forma generalizada será utilizado o termo tratamento criogênico, por ser o mais utilizado na literatura técnica atual.

\subsubsection{Reivindicações da literatura para o aço AISI D2}

As principais reivindicações apresentadas pela literatura devido à inserção da etapa criogênica são: aumento da resistência ao desgaste ${ }^{[8,6,17,15,18,19]}$, aumento da tenacidade ${ }^{[20,21]}$ e aumento na dureza ${ }^{[22,19,23]}$, podendo o aumento na dureza ser maior para temperaturas subzero do que para temperaturas criogênicas ${ }^{[8,9]}$.

É possível verificar que são atribuídas muitas melhorias ao aço AISI D2 quando tratado criogenicamente. No entanto, apesar de muitos autores atribuírem fenômenos, e até mesmo discutirem mecanismos para as transformações ocorrendo à temperatura criogênica ou no aquecimento subsequente, grande parte deles não apresenta uma caracterização microestrutural capaz de validar suas hipóteses. Em 
alguns artigos são propostas hipóteses absurdas do ponto de vista metalúrgico, como a precipitação de carbonetos micrométricos devido à inserção da etapa criogênica, como será apresentado adiante.

\subsubsection{Mecanismos Propostos}

\subsubsection{Transformação da austenita retida em martensita}

Segundo Barron ${ }^{[8]}$, materiais que são mais susceptíveis à presença de austenita retida $\left(\mathrm{Y}_{\mathrm{R}}\right)$ durante o tratamento térmico se beneficiarão mais do tratamento criogênico. Isto ocorreria devido ao fenômeno de estabilização da austenita a que estes materiais são submetidos se a têmpera for interrompida à temperatura ambiente, antes do tratamento criogênico. Este efeito de estabilização seria diminuído se o material fosse tratado criogenicamente a $-196^{\circ} \mathrm{C}$, com resultados superiores ao do tratamento subzero a $-84^{\circ} \mathrm{C}$. Assim, o melhor desempenho frente ao desgaste seria atribuído a uma transformação mais completa da austenita retida em martensita $\left(\alpha^{\prime}\right)$. No entanto, Barron ${ }^{[8]}$, não determina a $V v$ (fração volumétrica) de $Y_{R}$ e utiliza uma medida indireta, a dureza do material, que ele apresentou como maior para a temperatura de $-84^{\circ} \mathrm{C}$. Assim, talvez esteja sendo indicado que a transformação da $\gamma_{R} \rightarrow \alpha$ ' seja facilitada em temperaturas subzero e não criogênicas.

Moore e Collins ${ }^{[9]}$ atribuem as melhorias atingidas com o tratamento criogênico do aço AISI D2 à contínua transformação da austenita retida em martensita em temperaturas criogênicas. No entanto, da mesma forma, a máxima dureza atingida foi para as amostras com tratamento subzero a $-100^{\circ} \mathrm{C}$ (comparada com -40 e $-196^{\circ} \mathrm{C}$ ), o que segundo autores não permite determinar a que temperatura ocorre a transformação completa da austenita em martensita. Apesar dos autores não terem mencionado, este efeito pode indicar um comportamento em C na curva de cinética de transformação da austenita em martensita, como será discutido em item específico.

No mesmo trabalho, Moore e Collins ${ }^{[9]}$ verificaram que a dureza do aço AISI H13 apresentou valores crescentes com a diminuição da temperatura de tratamento criogênico. Estes resultados foram atribuídos à transformação isotérmica da martensita, apesar de em aços tratados termicamente a transformação dominante ser atérmica, a qual também será discutida em item específico. 
Oppenkowski ${ }^{[7]}$, em estudo sobre o efeito do tempo de permanência do aço AISI D2 a temperatura de $-196^{\circ} \mathrm{C}$ sobre a resistência ao desgaste verificou o aumento desta propriedade com o aumento do tempo de permanência a $-196^{\circ} \mathrm{C}$. A este resultado foi atribuída a possibilidade de transformação isotérmica da austenita retida em martensita durante a permanência a temperatura criogênica ou no aquecimento subsequente. Devido às baixas temperaturas, a transformação seria desacelerada e seriam necessários tempos maiores para a transformação (outra explicação, que sem ser citado diretamente pelos autores, conduziria a curva de cinética em $\mathrm{C}$ da transformação martensítica). Entretanto, os autores concluem que as razões para este comportamento ótimo de tempo e temperatura ainda permanecem obscuras do ponto de vista metalúrgico.

\subsubsection{Precipitação de carbonetos eta (n)}

Meng et al. ${ }^{[6]}$, conforme apresentado na figura 2, verificaram que os valores de austenita retida para as amostras tratadas a -50 e $-180^{\circ} \mathrm{C}$ eram praticamente os mesmos, em um aço AISI D2. No entanto, a resistência ao desgaste foi maior para as amostras tratadas a $-180^{\circ} \mathrm{C}$.

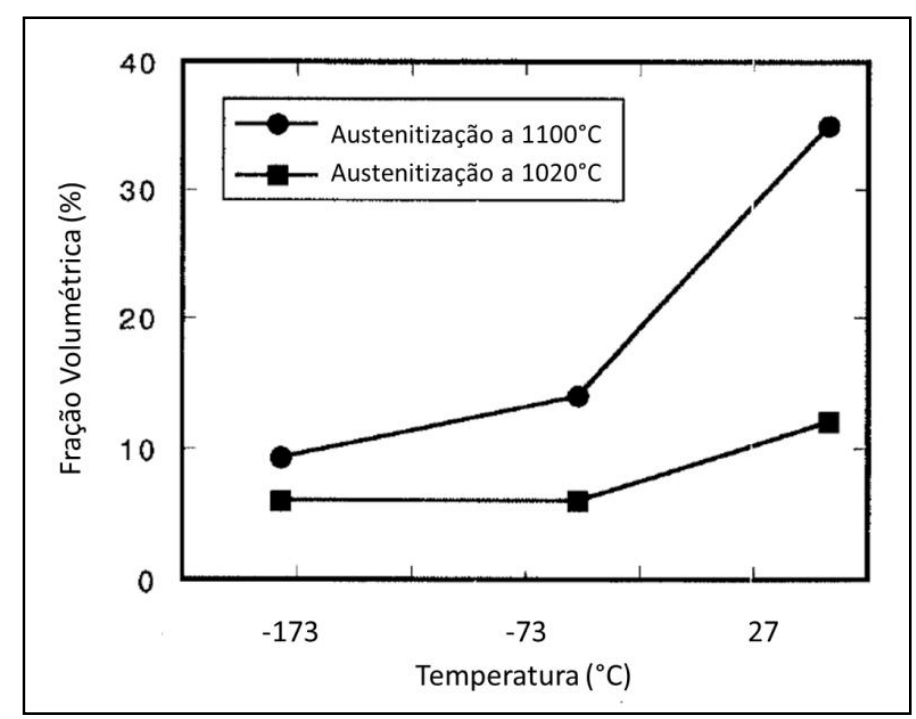

Figura 2 - Fração volumétrica de austenita retida em função da temperatura de tratamento criogênico. As amostras foram submetidas a uma etapa de envelhecimento intermediária entre a têmpera e o tratamento criogênico a $60^{\circ} \mathrm{C}$. Adaptado da referência [6].

Segundo Meng et al. ${ }^{[6]}$, é conhecido que ocorre deformação do reticulado da martensita em temperaturas criogênicas (será discutido em item posterior). De modo 
resumido, eles propõem que o mecanismo para a formação do carboneto $\eta$ consiste no ligeiro deslocamento dos átomos de carbono devido à deformação do reticulado. A nucleação dos carbonetos ocorreria de forma heterogênea ao longo das faixas ricas em carbono desenvolvidas por meio de uma decomposição espinodal da martensita (que será apresentada em item posterior) A identificação dos carbonetos foi feita por microscopia eletrônica de transmissão, após revenimento a $180^{\circ} \mathrm{C}$, os mesmos apresentaram-se na forma de bastonetes com tamanhos variando entre $5 \mathrm{e}$ $10 \mathrm{~nm}$ na seção transversal e de 20 a $40 \mathrm{~nm}$ no comprimento ${ }^{[6]}$.

Yun et al. ${ }^{[11]}$, detectaram a presença de carbonetos ultrafinos, da ordem de 2,6 a $6 \mathrm{~nm}$, após o tratamento criogênico (antes do revenimento) no aço AISI M2, utilizando microscopia eletrônica de transmissão. Verificaram também que após revenimento triplo a $560^{\circ} \mathrm{C}$, houve aumento no tamanho dos mesmos, mas, aparentemente permanecendo menores do que nos aços tratados convencionalmente. Segundo eles a capacidade dos átomos de carbono se difundirem aumenta com o aquecimento até a temperatura ambiente (o que é senso comum, a difusibilidade aumenta em função do aumento da temperatura), quando os átomos se movem curtas distâncias para os contornos de maclas ou outros defeitos, precipitando carbonetos finos coerentes com a martensita.

Huang et al. ${ }^{[12]}$, com o aço AISI M2, concluíram que o tratamento criogênico facilita a formação de carbonetos e aumenta a população e fração volumétrica dos mesmos, além de promover uma distribuição mais homogênea. Segundo os autores, os resultados apresentados estão consistentes com a literatura (especificamente, Meng et al. ${ }^{[6]}$ e Yun et al. $\left.{ }^{[11]}\right)$. No entanto, no trabalho de Huang et al. ${ }^{[12]}$, os carbonetos identificados são micrométricos (sendo os menores com $0,5 \mu \mathrm{m}$, ou seja, $500 \mathrm{~nm}$ ). O revenimento por eles realizado foi a $200^{\circ} \mathrm{C}$, o qual metalurgicamente não permitiria a precipitação de tais carbonetos. Para a precipitação de carbonetos micrométricos, seria necessária a difusão de elementos de liga substitucionais, o qual é um processo termicamente ativado, que ocorre somente em temperaturas de revenimento mais altas. O estudo foi realizado com microscopia eletrônica de transmissão.

Seguindo esta ideia de aumento da população de carbonetos com distribuição mais homogênea com a inserção da etapa criogênica, diversos outros trabalhos foram publicados sem a devida atenção aos aspectos metalúrgicos, ou seja, qual o 
tamanho dos carbonetos que poderiam ter sua precipitação modificada com a inserção da etapa criogênica.

Dentre eles, uma sequência de 10 artigos dos autores Das, Dutta e Ray (serão referenciados conforme necessidade), todos muito parecidos, entre si, mostraram melhorias significativas na resistência ao desgaste do aço AISI D2 tratado criogenicamente. No entanto, toda a discussão destes trabalhos pode ser questionada, questionando-se a metodologia utilizada para obtenção das amostras e o tipo de carboneto estudado.

Em um destes artigos, intitulado "On the refinement of carbides precipitates by cryotreatment in AISI D2 steel' [24], os autores apresentam a distribuição de carbonetos apresentada na figura 3 , na qual os carbonetos chamados de CSP (Carbonetos Secundários Pequenos) tem na faixa de $0,1 \mu \mathrm{m}(100 \mathrm{~nm})$ a $1 \mu \mathrm{m}(1000$ $\mathrm{nm})$. Carbonetos com este tamanho só poderiam precipitar no campo $\mathrm{y}+$ carbonetos, não há possibilidade destes carbonetos $\left(\mathrm{M}_{7} \mathrm{C}_{3}\right)$ dissolverem-se ou precipitarem em temperaturas criogênicas ou mesmo em temperaturas de revenimento (neste trabalho $210^{\circ} \mathrm{C}$ ), já que seria necessária a difusão de elementos substitucionais para tal transformação.

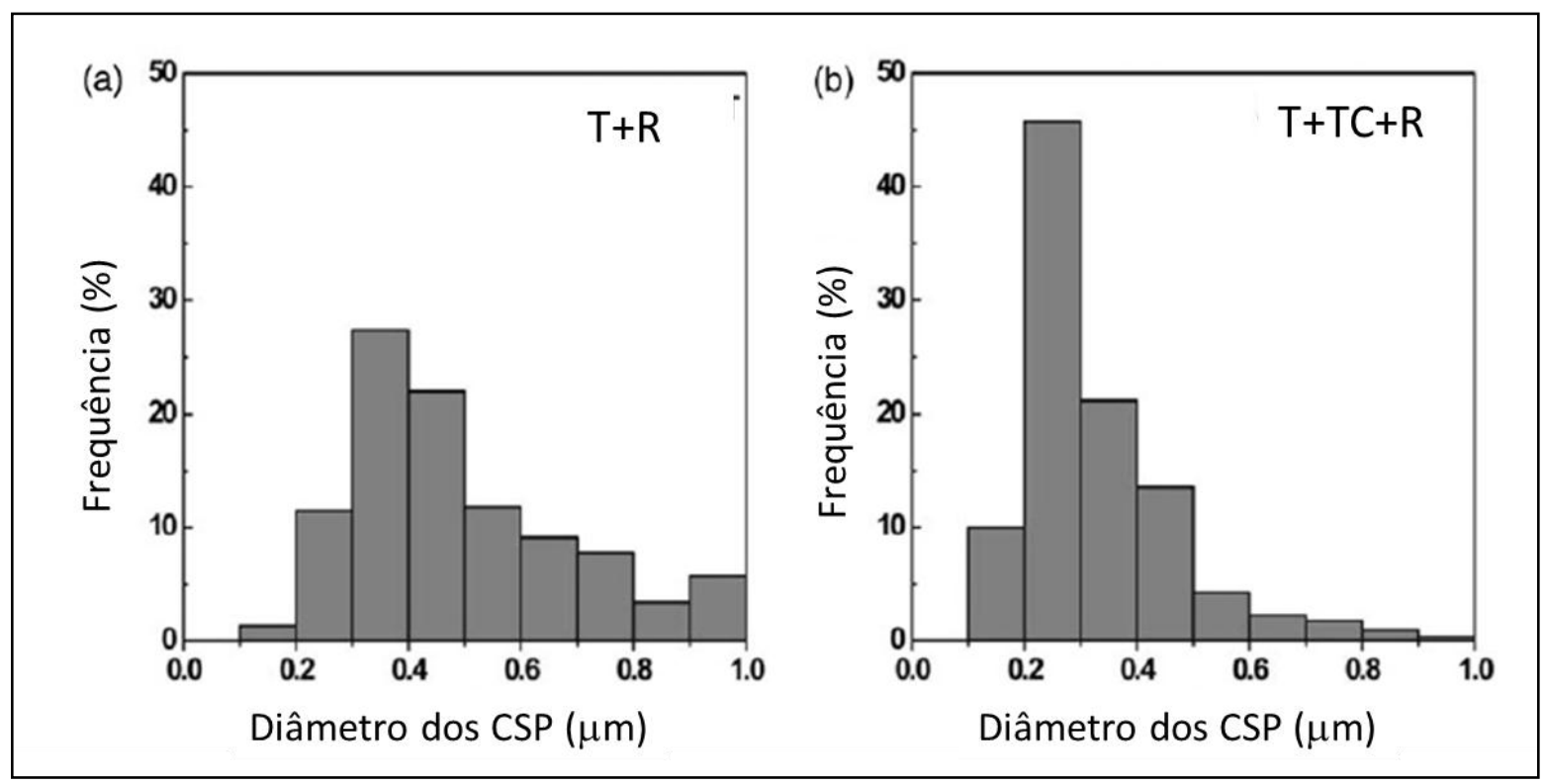

Figura 3 - Distribuição dos carbonetos secundários pequenos (CSP) apresentados sem (T+R) e com $(\mathrm{T}+\mathrm{TC}+\mathrm{R})$ o tratamento criogênico. Adaptado da referência [24].

Uma possível explicação para os resultados apresentados na figura 3 seria um artefato de observação, já que a microestrutura inicial era intrinsicamente 
heterogênea em relação à distribuição dos carbonetos, como apresentado em outro trabalho (figura 4) ${ }^{[25]}$. A microestrutura inicial do aço em estudo, conforme apresentado na figura 4, mostra que a estrutura eutética de carbonetos oriunda da solidificação ainda é visível, os carbonetos secundários (figura 5) provavelmente precipitaram no estado sólido durante $o$ resfriamento do lingote e foram esferoidizados durante a austenitização no campo $\mathrm{Y}+$ carbonetos. Das microestruturas por eles apresentadas, pode-se inferir que a deformação durante o forjamento das barras não foi suficiente para distribuir uniformemente os carbonetos eutéticos e, consequentemente, remover as heterogeneidades de composição oriundas do processo de solidificação. Apesar dos autores ${ }^{[25]}$ mencionarem a presença destes carbonetos eutéticos, eles afirmam que isto não é um problema, pois, todas as amostras possuem a mesma fração volumétrica e elas não são alteradas com o tratamento térmico.

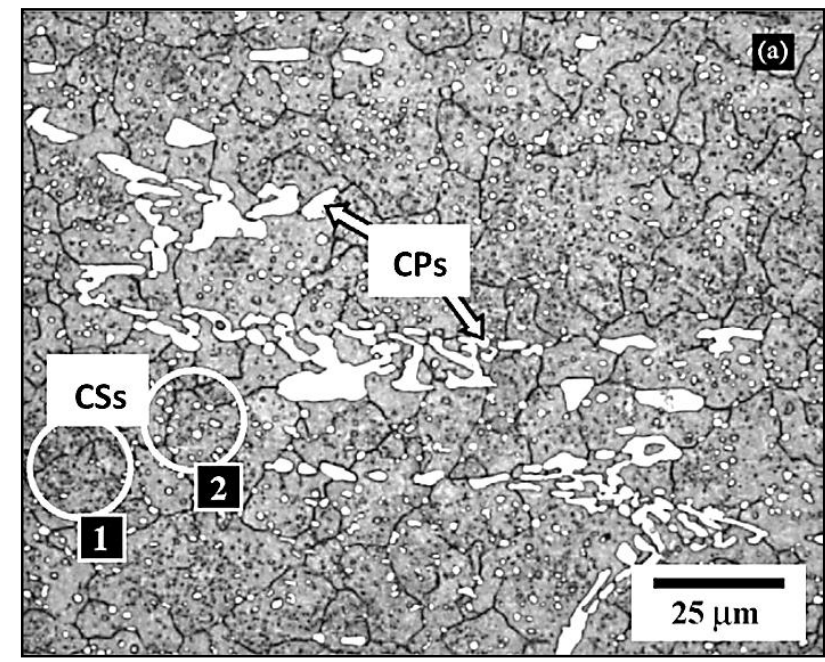

Figura 4 - Microestrutura inicial do aço AISI D2 estudado por Das et al. ${ }^{[2 b]}$. CSs: Carbonetos Secundários; CPs: Carbonetos Primários. Adaptados da referência [25]. 


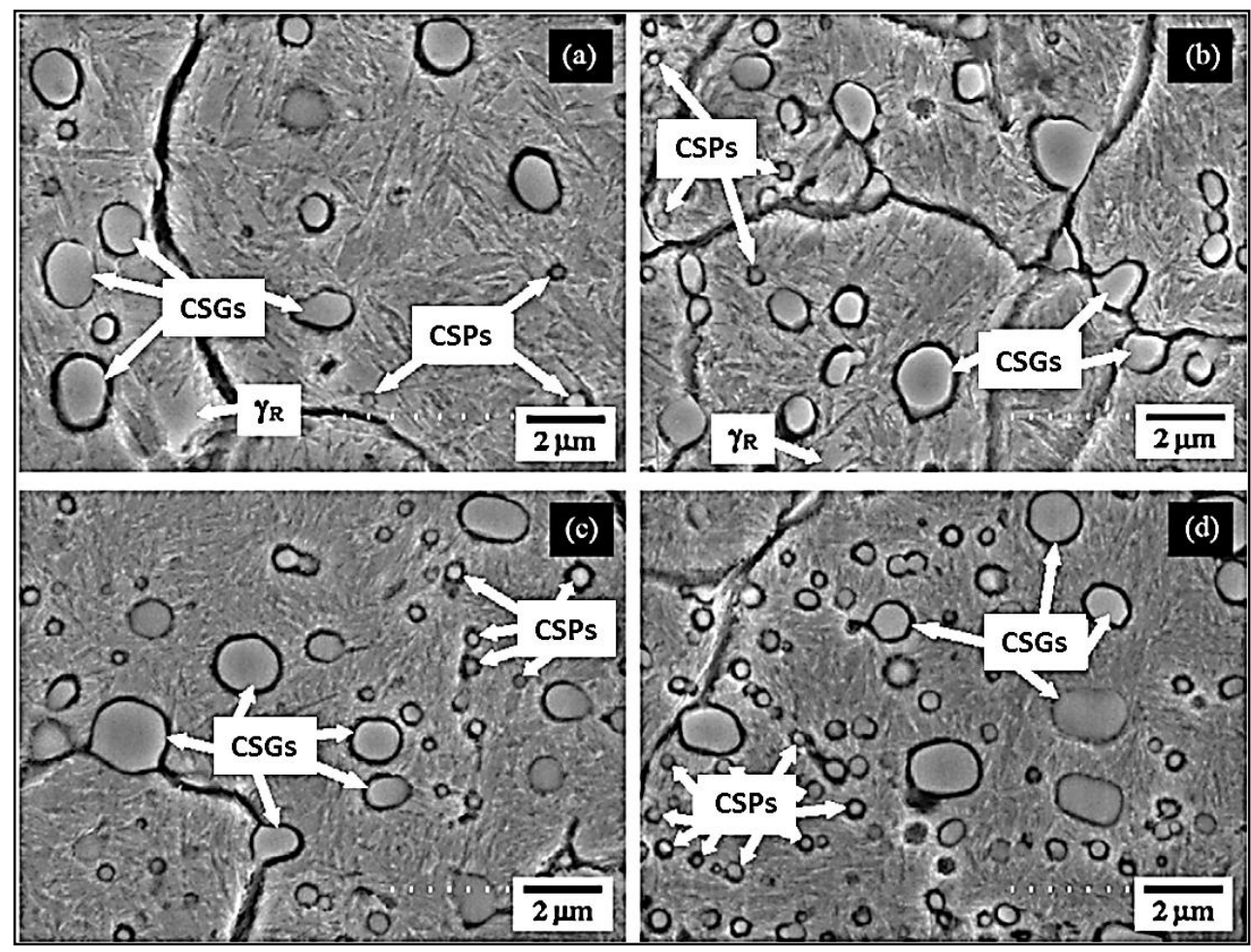

Figura 5 - Micrografias apresentadas por Das et al. ${ }^{25]}$ como representativas de (a) tratamento térmico convencional; (b) subzero a $-75^{\circ} \mathrm{C}$; (c) subzero a $-125^{\circ} \mathrm{C}$; e (d) criogênico a $-196^{\circ} \mathrm{C}$. Todas austenitizadas a $1020^{\circ} \mathrm{C}$ e revenidas a $210^{\circ} \mathrm{C}$ por duas horas ( $\mathrm{TC}$ entre têmpera e revenimento). CSGs: Carbonetos Secundários Grandes; CSPs: Carbonetos Secundários Pequenos. Adaptado da referência [25].

\subsubsection{Alívio de Tensões}

Devido ao gradiente térmico a que a peça é submetida durante o tratamento criogênico, frequentemente na prática industrial é necessária a realização de uma etapa de alívio de tensões entre a têmpera (resfriamento até a temperatura ambiente) e o tratamento criogênico.

O Heat Treater's Guide ${ }^{[26]}$, conhecido manual para tratadores térmicos, apresenta este tratamento com o nome de "Estabilização" e opcional no ciclo térmico dos aços da série D (aços para trabalho a frio com alto cromo). Segundo o manual [26] trata-se de um revenido de alívio de tensões entre 150 e $160^{\circ} \mathrm{C}$ por um curto período antes de resfriar a peça a $-85^{\circ} \mathrm{C}$, em especial para peças com geometrias complexas e com mudanças abruptas no tamanho das seções; com revenimento logo após a peça alcançar a temperatura ambiente. Aparentemente, o Heat Treater's Guide denomina de "Estabilização" a soma dos tratamentos térmicos de alívio de tensões (AT) e subzero. 
Como citado anteriormente, nenhum trabalho relacionado ao tratamento criogênico deu a devida atenção a este tratamento, apesar de tê-lo utilizado, mesmo que em temperatura inferiores.

Meng et al. ${ }^{[6]}$ realizaram uma etapa de envelhecimento a $60^{\circ} \mathrm{C}$ (não mencionaram o tempo) entre a têmpera e o tratamento criogênico. Utilizaram duas temperaturas de austenitização $\left(1100\right.$ e $\left.1020^{\circ} \mathrm{C}\right)$ e tratamentos subzero a $-50^{\circ} \mathrm{C}$ e criogênico a $-180^{\circ} \mathrm{C}$. Os valores de austenita retida por eles obtidos, antes e após os tratamentos criogênicos são apresentados na figura 2. Meng et al. ${ }^{[6]}$ não fizeram nenhuma discussão em relação a estabilização da austenita retida, no entanto, como pode ser observado na figura 2, não ocorre a transformação completa da austenita retida em martensita e, além disso, apesar da amostra austenitizada em menor temperatura conter menor teor de austenita retida após a têmpera, não há variação entre as duas temperaturas subzero. Na amostra austenitizada em temperatura mais elevada o efeito da estabilização da austenita é menor, ocorrendo maior transformação, fenômeno que será discutido adiante.

\subsubsection{Revenimento}

A etapa de revenimento é outro assunto muito discutido na literatura e que apresenta variações entre os trabalhos. Uma primeira discussão encontrada na literatura é a posição da etapa de revenimento, se antes ou após o tratamento criogênico, outros aspectos são a temperatura e o número de ciclos de revenimento. Além disso, há trabalhos que apresentam a formação de uma determinada fração volumétrica de carbonetos $\eta$ como o objetivo do revenimento após o tratamento criogênico.

Yun et al. ${ }^{[11]}$ afirmam que se o TC for realizado entre a etapa de têmpera e a de revenimento, após o tratamento criogênico somente 1,5\% da austenita retida permanecerá na microestrutura e que se o TC for realizado após a etapa de revenimento, cerca de $5 \%$ da austenita permanecerá retida na microestrutura do aço rápido AISI M2. Segundo os autores, isto ocorre devido à estabilização da austenita durante a etapa de revenimento quando a mesma é realizada antes do tratamento criogênico.

Moore e Collins ${ }^{[9]}$ realizaram uma série de experimentos para verificar o efeito dos parâmetros do tratamento criogênico na dureza de aços ferramenta (AISI D2 e 
Vanadis 4). Eles determinaram a curva de revenimento para estes dois aços, a figura 6 apresenta a curva de revenimento do aço AISI D2, com e sem o tratamento criogênico. As amostras foram austenitizadas a $1075^{\circ} \mathrm{C}$ em forno à vácuo e temperadas com nitrogênio gasoso até a temperatura de $50^{\circ} \mathrm{C}$ (note que esta temperatura pode ser considerada como temperatura de alívio de tensões em item posterior) e na sequência metade das amostras foram revenidas e metade foram tratadas criogenicamente a $-196^{\circ} \mathrm{C} / 15$ min e depois revenidas. As amostras tratadas criogenicamente foram submetidas a um único revenimento por 2 horas e as não tratadas criogenicamente a duplo revenimento por 2 horas cada. Segundo os autores era de se esperar a ausência do pico de dureza secundária nas amostras com TC devido à menor quantidade de austenita retida. Os autores partiram do pressuposto de que se não há austenita retida, não é necessário duplo revenimento. No entanto, os mecanismos envolvidos no primeiro revenimento dos aços ferramenta não se resumem a transformação da austenita retida em martensita, e o fato de os revenimentos não terem sido realizados da mesma forma, dificulta a interpretação destes resultados.

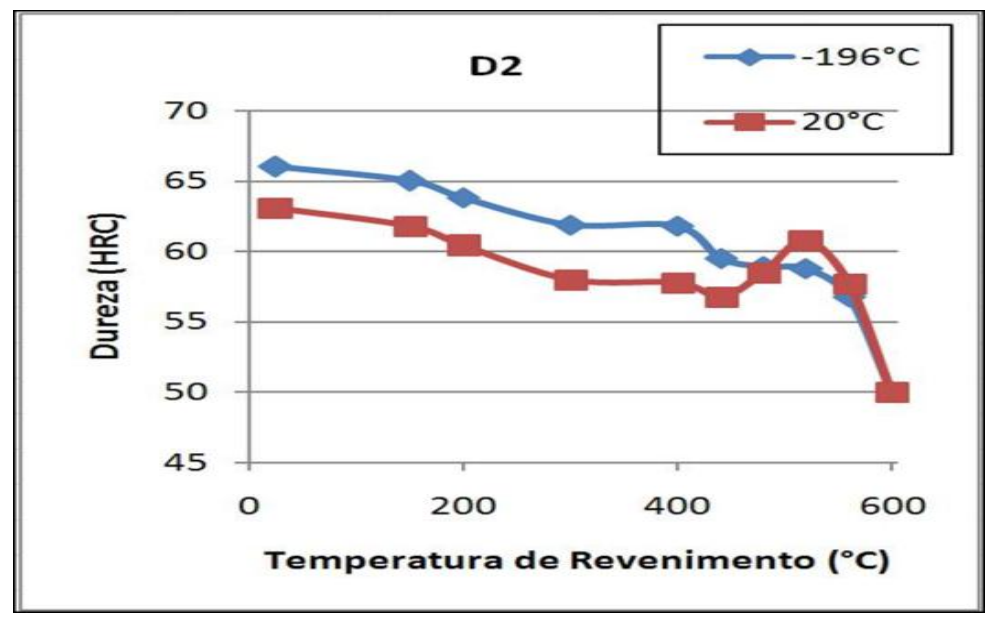

Figura 6 - Curva de revenimento do aço AISI D2. Tratamento convencional $\left(20^{\circ} \mathrm{C}\right)$ : têmpera $\left(1075^{\circ} \mathrm{C}\right)$ + revenimento duplo por duas horas. $\left(-196^{\circ} \mathrm{C}\right)$ : têmpera $\left(1075^{\circ} \mathrm{C}\right)+\mathrm{TC}\left(-196^{\circ} \mathrm{C} / 15 \mathrm{~min}\right)+$ revenimento único por duas horas. Adaptado da referência [9].

Silva et al. ${ }^{[27]}$ não detectaram mudança no pico de dureza secundária em um aço AISI D2 quando austenitizado para têmpera à $1010^{\circ} \mathrm{C}$ e $1040^{\circ} \mathrm{C}$ com a inserção de $\mathrm{TC}$ a $-196^{\circ} \mathrm{C} / 15$ minutos e de uma etapa de alívio de tensões ( $130^{\circ} \mathrm{C} / 90$ minutos) entre a têmpera e o TC, conforme figura 7. No entanto, foi detectado um pequeno 
desvio para a direita após o pico de dureza secundária nas amostras com tratamento criogênico.
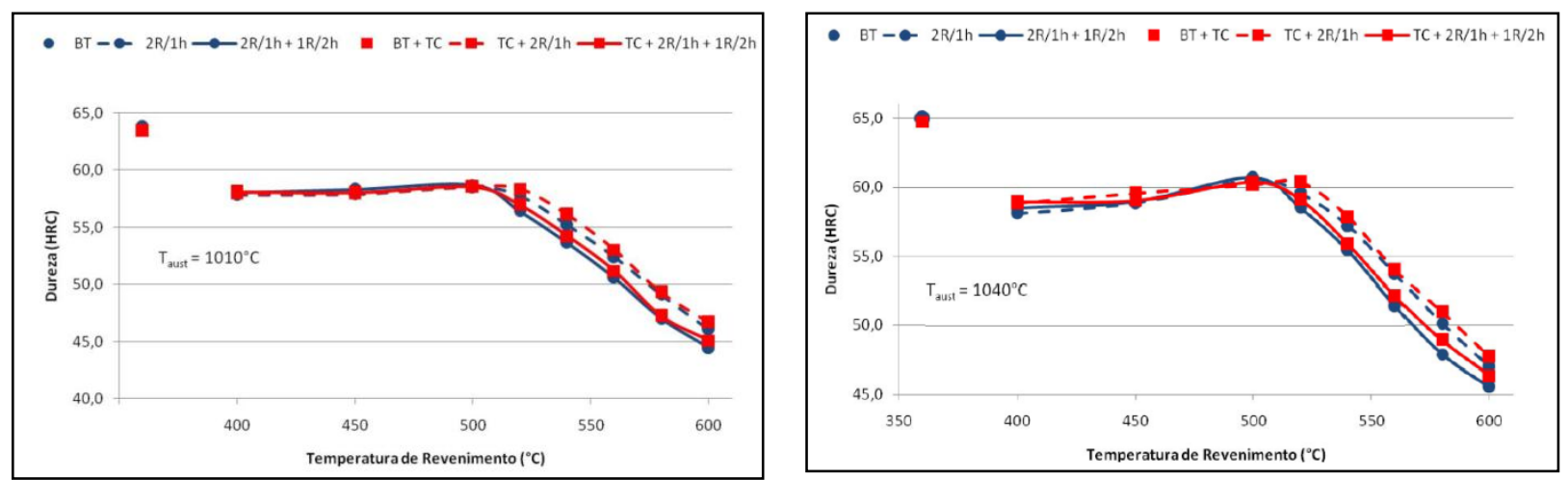

Figura 7 - Curva de revenimento para amostras de um aço AISI D2 austenitizadas a 1010 e $1040^{\circ} \mathrm{C}$, temperadas em óleo, com etapa de alívio de tensões $\left(130^{\circ} \mathrm{C} / 90\right.$ minutos) para as amostras com TC/15 minutos. BT - bruta de têmpera; $\mathrm{R}$ - revenimento; TC - tratada criogenicamente. Desvio de 0,2 HRC ${ }^{[27]}$.

Recentemente, Oppenkowski et al. ${ }^{[7]}$ determinaram as curvas de revenimento do aço AISI D2 para temperaturas de austenitização de $980^{\circ} \mathrm{C}$ e $1080^{\circ} \mathrm{C}$, conforme figura 8. No entanto, não fica claro no trabalho o número de revenimentos para as amostras sem TC, com TC foi um único revenimento. O comportamento das curvas é bastante parecido com os resultados de Moore e Collins ${ }^{[9]}$.

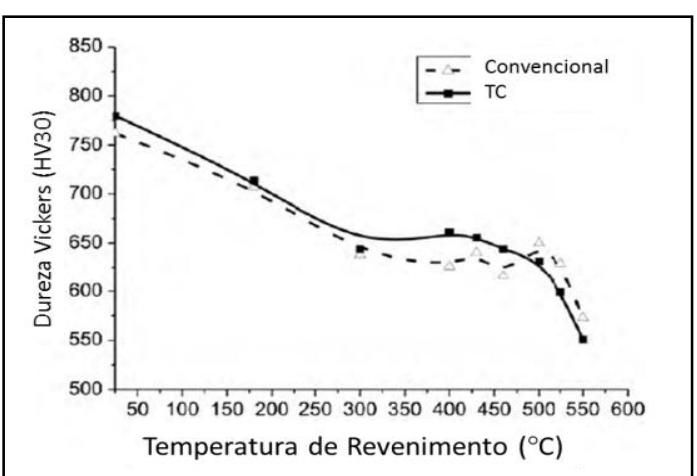

(a)

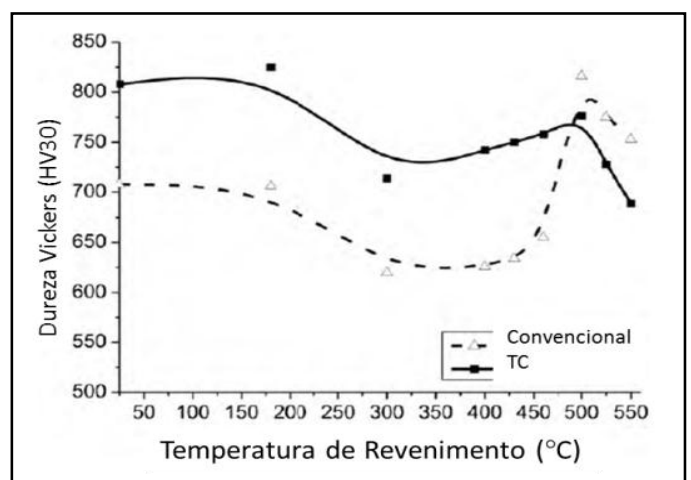

(b)

Figura 8 - Curvas de revenimento para amostras com tratamento térmico convencional e com tratamento criogênico para o aço AISI D2. (a) Temperatura de austenitização de $980^{\circ} \mathrm{C}$; (b) Temperatura de austenitização de $1080^{\circ} \mathrm{C}$. Adaptado da referência [7].

Pellizari e Molinari ${ }^{[17]}$ determinaram a curva de curva de revenimento do aço AISI D2 (sob a nomenclatura X155CrMoV12), como mostrado na figura 9, com somente um revenimento de 1 hora para todas as amostras (com e sem TC). As amostras foram austenitizadas a $980^{\circ} \mathrm{C}$ e verificou-se o mesmo comportamento apresentado nas figuras 6 e 8 com supressão do pico de dureza secundária para as 
amostras tratadas criogenicamente. A isto foi atribuída a menor presença de austenita retida disponível para as reações de revenimento, como a precipitação de carbonetos submicroscópicos de $\mathrm{Cr}$ e Mo ${ }^{[17]}$. No entanto, a precipitação de carbonetos no revenimento ocorre preferencialmente nos defeitos da martensita supersaturada em C, assim, a presença de maior fração volumétrica de austenita retida dificultaria as reações de revenido (da martensita).

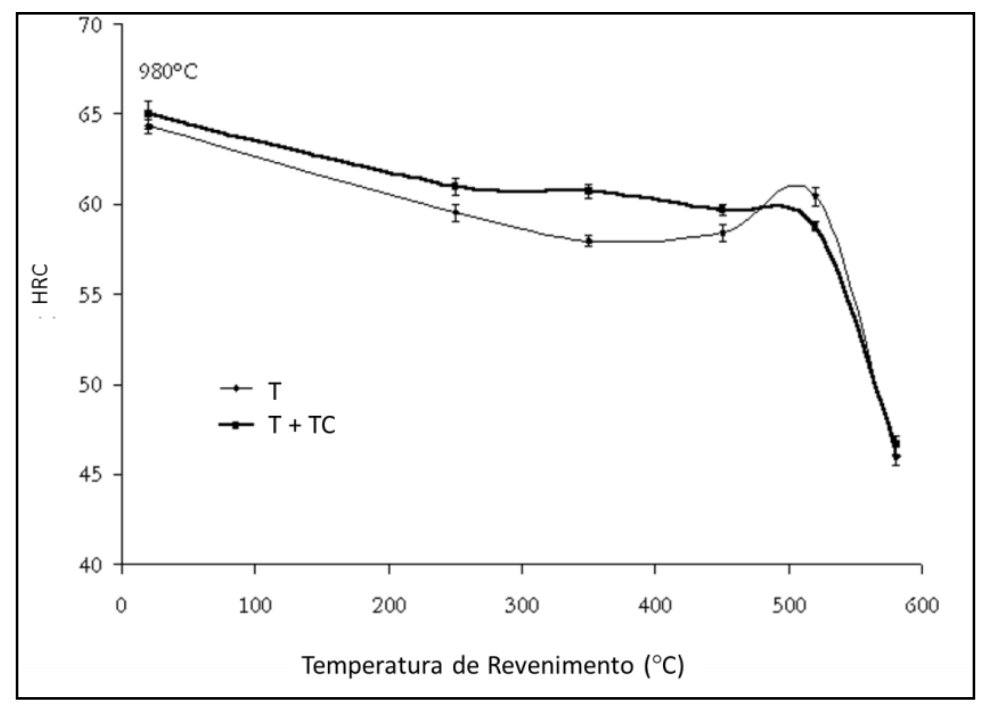

Figura 9 - Curva de revenimento para o aço AISI D2 com e sem tratamento criogênico. As amostras foram austenitizadas a $980^{\circ} \mathrm{C}$ e submetidas a um único revenimento de 1 hora. Adaptado da referência [17].

A figura 10 apresenta curvas de revenimento do aço AISI D2 para diversas temperaturas de austenitização e revenimentos duplos por duas horas cada ${ }^{[28]}$. Verifica-se que nas curvas apresentadas nas figuras $8^{[7]}$ e $9^{[17]}$, não foram realizados revenimentos para as temperaturas iniciais apresentadas nos gráficos (uma temperatura intermediária seria $100^{\circ} \mathrm{C}$ ). Segundo Mendanha ${ }^{[28]}$, a elevação da dureza verificada para baixas temperaturas de revenimento está associada à precipitação de carbonetos $\varepsilon$. Desta forma, as figuras $8^{[7]}$ e $9^{[17]}$ deveriam tratar o ponto de dureza "como temperado" como um ponto isolado, e não fazendo parte da curva de revenimento. 


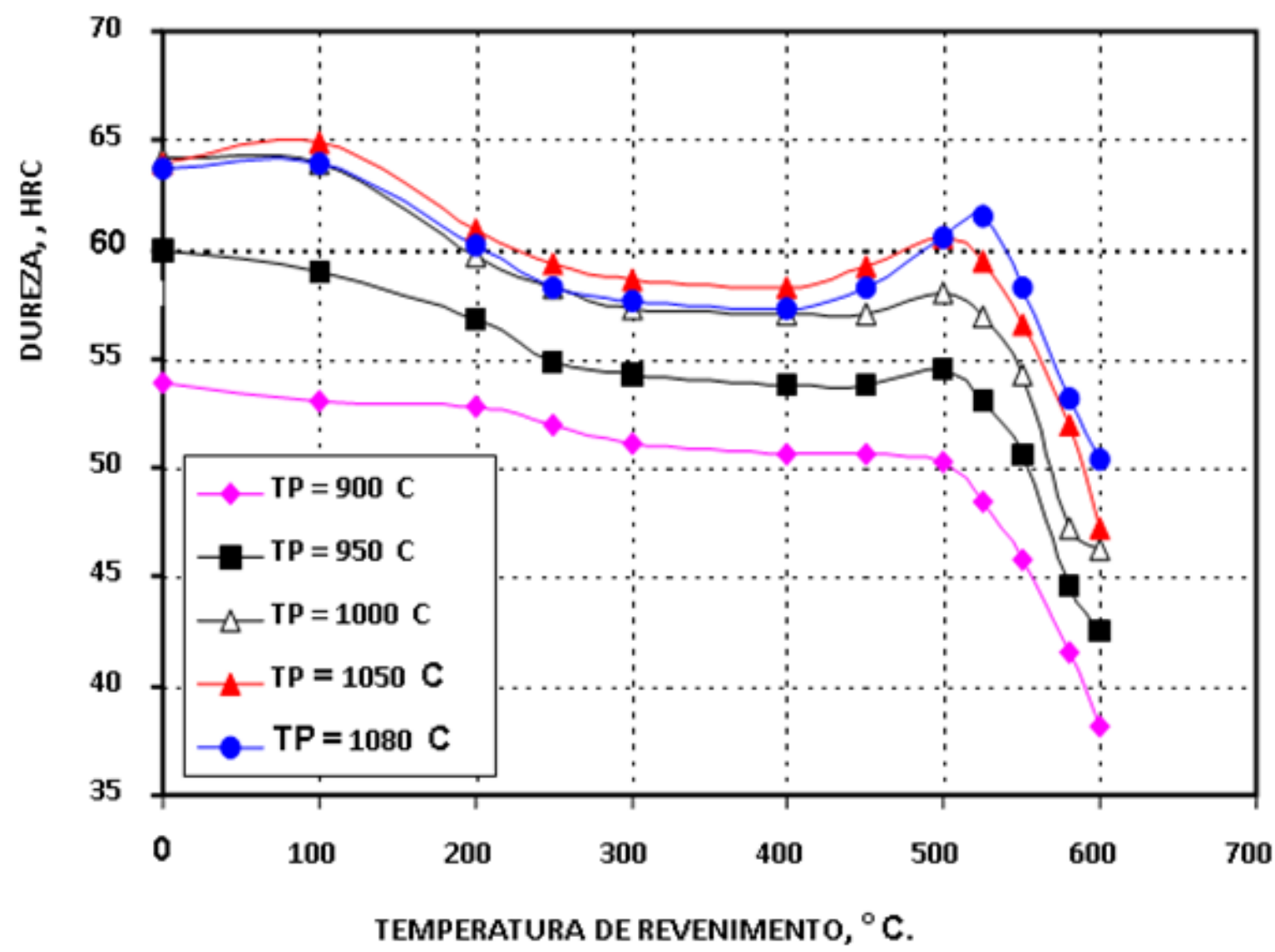

Figura 10 - Curvas de revenimento para o aço AISI D2. As amostras foram austenitizadas sob vácuo por 30 minutos e temperadas em óleo, os revenimentos duplos foram realizados por 2 horas cada ${ }^{[28]}$.

Nos experimentos de Mohan Lal et al. ${ }^{[29]}$ (com os aços AISI D3, AISI M2 e AISI T1) a etapa de tratamento criogênico foi realizada entre a têmpera e o revenimento e após têmpera + revenimento. Certificaram-se de que não havia austenita retida em nenhuma das amostras por meio de análise de difração de raios$X$. Nas primeiras a resistência ao desgaste foi maior, e em ambas a resistência ao desgaste foi maior do que nas amostras tratadas convencionalmente (têmpera + revenimento). Pellizari e Molinari ${ }^{[17]}$ estudaram o efeito da posição do tratamento criogênico em relação aos revenimentos (antes ou após) no aço AISI D2 e verificaram, da mesma forma que Mohan Lal et al. ${ }^{[29]}$, que o efeito do tratamento criogênico é mais pronunciado (em relação à resistência ao desgaste) quando realizado antes do revenimento. Além disso, Pellizari e Molinari ${ }^{[17]}$ obtiveram melhores resultados quando o segundo revenimento foi realizado a $240^{\circ} \mathrm{C}$ (comparado com duplo revenimento a $500^{\circ} \mathrm{C}$ ). Isto foi atribuído a não coalescência dos carbonetos em temperaturas mais baixas. 
Desta forma, os trabalhos ${ }^{[17,29]}$ apontam que a inclusão da etapa de criogenia no ciclo térmico melhora as propriedades mecânicas e tribológicas dos aços ferramenta qualquer que seja a sua posição. No entanto, se o tratamento criogênico for realizado entre a têmpera e o revenimento a melhora nestas propriedades é ainda maior.

Segundo Yen apud Kamody ${ }^{[30]}$ o ciclo térmico com a etapa de criogenia pode ser escolhido visando uma determinada fração volumétrica de carbonetos $\eta$ precipitados após têmpera + tratamento criogênico + revenimento, sendo esta uma função da temperatura e do tempo de revenimento. Eles não citaram o modo utilizado para medição de fração volumétrica dos carbonetos $\eta$, mas apresentaram resultados nos quais verifica-se que quanto maior o tempo e maior a temperatura de revenimento, maior será a fração volumétrica de carbonetos $\eta$. Segundo eles há uma fração volumétrica ótima para a resistência ao desgaste em torno de 5\%, acima disto a resistência ao desgaste torna-se constante (a máxima fração volumétrica de carbonetos $\eta$ obtida por eles foi de $6 \%$ ).

Yen apud Kamody ${ }^{[31]}$ determinou então ciclos de revenimento para a precipitação de 5\% de carbonetos (temperaturas altas - tempos curtos; temperaturas baixas - tempos longos), conforme apresentado na tabela 2. Estes resultados, no entanto, trazem dúvidas visto que a literatura, em geral, tem demonstrado dificuldades em identificar os carbonetos $\eta$ (que seriam nanométricos).

Tabela 2 - Temperatura de revenimento em função do tempo para precipitação de $5 \%$ de carbonetos $\eta^{[31]}$

\begin{tabular}{lcccccccccc}
\hline $\mathrm{T}\left({ }^{\circ} \mathrm{C}\right)$ & 650 & 595 & 540 & 480 & 425 & 370 & 315 & 260 & 205 & 150 \\
\hline $\mathrm{t}(\mathrm{min} / \mathrm{cm})$ & 2 & 4 & 8 & 12 & 30 & 45 & 75 & 90 & 120 & 150 \\
\hline
\end{tabular}

\subsubsection{Resumo do Ciclo Térmico do Aço AISI D2 com TC}

Mais uma vez, este trabalho não busca fazer uma revisão completa de todos os mecanismos que possam ocorrer durante o ciclo térmico dos aços. Pretende-se apresentar uma revisão das transformações de fases que possam, de alguma forma, ser influenciadas pela inserção da etapa criogênica.

Após a deformação a quente (forjamento ou laminação) o aço é recozido. $O$ objetivo do tratamento térmico de recozimento é produzir uma dispersão uniforme de carbonetos esferoidizados em uma matriz ferrítica. A uniformidade da microestrutura 
produzida pelo recozimento é importante nas etapas posteriores de tratamento térmico e nas aplicações deste aço. Se não houver uniformidade destes carbonetos podem ocorrer trincas durante a têmpera ou diminuição da vida das ferramentas em serviço ${ }^{[5]}$.

A austenitização do aço, para têmpera, é realizada no campo y + carbonetos. Uma vez que a austenita é formada ocorre a partição dos elementos de liga e do carbono entre a austenita e os carbonetos em função do equilíbrio a uma dada temperatura. Conforme os carbonetos são dissolvidos (carbonetos esferoidizados durante o recozimento, não ocorre dissolução em quantidade considerável dos carbonetos eutéticos) a composição da austenita é alterada, aumentando a quantidade de carbono e de elementos de liga na mesma ${ }^{[5]}$. Quanto maior a temperatura e o tempo de austenitização, mais carbonetos serão dissolvidos, produzindo uma austenita mais estável e grãos maiores, uma vez que os carbonetos agem como limitadores para o crescimento do grão. Quanto mais elementos de liga na austenita, maior o pico de dureza secundária, como observado nas figuras $8^{[7]} \mathrm{e}$ $10^{[28]}$, pois há mais elementos de liga e carbono disponíveis para a precipitação de carbonetos secundários de revenido.

Quanto maior a temperatura de austenitização, menor será a temperatura Mi (temperatura de início da transformação martensítica), devido à maior dissolução de carbonetos a qual enriquece a matriz austenítica em carbono e elementos de liga ${ }^{[28]}$. Em aços como o AISI D2, dificilmente a temperatura Mf (temperatura final de transformação martensítica) é alcançada. Desta forma, aplicam-se tratamentos subzero para que ocorra uma transformação adicional da austenita em martensita em temperaturas abaixo da temperatura ambiente ${ }^{[5]}$.

Estes tratamentos abaixo da temperatura ambiente também são denominados de tratamentos criogênicos e a eles vem sido atribuídos mais fenômenos do que simplesmente a transformação da austenita retida em martensita. Os principais são a decomposição e condicionamento da martensita ${ }^{[10,11,12]}$ e a precipitação ${ }^{[10,6]}$ ou aumento da fração volumétrica ${ }^{[11,12]}$ de carbonetos $\eta$ (eta).

No entanto, há muita confusão na literatura sobre tratamentos criogênicos dos aços ferramenta em relação a que tipo de carbonetos pode ter sua precipitação influenciada por tais tratamentos. Das et al. ${ }^{[25]}$ apresentam modificações nos carbonetos secundários micrométricos (formados no campo $\mathrm{Y}+$ carbonetos ou 
durante revenimento em altas temperaturas no campo $\alpha+$ carbonetos) devido a etapa criogênica.

No entanto, a única oportunidade para a precipitação de carbonetos após o tratamento criogênico é durante o revenimento. Os carbonetos precipitados durante o tratamento térmico de revenimento são finos, abundantes e distribuídos uniformemente, com tamanhos entre 30 e $70 \mathrm{~nm}^{[32]}$. Tais carbonetos secundários precipitam preferencialmente ao longo das ripas ou placas de martensita e frequentemente são coerentes com a matriz, com relações de orientação bem estabelecidas ${ }^{[33]}$.

\subsection{Martensita}

A transformação martensítica é uma transformação de estado sólido , a qual ocorre sem difusão (Nishiyama ${ }^{[34]}$ ). A nucleação não ocorre de forma aleatória. Ao contrário, há locais preferenciais pré-existentes para a nucleação e estes locais podem ser os defeitos do reticulado (Jones e Entwisle apud Nishiyama ${ }^{[34]}$ ).

A maior parte dos aços martensíticos pertence a uma categoria na qual a martensita é atérmica. Nesta categoria a transformação martensítica inicia à temperatura Mi e continua enquanto a temperatura diminui. Quando o resfriamento é interrompido, as reações param, e quando o resfriamento é reiniciado, a transformação recomeça. Estas reações ocorrem somente enquanto a temperatura está mudando (no resfriamento ou no aquecimento até temperaturas ambiente $\left.{ }^{j}\right)^{[34]}$.

A figura $11^{[34]}$ apresenta estruturas martensíticas típicas em aços carbono. Em (a) é apresentada a estrutura martensítica de um aço com $0,2 \% \mathrm{C}$, sendo ela na forma de ripas e contendo alta densidade de discordâncias. Em (b), um aço contendo $0,8 \% \mathrm{C}$ com estrutura de placas e ripas, com discordâncias e maclas. E em (c), um aço com 1,4\%C com martensita na forma de placas e grande quantidade de maclas $^{[34]}$

Verifica-se da figura 11 que quanto menor o teor de carbono na liga, mais refinada é a estrutura martensítica, ou seja, com martensita na forma de feixes de ripas e menos de placas. Também é amplamente conhecido que aumentando-se o

\footnotetext{
' Assume-se que a transformação é atérmica, no entanto, pode continuar ocorrendo ao aquecer a amostra submetida a temperaturas muito baixas, nas quais não haveria energia disponível para a reação.
} 
teor de carbono na austenita, a temperatura Mi diminui. Assim, pode-se dizer que a transformação martensítica que ocorre em temperaturas mais baixas produz uma martensita mais grosseira (desde que ainda haja espaço para o crescimento das mesmas).

A estrutura da martensita no aço AISI D2 corresponde (aproximadamente) à estrutura apresentada na figura 11(c), na forma de placas com muitas maclas internas. Na martensita em forma de ripas, a austenita retida apresenta-se em forma de filmes, entre as ripas. Na martensita em forma de placas, a austenita retida apresenta-se na forma de blocos entre as placas.
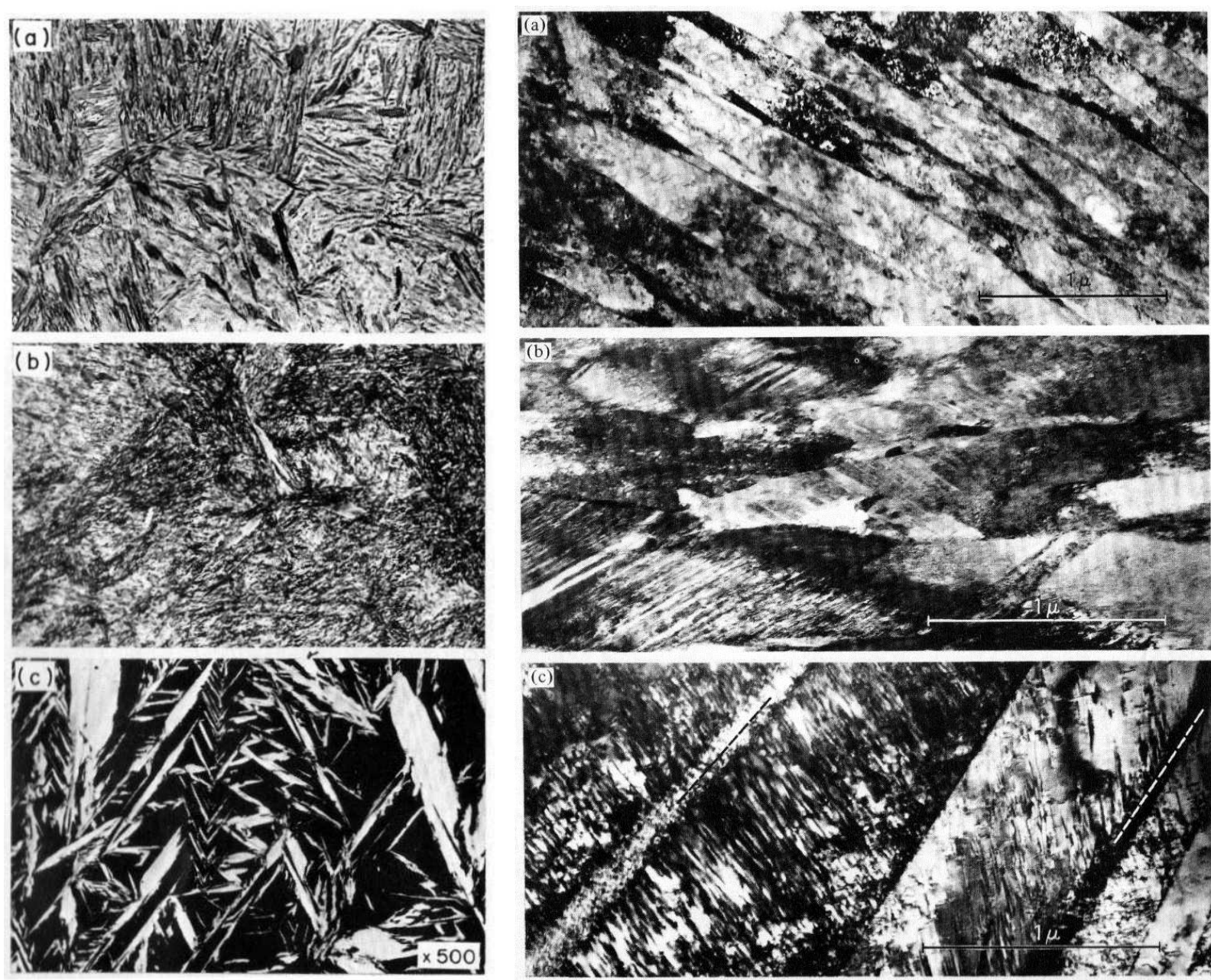

Microscopia ótica

Microscopia eletrônica de transmissão

Figura 11 - Estrutura martensítica de aços temperados. (a) $0,2 \% \mathrm{C}$; martensita na forma de ripas - a a' contem um grande número de discordâncias. (b) $0,8 \% \mathrm{C}$; martensita na forma de ripas e de placas - a a' contem discordâncias e maclas internas. (c) 1,4\%C, martensita na forma de placas - a $\alpha^{\prime}$ contem muitas maclas internas. Adaptado da referência [34] apud Inoue e Matsuda. 


\subsection{Martensita Isotérmica}

Em alguns casos a martensita pode ser formada isotermicamente, sendo chamada de martensita isotérmica (e não a bem conhecida martensita atérmica) ${ }^{[34]}$.

Kurdjumov e Maksimova apud Cech e Hollomon ${ }^{[35]}$ apresentaram trabalhos experimentais com aço manganês, aço alto carbono e com a liga $\mathrm{Fe}-\mathrm{Ni}-\mathrm{Mn}$ nos quais a martensita era formada isotermicamente em uma determinada faixa de temperaturas. Eles verificaram que em alguns casos a formação da martensita podia ser suprimida pelo resfriamento rápido até a temperatura do nitrogênio líquido. A partir de observações microestruturais da martensita formada isotermicamente, eles concluíram que este fenômeno é controlado por nucleação e não por crescimento.

Para validar os resultados de Kurdjumov e Maksimova, Cech e Hollomon fizeram experimentos que resultaram em curvas de tempo-temperaturatransformação para a martensita, conforme apresentado na figura $12^{[35]}$.

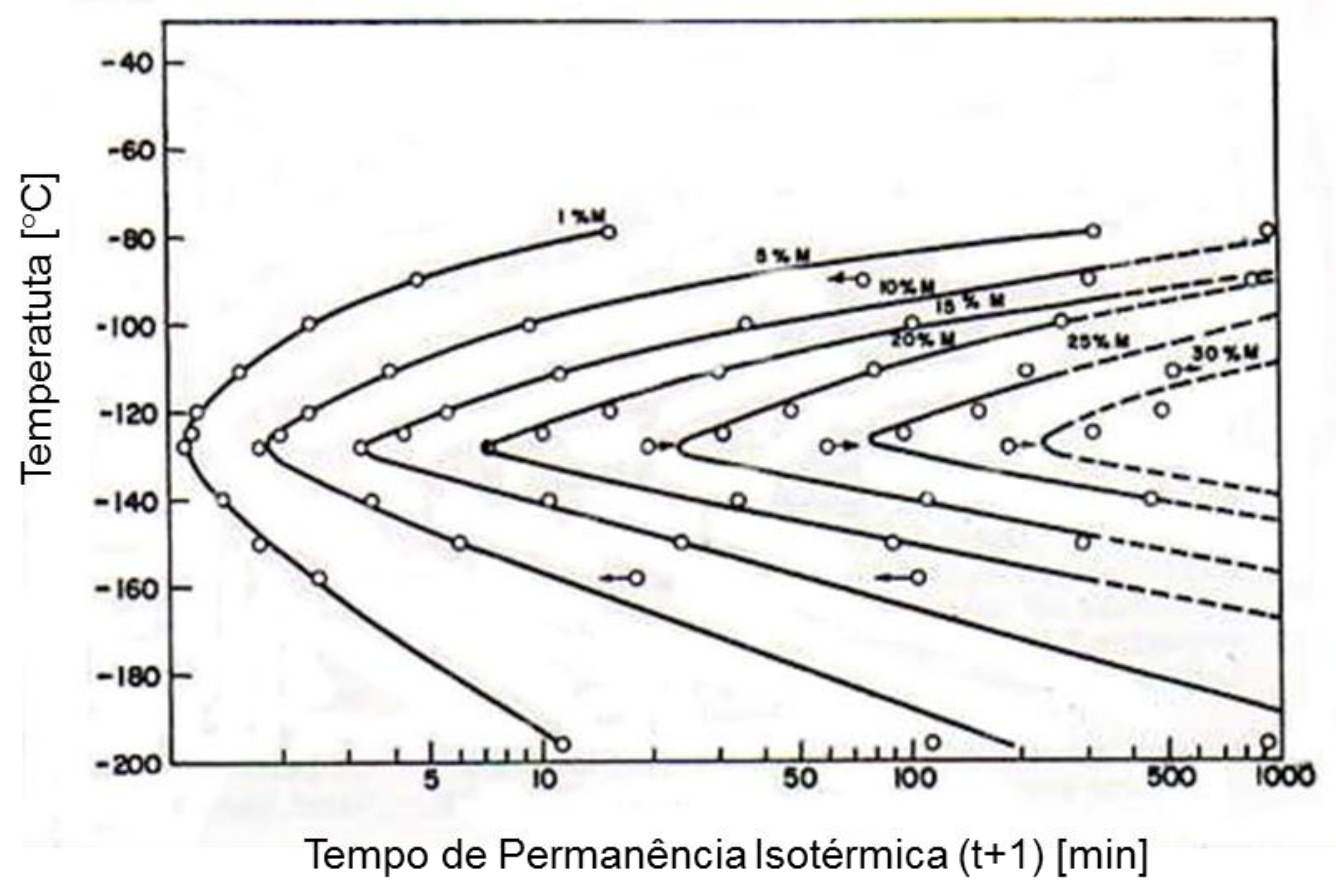

Figura 12 - Curva TTT para a formação de martensita em uma liga Fe-Ni-Mn. Adaptado da referência [35].

Eles ${ }^{[35]}$ concluíram que, para a liga Fe-Ni-Mn por eles estudada, com temperatura Mi abaixo da temperatura ambiente:

i. A formação isotérmica da martensita ocorre na faixa de temperaturas entre $-79^{\circ} \mathrm{C}$ e $-196^{\circ} \mathrm{C}$. A taxa de formação aumenta com a diminuição da 
temperatura até $-128^{\circ} \mathrm{C}$ e diminui com o resfriamento para temperaturas mais baixas.

ii. A formação de martensita pode ser suprimida completamente para esta liga com têmpera rápida abaixo da temperatura ambiente.

iii. Uma estabilização parcial da austenita pode ocorrer com o envelhecimento à temperatura ambiente, tanto antes do tratamento subzero como após alguma transformação isotérmica.

iv. A transformação isotérmica ocorre devido ao atraso na formação de núcleos de martensita seguido pelo crescimento rápido até o tamanho completo das ripas de martensita.

Estes resultados ${ }^{[35]}$ dão suporte ao argumento de Oppenkowski et al. ${ }^{[7]}$ de que a transformação martensítica seria desacelerada devido à temperatura criogênica $\left(-196^{\circ} \mathrm{C}\right)$ e de que seriam necessários tempos maiores para a transformação completa ${ }^{[7]}$. Esta hipótese, no entanto, não foi verificada em relação à $\mathrm{V} v$ de $\mathrm{Y}_{\mathrm{R}}$ (não medida), mas foi somente uma hipótese para explicar o aumento na resistência ao desgaste quando o TC foi realizado em tempos prolongados.

Segundo Nishiyama ${ }^{\left[{ }^{34]}\right.}$, mesmo no caso da transformação isotérmica da martensita não se poderia rejeitar por completo a hipótese de que ocorre uma nucleação autocatalítica. Pati e Cohen apud Nishiyama ${ }^{[34]}$, em uma liga Fe-24\%Ni$3 \% \mathrm{Mn}$, verificaram que o número de embriões é aproximadamente constante na faixa de temperaturas de -80 a $-196^{\circ} \mathrm{C}$. Verificaram também que a energia livre de ativação calculada a partir de medidas da cinética global da reação isotérmica diminui com a diminuição da temperatura.

Desta forma, o TC pode estar agindo na transformação martensítica de modo que não necessariamente seja uma "transformação mais completa", como citado por diversos autores, da $\bigvee_{R}$ em $\alpha$ '.

\subsection{Envelhecimento (Condicionamento) da Martensita Virgem}

Os tratamentos TC e TSZ possuem uma parcela dos mecanismos de transformações de fases envolvidos que pode ser atribuída ao envelhecimento da martensita, como será visto a seguir.

Taylor e Cohen ${ }^{[36]}$ definem o envelhecimento como todos os fenômenos relevantes de pré-precipitação de carbonetos (diferentemente do primeiro estágio do 
revenimento) que ocorrem na martensita virgem. Esta definição será utilizada no decorrer deste trabalho de modo a facilitar a divisão dos fenômenos/mecanismos que ocorrem antes/durante/depois do TC.

A figura 13 apresenta um resumo esquemático das principais mudanças microestruturais que ocorrem durante o envelhecimento (e revenimento) da martensita inicialmente virgem, em função da resistividade elétrica e tensão de escoamento (liga $\mathrm{Fe}-\mathrm{Ni}-\mathrm{C}$ ). $\mathrm{O}$ regime I, não apresentado na figura, corresponde à transformação da $V_{R}$ e não seria parte do processo de envelhecimento da martensita. O principal fenômeno do envelhecimento ocorre quando a martensita virgem se decompõe de forma espinodal, regime II, formando uma estrutura modulada com regiões de alto e baixo carbono. Nas imagens de MET (Microscopia Eletrônica de Transmissão), os respectivos aumentos na amplitude $(\Delta c)$ e comprimento de onda $(\lambda)$ das modulações de carbono são designados de subestágios $\mathrm{A} 1$ e $\mathrm{A} 2$. Um possível ordenamento dos átomos de carbono constitui o subestágio A3. Alternativamente, os subestágios A1 e A2 também podem estar associados à formação de agrupamentos de carbono distribuídos aleatoriamente $\mathrm{e}$ subsequente evolução da estrutura modulada pela tensão induzida pelo alinhamento destes agrupamentos. O regime III é incluído porque constitui o fim do envelhecimento e o início dos estágios subsequentes do revenimento, em particular, a precipitação de carboneto $\varepsilon$ (nos agrupamentos de carbono formados nas regiões de alto carbono) no estágio T1 e a precipitação de cementita no estágio T3 ${ }^{[36]}$. 


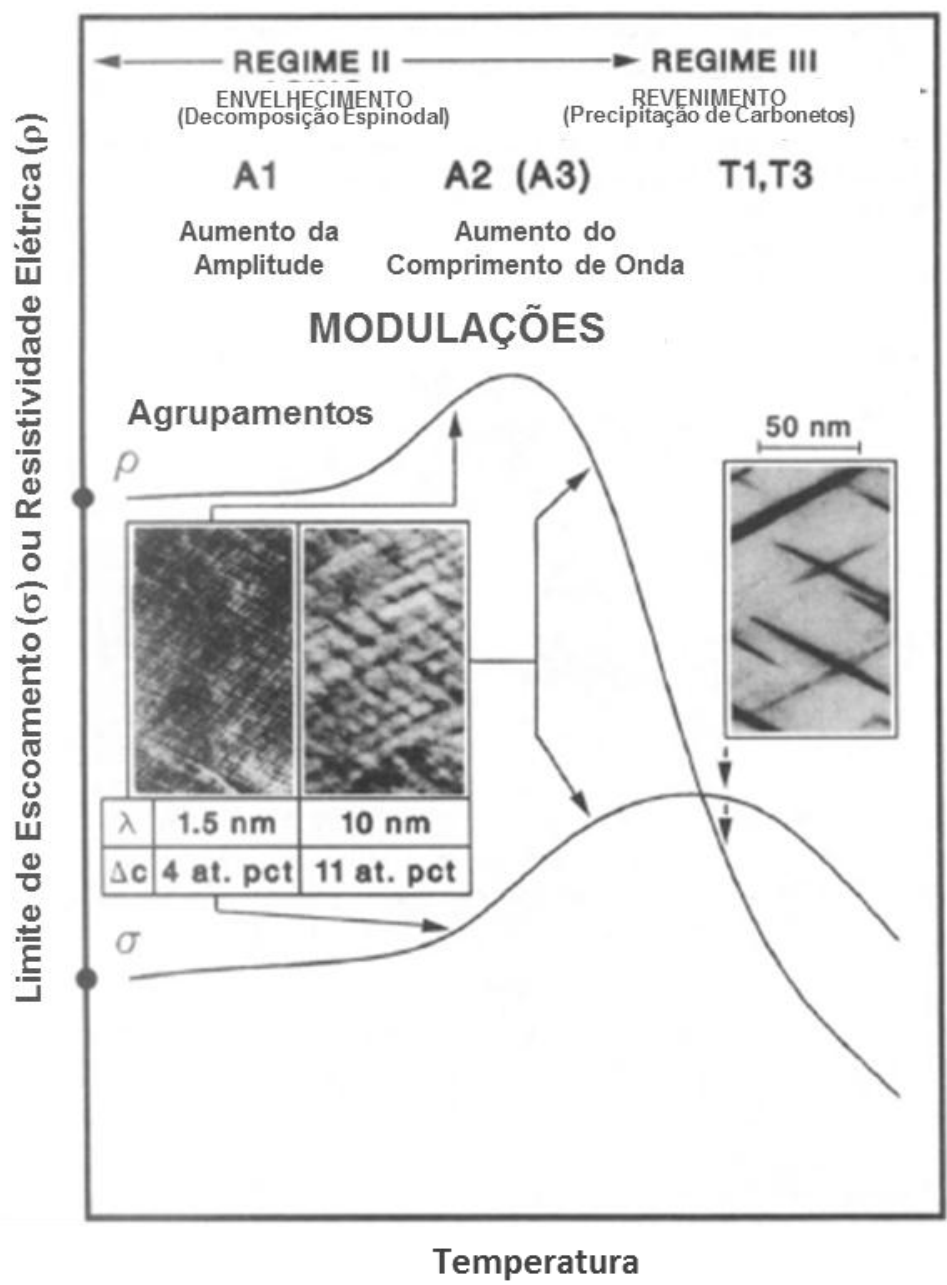

Figura 13 - Resumo esquemático das mudanças estruturais que ocorrem na martensita virgem (liga Fe-Ni-C) durante o envelhecimento da mesma. Adaptado da referência [36].

A decomposição espinodal é uma transformação na qual não existe nucleação. De acordo com a representação esquemática apresentada na Figura 14(I)(a), considerando um diagrama de equilíbrio com um "gap" de miscibilidade, se uma liga com composição $\mathrm{X}_{0}$ for solubilizada à temperatura $\mathrm{T} 1$ e então temperada à temperatura T2 a composição inicial será a mesma e a energia livre será $G_{0}$ na curva da Figura 14(I)(b). Entretanto, a liga (para composições dentro do "espinodal químico") estará imediatamente instável devido às pequenas flutuações na composição, que produzirão regiões ricas em $A$ e regiões ricas em $B$ que farão com que a energia livre total diminua. Desta forma uma difusão do tipo "up-hill" (montanha acima) acontecerá, como mostrado na Figura 14(II), até que um equilíbrio das composições $X_{1}$ e $X_{2}$ seja alcançado ${ }^{[37]}$. 


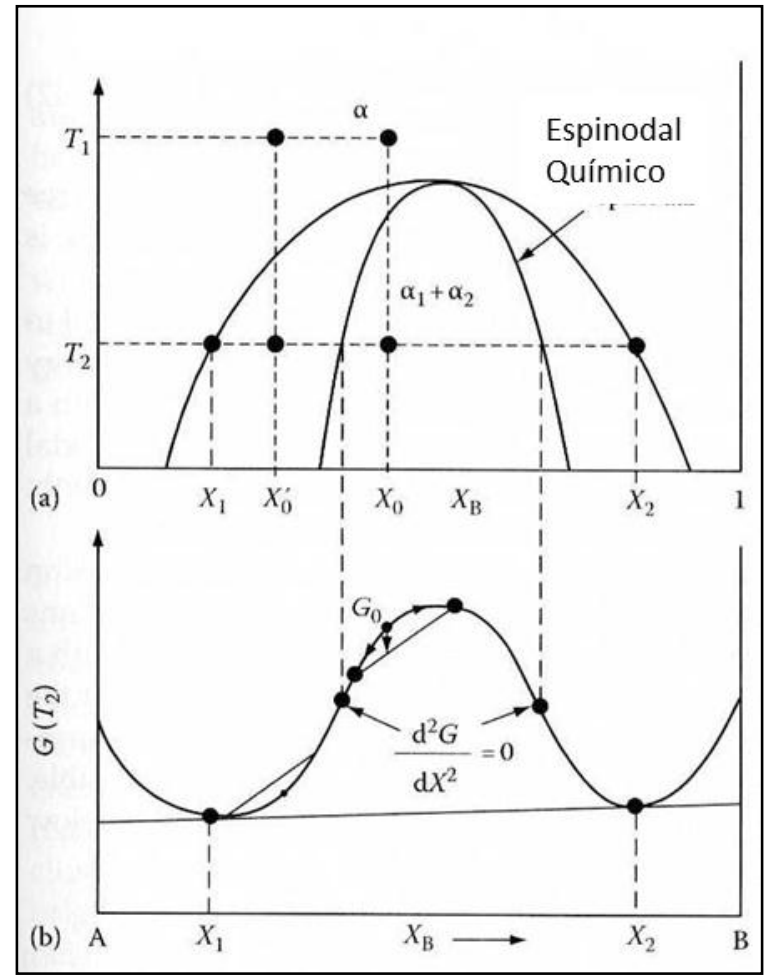

(I)

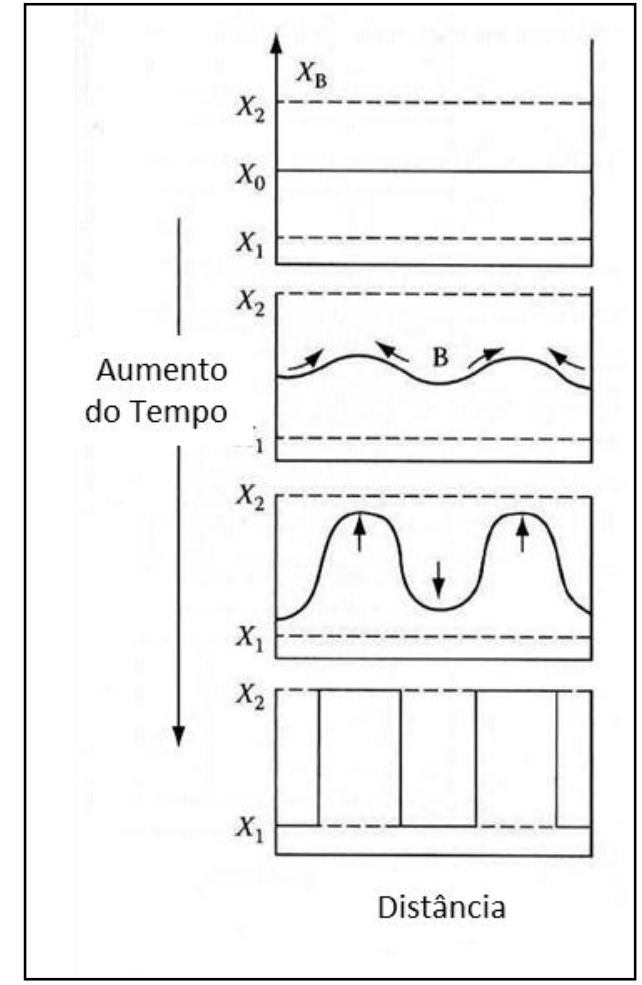

(II)

Figura 14 - Representação esquemática da decomposição espinodal. (la): diagrama de equilíbrio com um "gap" de miscibilidade; (Ib): curva de energia livre correspondente ao digrama acima; (II): representação esquemática dos perfis de composição para tempos crescentes em uma liga temperada dentro da região espinodal $\left(\mathrm{X}_{0} \mathrm{em}(\mathrm{la})\right)$. Adaptado da referência [37].

Meng et al. ${ }^{[6]}$ observaram a estrutura da martensita do aço AISI D2 por MET após o revenimento a $180^{\circ} \mathrm{C} / 10 \mathrm{~min}$, segundo eles a amostra sem TC apresenta uma martensita com estrutura modulada (com decomposição espinodal) grosseira e a amostra com tratamento subzero apresenta uma estrutura "tweedlike", que seria uma estrutura modulada mais fina. Apesar de não especificar diretamente a estrutura da martensita na amostra com TC, em suas discussões, indica que a estrutura é modulada e mais refinada que as anteriores.

\subsection{Estabilização da Austenita Retida}

Como já citado anteriormente, a etapa de alívio de tensões (também denominada de envelhecimento na literatura sobre tratamentos criogênicos ${ }^{[6]}$ ), realizada entre a têmpera e o tratamento criogênico, é importante no procedimento industrial para evitar trincas devido a gradientes térmicos durante o tratamento térmico. No entanto, esta etapa pode apresentar um forte efeito estabilizador da austenita, como descrito em trabalhos anteriores ${ }^{[38,39,40]}$. 
Cohen apud Roberts et al. ${ }^{[41]}$ mostrou que quanto maior o tempo de permanência a $60^{\circ} \mathrm{C}$, maior a porcentagem de austenita retida a não se transformar em martensita em temperaturas subzero, conforme a figura 15. Segundo este gráfico, uma amostra com $10 \%$ de austenita retida, mantida por 50 horas a $60^{\circ} \mathrm{C}$, quando submetida a $-150^{\circ} \mathrm{C}$ por outras 50 horas transformará apenas cerca de $2 \%$ da austenita retida em martensita.

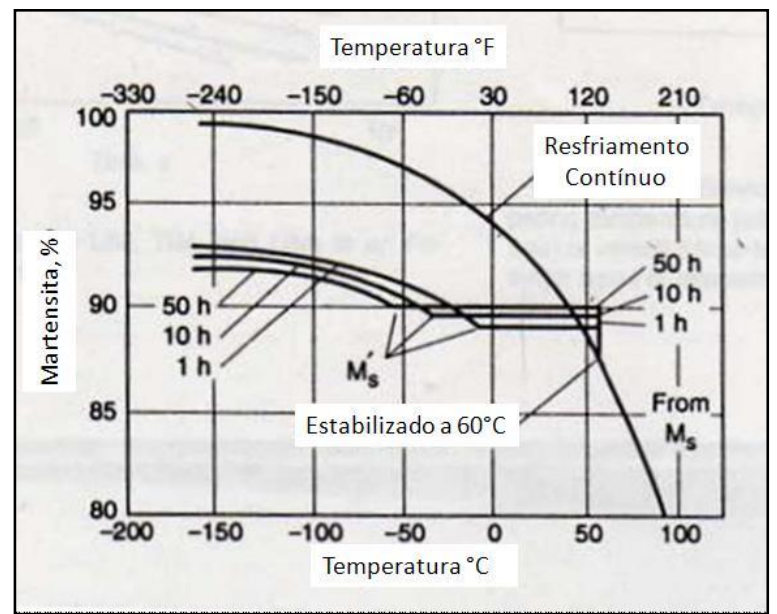

Figura 15 - Atraso na transformação martensítica em função do tempo de permanência a $60^{\circ} \mathrm{C}$, em um aço contendo 1,1\%C-0,2\%Si-0,3\%Mn. Adaptado da referência [41].

As explicações dos mecanismos que causam a estabilização da austenita com a inserção de patamar isotérmico são complexas. De acordo com Honeycombe [4], a formação de agulhas de martensita provoca deformação plástica na matriz em torno dela, o que pode resultar em altas concentrações de discordâncias na austenita. A interação de parte destas discordâncias (da austenita) com as discordâncias nos contornos da martensita fará com que as mesmas não possam mais se mover, e assim, as agulhas não possam mais crescer. Segundo Honeycombe ${ }^{[4]}$, qualquer fenômeno que encoraje este processo causará estabilização, como por exemplo, a permanência em temperaturas intermediárias que fornece tempo para a relaxação, ou seja, a movimentação das discordâncias, bem como, o travamento das discordâncias por átomos de carbono, formando atmosferas de Cottrelli".

\footnotetext{
ii Devido à deformação do reticulado causada pelos átomos intersticiais há um campo de tensões com alta energia em torno dos mesmos. Quando os átomos intersticiais movem-se para os campos de tensão das discordâncias há uma redução desta energia. A atmosfera de Cottrell é a formação de concentrações ou "atmosferas" de átomos intersticiais ao longo dos núcleos das discordâncias ${ }^{[4]}$.
} 
De acordo com Nishiyama ${ }^{[34]}$ quando o envelhecimento (alívio de tensões) é realizado acima da temperatura $\mathrm{Mi}$ a estabilização está relacionada com o efeito de ancoramento dos defeitos e discordâncias na interface entre as regiões transformadas e não transformadas devido à formação de atmosferas de Cottrell, tanto diminuindo o número de sítios para nucleação quanto envenenando os prénúcleos ou embriões, de forma que não possam mais crescer.

Como quanto maior a temperatura de austenitização menor é a Mi (para aços hipereutetóides), haverá menor quantidade de martensita em temperaturas intermediárias e consequentemente menor deformação plástica na austenita. Isto pode explicar a menor taxa de estabilização em amostras austenitizadas a $1100^{\circ} \mathrm{C}$ (comparada com $1020^{\circ} \mathrm{C}$ ), como apresentado na figura $2^{[6]}$.

No entanto, quando o envelhecimento é realizado abaixo da temperatura $\mathrm{Mi}$, ocorreria uma diminuição do número de sítios para nucleação. Os sítios para nucleação, interfaces $\alpha^{\prime} / \gamma_{R}$ e as imperfeições do reticulado que permaneceram na $Y_{R}$, seriam enriquecidos por difusão de átomos intersticiais durante 0 envelhecimento.

Em trabalho anterior ${ }^{[42]}$, foi verificado que há uma perda da tetragonalidade da martensita durante a permanência em temperaturas utilizadas no tratamento de alívio de tensões. Neste trabalho o aço AISI D2 foi austenitizado a $1040^{\circ} \mathrm{C}$ por 40 minutos sob vácuo e temperado em óleo (restando cerca de $25 \%$ de $\mathrm{Y}_{\mathrm{R}}$ ). As amostras foram então submetidas a tratamentos isotérmicos a $80^{\circ} \mathrm{C}$ e $130^{\circ} \mathrm{C}$ (em banho de óleo) por tempos crescentes de 6 minutos até 30 horas. Foram realizadas medidas de ruído magnético de Barkhausen (RMB) e difração de raios- $X$ em todas as amostras, como apresentado nas figuras 16 e 17. Verificou-se que houve perda da tetragonalidade da martensita e que o método de RMB foi eficiente para captar esta mudança. Não foi constatada diminuição na fração volumétrica de austenita retida. 


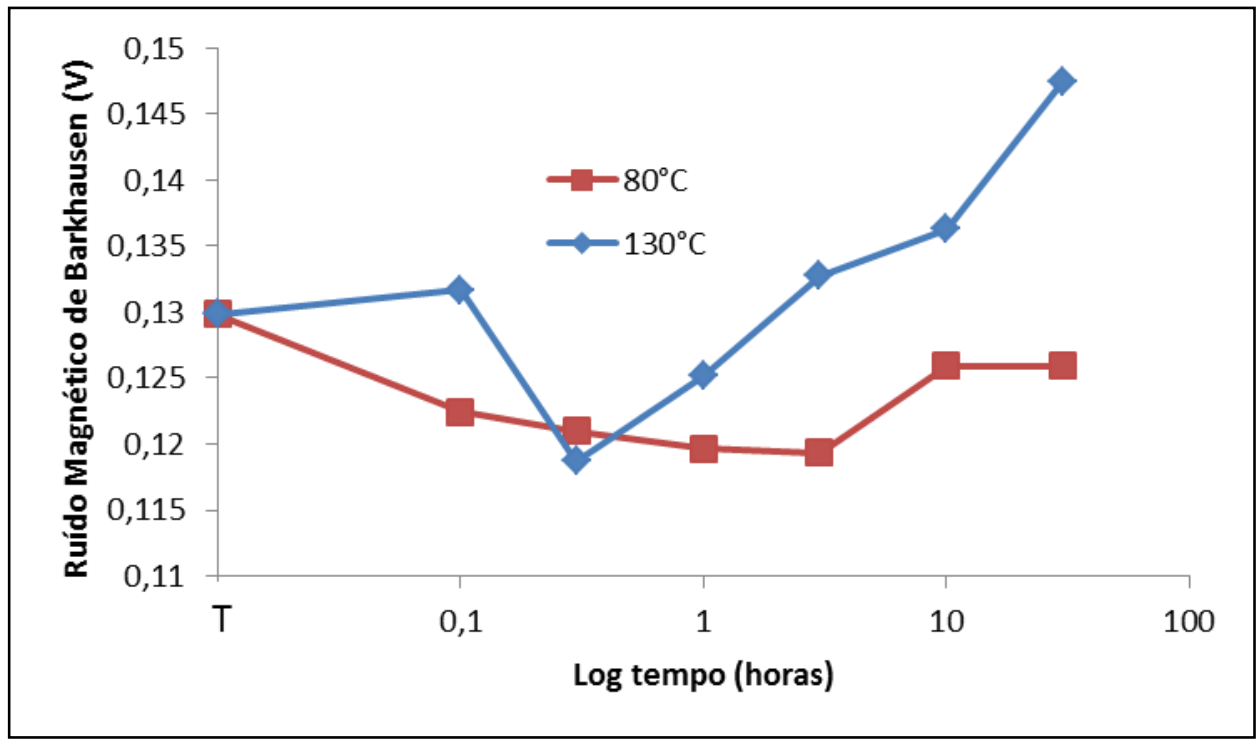

Figura 16 - Evolução do RMB em função do tempo de permanência a temperatura de envelhecimento. Amostra do aço AISI D2 austenitizado a $1040^{\circ} \mathrm{C} / 40 \mathrm{~min}$ e temperado em óleo. T condição como temperada ${ }^{[42]}$.

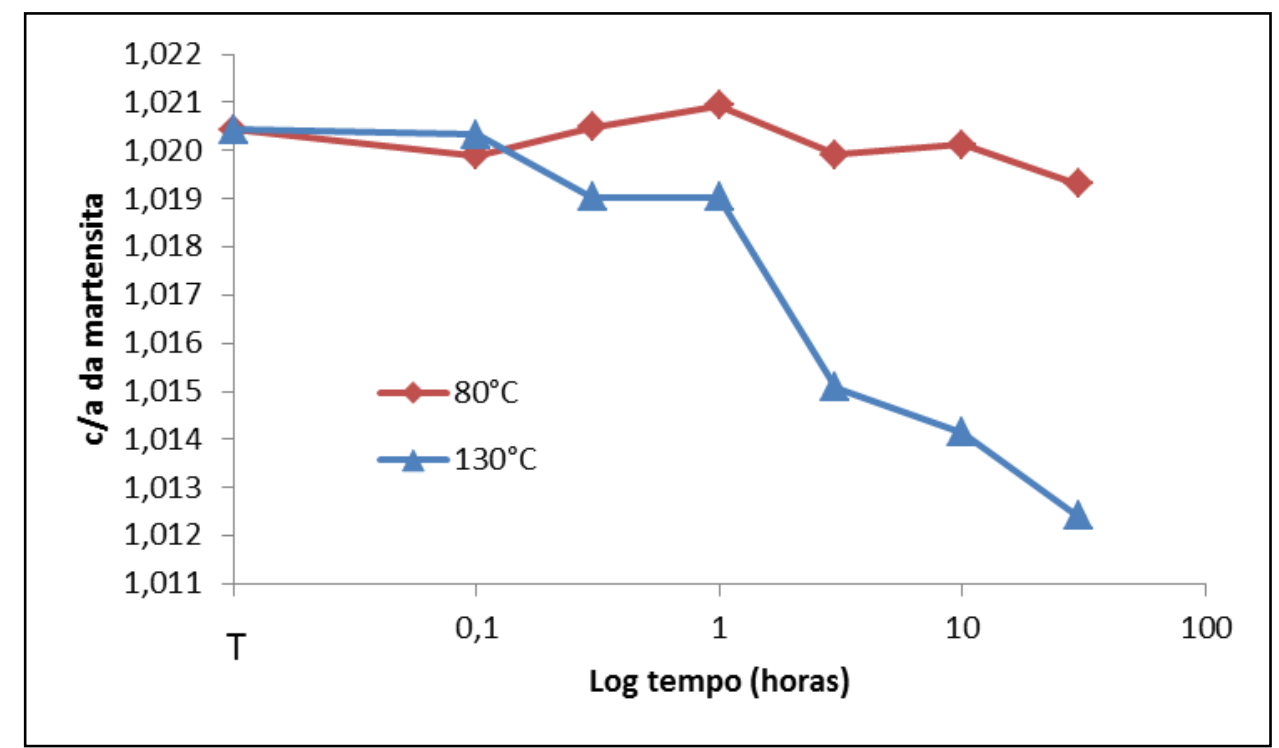

Figura 17 - Evolução do parâmetro c/a da martensita em função do tempo de permanência a temperatura de envelhecimento para o aço AISI D2 austenitizado a $1040^{\circ} \mathrm{C} / 40$ min e temperado em óleo. T - condição como temperado ${ }^{[42]}$.

Okamoto e Odaka apud Nishiyama ${ }^{[34]}$ apresentaram uma curva para o envelhecimento, figura 18, com forma bastante similar à apresentada na figura 16 . Note que na figura 16 (Mi em torno de $160^{\circ} \mathrm{C}$ ) para a temperatura de $130^{\circ} \mathrm{C}$ o valor do RMB primeiro diminui, depois aumenta até 30 horas. Na figura 18 (Mi em torno de $110^{\circ} \mathrm{C}$ ), o valor $\theta$ (quantos ${ }^{\circ} \mathrm{C}$ diminui a temperatura Mi) primeiro aumenta e depois diminui $\left(10^{5} \mathrm{~s}\right.$ equivale a 28 horas). Provavelmente as duas curvas estejam 
detectando o mesmo fenômeno. Segundo Nishiyama ${ }^{[34]} \mathrm{o}$ aumento inicial de $\theta$ com o tempo de envelhecimento é devido tanto à segregação ou difusão de átomos intersticiais para dentro dos sítios de nucleação quanto à difusão de átomos intersticiais da $\alpha^{\prime}$ para a $Y_{R}$ (aumentando a $\mathrm{Mi}$ ). $\mathrm{Na}$ sequência, os átomos de $\mathrm{C}$ segregados começam a formar agrupamentos. Átomos de $\mathrm{C}$ da $\mathrm{Y}_{\mathrm{R}}$ participam deste processo de agrupamento empobrecendo-a em $\mathrm{C}$ e assim aumentando a $\mathrm{Mi}$ (diminuindo $\theta$ ) após passar por um pico. $\mathrm{O}$ crescimento anormal de $\theta$ a $200^{\circ} \mathrm{C}$ (acima da Mi) após a queda é atribuído a uma transformação bainítica.

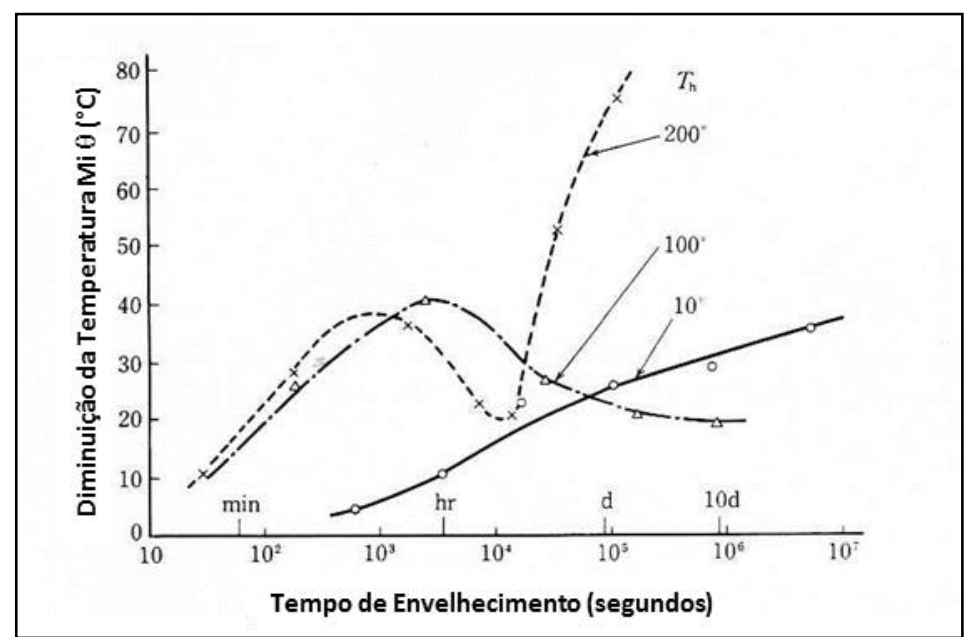

Figura 18 - Diminuição da temperatura $\mathrm{Mi}$ da austenita retida devido ao envelhecimento ( $\mathrm{Fe}$ $1,63 \% \mathrm{Cr}-1,06 \% \mathrm{C})$. Adaptado da referência [34].

Como citado anteriormente, segundo Taylor e Cohen ${ }^{[36]}$ o fenômeno de envelhecimento da martensita virgem está relacionado com os fenômenos de préprecipitação de carbonetos ${ }^{[36]}$. Desta forma, neste trabalho serão tratados de forma diferenciada os fenômenos de difusão de $C$ da martensita para austenita e para agrupamentos de $\mathrm{C}$ (pré-precipitação). $\mathrm{O}$ fenômeno de difusão de $\mathrm{C}$ da martensita para a $\gamma_{R}$ será chamado de partição, como apresentado por Speer et al. ${ }^{[43]}$.

Speer et al. ${ }^{[43]}$ apresentam um modelo de partição de carbono para a austenita retida após a transformação martensítica, que talvez possa ser aplicado aos fenômenos em questão, considerando-se haver uma interface "pura" austenita/martensita, sem a presença de carbonetos. Eles consideram a ausência de carbonetos secundários dispersos devido à presença de elementos de liga inibidores da precipitação de carbonetos de ferro (como o Si, por exemplo).

Sarikaya et al. apud Speer et al. ${ }^{[43]}$ apresentaram evidências da partição de carbono saindo da martensita em direção à austenita para os finos filmes entre ripas 


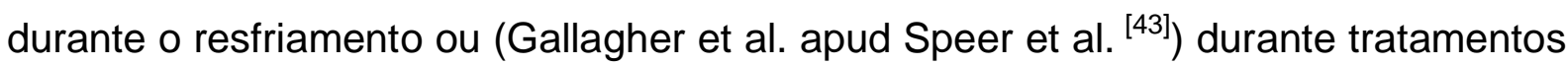
isotérmicos, após a transformação martensítica, em aços contendo Si. A partição de carbono entre a martensita e a austenita, em geral, não é considerada, pois, a temperatura seria tão baixa para ser considerada uma quantidade significativa de difusão ou por que a supersaturação é considerada como sendo eliminada por processos competitivos, como a precipitação de carbonetos.

O processo chamado de Q\&P (têmpera e partição) ${ }^{[43]}$ apresenta um modelo no qual é assumida uma interface estacionária entre a ferrita (martensita) e a austenita e requer um potencial químico de carbono uniforme nas duas fases, criando uma condição de equilíbrio metaestável identificada como um paraequilíbrio forçado ${ }^{\mathrm{iii}}$ (constrained paraequilibrium). O processo Q\&P cria uma mistura de martensita menos saturada em carbono com uma austenita enriquecida em carbono.

Em continuação ao trabalho de Speer et al. ${ }^{[43]}$, Moor et al. ${ }^{[44]}$ realizaram um estudo em ligas FeCMnSi, FeCMnAl e FeCMnAlSi por meio de dilatometria para estudar o revenimento nestas ligas apresentadas como promissoras para o processo de Q\&P. A figura 19 apresenta a curva de dilatometria por eles obtida para a liga FeCMnAl. É interessante notar que a temperatura de partição destas ligas é de $300^{\circ} \mathrm{C}$, ou seja, acima da temperatura de pré-precipitação de carbonetos (segregação e agrupamento de C) e de precipitação do carboneto $\varepsilon / \eta$.

\footnotetext{
iii A condição de paraequilíbrio forçado é definida pela ausência completa de movimentos de átomos de $\mathrm{Fe}$ ou substitucionais, com liberdade para os átomos de $\mathrm{C}$ ou intersticiais migrarem conforme necessário. Como no paraequilíbrio, o paraequilíbrio forçado pressupõe que somente átomos intersticiais movem-se em distâncias maiores do que as dimensões de uma célula unitária. Diferentemente do paraequilíbrio, sob as condições do paraequilíbrio forçado não ocorrem movimentos em curtas distâncias (short-range) de átomos de Fe ou substitucionais nas interfaces e não ocorre migração de interface ${ }^{[44]}$.
} 


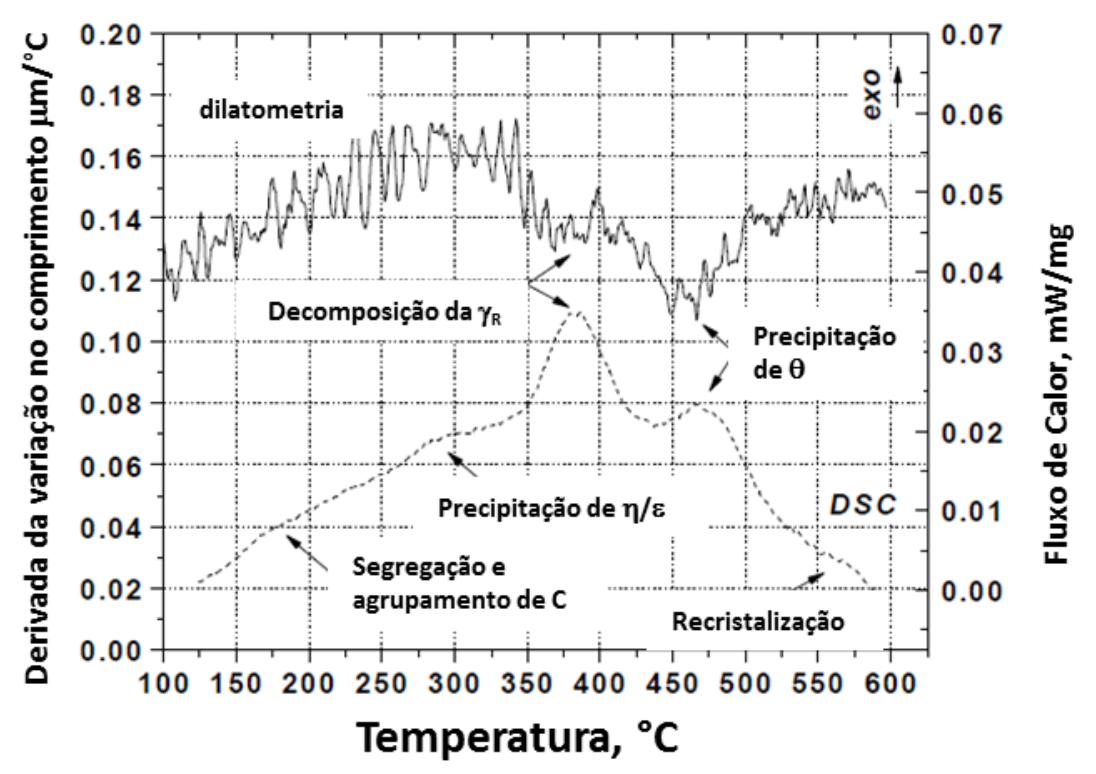

Figura 19 - Derivada da curva de dilatometria de um aço FeCMnAl, mostrando 5 eventos sendo 1 de pré-precipitação e 4 de revenimento. Adaptado da referência [44].

O gráfico apresentado por Speer et al. ${ }^{[43]}$, figura 20 , ilustra o que já é de conhecimento comum: a solubilidade de $\mathrm{C}$ na ferrita é menor em temperaturas mais baixas.

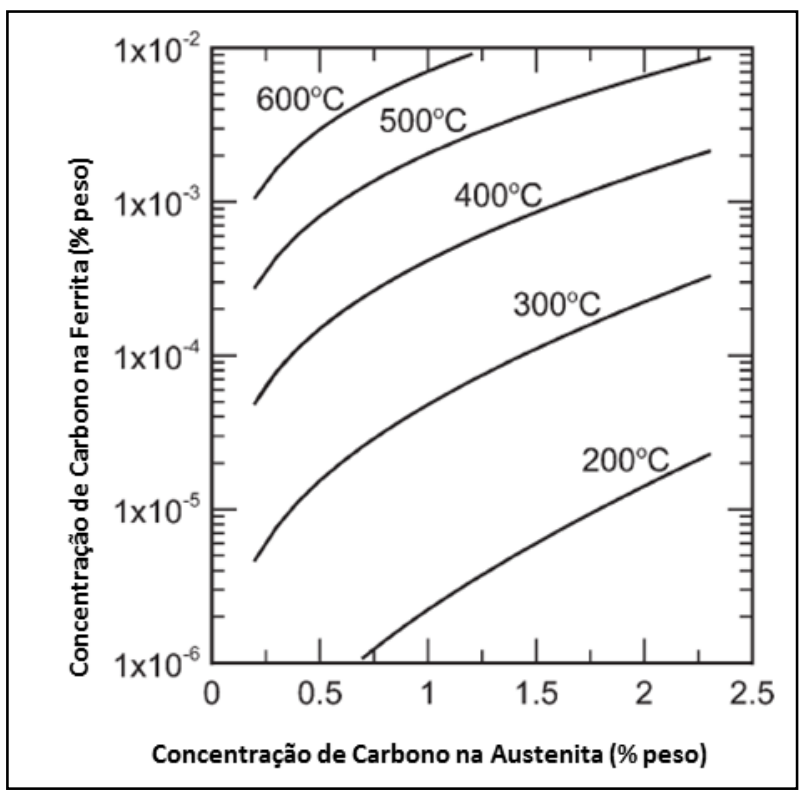

Figura 20 - Composições locais calculadas da ferrita e da austenita tendo atividades de $\mathrm{C}$ iguais em temperaturas entre 200 e $600^{\circ} \mathrm{C}$ para uma liga Fe-C. Adaptado da referência [43].

Com o que foi apresentado neste item, parece bastante razoável a hipótese de partição de $C$ saindo da $\alpha^{\prime}$ para a $Y_{R}$, mesmo com a presença de carbonetos, desde que haja uma interface $\alpha^{\prime} / Y_{R}$ sem carbonetos. 


\subsection{Precipitação de Carbonetos Secundários}

O revenimento do aço AISI D2, em geral, é feito em duas diferentes faixas de temperaturas, podendo ser revenimento em baixas temperaturas (entre $180 \mathrm{e}$ $250^{\circ} \mathrm{C}$ ) ou em altas temperaturas (entre 500 e $550^{\circ} \mathrm{C}$ ).

Segundo Speich ${ }^{[45]}$, em aços médio carbono, a faixa de temperaturas entre 180 e $250^{\circ} \mathrm{C}$ pode incluir os três primeiros estágios do revenimento, sendo eles: i) segregação de carbono + precipitação de carbonetos $\varepsilon$; ii) decomposição da austenita retida; e iii) precipitação de cementita com morfologia de bastonetes. Hirotsu and Nagakura ${ }^{[46]}$, em um estudo em aços martensíticos com alto carbono, mostrou que o primeiro carboneto a precipitar durante a têmpera é o carboneto $\eta$ com estrutura similar, porém, diferente, do carboneto hexagonal $\varepsilon$, sendo que o carboneto $\eta$ tem morfologia de plaquetas com espessura de 3 a $5 \mathrm{~nm}$ e precipita periodicamente ao longo das discordâncias, com intervalo de cerca de $10 \mathrm{~nm}$. Da mesma forma, Meng et al. ${ }^{[6]}$ propuseram que o tratamento criogênico facilita a precipitação preferencial de carbonetos $\eta$ finos.

Segundo Speich ${ }^{[47]}$, a precipitação de carbonetos $\varepsilon$ ocorre devido à supersaturação em carbono nas discordâncias que tem baixa energia. Hirotsu e Nagakura ${ }^{[46]}$, no entanto, apresentam o carboneto $\eta-\mathrm{Fe}_{2} \mathrm{C}$ como o fruto do primeiro estágio do revenimento em martensitas com alto carbono. No procedimento experimental utilizado por eles ${ }^{[46]}$, no entanto, as amostras são resfriadas em nitrogênio líquido antes do revenimento a $120^{\circ} \mathrm{C}$, primeiro estágio do revenimento.

$O$ trabalho de Hirotsu e Nagakura ${ }^{[46]}$ não é muito citado pela literatura técnicacientífica. No entanto, note-se que eles trabalharam com martensita de alto carbono e fizeram um tratamento criogênico entre a têmpera e o revenimento. Não consideraram isto, no entanto, como uma variável extra aos experimentos, visto que o objetivo era simplesmente obter uma estrutura completamente martensítica.

Desta forma, a precipitação de carbonetos $\eta$ no primeiro estágio do revenimento, em detrimento dos carbonetos $\varepsilon$, devido à introdução da etapa criogênica, conforme apresentado por Meng et al. ${ }^{[6]}$ é plausível.

No revenimento em altas temperaturas ocorre também o quarto estágio do revenimento ou endurecimento secundário ${ }^{[45]}$, se houver a presença de elementos de liga formadores de carboneto, como é o caso do AISI D2. 
A literatura não apresenta de forma conclusiva se estes carbonetos que precipitam no quarto estágio do revenimento (após têmpera $+\mathrm{TC}$ ), precipitam in situ a partir dos carbonetos metaestáveis precipitados em estágios anteriores, primeiro $\eta$ ou $\varepsilon$, depois, eventualmente, $\theta$ (cementita), ou se o mesmo é dissolvido para a então precipitação de novos carbonetos. No entanto, Thomson e Miller ${ }^{[48]}$, apresentam evidências de que $\mathrm{o}$ carboneto $\left(\mathrm{Mo}_{2} \mathrm{C}\right)$ precipitado inicialmente no primeiro estágio do revenimento (em um aço resistente a fluência) vai sendo enriquecido em cromo com o aumento do tempo e da temperatura de revenimento, sendo assim, um processo de crescimento in situ e não de dissolução e precipitação de novos carbonetos. No único trabalho sobre tratamento criogênico do aço AISI D2 que mostra evidências do carboneto $\eta$, o revenimento foi realizado a $180^{\circ} \mathrm{C}{ }^{[6]}$. No trabalho realizado com o aço AISI M2, que mostra o aparente refino dos carbonetos após triplo revenimento a $560^{\circ} \mathrm{C}$, os carbonetos não são identificados ${ }^{[11]}$.

Conforme citado anteriormente, Meng et al. ${ }^{[6]}$ afirmam que é conhecido que ocorre deformação do reticulado da martensita em temperaturas criogênicas, o que outros autores denominam de condicionamento da martensita. Para tanto ele cita o trabalho de Hayakawa et al. ${ }^{[49]}$. No entanto, neste trabalho ${ }^{[49]}$ a temperatura Mi da liga é $-73^{\circ} \mathrm{C}$, enquanto no aço AISI D2 é em torno de $160^{\circ} \mathrm{C}$.

Hayakawa et al. ${ }^{[49]}$ apresentaram os resultados como uma etapa de envelhecimento da martensita na liga Fe-24,67Ni-0,87C, e concluíram que o mesmo ocorre em dois estágios:

- Estágio I (de -150 a $-50^{\circ} \mathrm{C}$ ) a reação é sem difusão e apresenta: i) redução do parâmetro c/a; ii) volume constante da célula unitária;

- Estágio II (a temperatura ambiente) a reação envolve difusão de carbono e apresenta: i) redução no parâmetro c/a; ii) um novo pico de difração representando uma estrutura cúbica; iii) redução no volume da célula unitária; iv) relação de intensidade anômala nos picos tetragonais.

Estes resultados ${ }^{[49]}$ coincidem com os fenômenos apresentados no item sobre estabilização da austenita abaixo da temperatura Mi (aqui não se pretende definir se o uso da nomenclatura envelhecimento da $\alpha^{\prime}$ é adequado ou não, mas, somente foi separado para facilitar o desenvolvimento do texto).

Assim, houve um erro de Meng et al. ${ }^{[6]}$ ao afirmar que é sabido que ocorre deformação do reticulado da a' em temperaturas criogênicas. Pois, trata-se de duas ligas com temperaturas Mi muito diferentes. E, neste trabalho, está sendo admitido 
que os fenômenos ocorrendo dentro de cada faixa estão diretamente relacionados com a posição que a temperatura se encontra dentro da faixa Mi - Mf.

Admitindo-se que ocorre um envelhecimento da a' (com a formação de uma estrutura modulada devido à decomposição espinodal) em temperaturas criogênicas, no aço AISI D2, no aquecimento subsequente a zona enriquecida em C será preferencial para a precipitação de carbonetos. 


\section{OBJETIVOS}

O presente trabalho objetiva estudar o efeito das variáveis envolvidas no ciclo de tratamento térmico do aço AISI D2 contendo a etapa criogênica, dentre elas: i) o tempo de permanência a temperatura criogênica; ii) a temperatura criogênica (ou subzero); iii) o alívio de tensões $\left(130^{\circ} \mathrm{C}\right)$ antes do tratamento criogênico; e iv) a etapa de revenimento.

O efeito destas variáveis será avaliado por meio de: i) caracterização micro/nanoestrutural, ii) determinação da fração volumétrica de carbonetos; iii) determinação da fração volumétrica de austenita retida; iv) determinação do parâmetro c/a da martensita; e v) determinação da evolução do potencial termoelétrico.

São utilizadas as técnicas de: i) difração de raios- $X$; e ii) microscopia eletrônica de varredura.(MEV e MEV-FEG); e iii) potencial termo-elétrico. 


\section{MATERIAIS E MÉTODOS}

\subsection{Material}

Os experimentos foram realizados com amostras do aço ferramenta AISI D2 para trabalho a frio, lingotado convencionalmente e laminado a quente até o diâmetro de $52 \mathrm{~mm}$, com grau de deformação de aproximadamente 90 vezes. $O$ diâmetro da barra foi escolhido de forma que fosse possível retirar os diversos tipos de corpos de prova e, além disso, que toda a estrutura bruta de fundição fosse quebrada, com carbonetos distribuídos de forma mais homogênea. As amostras foram sempre retiradas do meio raio da barra e a microestrutura inicial é apresentada na figura 21. O aço foi produzido pela Villares Metals S.A. (Sumaré Brasil) sob a nomenclatura VD2, e sua composição química é apresentada na tabela 3.

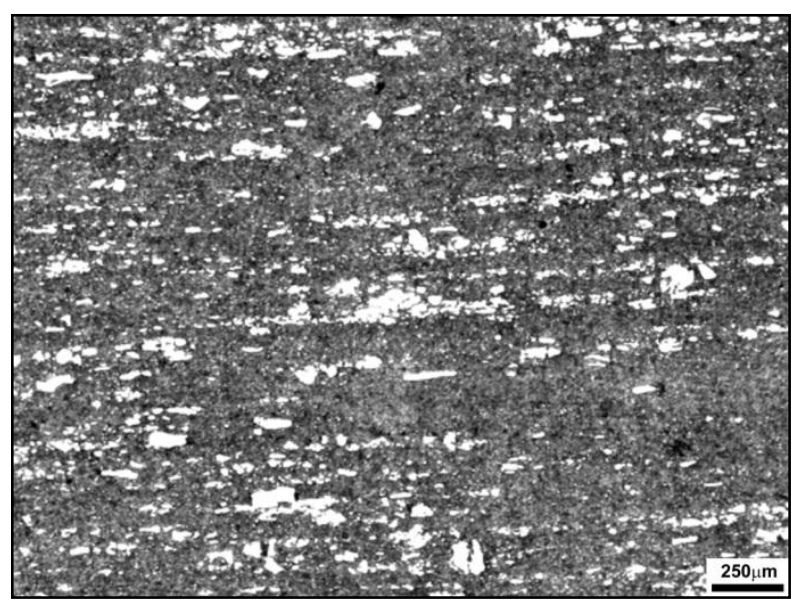

Seção Longitudinal

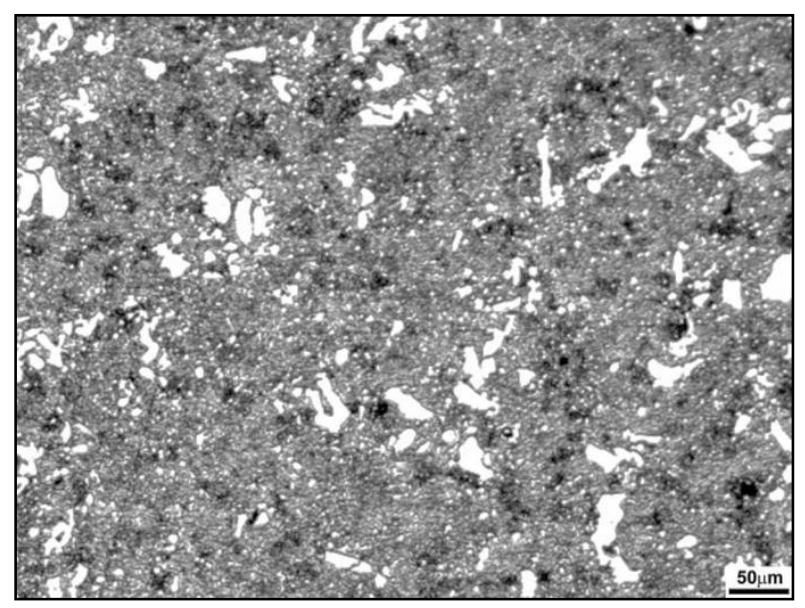

Seção Transversal

Figura 21 - Microestrutura do aço AISI D2. Estado inicial na condição recozida. Microscopia ótica. Ataque: Villela.

Tabela 3 - Composição química do aço AISI D2 em \% peso, Fe - balanço.

\begin{tabular}{cccccc}
\hline $\mathrm{C}$ & $\mathrm{Mn}$ & $\mathrm{Si}$ & $\mathrm{Cr}$ & $\mathrm{V}$ & $\mathrm{Mo}$ \\
\hline 1,51 & 0,36 & 0,35 & 11,9 & 0,78 & 0,73 \\
\hline
\end{tabular}




\subsection{Ciclos Térmicos e Identificação das Amostras}

\subsubsection{Primeira Série de Experimentos}

Na primeira série de experimentos as amostras foram submetidas aos ciclos térmicos apresentados de forma esquemática na figura 22. As identificações das amostras são apresentas na tabela 4 As amostras foram austenitizadas sob vácuo a $1020^{\circ} \mathrm{C} / 40$ min e resfriadas em óleo. Os tratamentos de duplo revenimento foram realizados a $210^{\circ} \mathrm{C} / 2 \mathrm{~h}$ cada, em forno tipo mufla. O TC a $-196^{\circ} \mathrm{C} / 36 \mathrm{~h}$ foi realizado por meio de imersão em nitrogênio líquido e os tratamentos $S Z\left(-125^{\circ} \mathrm{C} / 10 \mathrm{~min}\right.$ e $75^{\circ} \mathrm{C} / 10 \mathrm{~min}$ ) foram realizados em criostato disponível no Laboratório de Transformações de Fases da EPUSP, figura 23.

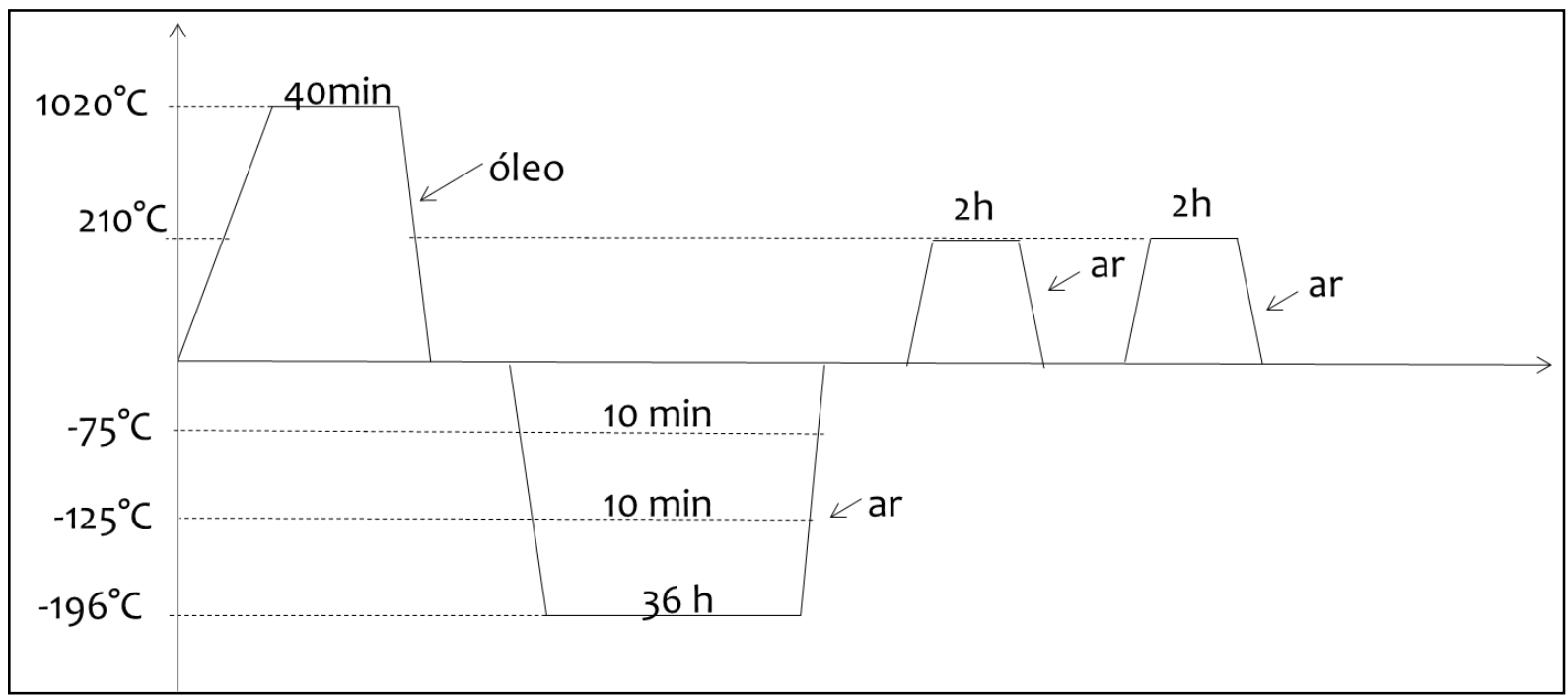

Figura 22 - Representação esquemática dos ciclos térmicos da primeira série de experimentos, contendo diversas combinações de ciclo. Aço AISI D2.

Tabela 4 - Identificações das amostras da primeira série de experimentos.

\begin{tabular}{ll}
\hline Identificação & Ciclo Térmico \\
\hline T1020 & $1020^{\circ} \mathrm{C} / 40 \min$ (óleo) \\
TR210 & $1020^{\circ} \mathrm{C} / 40 \min$ (óleo) $+2 \times 210^{\circ} \mathrm{C} / 2 \mathrm{~h}$ \\
$\mathrm{~T}-196 / 36 \mathrm{hR}$ & $1020^{\circ} \mathrm{C} / 40 \min$ (óleo) $+\left(-196^{\circ} \mathrm{C} / 36 \mathrm{~h}\right)+2 \times 210^{\circ} \mathrm{C} / 2 \mathrm{~h}$ \\
$\mathrm{~T}-125 / 10 \operatorname{minR}$ & $1020^{\circ} \mathrm{C} / 40 \min \left(\right.$ óleo) $+\left(-125^{\circ} \mathrm{C} / 10 \mathrm{~min}\right)+2 \times 210^{\circ} \mathrm{C} / 2 \mathrm{~h}$ \\
$\mathrm{T}-75 / 10 \operatorname{minR}$ & $1020^{\circ} \mathrm{C} / 40 \min$ (óleo) $+\left(-75^{\circ} \mathrm{C} / 10 \mathrm{~min}\right)+2 \times 210^{\circ} \mathrm{C} / 2 \mathrm{~h}$ \\
\hline
\end{tabular}




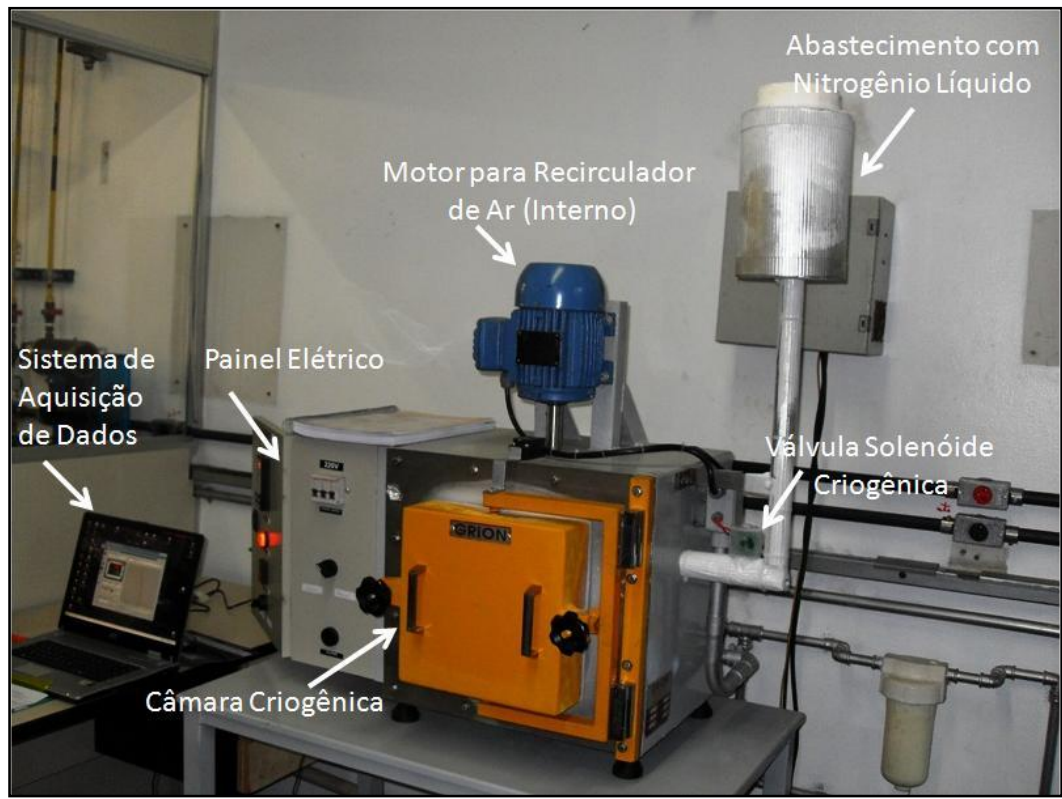

Figura 23 - Criostato disponível no Laboratório de Transformações de Fases da EPUSP.

\subsubsection{Segunda Série de Experimentos}

$\mathrm{Na}$ segunda série de experimentos, as amostras foram austenitizadas a $1040^{\circ} \mathrm{C}$ sob vácuo por 40 minutos e temperadas em óleo. Os tratamentos criogênicos foram realizados por imersão em nitrogênio líquido $\left(-196^{\circ} \mathrm{C}\right)$ e em gelo seco $\left(-80^{\circ} \mathrm{C}\right)$. Os tratamentos de alívio de tensões e de revenimento foram realizados em forno tipo mufla. A figura 24 apresenta os ciclos térmicos, de forma esquemática, e a tabela 5 apresenta as identificações das amostras.

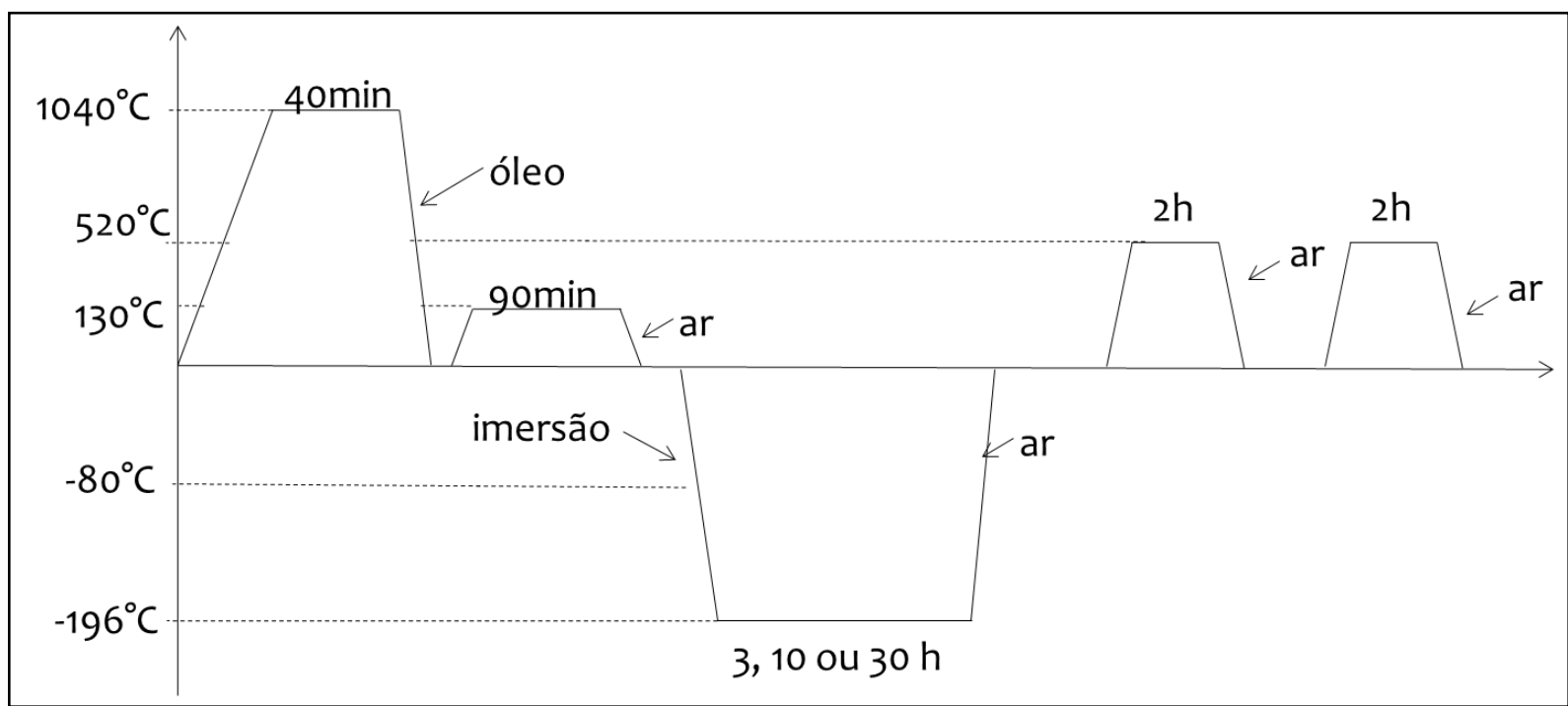

Figura 24 - Representação esquemática dos ciclos térmicos da segunda série de experimentos, contendo diversas combinações de ciclo. Aço AISI D2. 
Tabela 5 - Identificações das amostras da segunda série de experimentos.

\begin{tabular}{|c|c|c|}
\hline \multicolumn{2}{|c|}{ Identificação } & Ciclo térmico \\
\hline $\mathrm{R}$ & S20 & Recozida \\
\hline $\mathrm{T}$ & S21 & 1040\%/40min (óleo) - Temperada \\
\hline$T+T C / 3$ & S6 & $1040 \% / 40 \min \left(\right.$ óleo) $+-196^{\circ} \mathrm{C} / 3 \mathrm{~h}$ \\
\hline $\mathrm{T}+\mathrm{TC} / 10$ & S7 & 1040/40min (óleo) $+-196^{\circ} \mathrm{C} / 10 \mathrm{~h}$ \\
\hline $\mathrm{T}+\mathrm{TC} / 30$ & S8 & 1040/40min (óleo) + -196C/30h \\
\hline $\mathrm{T}+\mathrm{TSZ} / 3$ & s9 & $1040 \% / 40 \mathrm{~min}$ (óleo) $+-80^{\circ} \mathrm{C} / 3 \mathrm{~h}$ \\
\hline$T+T S Z / 10$ & $\mathrm{~S} 10$ & 1040\%/40min (óleo) +-80C/10h \\
\hline$T+T S Z / 30$ & S11 & 1040\%/40min (óleo) +-80C/30h \\
\hline$T+A T$ & S12 & 1040/40min (óleo) +130C/1,5h \\
\hline $\mathrm{T}+\mathrm{AT}+\mathrm{TC} / 3$ & $\mathrm{~s} 13$ & $1040^{\circ} / 40 \min ($ óleo $)+130^{\circ} \mathrm{C} / 1,5 \mathrm{~h}+-196^{\circ} \mathrm{C} / 3 \mathrm{~h}$ \\
\hline$T+A T+T C / 10$ & S14 & $1040^{\circ} / 40 \min$ (óleo) $+130^{\circ} \mathrm{C} / 1,5 \mathrm{~h}+-196^{\circ} \mathrm{C} / 10 \mathrm{~h}$ \\
\hline $\mathrm{T}+\mathrm{AT}+\mathrm{TC} / 30$ & S15 & $1040^{\circ} / 40 \min$ (óleo) $+130^{\circ} \mathrm{C} / 1,5 \mathrm{~h}+-196^{\circ} \mathrm{C} / 30 \mathrm{~h}$ \\
\hline$T+A T+T C / 30+R$ & S16 & $1040^{\circ} / 40 \min ($ óleo $)+130^{\circ} \mathrm{C} / 1,5 \mathrm{~h}+-196^{\circ} \mathrm{C} / 30 \mathrm{~h}+2 \times 520^{\circ} \mathrm{C} / 2 \mathrm{~h}$ \\
\hline$T+T C / 30+R$ & $\mathrm{~S} 17$ & $1040^{\circ} / 40 \min ($ óleo $)+-196^{\circ} \mathrm{C} / 30 \mathrm{~h}+2 \times 520^{\circ} \mathrm{C} / 2 \mathrm{~h}$ \\
\hline $\mathrm{T}+\mathrm{AT}+\mathrm{R}$ & S18 & $1040^{\circ} / 40 \min$ (óleo) $+130^{\circ} \mathrm{C} / 1,5 \mathrm{~h}+2 \times 520^{\circ} \mathrm{C} / 2 \mathrm{~h}$ \\
\hline$T+R$ & S19 & 1040\%/40min (óleo) + 2x520C/2h \\
\hline
\end{tabular}

\subsubsection{Terceira Série de Experimentos}

$\mathrm{Na}$ terceira série de experimentos as amostras foram submetidas a 4 ciclos térmicos iniciais, seguidos de tratamentos isotérmicos cumulativos a $130^{\circ} \mathrm{C}, 210^{\circ} \mathrm{C}$, $350^{\circ}, 450^{\circ}$ e $520^{\circ} \mathrm{C}$, conforme apresentados de forma esquemática na figura 25 . As amostras foram encapsuladas sob vácuo em tubo de quartzo e austenitizadas em forno tipo mufla a $1040^{\circ} \mathrm{C}$ por 40 minutos. A têmpera foi feita em água. $\mathrm{O}$ tratamento de alívio de tensões e os tratamentos isotérmicos a $130^{\circ} \mathrm{C}$ foram feitos em banho de óleo (dentro de um forno tipo mufla). Para o TC as amostras foram imersas em nitrogênio líquido, com aquecimento em água à temperatura ambiente. Os demais tratamentos isotérmicos foram realizados em banho de sal. Os tratamentos isotérmicos cumulativos consistiram de imersão da amostra no banho isotérmico, resfriamento em água à temperatura ambiente, realização de medições e as mesmas amostras imersas novamente no banho de sal por um acréscimo de tempo, e assim sucessivamente. As identificações dos ciclos térmicos são apresentas na tabela 6. Esta série de experimentos foi realizada no Laboratório Mateis (Materiaux: Ingénierie et Science) do INSA-Lyon (Institut National des Sciences Appliquées de Lyon). 


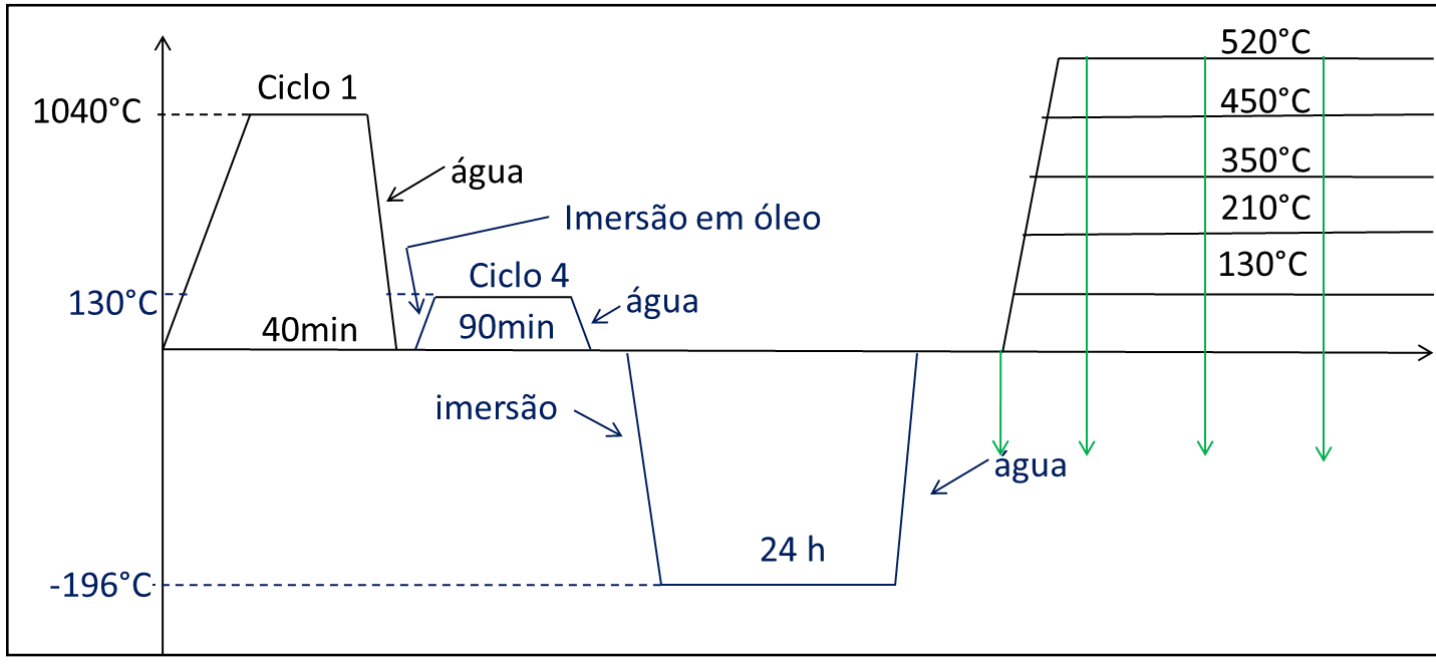

(a)

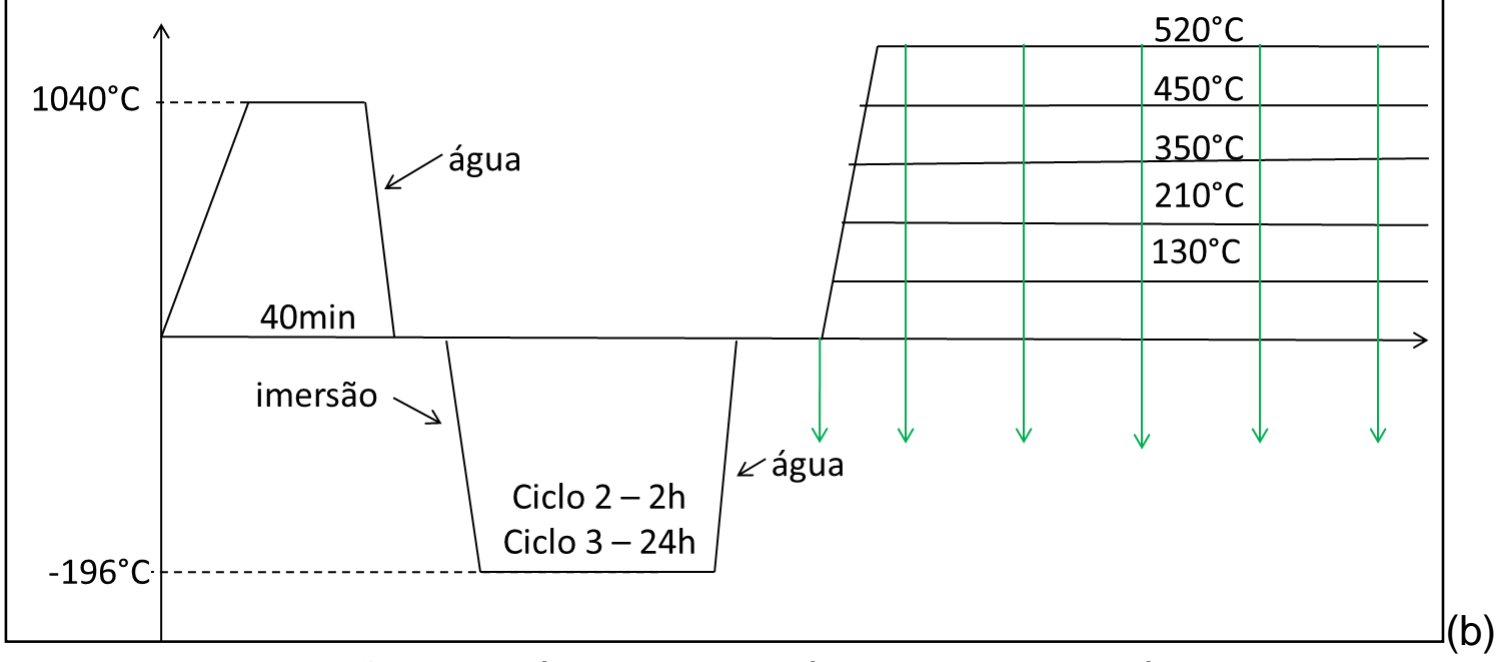

Figura 25 - Representação esquemática dos ciclos térmicos da terceira série de experimentos. (a) ciclos 1 e 4; (b) ciclos 2 e 3 . Aço AISI D2.

Tabela 6 - Identificações dos ciclos térmicos da terceira série de experimentos.

Ciclo $1 \quad 1040 \% / 40$ min (água) + tratamento isotérmico

Ciclo $2 \quad 1040 \% / 40 \mathrm{~min}$ (água) $+-196 \% \mathrm{C} / 2 \mathrm{~h}+$ tratamento isotérmico

Ciclo $3 \quad 1040 \% / 40 \min$ (água) $+-196^{\circ} \mathrm{C} / 24 \mathrm{~h}+$ tratamento isotérmico

Ciclo $4 \quad 1040 \% / 40 \min$ (água) $+130^{\circ} \mathrm{C} / 1,5 \mathrm{~h}+-196^{\circ} \mathrm{C} / 24 \mathrm{~h}+$ tratamento isotérmico

\subsection{Caracterização Metalográfica dos Corpos de Prova}

A caracterização qualitativa dos corpos de prova foi realizada por meio de microscopia eletrônica de varredura (MEV) e com MEV-FEG (MEV com canhão com emissão por efeito de campo) e caracterização quantitativa por meio de analisador de imagens.

Para a caracterização em MEV e MEV-FEG, os corpos de prova foram preparados por técnicas metalográficas convencionais e submetidos a ataque com reagente Villela entre 10 e $30 \mathrm{~s}$, o qual ataca a martensita preferencialmente a 
austenita. Assim, possibilitando a identificação da austenita retida e dos carbonetos, os últimos não sendo atacados e ficando em destaque na microestrutura.

Para a determinação da fração volumétrica e distribuição de carbonetos micrométricos, foram obtidas imagens em MEV com elétrons retro-espalhados (BSE - Back Scaterred Eletrons) das amostras não atacadas, com aumento de 2.000x. Para cada amostra foram analisadas três micrografias com ajuda do programa ImageJ. O processo de análise, conforme descrito na figura 26 , foi o seguinte: (a) a partir da imagem original; (b) o arquivo de imagem foi convertido para cor binária e determinada a fração volumétrica da área. Os diferentes tamanhos de carbonetos foram separados (máscara) e analisados individualmente (figura 26 - (c) a (f)). Com os resultados das três imagens para cada amostra, foi obtido um histograma de distribuição e fração volumétrica dos carbonetos.

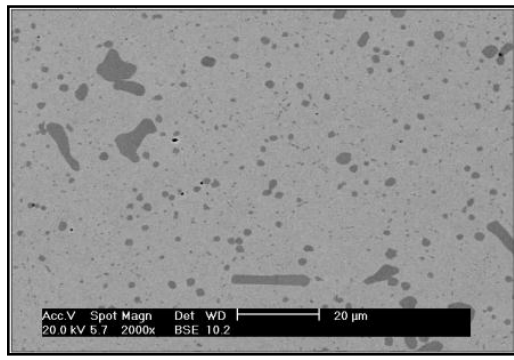

(a)

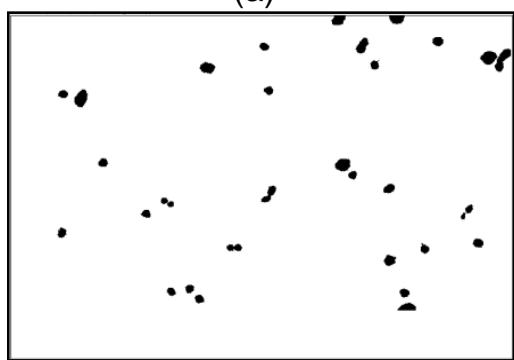

(d)

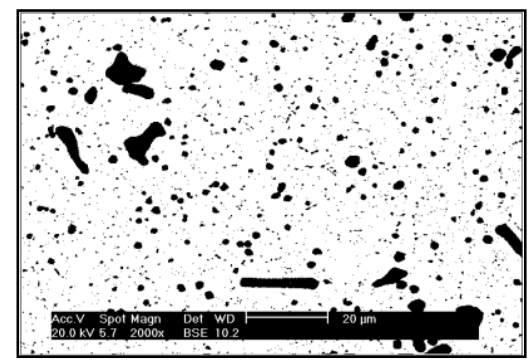

(b)

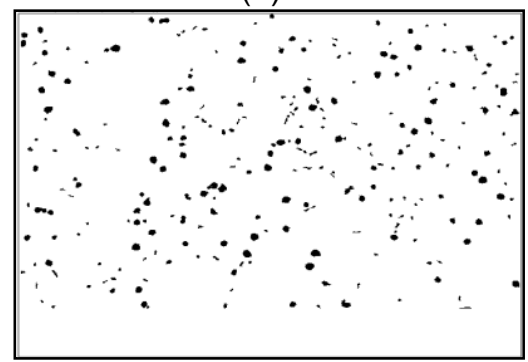

(e)

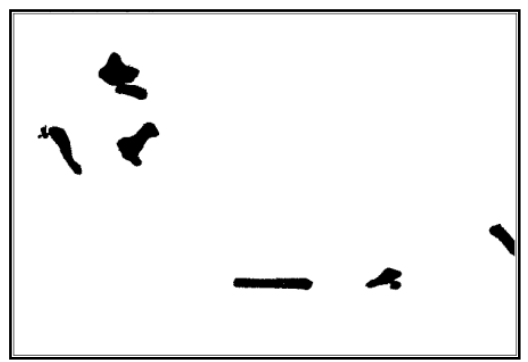

(c)

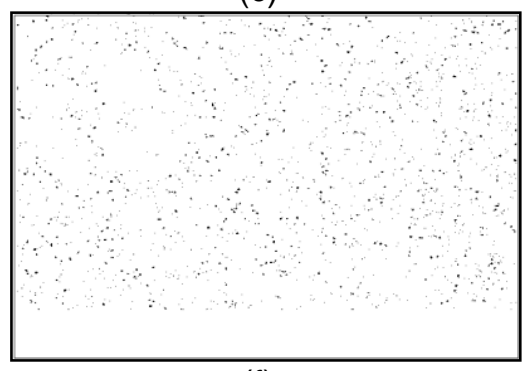

(f)

Figura 26 - Sequência utilizada para determinação da fração volumétrica de carbonetos com o uso do programa Image J. (a) microestrutura original - elétrons retro-espalhados; (b) imagem binária; (c) mácara mostrando os carbonetos maiores que $5 \mu \mathrm{m}$; (d) máscara mostrando os carbonetos com

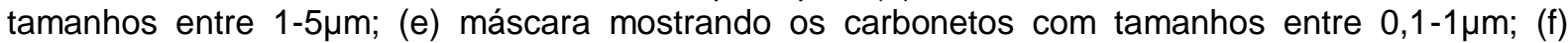
máscara mostrando os carbonetos menores que $0,1 \mu \mathrm{m}$ (provavelmente artefatos ou ruído).

A escolha pelas amostras sem ataque para determinação da fração volumétrica de carbonetos foi feita objetivando minimizar os efeitos que o ataque químico poderia causar nos resultados: i) fração volumétrica de carbonetos maior devido a maior área aparente de carbonetos; e ii) menor fração volumétrica de carbonetos, especialmente dos carbonetos menores, se os mesmos forem arrancados. 


\subsection{Difração de Raios-X utilizando Radiação Síncroton}

As difrações de Raios-X foram realizadas na linha de luz D10B-XPD do Laboratório Nacional de Luz Síncroton. Os difratogramas foram obtidos com energia de 6,936 keV (compatível com o comprimento de onda da radiação CoK $_{\alpha 1}$ $1,78901 \hat{A})$. A determinação do comprimento de onda da radiação utilizada foi realizada através do refino Rietveld com o programa TOPAS Academic de um padrão de Si ultra puro (NIST) cujo parâmetro de rede é conhecido. Da indexação do padrão de $\mathrm{Si}$, também foram determinados os parâmetros intrínsecos ao difratômetro que foram utilizados nas análises dos difratogramas da segunda série de ensaios. Os difratogramas das amostras do aço AISI D2 foram tomados no espaço entre $35^{\circ}$ e $125^{\circ}$ com passo $0,02^{\circ}$ e tempo de contagem de 30 mil detecções pelo contador do monitor por passo. Adicionalmente foi escolhido o uso de um cristal analisador de grafita de modo a eliminar a radiação de fundo tornando possível a avaliação de picos de baixa intensidade além de permitir a separação dos picos de difração para posterior indexação com o programa TOPAS Academic. Após a obtenção dos difratogramas eles foram avaliados com auxílio do programa TOPAS Academic para refino por método de Rietveld, indexação dos picos de difração e determinação dos parâmetros de rede e das frações de fases presentes. Nesta série de ensaios foram quantificadas as frações atômicas das fases austenita, ferrita e do carboneto $\mathrm{M}_{7} \mathrm{C}_{3}$ e $\mathrm{M}_{2} \mathrm{C}$. Foram identificados também picos de difração em baixos ângulos $\left(30^{\circ}<2 \theta<40^{\circ}\right)$ que não foram indexados. Devido à baixíssima fração volumétrica destes precipitados (menor que $0,5 \%$ ) e a não sobreposição dos picos de difração, decidiu-se por não considerar a presença destes carbonetos nas análises ${ }^{\text {iv }}$.

\subsection{Ensaios de Potencial Termo-Elétrico (TEP)}

Os ensaios de TEP (ou efeito Seebeck) foram realizados no laboratório Mateis do INSA-Lyon, conforme procedimento experimental apresentado por Perez et al. ${ }^{[50]}$. A figura $27(\mathrm{a})$ apresenta a vista geral do equipamento utilizado para

\footnotetext{
iv As análises dos padrões obtidos no LNLS, bem como a determinação dos parâmetros para aquisição dos mesmos, foram gentilmente realizadas pelo M. Eng. Alexandre Bellegard Farina.
} 
determinação do TEP e a figura 27(b) apresenta a representação esquemática da amostra com respectivos blocos de cobre.

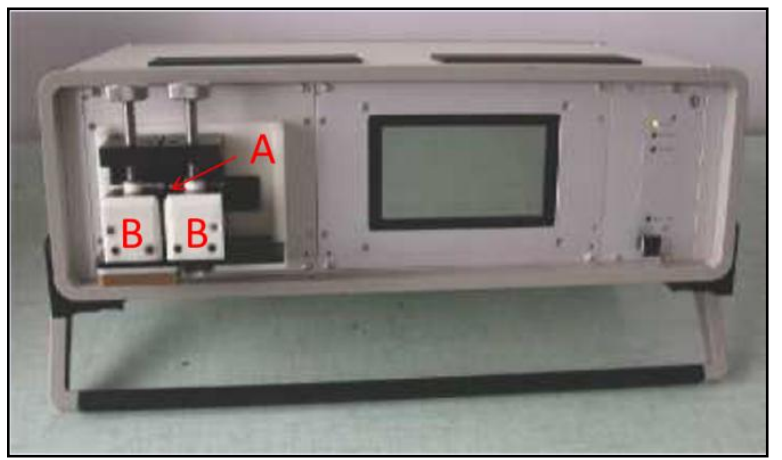

(a)

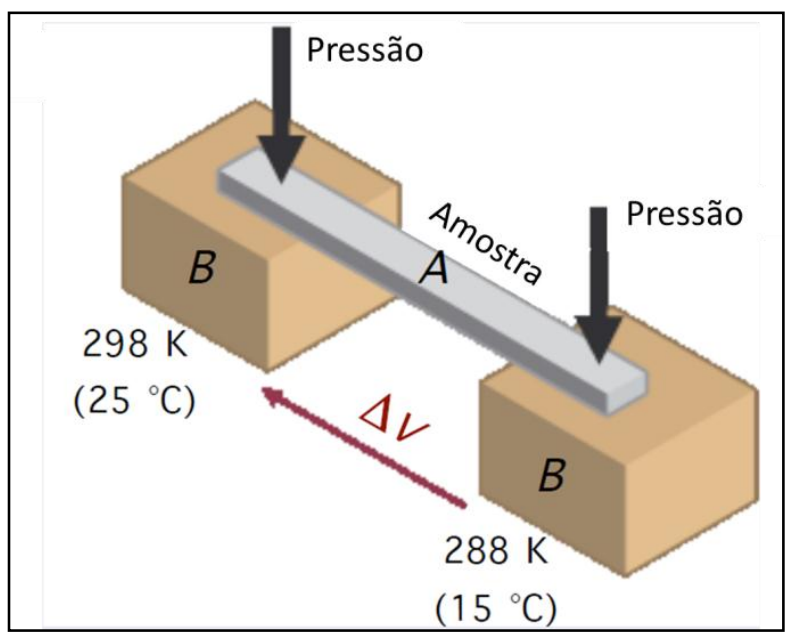

(b)

Figura 27 - (a) vista geral do equipamento utilizado para determinação do TEP, ou coeficiente de Seebeck. (b) representação esquemática da amostra (A) e dos blocos de cobre (B), com as respectivas diferenças de temperatura que causam uma diferença de potencial $\Delta \mathrm{V}$. Adaptado da referência [50].

Para a determinação do TEP, considere um circuito aberto B/A/B composto por dois metais A e B (figura 27(b)). Se for criada uma diferença de temperatura entre as duas junções $A / B$ deste circuito, surgirá uma diferença de voltagem $(\Delta V)$ entre os dois segmentos $B$. O TEP $\left(S_{A B}\right)$ de tal circuito, também conhecido como coeficiente de Seebeck, é definido por:

$$
\mathrm{S}_{\mathrm{AB}}=\frac{\Delta V}{\Delta T}
$$

$S_{A B}$ é o TEP relativo do metal $A$ em relação ao metal $B$, ou seja, é a diferença entre o TEP absoluto dos dois metais: $S_{A B}=S_{A}^{*}-S_{B}^{*}$.

Foram utilizadas amostras com dimensões $50 \times 4 \times 1 \mathrm{~mm}$. As mesmas foram colocadas no equipamento conforme a figura 27 e fixadas aos dois blocos do metal de referência (cobre). Os dois blocos são mantidos às temperaturas $T\left(15^{\circ} \mathrm{C}\right)$ e $\mathrm{T}$ + $\Delta \mathrm{T}\left(25^{\circ} \mathrm{C}\right)$. As temperaturas das duas junções são determinadas por um termopar ultra-fino localizado logo abaixo da superfície do bloco de referência. O TEP relativo é dado pela temperatura média das duas amostras. 


\subsubsection{Interpretação dos resultados ${ }^{[50]}$}

O valor absoluto do TEP $\left(S^{*}\right)$ em um material metálico é afetado, em diferentes níveis, por todos os defeitos do reticulado (por exemplo, átomos em solução, discordâncias e precipitados). Assim, pode ser escrito como:

$$
S^{*}=S_{0}^{*}+\Delta S_{S S}+\Delta S_{d}+\Delta S_{P P}
$$

onde, $S^{*}$ é o TEP do metal puro (sem defeitos) e $\Delta S_{S S}, \Delta S_{d}$ e $\Delta S_{P P}$ são as variações do TEP devido aos elementos em solução sólida, discordâncias e precipitados, respectivamente.

A figura 28(a) apresenta a curva de TEP em função do tempo utilizada para acompanhar a cinética de segregação de átomos intersticiais ( $\mathrm{C}$ e/ou $\mathrm{N}$ ) para as discordâncias, em aços ultra-baixo carbono altamente deformados. Como a $120^{\circ} \mathrm{C}$, neste aço, não ocorrem os fenômenos de recuperação e precipitação, as variações do TEP ocorrem devido à segregação de átomos intersticiais. A curva apresenta uma evolução sigmoidal.

A figura 28(b) apresenta a evolução do TEP, em uma liga $\mathrm{Fe}-\mathrm{Cu}$, para diferentes temperaturas de envelhecimento (de $450^{\circ} \mathrm{C}$ a $700^{\circ} \mathrm{C}$ ). Para as temperaturas acima de $500^{\circ} \mathrm{C}$, a cinética foi acompanhada até o final da precipitação, caracterizada pela estabilização do TEP em um valor final dependente da temperatura.

Ainda sobre a figura $28(\mathrm{~b})$, dois pontos foram deduzidos a partir destas evoluções: i) a evolução sigmoidal da curva mostra quão rápido a precipitação ocorre; com o aumento da temperatura a precipitação é acelerada, até $575^{\circ} \mathrm{C}$ (acima desta temperatura, a velocidade de precipitação diminui com a temperatura - típico de uma curva com cinética em $\mathrm{C}$ ); ii) o valor final do TEP é diretamente relacionado com o limite de solubilidade do $\mathrm{Cu}$ no $\mathrm{Fe}$ (e, portanto, com a fração volumétrica de precipitados). 


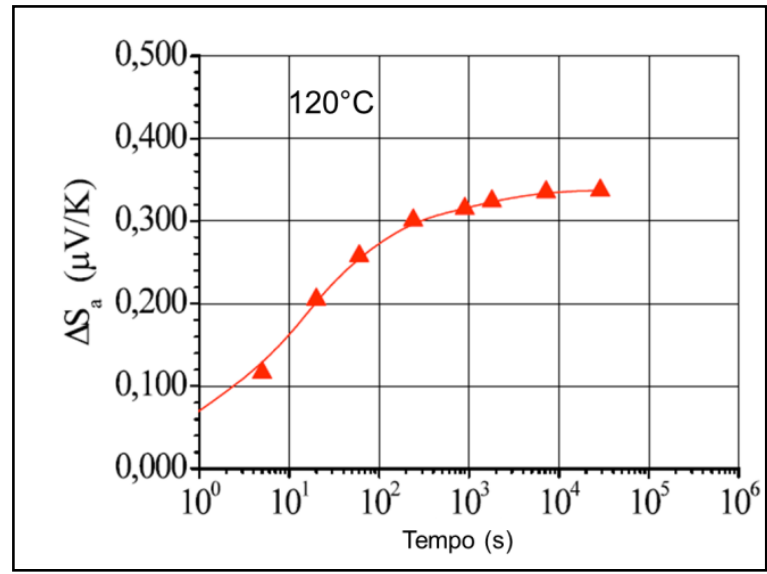

(a)

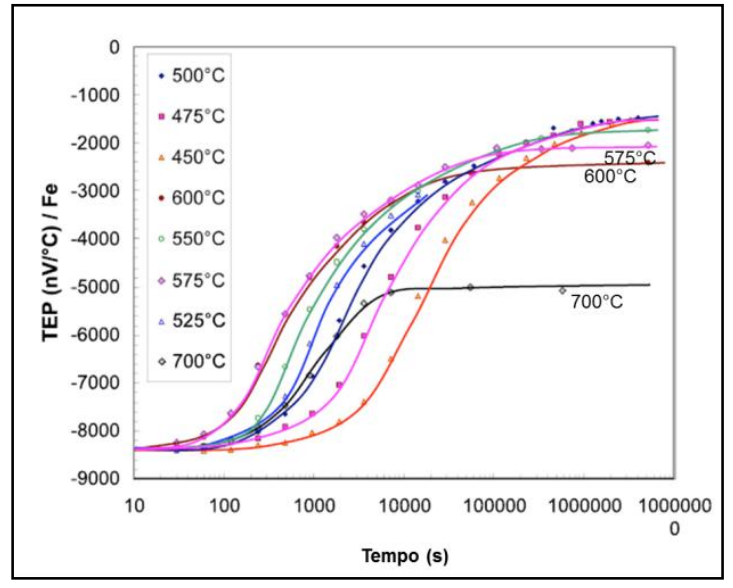

(b)

Figura 28 - Curvas típicas do TEP em função da temperatura. (a) Cinética da segregação de $\mathrm{C}$ e $\mathrm{N}$ nas discordâncias de aços ultra baixo carbono altamente deformados. (b) Cinética de precipitação do cobre no ferro. Adaptado da referência [50]. 


\section{RESULTADOS}

\subsection{Primeira Série de Experimentos}

A figura 29 apresenta a microestrutura das amostras analisadas por MEV com elétrons secundários; é possível observar os carbonetos eutéticos e secundários. Foram utilizadas amostras com 2.000x de aumento para determinação da fração volumétrica de carbonetos, visando a detecção dos carbonetos finos (devido ao alto aumento utilizado, a determinação da fração volumétrica dos carbonetos eutéticos "grandes" foi prejudicada).

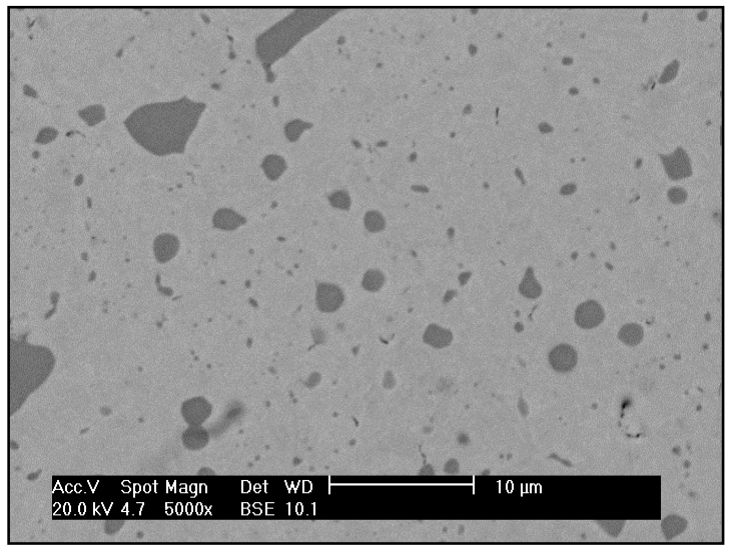

(a)

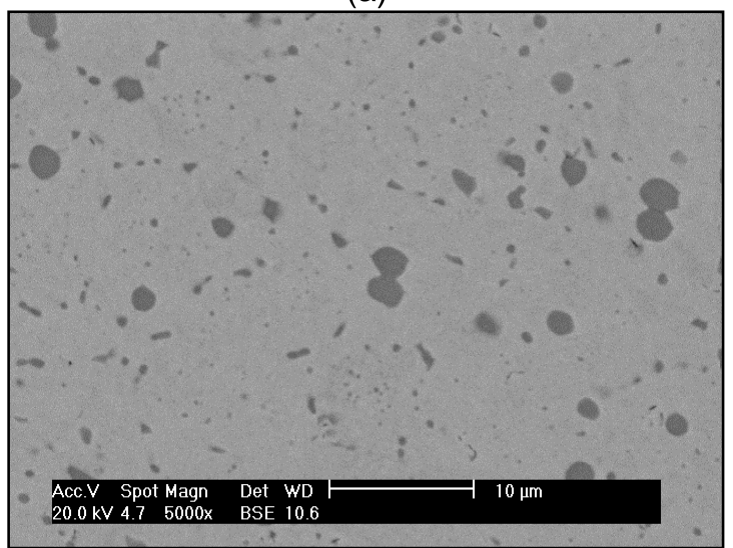

(c)

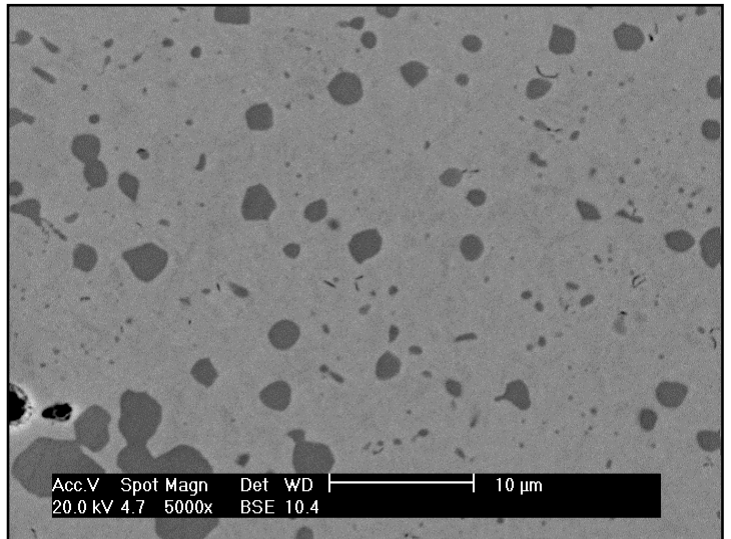

(b)

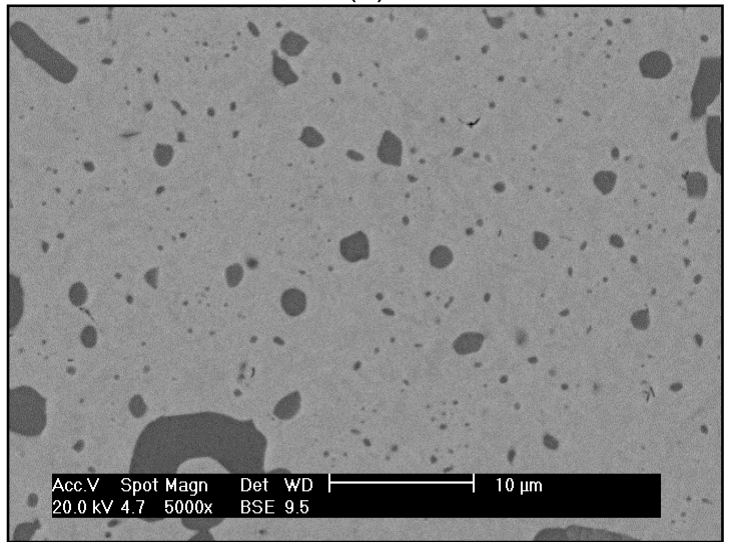

(d)

Figura 29 - Microestrutura das amostras (a) TR210, (b) T-196/36hR, (c) T-125/10minR e (d) T75/10minR. Não atacadas. MEV - elétrons retro-espalhados.

A figura 30 apresenta a fração volumétrica de carbonetos, separada por faixa de tamanhos: i) maior que $5 \mu \mathrm{m}$; ii) entre 5 e $1 \mu \mathrm{m}$; iii) entre 1 e $0,1 \mu \mathrm{m}$; e iv) menor que $0,1 \mu \mathrm{m}$. Não sendo um valor totalmente confiável a fração volumétrica dos carbonetos menores que $0,1 \mu \mathrm{m}$, devido a possibilidade da presença de ruído de 
fundo afetando os resultados. A partir destes resultados é possível verificar que não há diferença na fração volumétrica de carbonetos (eutéticos e secundários) nas amostras com e sem tratamento criogênico, dentro da faixa de tamanhos verificada. O erro apresentado para os carbonetos eutéticos (maiores que $5 \mu \mathrm{m}$ ) é devido ao aumento utilizado (seria necessário um número de campos maior para uma detecção aceitável de carbonetos eutéticos com o aumento utilizado), que objetivou a determinação da fração volumétrica dos carbonetos menores. Não foi realizado nenhum esforço para a medição mais acurada dos carbonetos eutéticos (menor aumento ou maior número de campos). Para os demais tamanhos de carbonetos, não há diferença entre as amostras submetidas aos diversos ciclos térmicos. Desta forma, está claro que os carbonetos avaliados não precipitam após o tratamento criogênico ou durante/após o revenimento porque toda a fração volumétrica de carbonetos é a mesma que para a amostra T1020, que é a amostra "como temperada".

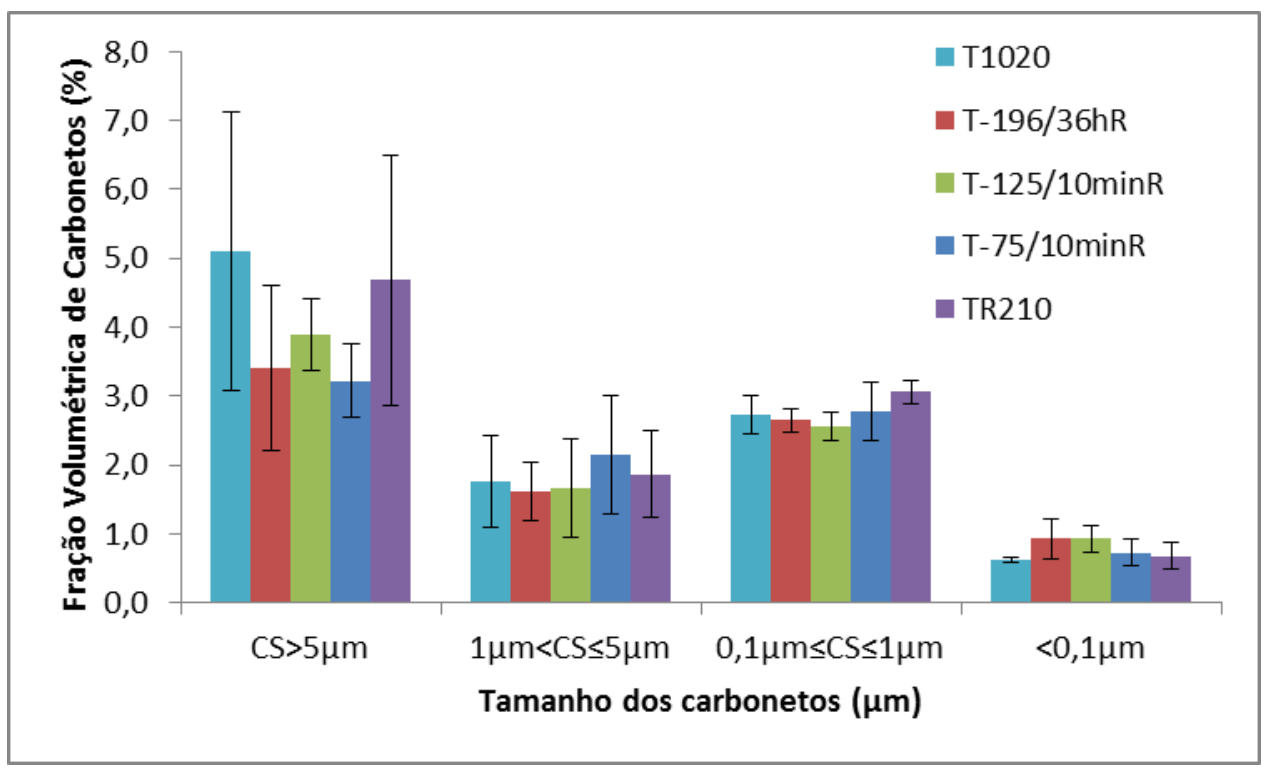

Figura 30 - Fração volumétrica dos diferentes tamanhos de carbonetos das amostras T1020, TR210, T-196/36hR, T-125/10minR e T-75/10minR. Variação para um intervalo de confiança de 95\%.

A figura 31 apresenta a microestrutura das amostras após revenimento (a) TR210, (b) T-196/36hR, (c) T-125/10minR e (d) T-75/10minR. É possível notar a presença de carbonetos nanométricos, somados aos carbonetos micrométricos. A amostra TR210, sem tratamento criogênico, foi a única com a presença de austenita retida (visível ao $\mathrm{MEV}$ ) após revenimento, mostrando que o tratamento criogênico foi eficiente para eliminar a austenita. 


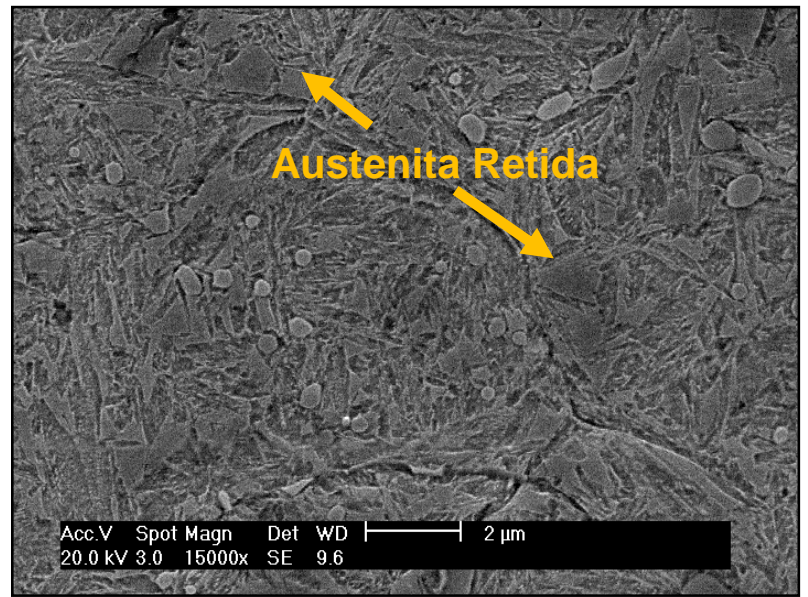

(a)

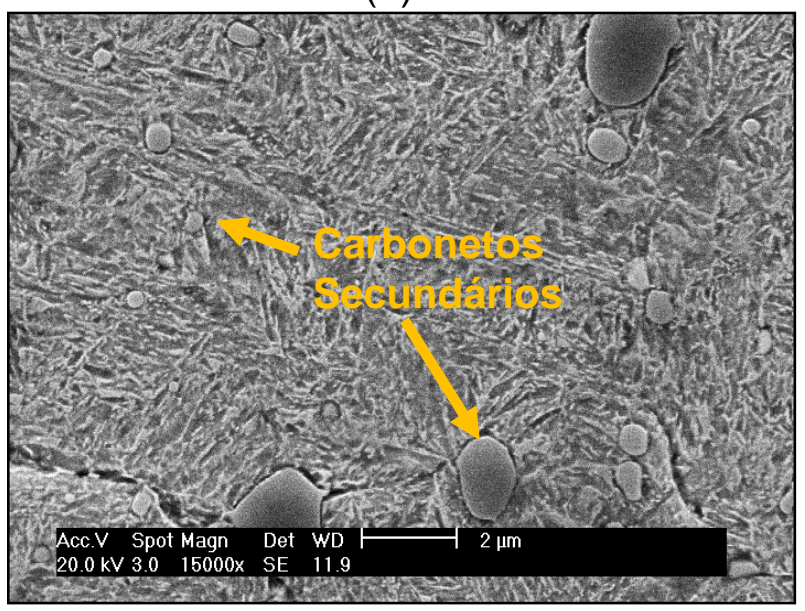

(c)

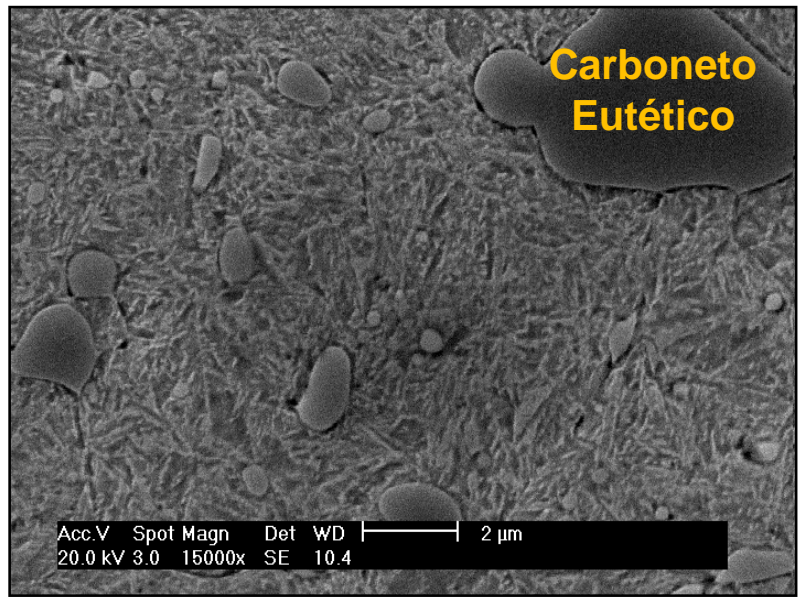

(b)

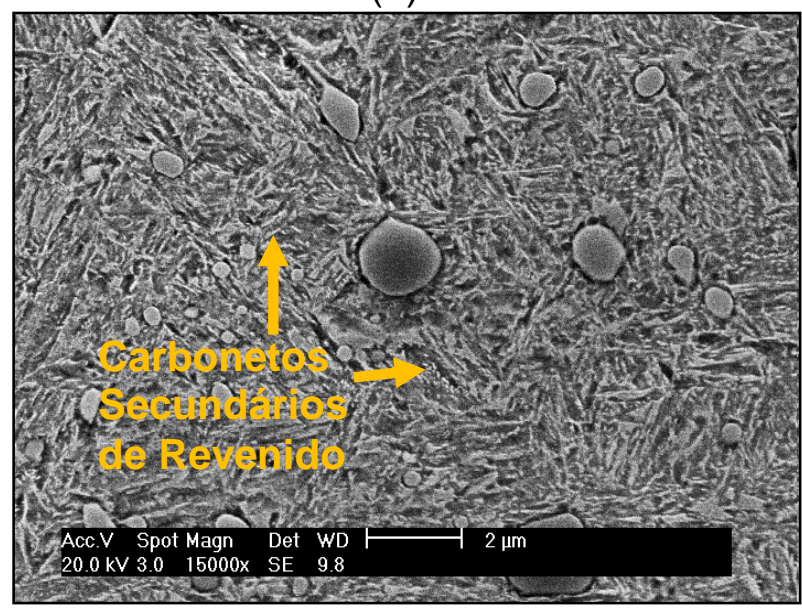

(d)

Figura 31 - Microestrutura das amostras (a) TR210, (b) T-196/36hR, (c) T-125/10minR e (d) T75/10minR, mostrando: (a) austenita retida; (a), (b), (c) e (d) - carbonetos eutéticos e nanométricos de revenido. Ataque: Villela/10s. MEV - elétrons secundários.

A figura 32 apresenta em detalhe a micro/nanoestrutura da amostra T125/10minR. Verifica-se claramente a presença de nanocarbonetos precipitados durante o revenimento delineando as ripas de martensita e a presença de carbonetos secundários. 


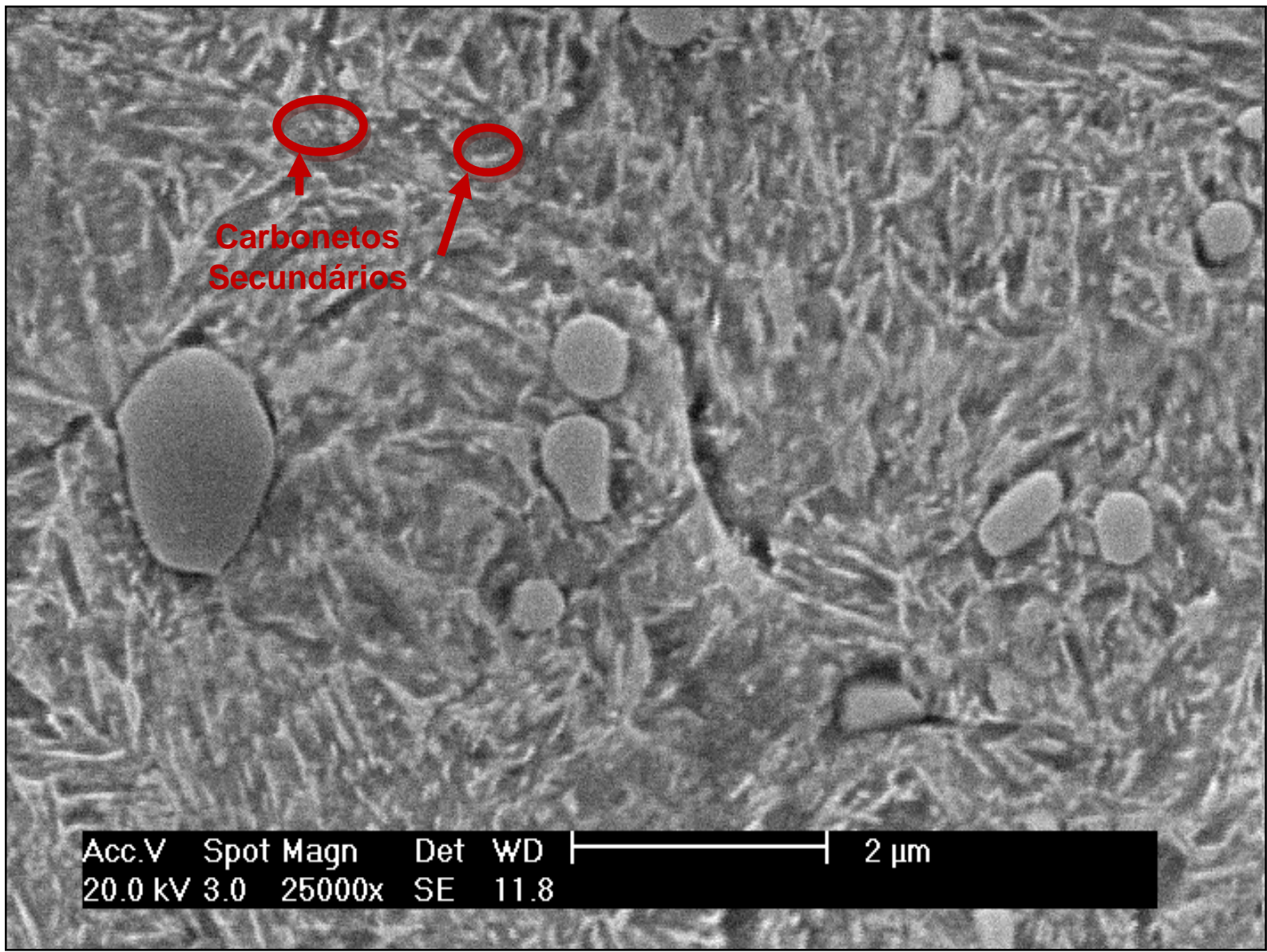

Figura 32 - Detalhe da microestrutura da amostra T-125/10minR, mostrando os carbonetos de revenido nanométricos, os quais delineiam a estrutura martensítica. Ataque: Villela/10s. MEV elétrons secundários.

A figura 33 apresenta em detalhe a micro/nanoestrutura da amostra TR210, sem tratamento criogênico. É possível verificar a presença de austenita retida (estrutura de blocos), carbonetos secundários e os nanocarbonetos precipitados durante o revenimento. 


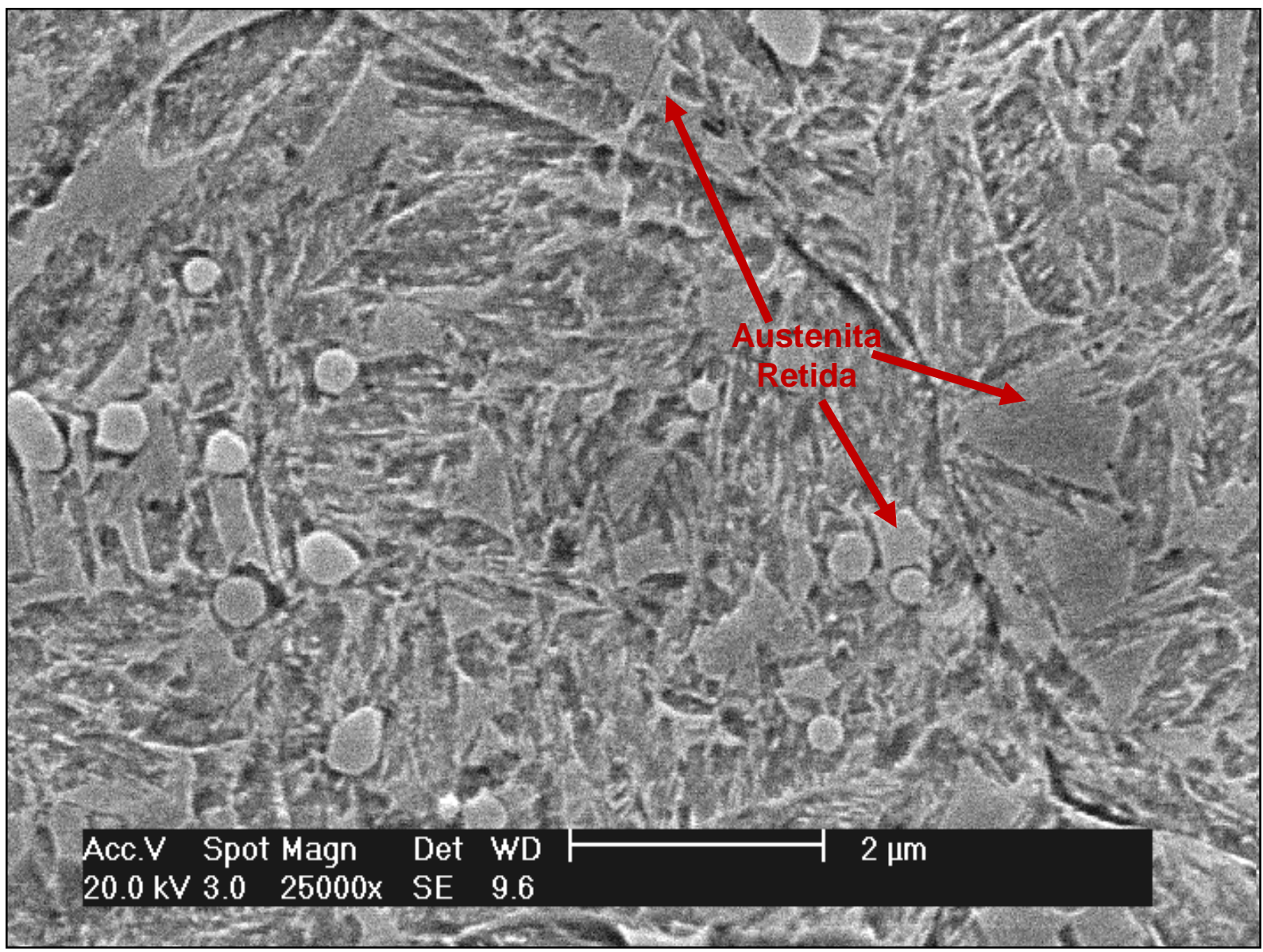

Figura 33 - Detalhe da microestrutura da amostra TR210, mostrando a austenita retida (blocos), os carbonetos eutéticos e os carbonetos de revenido nanométricos, os quais delineiam a estrutura martensítica. Ataque: Villela/10s. MEV - elétrons secundários.

Da comparação das figuras 32 e 33 pode ser dito que o tratamento criogênico causa uma diferença na distribuição de carbonetos secundários de revenido, entretanto, esta diferença não pode ser quantificada: os carbonetos secundários de revenido parecem estar mais alongados na figura 33, indicando um refinamento da nanoestrutura nas amostras tratadas criogenicamente.

As figuras 34 e 35 apresentam em maior detalhe as micro/nanoestruturas das amostras T-196/36hR e TR, respectivamente. Nota-se tanto na figura 34 quanto na figura 35 a presença de $Y_{R}$ na forma de blocos (provavelmente entre as placas de $\left.\alpha^{\prime}\right)$. 


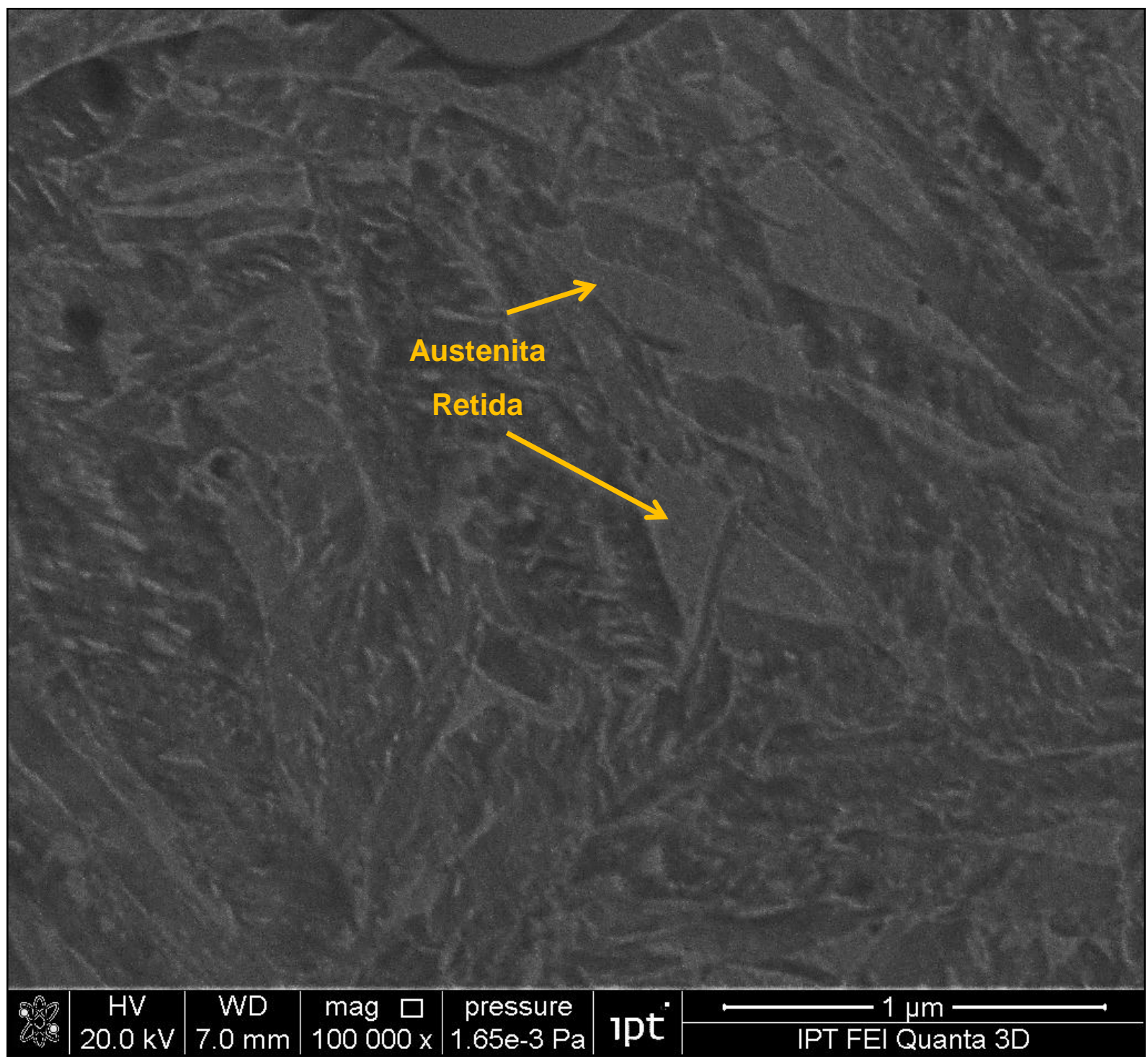

Figura 34 - Detalhe da microestrutura da amostra T-196/36hR, mostrando a austenita retida (blocos) e carbonetos secundários. Ataque: Villela/10s. MEV-FEG - elétrons secundários. 


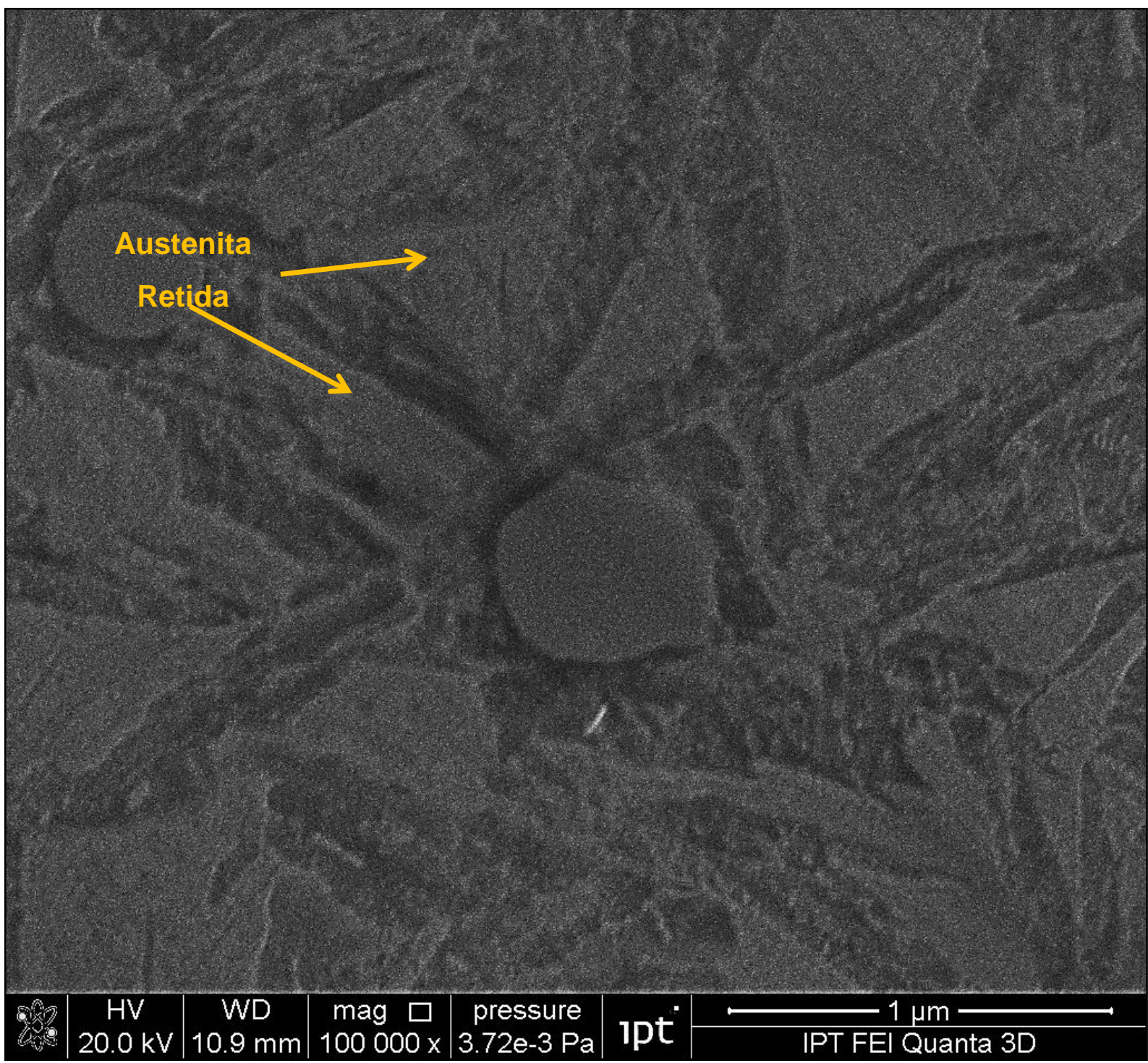

Figura 35 - Detalhe da microestrutura da amostra TR210, mostrando a austenita retida (blocos) e carbonetos secundários. Ataque: Villela/10s. MEV-FEG - elétrons secundários.

\subsection{Segunda Série de Experimentos}

A figura 36 apresenta a microestrutura da amostra somente temperada (T). É possível observar a presença de carbonetos eutéticos e secundários, de austenita retida e de martensita. Das fases presentes, a martensita é a única atacada pelo reagente Villela. 


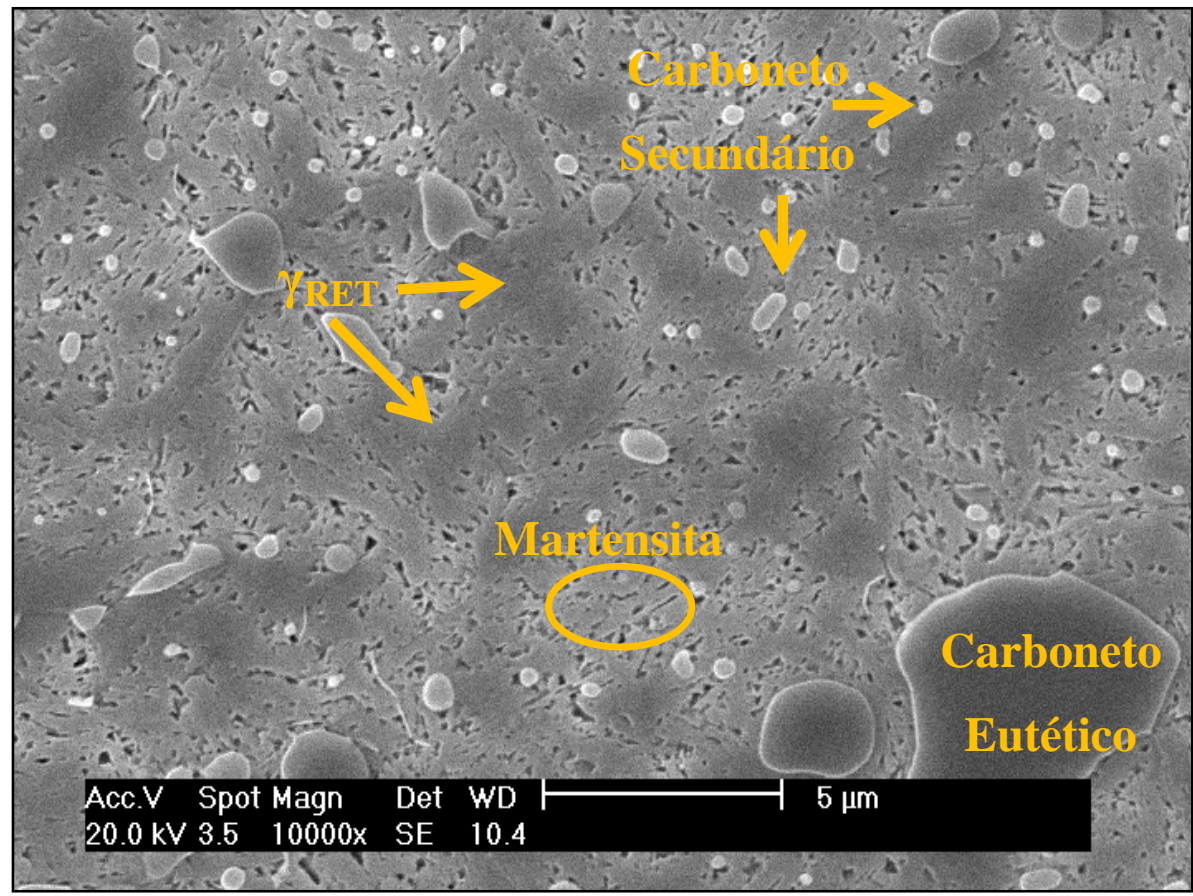

Figura 36 - Microestrutura da amostra T (S21), somente temperada, mostrando a presença de carbonetos eutéticos e secundários e de martensita e austenita retida. Ataque: Villela/10s. MEV elétrons secundários.

A figura 37 apresenta as micro/nanoestruturas das quatro amostras após serem submetidas a duplo revenimento. Nas quatro amostras verifica-se, além dos carbonetos eutéticos e secundários, a presença de carbonetos nanométricos de revenido. Na figura $37(\mathrm{c})$ é possível observar uma pequena região não atacada, possivelmente com alguma austenita retida residual. 


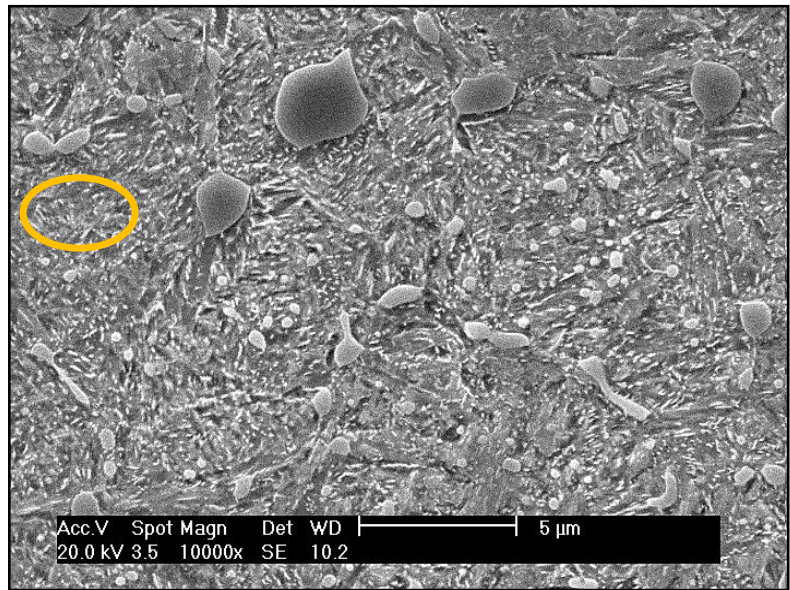

(a) $\mathrm{T}+\mathrm{AT}+\mathrm{TC} / 30+\mathrm{R}(\mathrm{S} 16)$

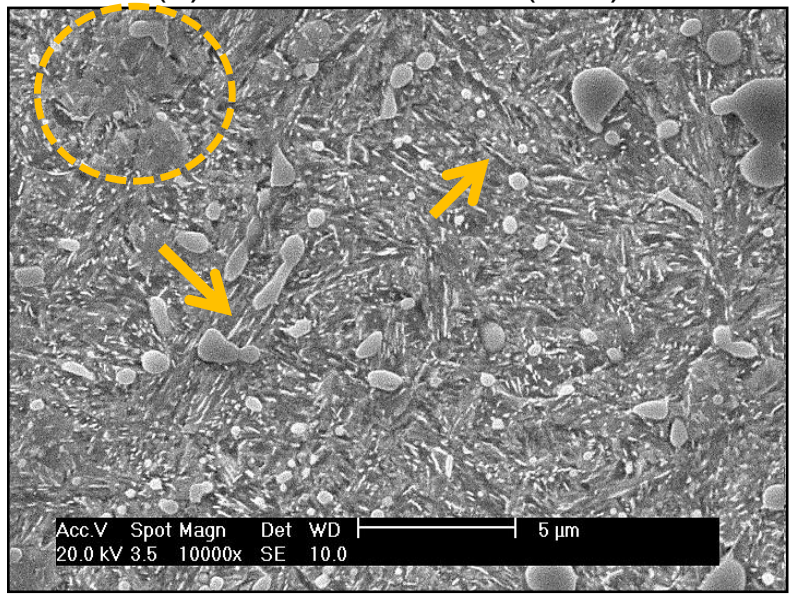

(c) $T+A T+R(S 18)$

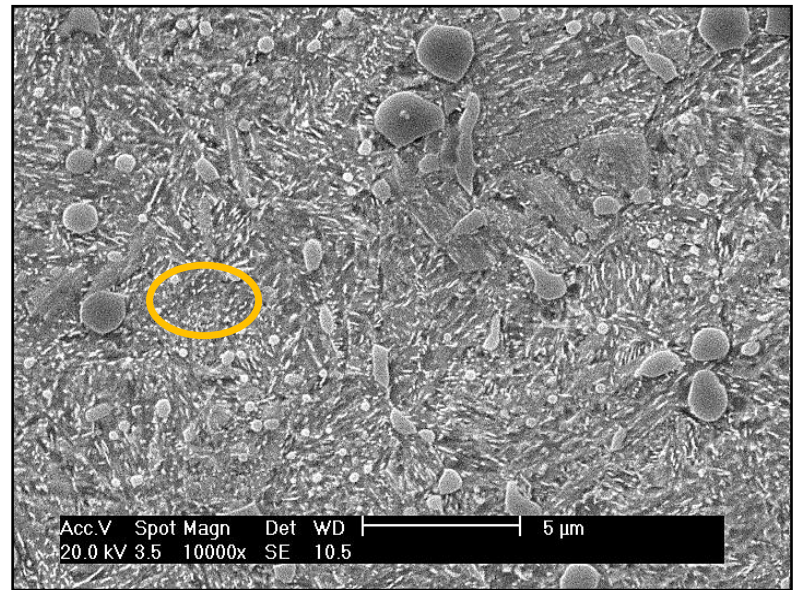

(b) $\mathrm{T}+\mathrm{TC} / 30+\mathrm{R}(\mathrm{S} 17)$

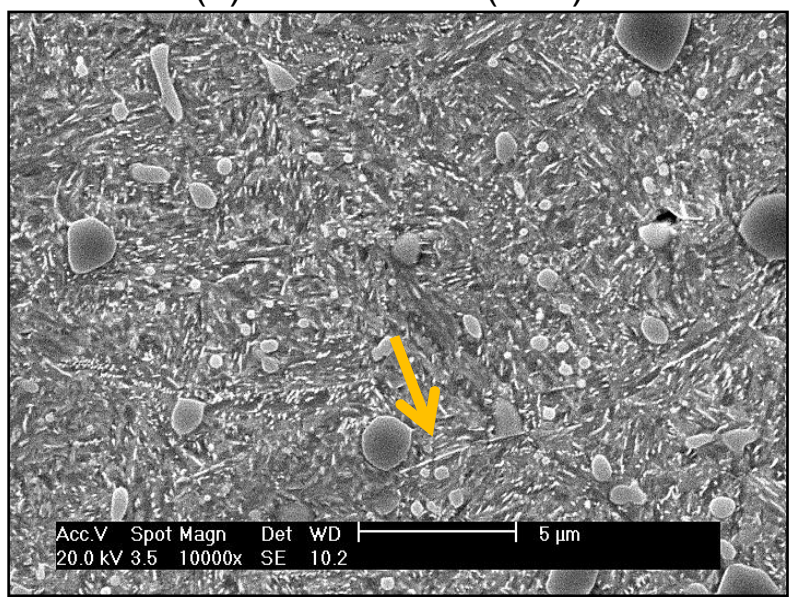

(d) $T+R(S 19)$

Figura 37 - Microestruturas das amostras após duplo revenimento (S16, S17, S18 e S19) mostrando a presença dos carbonetos nanométricos de revenido (marcações com linha cheia), além de carbonetos eutéticos e secundários e possível austenita retida (marcação com linha tracejada). Ataque: Villela/10s. MEV - elétrons secundários.

As figuras de 38 a 42 apresentam em detalhe as microestruturas apresentadas na figura 37. É possível observar de forma mais clara os carbonetos nanométricos de revenido os quais delineiam a estrutura martensítica. 


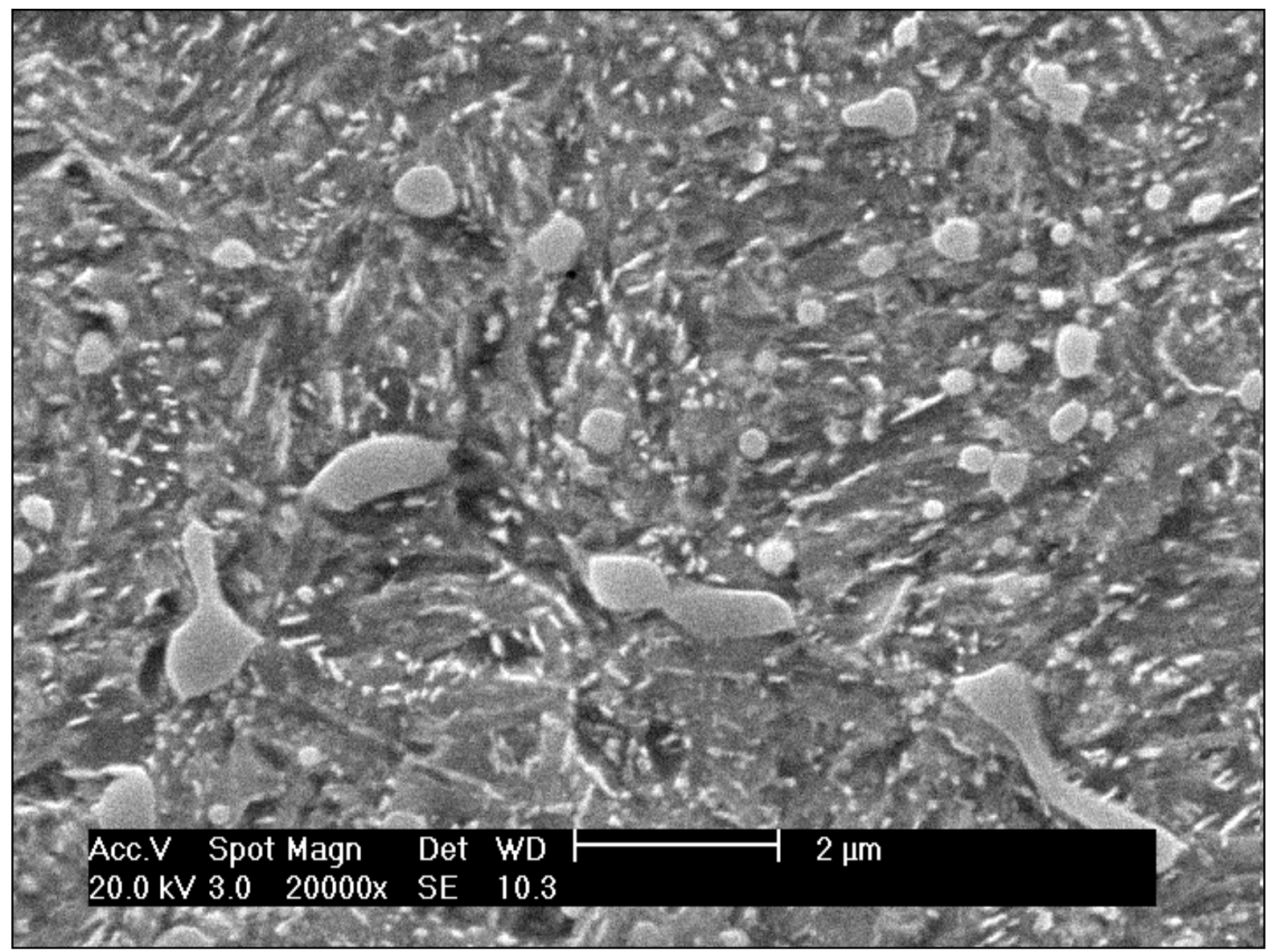

Figura 38 - Detalhe da figura 37(a), microestrutura da amostra S16 (T+AT+TC/30+2R) mostrando a distribuição dos carbonetos de revenido nanométricos, os quais delineiam a estrutura martensítica e carbonetos secundários (micrométricos). Ataque: Villela/10s. MEV - elétrons secundários. 


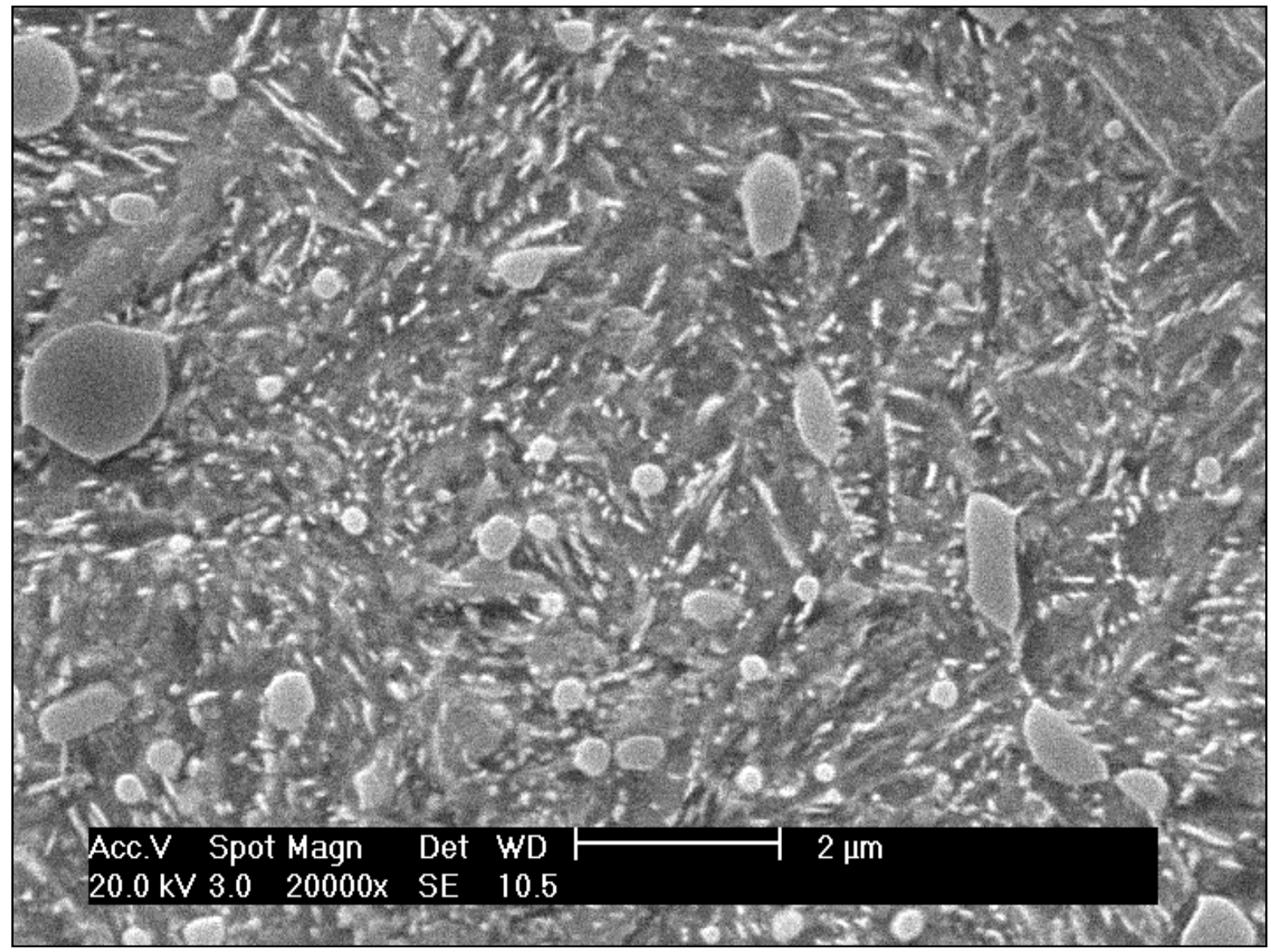

Figura 39 - Detalhe da figura 37(b), microestrutura da amostra S17 (T+TC/30+2R) mostrando a distribuição dos carbonetos de revenido nanométricos, os quais delineiam a estrutura martensítica e carbonetos secundários (micrométricos). Ataque: Villela/10s. MEV - elétrons secundários. 


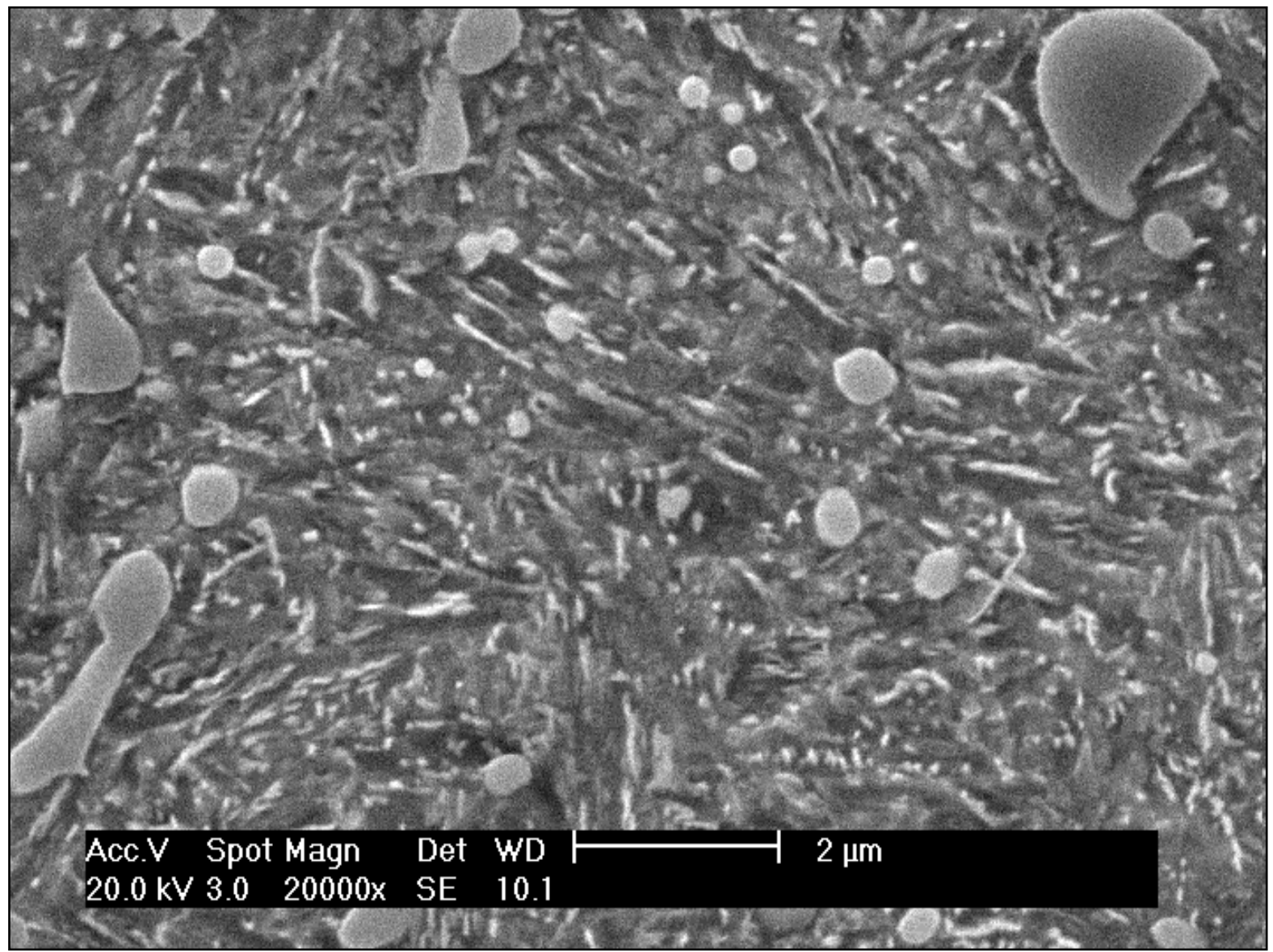

Figura 40 - Detalhe da figura 37(c), microestrutura da amostra S18 (T+AT+2R) mostrando a distribuição dos carbonetos de revenido nanométricos, os quais delineiam a estrutura martensítica e carbonetos secundários (micrométricos). Ataque: Villela/10s. MEV - elétrons secundários. 


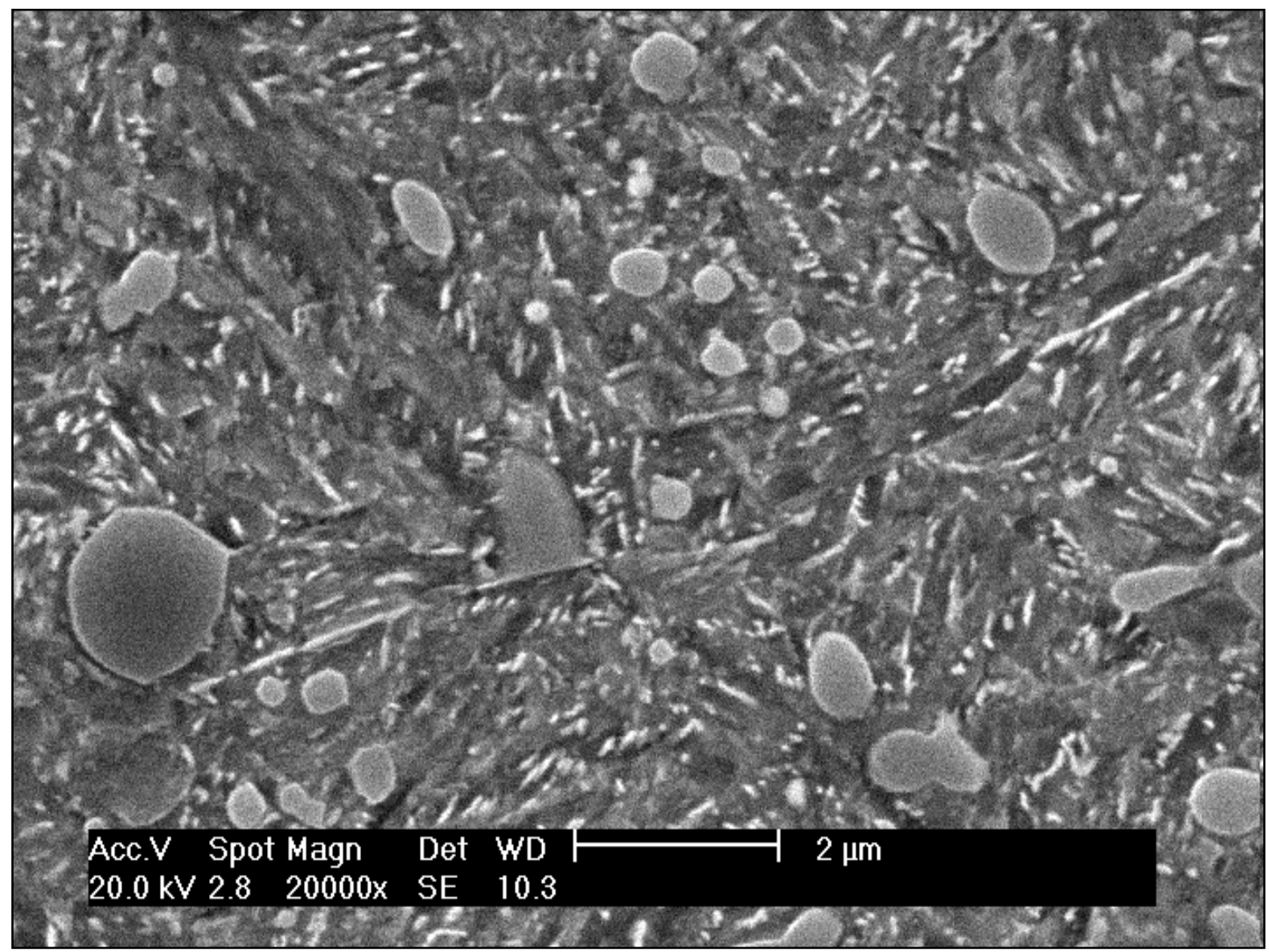

Figura 41 - Detalhe da figura 37(d), microestrutura da amostra S19 (T+2R) mostrando a distribuição dos carbonetos de revenido nanométricos, os quais delineiam a estrutura martensítica e carbonetos secundários (micrométricos). Ataque: Villela/10s. MEV - elétrons secundários.

As figuras 42 e 43 mostram em detalhe ainda maior as microestruturas apresentadas nas figuras 39 e 41, sendo possível observar a morfologia dos carbonetos de revenido nanométricos. 


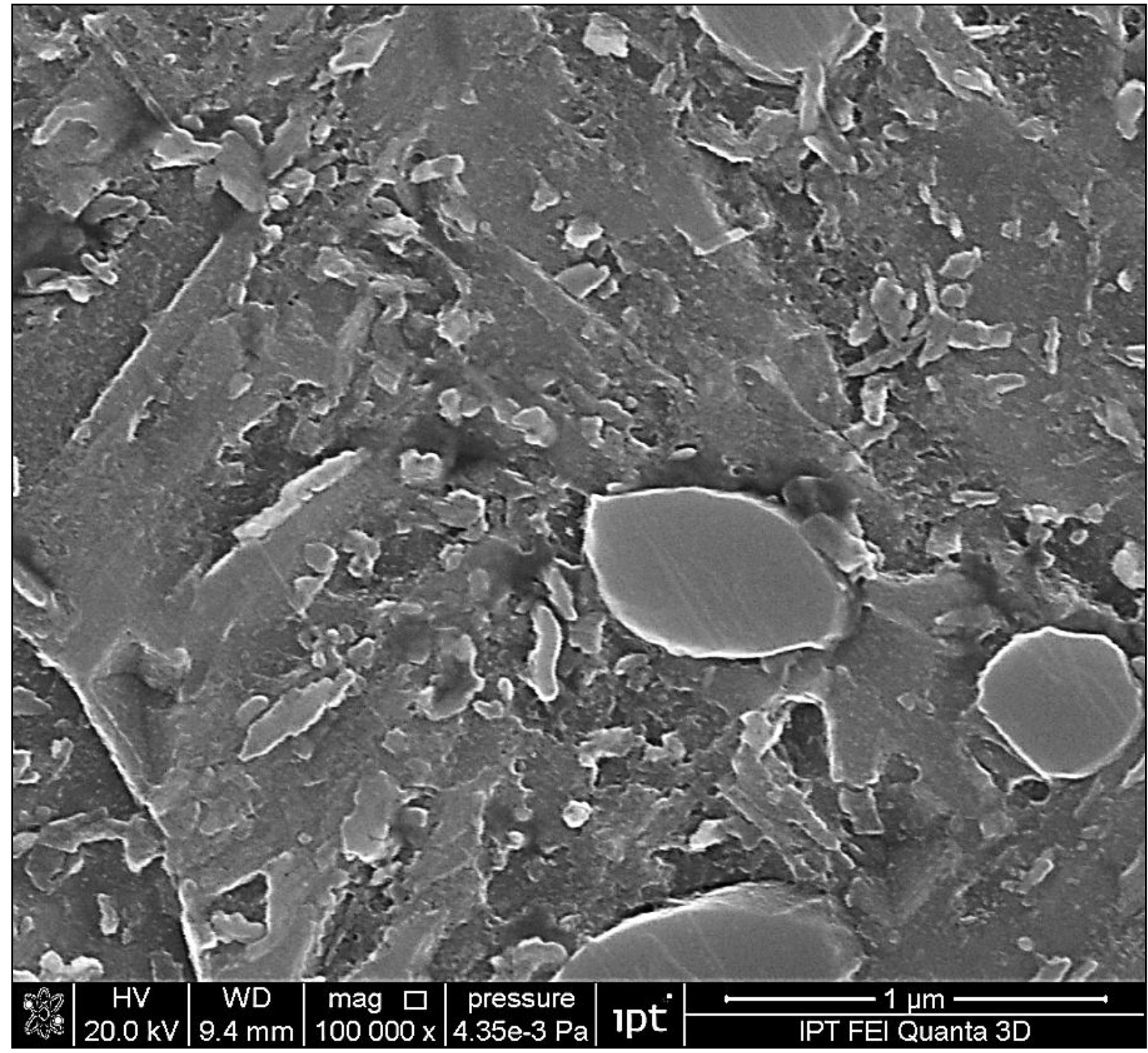

Figura 42 - Microestrutura da amostra S17 (T+TCP/30h+2R) - figuras 37(b) e 39 - mostrando a distribuição dos carbonetos de revenido nanométricos, os quais delineiam a estrutura martensítica e carbonetos secundários (micrométricos). Ataque: Villela/10s. MEV/FEG - elétrons secundários. 


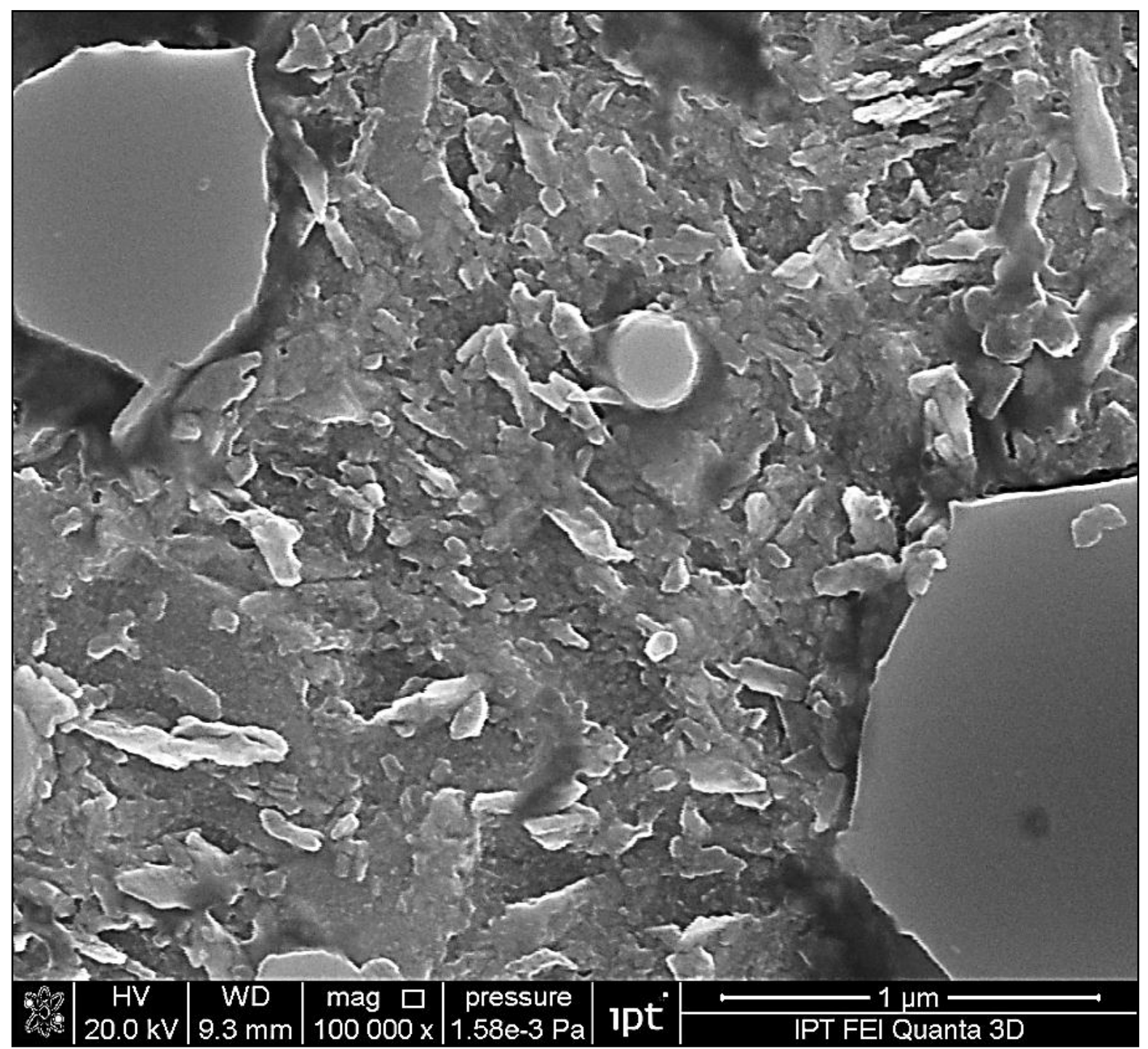

Figura 43 - Microestrutura da amostra S19 $(T+2 R)$ - figuras 37(d) e 41 - mostrando a distribuição dos carbonetos de revenido nanométricos, os quais delineiam a estrutura martensítica e carbonetos secundários (micrométricos). Ataque: Villela/10s. MEV/FEG - elétrons secundários.

A figura 44 apresenta os difratogramas obtidos por difração de raios- $X$ utilizando luz síncroton. A figura 45 apresenta os respectivos difratogramas calculados após refinamento por Rietveld, apresentando as indexações correspondentes. Por fim, as figuras 46 e 47 apresentam separadamente os difratogramas calculados para as fases presentes na matriz (ferrita/martensita e austenita) e os carbonetos identificados $\left(\mathrm{M}_{7} \mathrm{C}_{3}\right.$ e $\left.\mathrm{M}_{2} \mathrm{C}\right)$, respectivamente. 


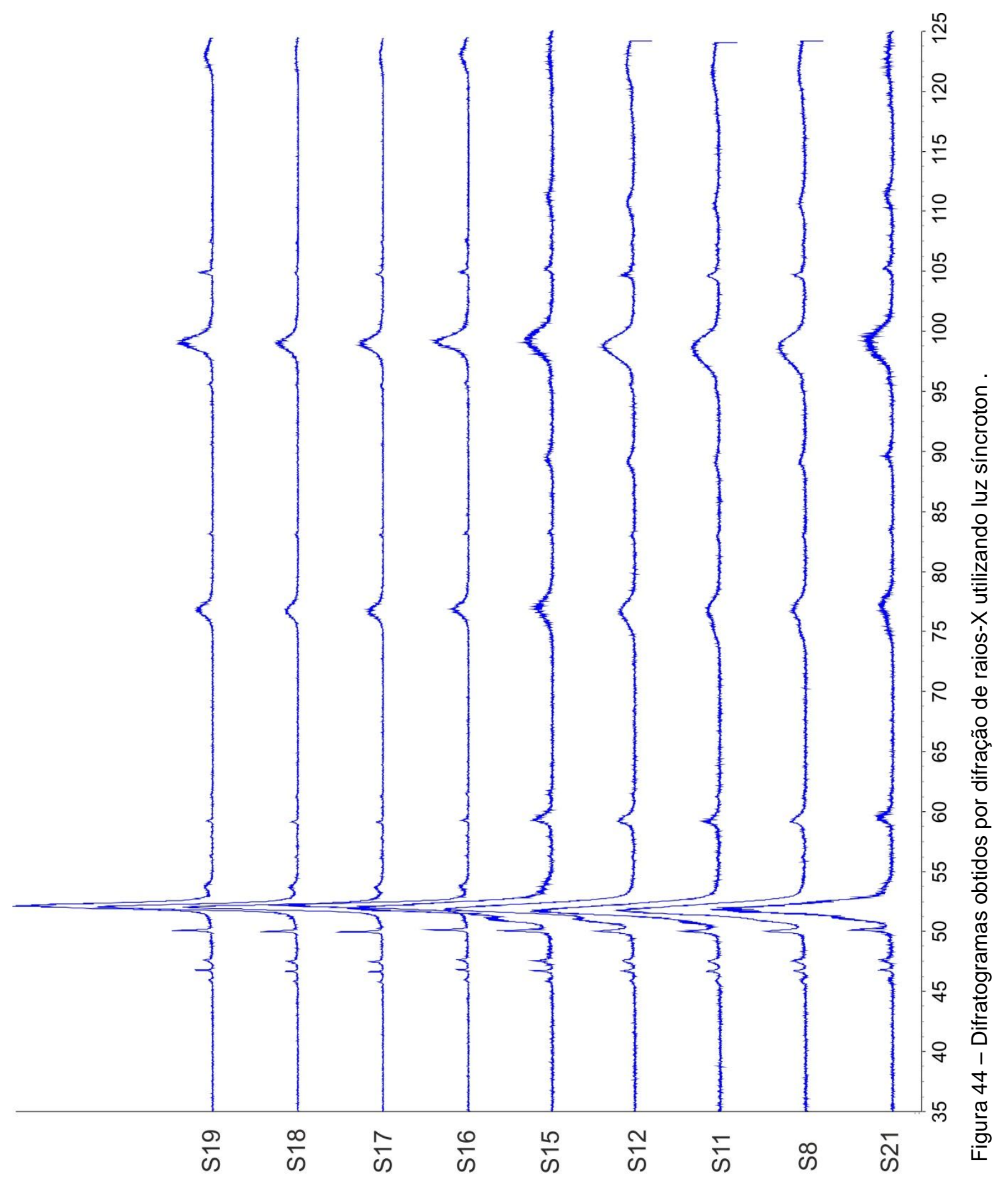




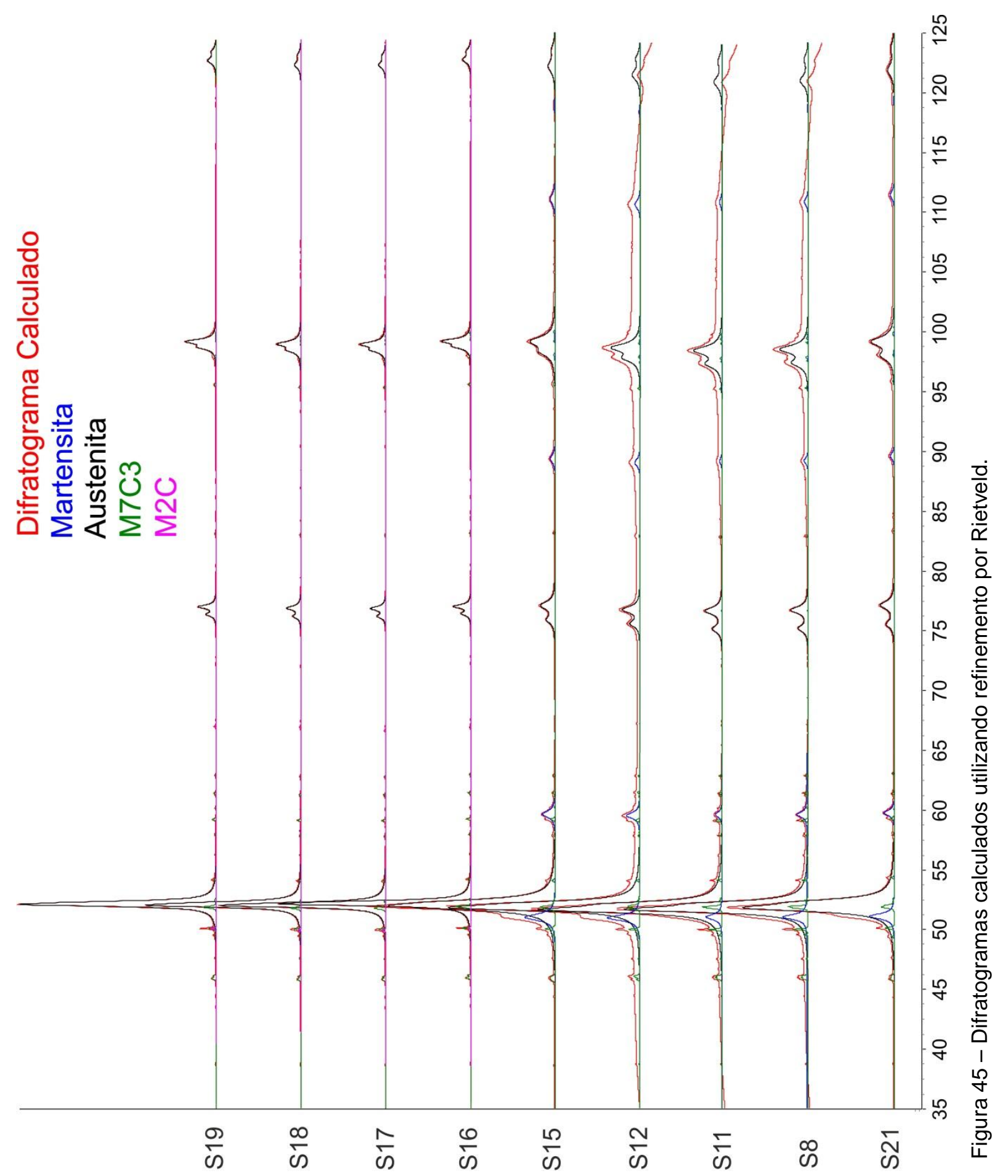




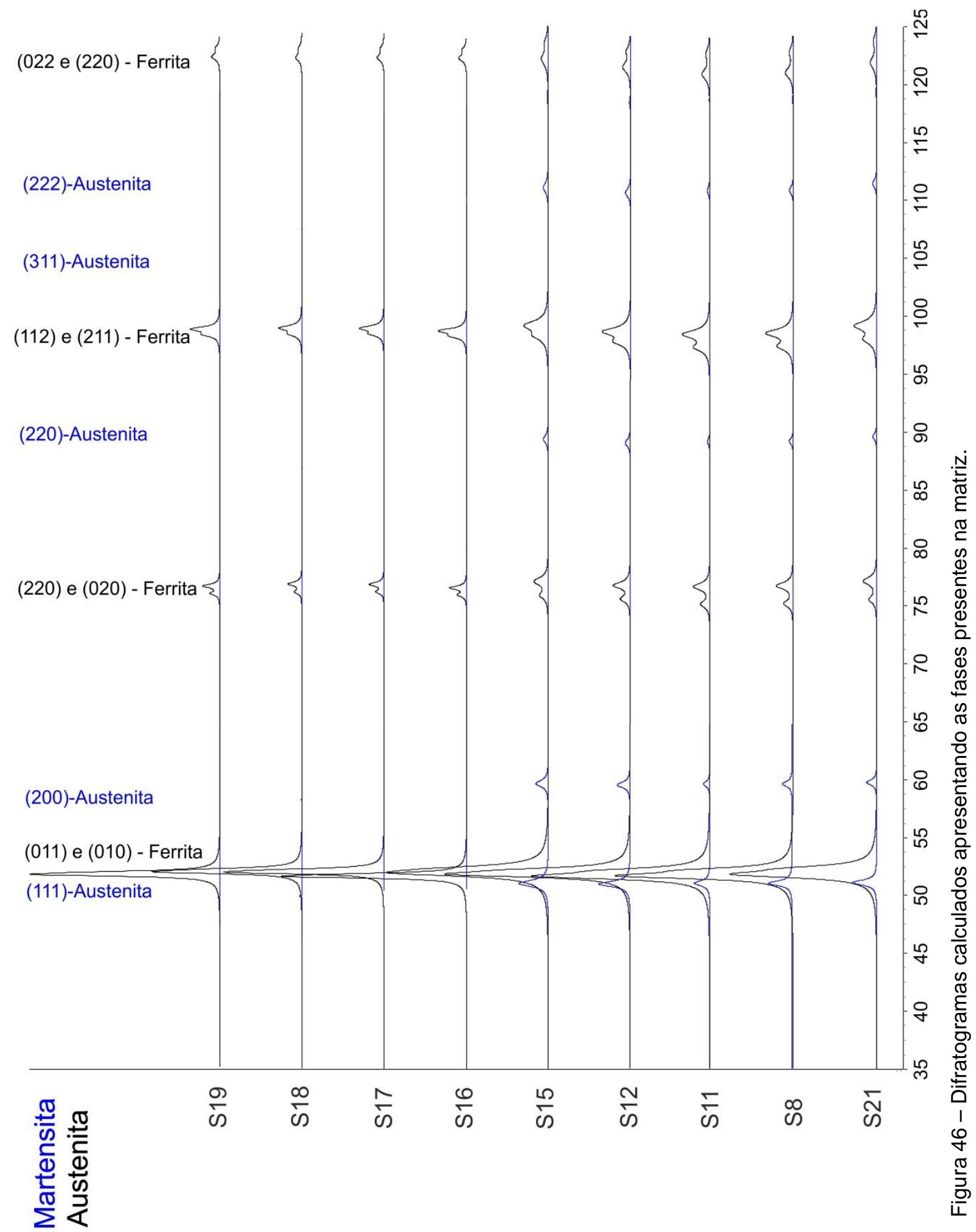


(021) - M2C

(211) - M7C3

(112) - M7C3

(306) - M7C3

(322) - M7C3

(144) - M7C3

$(012): M 2 C$
$(230)=M 7 C 3$

(223) - M7C3

(214) - M7C3

(222) - M7C3

220 - M7C3

(132) - M7C3

211) - M7C3

011 - M2C

(210) - M7C3

(201) - M7C3

(031) - M7C3

(010) - M2C

(121) - M7C3

30
$\Sigma$

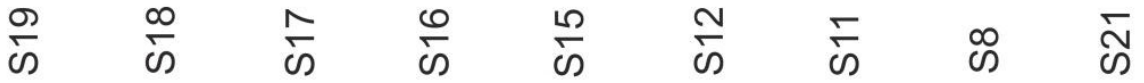

$\stackrel{\stackrel{N}{N}}{\stackrel{0}{2}}$

ิㅗำ

$\stackrel{ }{=}$

울

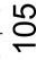

우

น̊

8

$\infty$

$\infty$

$\frac{1}{8}$

$\stackrel{10}{\wedge}$

웅

$-8$

8

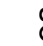

ᄂ

요

.

เ

암

吕

숭 
As tabelas 7 e 8 apresentam os parâmetros de rede da martensita e da austenita e dos carbonetos $\mathrm{M}_{7} \mathrm{C}_{3}$ e $\mathrm{M}_{2} \mathrm{C}$, respectivamente, bem como as respectivas frações volumétricas de cada fase. Dados obtidos a partir do refinamento por Rietveld dos difratogramas obtidos por difração de raios-X com luz síncroton. $O$ erro experimental para as determinações de frações volumétricas das fases é de $0,5 \%$ e para os parâmetros de rede está na quarta casa decimal.

Tabela 7 - Valores dos parâmetros a e c da martensita e a da austenita e frações volumétricas presentes destas fases. Para a amostra S20, os valores na coluna da martensita correspondem à fase ferrita.

\begin{tabular}{|c|c|c|c|c|c|c|c|}
\hline \multirow{2}{*}{ Amostra } & & \multicolumn{4}{|c|}{ Martensita } & \multicolumn{2}{|c|}{ Austenita } \\
\hline & & $\mathbf{a}$ & c & c/a & $\%$ & $\mathbf{a}$ & $\%$ \\
\hline $\mathrm{R}$ & (S20) & 2,872 & 2,869 & 0,9992 & 90,64 & 3,612 & 0,01 \\
\hline T & (S21) & 2,869 & 2,920 & 1,0179 & 82,78 & 3,590 & 11,58 \\
\hline$T+T C / 3$ & (S6) & 2,866 & 2,920 & 1,0189 & 84,06 & 3,587 & 9,01 \\
\hline $\mathrm{T}+\mathrm{TC} / 10$ & (S7) & 2,871 & 2,921 & 1,0175 & 83,04 & 3,588 & 10,70 \\
\hline $\mathrm{T}+\mathrm{TC} / 30$ & (S8) & 2,871 & 2,921 & 1,0174 & 83,74 & 3,588 & 10,02 \\
\hline $\mathrm{T}+\mathrm{SZ} / 3$ & (S9) & 2,868 & 2,918 & 1,0176 & 86,86 & 3,587 & 7,00 \\
\hline $\mathrm{T}+\mathrm{SZ} / 10$ & (S10) & 2,874 & 2,922 & 1,0168 & 87,78 & 3,584 & 6,13 \\
\hline$T+S Z / 30$ & (S11) & 2,871 & 2,921 & 1,0172 & 86,56 & 3,586 & 7,41 \\
\hline$T+A T$ & (S12) & 2,870 & 2,908 & 1,0133 & 80,14 & 3,593 & 14,59 \\
\hline$T+A T+T C / 3$ & (S13) & 2,869 & 2,907 & 1,0133 & 80,42 & 3,591 & 14,69 \\
\hline $\mathrm{T}+\mathrm{AT}+\mathrm{TC} / 10$ & (S14) & 2,872 & 2,910 & 1,0133 & 78,24 & 3,597 & 15,68 \\
\hline$T+A T+T C / 30$ & (S15) & 2,872 & 2,910 & 1,0133 & 78,26 & 3,599 & 15,56 \\
\hline$T+A T+T C / 30+R$ & (S16) & 2,865 & 2,885 & 1,0068 & 92,30 & 3,606 & $<0,05$ \\
\hline$T+T C / 30+R$ & $(\mathrm{~S} 17)$ & 2,870 & 2,891 & 1,0072 & 91,42 & 3,622 & $<0,05$ \\
\hline$T+A T+R$ & (S18) & 2,870 & 2,892 & 1,0076 & 92,44 & 3,668 & 0,45 \\
\hline$T+R$ & (S19) & 2,865 & 2,886 & 1,0071 & 91,50 & 3,646 & $<0,05$ \\
\hline
\end{tabular}


Tabela 8 - Valores dos parâmetros $\mathbf{a}, \mathbf{b}$ e $\mathbf{c}$ do carboneto $M_{7} C_{3}$ e a e c do carboneto $M_{2} C$, e frações volumétricas dos carbonetos.

\begin{tabular}{lrrrrrrrrr}
\hline \multicolumn{2}{c}{ Amostra } & & \multicolumn{4}{c}{$\mathbf{M}_{\mathbf{7}} \mathbf{C}_{3}$} & \multicolumn{3}{c}{$\mathbf{M}_{\mathbf{2}} \mathbf{C}$} \\
\cline { 3 - 10 } & & $\mathbf{a}$ & $\mathbf{b}$ & $\mathbf{c}$ & $\%$ & $\mathbf{a}$ & $\mathbf{c}$ & $\%$ \\
\hline $\mathrm{R}$ & $(\mathrm{S} 20)$ & 4,503 & 7,013 & 12,115 & 9,35 & - & - & - \\
$\mathrm{T}$ & $(\mathrm{S} 21)$ & 4,503 & 6,985 & 12,157 & 5,75 & - & - & - \\
$\mathrm{T}+\mathrm{TC} / 3$ & $(\mathrm{~S} 6)$ & 4,501 & 7,067 & 12,061 & 6,93 & - & - & - \\
$\mathrm{T}+\mathrm{TC} / 10$ & $(\mathrm{~S} 7)$ & 4,506 & 7,007 & 12,086 & 6,26 & - & - & - \\
$\mathrm{T}+\mathrm{TC} / 30$ & $(\mathrm{~S} 8)$ & 4,506 & 7,006 & 12,084 & 6,24 & - & - & - \\
$\mathrm{T}+\mathrm{SZ} / 3$ & $(\mathrm{~S} 9)$ & 4,503 & 7,012 & 12,090 & 6,15 & - & - & - \\
$\mathrm{T}+\mathrm{SZ} / 10$ & $(\mathrm{~S} 10)$ & 4,509 & 7,008 & 12,088 & 6,09 & - & - & - \\
$\mathrm{T}+\mathrm{SZ} / 30$ & $(\mathrm{~S} 11)$ & 4,506 & 7,003 & 12,083 & 6,03 & - & - & - \\
$\mathrm{T}+\mathrm{AT}$ & $(\mathrm{S} 12)$ & 4,506 & 7,014 & 12,068 & 5,27 & - & - & - \\
$\mathrm{T}+\mathrm{AT}+\mathrm{TC} / 3$ & $(\mathrm{~S} 13)$ & 4,505 & 7,014 & 12,071 & 4,89 & - & - & - \\
$\mathrm{T}+\mathrm{AT}+\mathrm{TC} / 10$ & $(\mathrm{~S} 14)$ & 4,511 & 7,033 & 12,123 & 6,07 & - & - & - \\
$\mathrm{T}+\mathrm{AT}+\mathrm{TC} / 30$ & $(\mathrm{~S} 15)$ & 4,512 & 7,035 & 12,125 & 6,18 & - & - & - \\
$\mathrm{T}+\mathrm{AT}+\mathrm{TC} / 30+\mathrm{R}$ & $(\mathrm{S} 16)$ & 4,500 & 7,001 & 12,102 & 6,92 & 2,780 & 4,376 & 0,76 \\
$\mathrm{~T}+\mathrm{TC} / 30+\mathrm{R}$ & $(\mathrm{S} 17)$ & 4,507 & 7,020 & 12,122 & 7,46 & 2,787 & 4,394 & 1,10 \\
$\mathrm{~T}+\mathrm{AT}+\mathrm{R}$ & $(\mathrm{S} 18)$ & 4,507 & 7,024 & 12,131 & 6,63 & 2,793 & 4,360 & 0,48 \\
$\mathrm{~T}+\mathrm{R}$ & $(\mathrm{S} 19)$ & 4,500 & 7,004 & 12,103 & 7,58 & 2,783 & 4,359 & 0,93 \\
\hline
\end{tabular}

\subsection{Terceira Série de Experimentos}

As figuras de 48 a 52 apresentam as curvas da variação do TEP normalizada $(\triangle T E P)$ em função do tempo de permanência à temperatura isotérmica (em escala logarítmica). Note que o valor de $\Delta$ TEP é um número adimensional, pois todos os valores foram divididos pelo maior valor para a normalização. São apresentadas as curvas completas e detalhes (ampliados) das faixas determinadas como mais importantes. Os valores do TEP variaram de aproximadamente $4.000 \mathrm{nV} /{ }^{\circ} \mathrm{C}$ até aproximadamente $8.500 \mathrm{nv} /{ }^{\circ} \mathrm{C}$. A variação do TEP foi calculada para cada amostra, ou seja, para cada temperatura em cada ciclo. Isto porque o aço AISI D2 é heterogêneo (devido principalmente à presença de carbonetos eutéticos) e a condição inicial (temperada) de cada amostra não apresenta valores exatamente iguais. Para a normalização das variações, foi assumido o maior valor de $\triangle$ TEP (ciclo $1,520^{\circ} \mathrm{C}, 1024$ minutos) como 1 , e calculados os demais a partir deste valor, para possibilitar a comparação entre temperaturas e entre ciclos.

A figura 48 apresenta os valores de $\triangle$ TEP para a temperatura de $130^{\circ} \mathrm{C}$. É possível notar que o comportamento das amostras somente com TC (ciclos 2 e 3) foi 
diferente dos demais. A forma da curva dos 3 primeiros ciclos foi bem semelhante, enquanto o ciclo 4 (com AT) apresentou comportamento distinto.

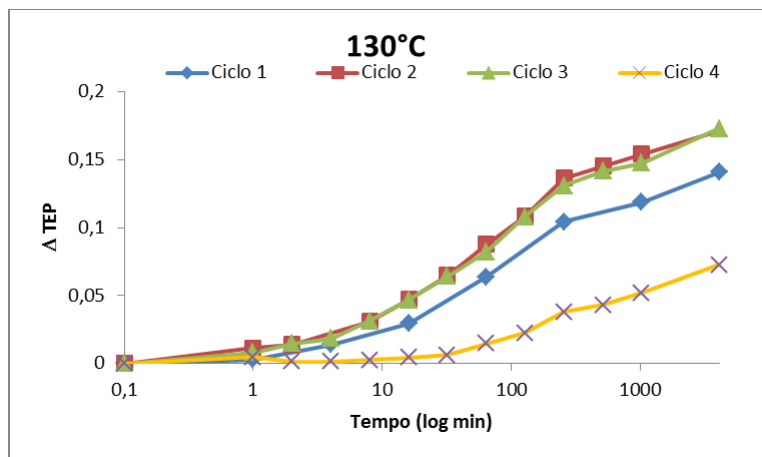

(a)

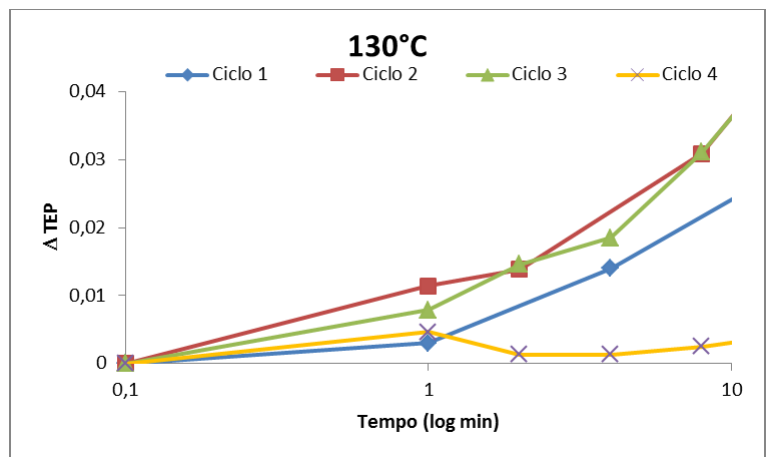

(b)

Figura 48 - Evolução do TEP em função do tempo de permanência à $130^{\circ} \mathrm{C}$. (a) curvas completas; (b) destaque para os tempos iniciais. Ciclo 1: T + Tisotérmico; Ciclo 2: T + TC/2h + Tisotérmico; Ciclo 3: T + TC/24h + Tisotérmico; Ciclo 4: T + AT + TC/24h + Tisotérmico. Aço AISI D2.

A figura 49 apresenta os valores de $\triangle$ TEP para a temperatura de $210^{\circ} \mathrm{C}$. Nesta temperatura é possível observar que os três primeiros ciclos praticamente se igualam, enquanto o ciclo 4 tem comportamento distinto. $O$ primeiro ponto determinado (após a condição inicial = tempo zero) foi com 1 minuto. Note que neste tempo, o valor de $\Delta$ TEP é $\sim 0,12$, próximo ao valor da mudança da inclinação da curva a $130^{\circ} \mathrm{C}(\triangle \mathrm{TEP} \sim 0,13)$. No detalhe em (b), é possível verificar uma tendência do ciclo 3 de ultrapassar os valores de $\triangle$ TEP dos ciclos 1 e 2.

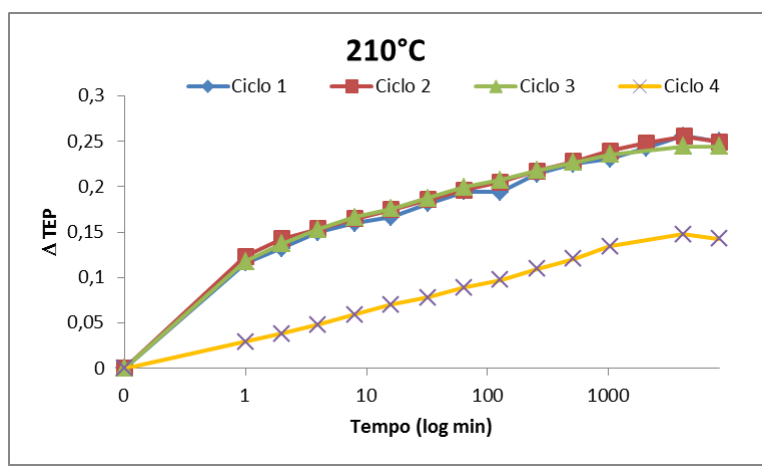

(a)

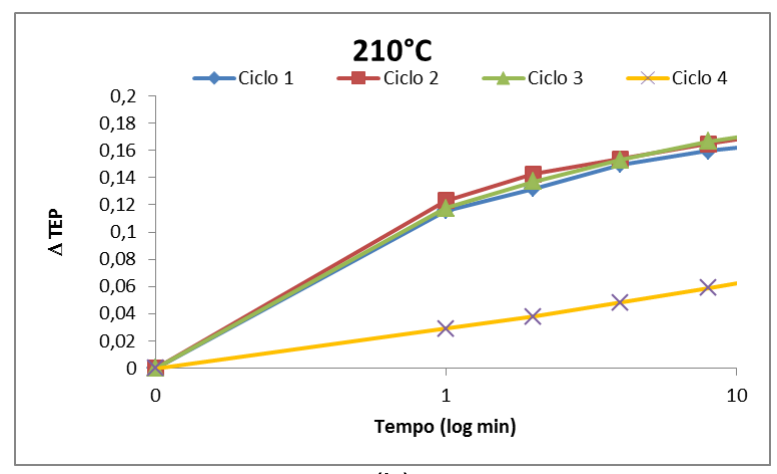

(b)

Figura 49 - Evolução do TEP em função do tempo de permanência à $210^{\circ} \mathrm{C}$. (a) curvas completas; (b) destaque para os tempos iniciais. Ciclo 1: T + Tisotérmico; Ciclo 2: T + TC/2h + Tisotérmico; Ciclo 3: T + TC/24h + Tisotérmico; Ciclo 4: T + AT + TC/24h + Tisotérmico. Aço AISI D2.

A figura 50 apresenta os valores de $\triangle$ TEP para a temperatura de $350^{\circ} \mathrm{C}$. Observando-se inicialmente o mesmo comportamento apresentado à $210^{\circ} \mathrm{C}$, seguido de um patamar (ou leve aumento) no valor de $\triangle$ TEP. 


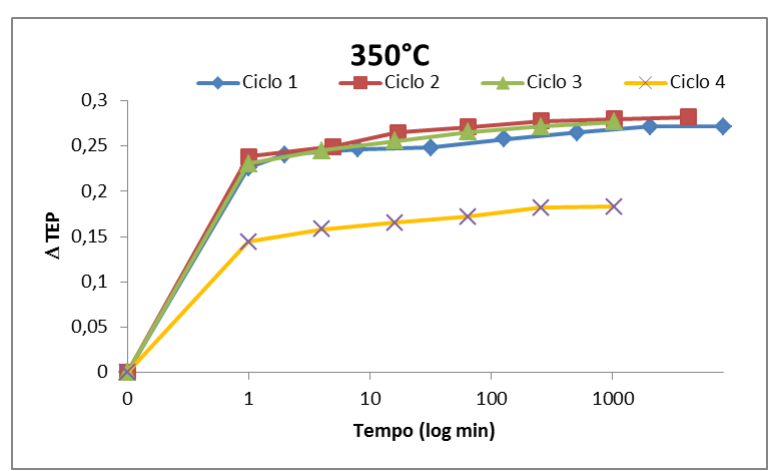

(a)

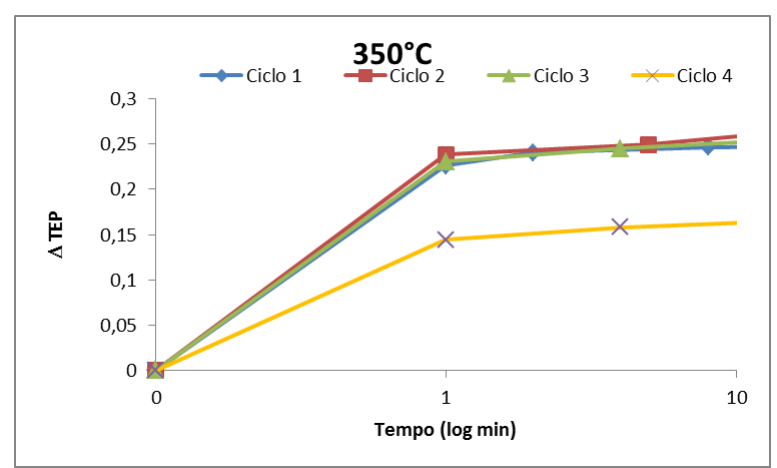

(b)

Figura 50 - Evolução do TEP em função do tempo de permanência à $350^{\circ} \mathrm{C}$. (a) curvas completas (tempo final diferente entre ciclos); (b) destaque para os tempos iniciais. Ciclo 1: T + Tisotérmico; Ciclo 2: T + TC/2h + Tisotérmico; Ciclo 3: T + TC/24h + Tisotérmico; Ciclo 4: T + AT + TC/24h + Tisotérmico. Aço AISI D2.

A figura 51 apresenta os valores de $\triangle$ TEP para a temperatura de $450^{\circ} \mathrm{C}$. Observa-se inicialmente o mesmo comportamento apresentado a $350^{\circ} \mathrm{C}$. No detalhe em (c) é possível observar que há um leve aumento no valor de $\Delta$ TEP, para todos os ciclos, durante o "aparente patamar". Em (a), observa-se que para o ciclo 2, há um ponto com tempo maior que as demais amostras. Apesar deste ponto não ser comparativo a esta temperatura, ele indica uma nova mudança de inclinação da curva.

A figura 52 apresenta os valores de $\triangle$ TEP para a temperatura de $520^{\circ} \mathrm{C}$. Observa-se uma curva em forma sigmoidal, com a inclusão de duas novas inclinações, a partir de 16 e 64 minutos, respectivamente. No inclinação iniciada em torno de 16 minutos, verifica-se que a curva do ciclo 4 apresenta maior inclinação, alcançando os valores de $\triangle$ TEP dos demais ciclos. Na última inclinação, verifica-se que as curvas de $\triangle$ TEP para os ciclos 1 e 4 ultrapassam as curvas dos ciclos 2 e 3. 


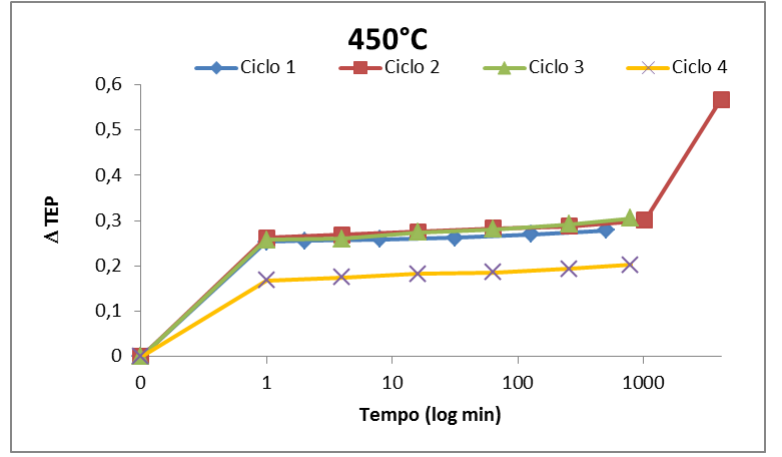

(a)

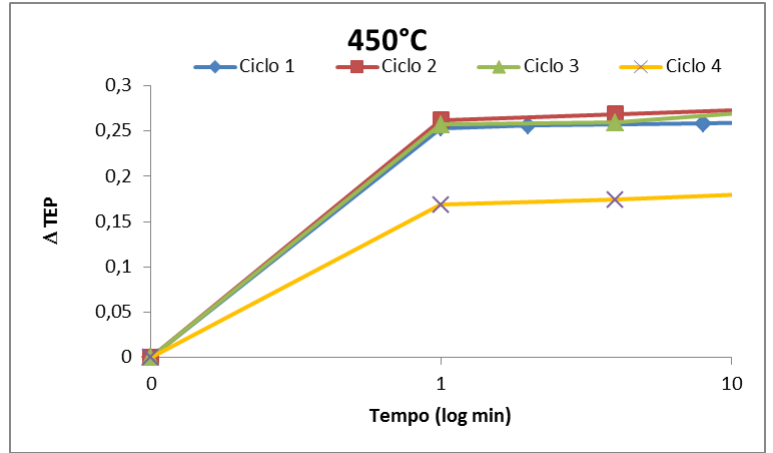

(b)

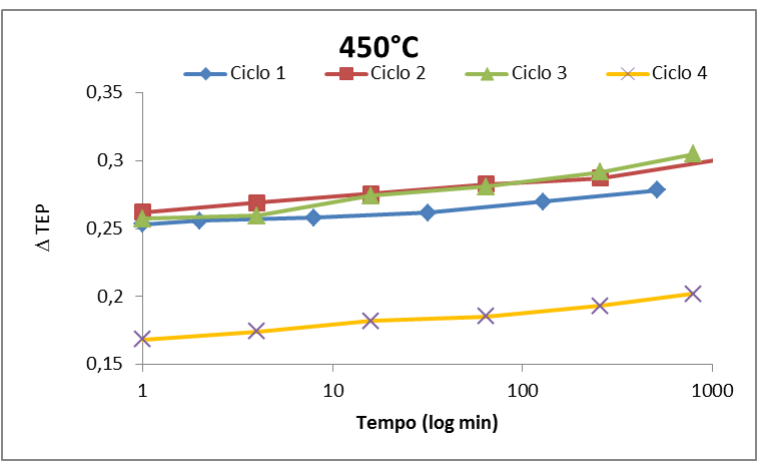

(c)

Figura 51 - Evolução do TEP em função do tempo de permanência à $450^{\circ} \mathrm{C}$. (a) curvas completas (tempo final diferente entre os ciclos); (b) curvas mostrando patamar no valor do TEP (com leve aumento com o tempo); e (c) destaque para os tempos iniciais. Ciclo 1: $\mathrm{T}+$ Tisotérmico; Ciclo 2: $\mathrm{T}+$ TC/2h + Tisotérmico; Ciclo 3: T + TC/24h + Tisotérmico; Ciclo 4: T + AT + TC/24h + Tisotérmico. Aço AISI D2.

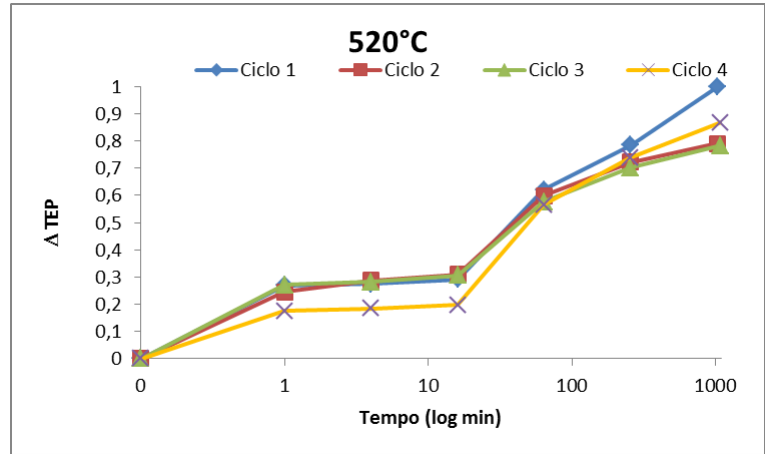

(a)

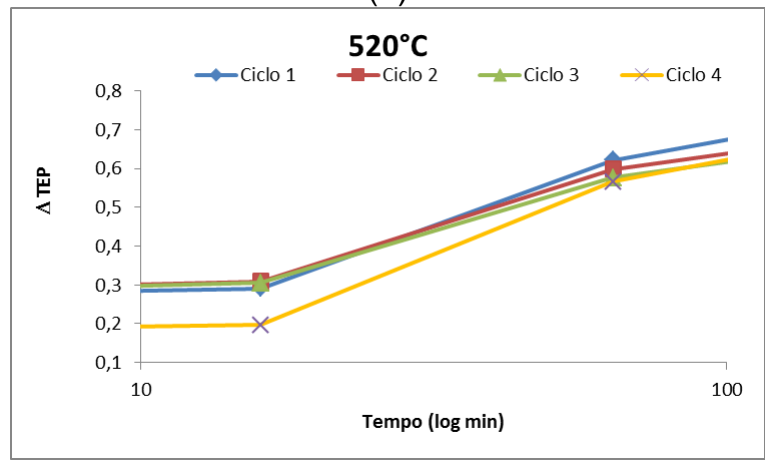

(c)

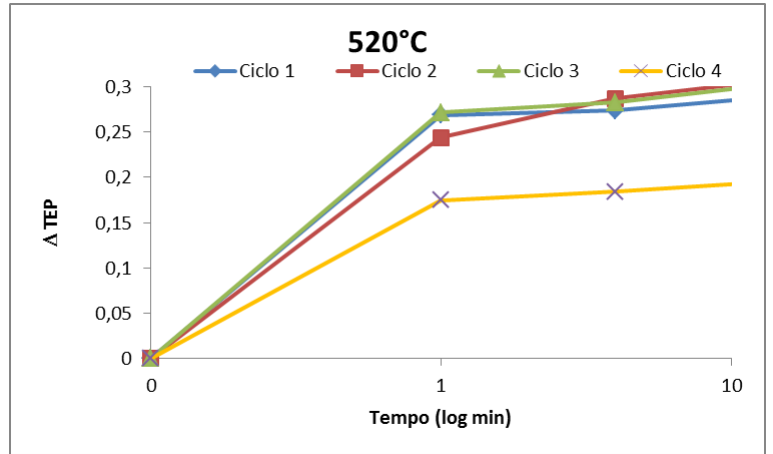

(b)

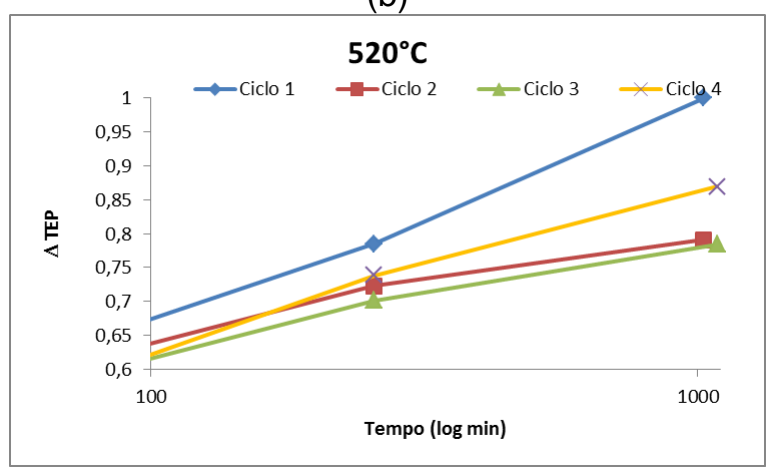

(d)

Figura 52 - Evolução do TEP em função do tempo de permanência à $520^{\circ} \mathrm{C}$. (a) curvas completas; (b) destaque para os tempos iniciais; (c) detalhe para as diferentes inclinações com o aumento do tempo de permanência à $520^{\circ} \mathrm{C}$; e (d) curvas com o tempo em escala logarítmica, mostrando a característica sigmoidal das mesmas. Ciclo 1: T + Tisotérmico; Ciclo 2: T + TC/2h + Tisotérmico; Ciclo 3: T + TC/24h + Tisotérmico; Ciclo 4: T + AT + TC/24h + Tisotérmico. Aço AISI D2. 


\section{DISCUSSÕES}

\subsection{Primeira Série de Experimentos}

Esta série de experimentos mostrou que para os carbonetos secundários micrométricos, precipitados a partir do campo austenita + carbonetos, não há diferença na sua fração volumétrica ou tamanho com a inserção da etapa de criogenia no ciclo térmico. Com este resultado refutam-se as conclusões apresentadas em uma sequência recente de trabalhos por Das et al. ${ }^{[25]}$, segundo os quais haveria um refinamento de tais carbonetos com o tratamento subzero, além de aumento de suas quantidade e uma distribuição mais uniforme na microestrutura.

Embora não tenha sido encontrado refino dos carbonetos micrométricos, o aumento aparente da população e refinamento dos nanocarbonetos precipitados no revenimento encontrado está de acordo com o trabalho de Meng et al. ${ }^{[6]}$ e Dong et al. ${ }^{[51]}$. Dong et al ${ }^{[51]}$ afirmaram que os carbonetos ultrafinos que precipitam devido ao tratamento criogênico crescem durante o revenimento subsequente, mas, aparentemente são menores e mais uniformemente distribuídos que os encontrados após o tratamento térmico convencional.

O TC foi eficiente para diminuir a $V_{V}$ de $\gamma_{R}$, no entanto, como observado na figura 34 ela não foi totalmente eliminada. A austenita retida está presente entre as placas de martensita, na forma de blocos (evidenciando que a martensita tem estrutura de placas). Na amostra sem tratamento criogênico as regiões com $\gamma_{R}$ são visíveis em MEV enquanto nas amostras com TC somente são visíveis em MEVFEG (com 100.000 vezes de aumento). A maior população de carbonetos de revenido encontrada nas amostras tratadas criogenicamente deve estar relacionada ao fato de haver menor $V v$ de austenita retida nestas amostras. A austenita é capaz de reter mais carbono em solução sólida do que a martensita, desta forma, limitando o volume de carbonetos que podem ser formados durante o revenimento.

\subsection{Segunda Série de Experimentos}

Da observação das figuras de 37 a 41 é possível fazer uma análise qualitativa da influência dos diferentes ciclos térmicos sobre a precipitação dos carbonetos 
nanométricos de revenido, conforme apresentado na tabela 9. Os sinais $(++++)$ indicam os maiores refinamento e fração volumétrica enquanto (+) indica os menores refinamento e fração volumétrica.

Tabela 9 - Análise qualitativa das figuras de 37 a 41, ranqueando as amostras quanto ao refinamento e a fração volumétrica dos carbonetos nanométricos observados. Os sinais (++++) indicam os maiores refinamento e fração volumétrica enquanto (+) indica o menores refinamento e fração volumétrica.

\begin{tabular}{|c|c|c|c|}
\hline Amostra & $\mathrm{T}+\mathrm{AT}+\mathrm{TC} / 30+\mathrm{R} \quad(\mathrm{S} 16)$ & $\mathrm{T}+\mathrm{TC} / 30+\mathrm{R}$ & (S17) \\
\hline Refinamento & ++ & \multicolumn{2}{|c|}{++++} \\
\hline $\mathrm{Vv}$ & ++ & \multicolumn{2}{|c|}{++++} \\
\hline Amostra & $\mathrm{T}+\mathrm{AT}+\mathrm{R}$ & $\mathrm{T}+\mathrm{R}$ & (S19) \\
\hline Refinamento & + & ++ & \\
\hline Vv & + & ++ & \\
\hline
\end{tabular}

A tabela 10 apresenta os resultados de fração volumétrica de carbonetos de forma comparativa. Considerando que o erro experimental é de $0,5 \%$, é possível afirmar que nas quatro amostras sem revenimento a fração volumétrica do carboneto $\mathrm{M}_{7} \mathrm{C}_{3}$ é estatisticamente a mesma. Considera-se também que após 0 revenimento (amostras de $\mathrm{S} 16$ a $\mathrm{S19}$ ) há aumento na fração volumétrica deste carboneto, porém, quando comparadas entre si, as quatro condições de tratamento térmico tem $V v$ equivalentes após o revenimento. No entanto, considerando-se o erro experimental, as amostras com a etapa de alívio de tensões ( $\$ 16$ e S18) tem a mesma $\mathrm{Vv}$ de carbonetos $\mathrm{M}_{7} \mathrm{C}_{3}$ que as amostras sem revenimento. Enquanto as amostras $\mathrm{S} 17$ e $\mathrm{S} 19$ apresentaram aumento comprovado na $\mathrm{Vv}$ deste carboneto. Estes resultados indicam que há maior precipitação do carboneto secundário (nanométrico) $\mathrm{M}_{7} \mathrm{C}_{3}$ nas amostras sem alívio de tensões.

Da mesma forma, para os carbonetos secundários de revenimento (nanométricos) do tipo $\mathrm{M}_{2} \mathrm{C}$ (note que estes carbonetos somente foram identificados após o revenimento), pode-se dizer que as quatro amostras possuem $V v$ que não são estatisticamente diferentes. No entanto os valores crescentes indicam uma tendência de aumento da Vv nas amostras sem a etapa de alívio de tensões (S17 e S19).

As comparações quantitativas da tabela 10 corroboram as comparações qualitativas da tabela 9. Estas comparações permitem afirmar que há maior $\mathrm{Vv}$ de carbonetos de revenido do tipo $M_{7} C_{3}$ e $M_{2} C$ nas amostras sem alívio de tensões 
(S17 e S19) e que na amostra com tratamento criogênico (S17) esta $V v$ é ainda maior.

Tabela 10 - Valores das frações volumétricas dos carbonetos $\mathrm{M}_{7} \mathrm{C}_{3}$ e $\mathrm{M}_{2} \mathrm{C}$.

\begin{tabular}{|c|c|c|c|c|c|c|}
\hline & & \multicolumn{4}{|c|}{$\mathrm{M}_{7} \mathrm{C}_{3}$} & $\mathrm{M}_{2} \mathrm{C}$ \\
\hline 1 & (S2I) & & & & & \\
\hline $\mathrm{T}+\mathrm{TC} / 30$ & (S8) & & 6,24 & & & \\
\hline $\mathrm{T}+\mathrm{AT}$ & (S12) & & & 5,27 & & \\
\hline $\mathrm{T}+\mathrm{AT}+\mathrm{TC} / 30$ & (S15) & & & & 6,18 & \\
\hline$T+R$ & (S19) & 7,58 & & & & 0,93 \\
\hline $\mathrm{T}+\mathrm{TC} / 30+\mathrm{R}$ & (S17) & & 7,46 & & & 1,10 \\
\hline $\mathrm{T}+\mathrm{AT}+\mathrm{R}$ & (S18) & & & 6,63 & & 0,48 \\
\hline $\mathrm{T}+\mathrm{AT}+\mathrm{TC} / 30+\mathrm{R}$ & (S16) & & & & 6,92 & 0,76 \\
\hline
\end{tabular}

$\mathrm{Na}$ tabela 11 são apresentados a relação c/a dos parâmetros de rede da martensita, o parâmetro a da austenita e as respectivas $V v$ destas duas fases. Observando-se primeiramente as amostras sem revenimento, verifica-se que, quando comparadas com a amostra somente temperada (S21), as amostras com a etapa de alívio de tensões (S12 e S15) apresentam i) diminuição na relação c/a da martensita, ii) aumento no parâmetro a da austenita e iii) aumento na fração volumétrica de austenita.

Tabela 11 - Relação c/a dos parâmetros de rede da martensita, parâmetro a da austenita e respectivas frações volumétricas.

\begin{tabular}{|c|c|c|c|c|c|}
\hline & & \multicolumn{2}{|c|}{ Martensita } & \multicolumn{2}{|c|}{ Austenita } \\
\hline & & $\mathrm{c} / \mathrm{a}$ & $\%$ & a & $\%$ \\
\hline $\mathrm{T}$ & (S21) & 1,0179 & 82,8 & 3,590 & 11,6 \\
\hline $\mathrm{T}+\mathrm{TC} / 30$ & (S8) & 1,0174 & 83,7 & 3,588 & 10,0 \\
\hline $\mathrm{T}+\mathrm{SZ} / 30$ & (S11) & 1,0172 & 86,6 & 3,586 & 7,4 \\
\hline $\mathrm{T}+\mathrm{AT}$ & (S12) & 1,0133 & 80,1 & 3,593 & 14,6 \\
\hline $\mathrm{T}+\mathrm{AT}+\mathrm{TC} / 30$ & (S15) & 1,0133 & 78,3 & 3,599 & 15,6 \\
\hline$T+R$ & (S19) & 1,0071 & 91,5 & 3,646 & $<0,03$ \\
\hline $\mathrm{T}+\mathrm{TC} / 30+\mathrm{R}$ & (S17) & 1,0072 & 91,4 & 3,622 & $<0,03$ \\
\hline$T+A T+R$ & (S18) & 1,0076 & 92,4 & 3,668 & 0,45 \\
\hline $\mathrm{T}+\mathrm{AT}+\mathrm{TC} / 30+\mathrm{R}$ & (S16) & 1,0068 & 92,3 & 3,606 & $<0,03$ \\
\hline
\end{tabular}

A literatura apresenta a etapa de alívio de tensões como uma etapa de envelhecimento da martensita, no qual, precipitariam carbonetos $\left(130^{\circ} \mathrm{C}\right.$, seria o primeiro estágio do revenimento) que agiriam como barreiras para o crescimento da martensita, assim estabilizando a austenita retida. No entanto, não houve aumento 
da $V v$ de carbonetos, identificados por difração de raios-X utilizando luz síncroton, com a inserção do tratamento térmico de alívio de tensões.

Desta forma, com base no parâmetro de rede da austenita que aumentou durante a etapa de alívio de tensões e do parâmetro c/a da a' que diminuiu, sugerese que ocorre uma partição do carbono (saindo da martensita supersaturada e indo para a austenita) enquanto não ocorre a precipitação de carbonetos. A partição de carbono da martensita para a austenita promove a estabilização da austenita. Algo semelhante é proposto para o processo de Q\&P apresentado por Speer et al. ${ }^{[43]}$.

Na tabela 11 também é possível verificar que o TSZ foi mais eficiente que o TC para a transformação da austenita retida em martensita, confirmando a hipótese de que há uma curva cinética em forma de C para a transformação martensítica, como apresentado em trabalhos anteriores ${ }^{[52,40]}$.

Há uma pequena diminuição do parâmetro c/a da martensita nas amostras com tratamentos TSZ e TC (tabela 11 - S11 e S8). Indicando o início da formação de agrupamentos de C na estrutura modulada da $\alpha$, fruto do envelhecimento. $O$ envelhecimento, conforme apresentado na introdução, produz regiões moduladas, ricas e pobres em carbono, por meio de uma decomposição espinodal, como descrito por Taylor e Cohen ${ }^{[36]}$. As regiões ricas em carbono produziriam agrupamentos de carbono que agiriam como núcleos para a precipitação de carbonetos. Esta teoria do envelhecimento, aliada aos resultados mostrando queda no valor do parâmetro c/a da martensita podem explicar o efeito de refinamento dos carbonetos secundários com a inserção do TC (figuras 37 a 41; tabela 9).

Analisando as amostras revenidas (S16 a S19) na tabela 11, pode ser afirmado que a etapa de alívio de tensões foi capaz de estabilizar a austenita de forma tão intensa que após dois revenimentos a $520^{\circ} \mathrm{C}$ ainda há a presença de alguma austenita retida na matriz. Como os carbonetos de revenido precipitam entre as ripas de martensita, há menor número de sítios para nucleação dos mesmos nas amostras com alívio de tensões. Como há um número de núcleos menores, estes carbonetos crescem mais, apresentando-se mais grosseiros (tabela 9).

Por fim, analisando o parâmetro a da austenita nas amostras com revenimento (S16 a S19), na tabela 11, verifica-se que há aumento do mesmo. Desta forma, fica evidente que durante o estágio de revenimento continua havendo partição de $\mathrm{C}$ da martensita para a austenita. Na amostra com alívio de tensões 
(S18), que apresentou $0,45 \%$ de $\mathrm{Y}$ após dois revenimentos, o parâmetro a da austenita é o maior, indicando intensa partição de C para a austenita retida.

A figura 53 apresenta a \% de C calculada em função do parâmetro de rede do reticulado cristalino da austenita retida, segundo a equação abaixo:

$$
a_{\gamma}=3,564+0,044 . \% C
$$

onde, ay corresponde ao parâmetro de rede da austenita retida, em $\AA$; 3,564 corresponde ao parâmetro de rede da austenita de equilíbrio à $1040^{\circ} \mathrm{C}$, em $\AA$; e 0,044 é a inclinação da curva do parâmetro do reticulado da $\alpha^{\prime}$ em função do teor de carbono determinada a partir de dados experimentais ${ }^{[53]}$ (Pearson apud Ridley et al.).

Esta equação foi adaptada da referência ${ }^{[53]}$ (Zwell apud Ridley et al.) na qual

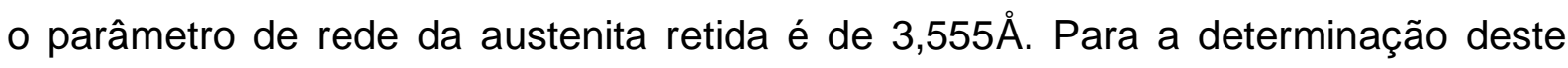
coeficiente, foram utilizados os dados apresentados por Farina ${ }^{[54]}$, calculados para o aço em estudo. No qual foi determinada, por meio do uso do programa ThermoCalc® , a composição da austenita à temperatura de $1040^{\circ} \mathrm{C}$. O teor de $\mathrm{C}$ de equilíbrio calculado para a austenita de equilíbrio a $1040^{\circ} \mathrm{C}$ foi de $0,591 \%$.

É possível que o confinamento da austenita retida e sua deformação plástica e elástica devida à transformação da martensita estejam introduzindo erros consideráveis nesta estimativa, mas apesar de reconhecer os erros implícitos ao cálculo foi possível ter uma ideia da variação de carbono na austenita com os dados obtidos. A partir da composição calculada da austenita a temperatura estimada através da equação de Andrews (linear) Mi foi de $185^{\circ} \mathrm{C}$, enquanto a temperatura Mi determinada por ensaio de dilatometria para a temperatura de austenitização de $1040^{\circ} \mathrm{C}$ foi de $160^{\circ} \mathrm{C}{ }^{[54]}$. Não foi feito um esforço para realizar um cálculo reverso para determinar a composição real da austenita, pois, provavelmente há mais uma variação na temperatura Mi nas condições de tratamento térmico deste trabalho quando comparada com a temperatura encontrada no ensaio de dilatometria.

Verifica-se na figura 53 que há um aumento pequeno, no entanto considerável (diminui a $\mathrm{Mi}$ em $22^{\circ} \mathrm{C}$, desconsiderando os demais elementos de liga) com a inserção da etapa de alívio de tensões após a têmpera. Verifica-se ainda que o teor de carbono na austenita retida continua aumentando durante a etapa de revenimento. Assim, a $\gamma_{R}$ residual na amostra $T+A T+R\left(V v=0,45 \% \gamma_{R}\right)$ contém um 
teor de $\mathrm{C}$, calculado com a equação empírica discutida acima, 4 vezes maior que o teor de $\mathrm{C}$ da amostra $\mathrm{T}\left(\mathrm{Vv}=11,6 \% \mathrm{YR}_{\mathrm{R}}\right)$.

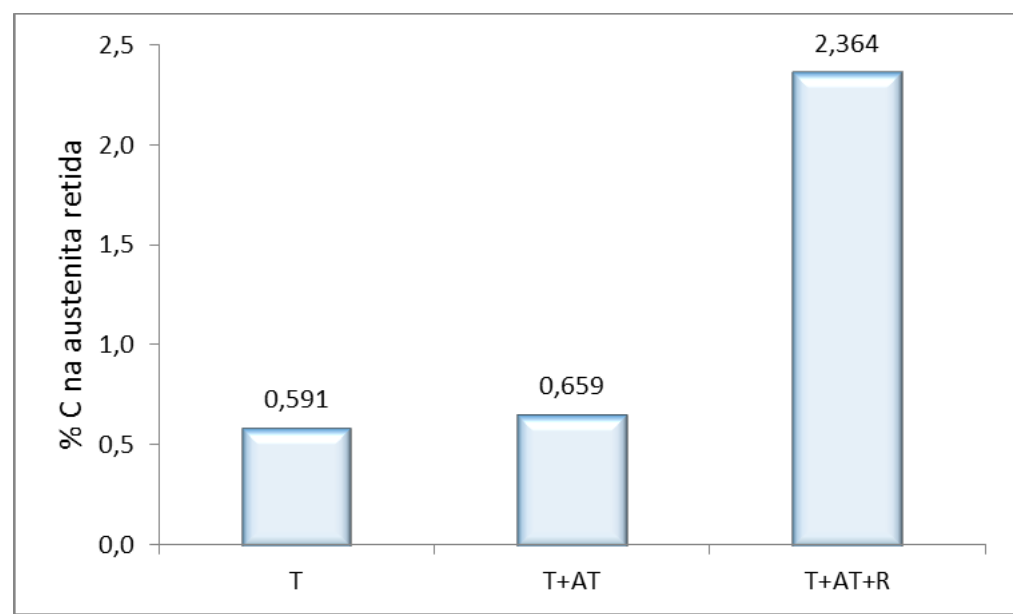

Figura 53 - Porcentagem de carbono na austenita para as amostras $T$ (S21), T+AT (S12) e T+AT+R (S18). Calculados com a equação: $a_{v}=3,564+0,044 \times$ \%C.

Desta forma, fica evidente que o fenômeno de partição de $C^{[34,43]}$ da a' para a Y continua ocorrendo durante a etapa de revenimento. No entanto, não necessariamente estabilizando a $Y_{R}$, visto que há outros fenômenos ocorrendo durante o revenimento; sendo o principal deles a precipitação de carbonetos.

\subsection{Terceira série de experimentos}

Para a discussão da terceira série de experimentos, foi realizado um esforço no sentido de colocar todas as temperaturas na mesma curva para cada ciclo. Para tanto foi utilizado o parâmetro empírico de Hollomon-Jaffe $(P)-P=T(k+\log t)$; onde T é a temperatura em Kelvin; $k$ é a constante de Hollomon-Jaffe que depende do material; e t é o tempo em minutos à temperatura isotérmica. O parâmetro de Hollomon-Jaffe é uma relação clássica entre tempo e temperatura em reações de revenido ${ }^{[55]}$.

De acordo com a revisão sobre parâmetros de revenimento apresentada por Canale et al. ${ }^{[56]}$, o valor de $\mathrm{k}$ para aços ferramenta com \%C entre 0,9 e 1,2 é 15, sendo 20 o valor mais comumente utilizado. E, este valor diminui linearmente com a quantidade de carbono. Além disso, para uma correlação entre tempo e temperatura o valor de k não é considerado como crítico ${ }^{[56]}$. 
Desta forma, a figura 54 apresenta as curvas de $\Delta$ TEP em função do parâmetro de Hollomon-Jaffe, utilizando o valor 20 para k. (Utilizando k=15, modifica os valores de $\mathrm{P}$, no entanto, não modifica a forma e as mudanças de inclinação das curvas. Este número é utilizado para definir/prever os valores de dureza obtidos durante o revenimento). A queda abrupta na curva em torno de $\mathrm{P}=9.500$ pode ser devido ao não ajuste com o parâmetro $P$ utilizado ou devido a uma modificação no fenômeno que está ocorrendo. Neste trabalho será considerada a segunda opção, mudança de mecanismo (que pode estar associada ao ajuste imperfeito da curva).

Na figura 54(a) observa-se o comportamento geral para os 5 ciclos térmicos, apresentando curvas sigmoidais (curva típica de transformações de fases em função do tempo e da temperatura). É possível separar cada curva em cinco estágios, de acordo com a inclinação das curvas, sendo eles:

- Estágio 1: P variando de 7.500 até 9.500;

- Estágio 2: P variando de 9.500 até 11.500 ;

- Estágio 3: P variando de 11.500 até 16.500;

- Estágio 4: $\mathrm{P}$ variando de 16.500 até $\sim 17.200$;

- Estágio 5: P acima de 17.200.

No estágio 1, figura 54(b), fica evidente a diferença entre os ciclos com TC e sem AT (ciclos 2 e 3 ) e os demais. Aparentemente todos os ciclos possuem curvas com a mesma forma, indicando que os mesmos fenômenos devem estar ocorrendo, no entanto, com cinética diferente. O ciclo com AT (ciclo 4) apresenta a menor inclinação, sendo provavelmente o AT responsável por inibir o mecanismo predominante. $\mathrm{O}$ ciclo 1 nitidamente tem sua cinética neste tempo inicial atrasada em relação aos ciclos 2 e 3.

Nos estágios 2 e 3, figura 54(b) e (c), a curva do ciclo 1 encontra-se com as curvas dos ciclos 2 e 3 , indicando que neste segundo estágio a cinética é a mesma para os três ciclos. A curva do ciclo 4 continua com valores de $\Delta$ TEP inferiores.

No estágio 4, figura 54(d), a curva do ciclo 4 apresenta maior inclinação alcançando os valores de $\triangle$ TEP dos demais ciclos.

E, por fim, no estágio 5 - figura 54(d), as curvas dos ciclos 1 e 4 ultrapassam as curvas dos ciclos 2 e 3, indicando que neste estágio a cinética é favorável aos ciclos 1 e 4. 


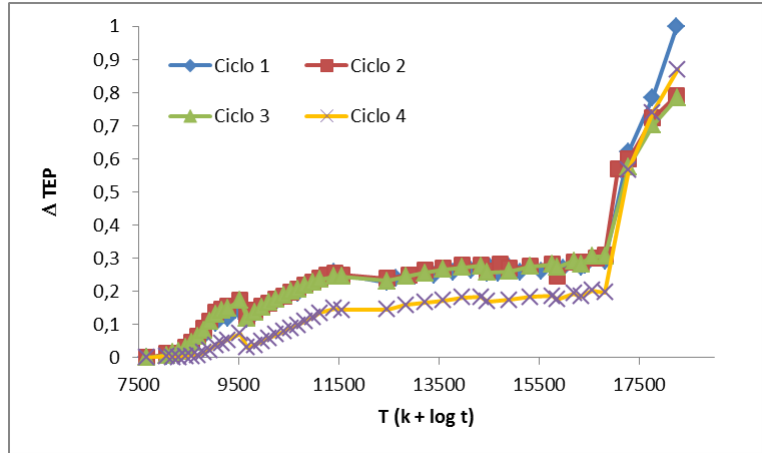

(a)

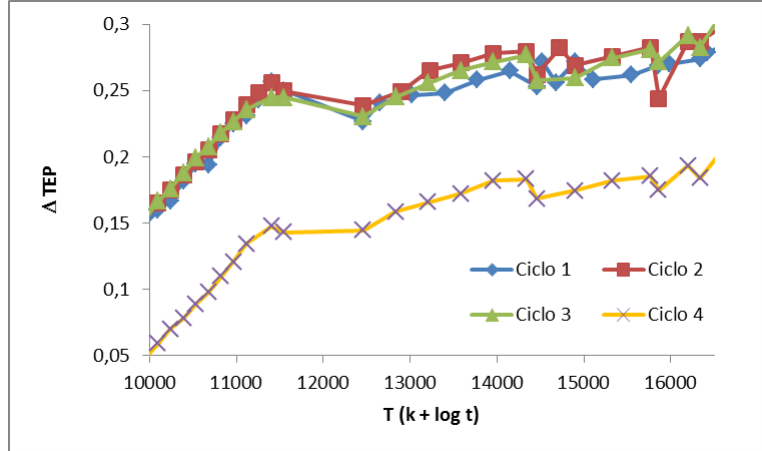

(c)

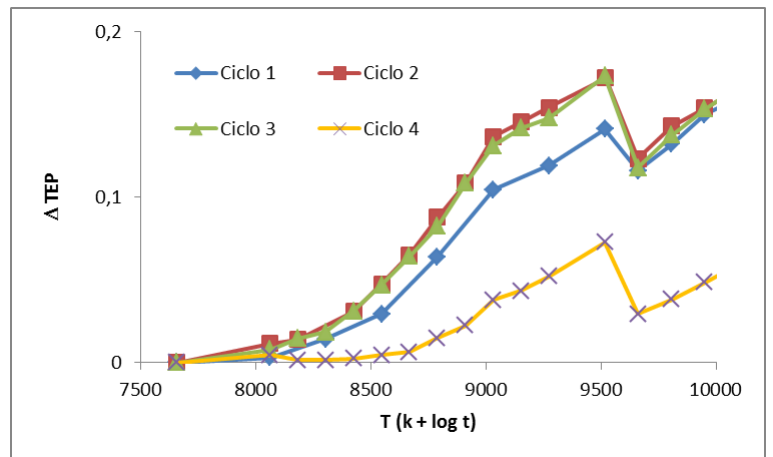

(b)

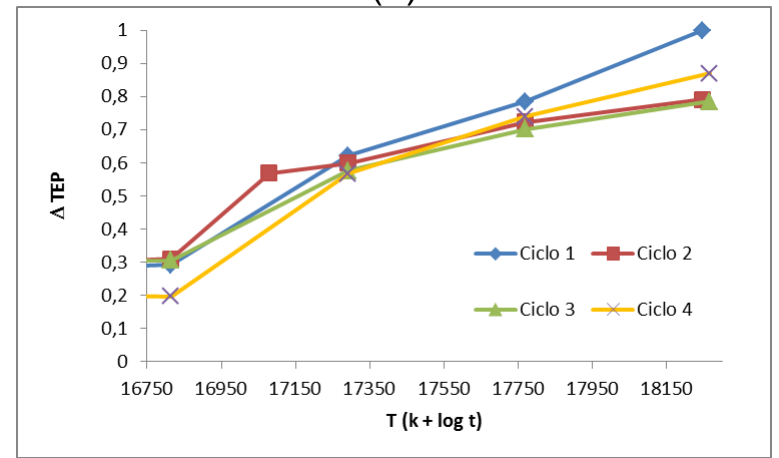

(d)

Figura 54 - Evolução do $\Delta$ TEP em função do parâmetro de Hollomon-Jaffe. (a) curvas completas; (b) destaque para os tempos iniciais; (c) destaque para os tempos intermediários; e (d) destaque para os tempos finais. Ciclo 1: $T$ + Tisotérmico; Ciclo 2: T + TC/2h + Tisotérmico; Ciclo 3: T + TC/24h + Tisotérmico; Ciclo 4: T + AT + TC/24h + Tisotérmico. Aço AISI D2.

\subsubsection{Proposição de mecanismos}

A figura 55 apresenta de forma esquemática a estrutura inicial do material. Em (a) é apresentado um grão com placas de $\alpha$ ', entre as placas existem blocos de $Y_{R}$. A $\alpha^{\prime}$ de alto carbono é altamente defeituosa, contendo maclas, interfaces $\alpha^{\prime} / \alpha^{\prime}$, $\alpha^{\prime} / \gamma_{R}$, entre outros, conforme representado. Devido ao envelhecimento da martensita, forma-se uma estrutura modulada com a' enriquecida em C e empobrecida em C. Se o envelhecimento for realizado em temperaturas criogênicas, a estrutura modulada será mais refinada ${ }^{[6]}$.

A figura 56 apresenta de forma esquemática a proposição de mecanismos para os cinco estágios de evolução do $\triangle$ TEP apresentados no item anterior. Estes mecanismos estão totalmente baseados na sequência de precipitação de carbonetos. No estágio 3 da evolução do $\triangle \mathrm{TEP}$, o qual ocorre predominantemente para a temperatura de $350^{\circ} \mathrm{C}$, ocorre também a transformação $\gamma_{R} \rightarrow \alpha^{\prime}$. 


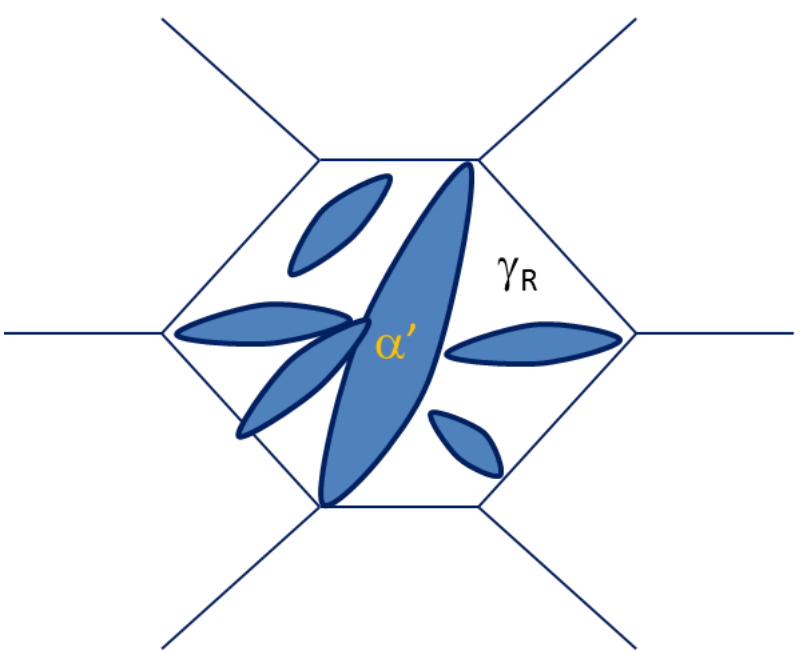

(a)

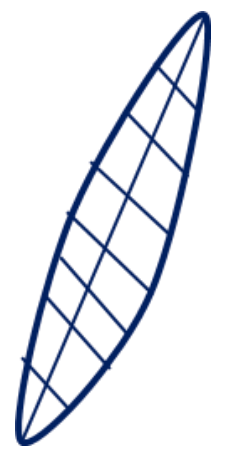

(b)

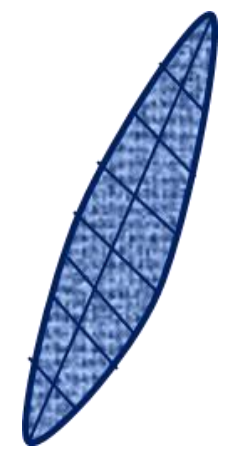

(c)

Figura 55 - Representação esquemática da estrutura do material na condição inicial. (a) grão com placas de martensita e blocos de austenita retida; interfaces $\alpha^{\prime} / \gamma_{R}$ e $\alpha^{\prime} / \alpha^{\prime}$. (b) maclas internas na placa de martensita. (c) estrutura modulada da martensita devido ao envelhecimento; interfaces $\alpha^{\text {' }}$ enriquecida em C/a' empobrecida em C.

$\mathrm{Na}$ condição inicial representada na figura 56, é apresentada uma $\alpha^{\prime}$ enriquecida em carbono, contendo defeitos internos no reticulado cristalino. No estágio 1 , temperaturas de 130 e $210^{\circ} \mathrm{C}$, ocorre o agrupamento de $\mathrm{C}$ seguido da precipitação de carboneto de $\mathrm{Fe}$ ( $\eta$ ou $\varepsilon$ ). No estágio 2 ocorre o crescimento do carboneto de ferro. Note que para estes dois estágios iniciais o ciclo 4 apresenta valores de $\triangle$ TEP inferiores, apesar de as curvas apresentarem as mesmas inclinações que os demais ciclos.

No estágio 3, provavelmente ocorre uma etapa intermediária entre os estágios 2 e 4 em relação aos carbonetos, com precipitação de cementita e ocorra também a decomposição da austenita retida (não total).

No estágio 4 , temperaturas de 450 e $520^{\circ} \mathrm{C}$, ocorre a precipitação de carbonetos de liga, carbonetos secundários de revenido. No estágio 5 é representado um crescimento deste carboneto de liga. 
Condição Inicial

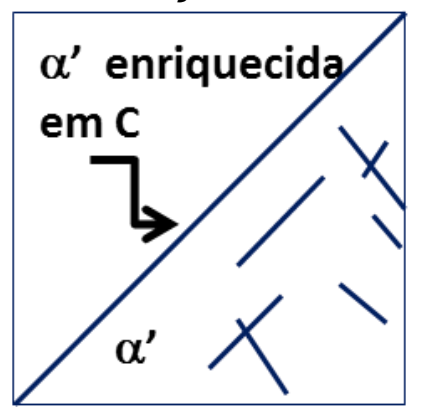

Estrutura martensítica modulada com regiões enriquecidas (linhas) e empobrecidas em C. Possível agrupamento de $\mathrm{C}$.

\section{Estágio 3}

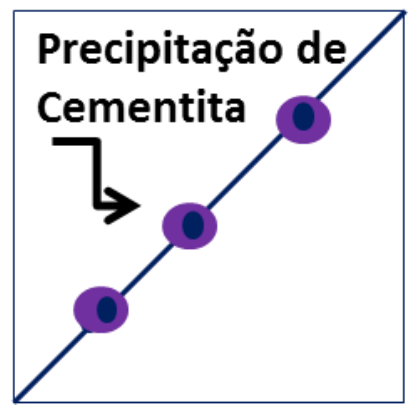

Precipitação de $\theta$ in situ no carboneto $\eta$.
Estágio 1

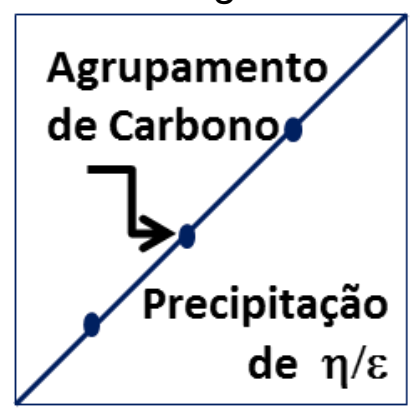

Agrupamento de $\mathrm{C}$ e precipitação do carboneto $\eta$ (ou

$\varepsilon)$ nos defeitos do reticulado (contornos de macla, discordâncias, interfaces e outros), preferencialmente na $\alpha$ ' enriquecida em $\mathrm{C}$.

Estágio 4

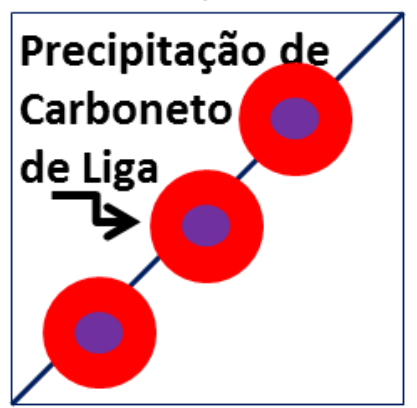

Precipitação de carbonetos de liga in situ na $\theta$.
Estágio 2

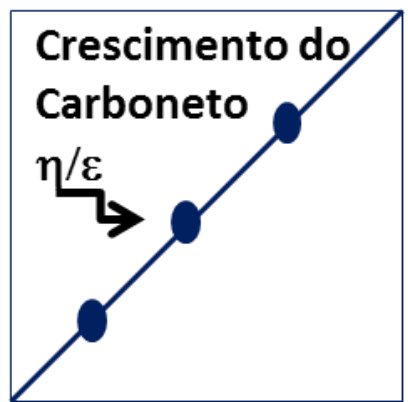

Crescimento do carboneto $\eta$.

\section{Estágio 5}

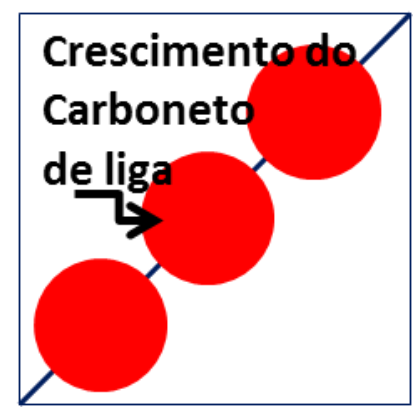

Crescimento do carboneto de liga (carboneto secundário de revenido).

Figura 52 - Representação esquemática dos mecanismos propostos para a evolução do $\Delta$ TEP em função do tempo e da temperatura.

Neste modelo proposto, assume-se que a sequência de precipitação de carbonetos ocorre sempre in situ nos carbonetos pré-existentes, o que justificaria um possível efeito do TC de refinar os carbonetos. Há evidências na literatura ${ }^{[48]}$ de que em ligas contendo cromo (em um aço baixa liga) a cementita precipita a partir de um carboneto $\mathrm{M}_{2} \mathrm{C}$ formado no primeiro estágio do revenido (poderia ser considerado o $\left.\eta-\mathrm{Fe}_{2} \mathrm{C}\right)$. 


\subsection{Discussão Geral}

Da primeira série de experimentos é verificado que, como previsto metalurgicamente, não há mudança na precipitação de carbonetos secundários micrométricos com a inserção da etapa de tratamento criogênico no ciclo térmico do aço AISI D2. No entanto, há uma forte indicação de que haja maior fração volumétrica de carbonetos secundários de revenido (nanométricos) com a inserção desta etapa. Esta indicação é confirmada na segunda série de experimentos e a mudança na cinética de precipitação destes carbonetos é confirmada na terceira série de experimentos.

Conforme verificado na segunda série de experimentos há maior fração volumétrica de carbonetos de revenido $\left(\mathrm{M}_{7} \mathrm{C}_{3}\right.$ e $\left.\mathrm{M}_{2} \mathrm{C}\right)$ nas amostras com tratamento criogênico logo após a têmpera. Bem como estes carbonetos apresentam-se mais refinados que nas demais amostras. Com base nos resultados da terceira série de experimentos, pode ser afirmado que estes resultados estão diretamente relacionados com os estágios 1 e 2 da evolução do $\Delta$ TEP em função da temperatura e do tempo de permanência a esta temperatura. Ou seja, o maior valor de $\triangle$ TEP indica maior perda de átomos intersticiais da $\alpha^{\text {, }}{ }^{[50]}$ para os defeitos do reticulado e, consequentemente, maior número de locais para a precipitação de carboneto $\eta$ (ou $\varepsilon$ ). Não foi verificada diferença de comportamento, na terceira série de experimentos, para os TC por 2 ou 24 horas. A forma encontrada para explicar o refino dos carbonetos de revenido nas amostras com TC baseou-se na hipótese de que a sequência de precipitação de carbonetos ocorre in situ ( $n \rightarrow \theta \rightarrow M_{7} C_{3}$ ou $\left.M_{2} C\right)$, cada sucessiva reação de precipitação herdando os sítios da anterior.

Com base nos dados da literatura ${ }^{[6,36]}$ pode-se fazer a hipótese de que em temperaturas criogênicas está ocorrendo um envelhecimento da a' virgem. Este envelhecimento produz uma estrutura modulada (devido à decomposição espinodal) com regiões enriquecidas em carbono. Da mesma forma, ocorre envelhecimento da $\alpha$ ' nas amostras sem TC. No entanto, este envelhecimento é mais pronunciado nas amostras com TC produzindo uma estrutura modulada mais fina, que por sua vez influenciará na precipitação, produzindo um refino dos carbonetos na 1 etapa do revenimento.

Comparando-se as amostras com e sem TC, pode ser dito que: devido ao maior número de sítios para nucleação de carbonetos no estágio 1, estes 
carbonetos crescerão menos,. o que é confirmado pelo maior valor de $\Delta$ TEP nas amostras sem TC para temperaturas e tempos maiores. Isto explica o maior refinamento dos carbonetos nas amostras com TC. A maior Vv é explicada pelo maior número de partículas precipitadas, facilitando assim a difusão de elementos substitucionais para as mesmas, além de ter menos $\gamma_{R}$ nas amostras submetidas a TC.

Nas amostras com a etapa de AT, foi constatada a estabilização da $\bigvee_{R}$. Esta estabilização ocorreu devido à partição de átomos de carbono saindo da $\alpha^{\prime}$ supersaturada em $C$ para a $\gamma_{R}{ }^{[34,43]}$. A diminuição do parâmetro c/a da $\alpha^{\prime}$ e o aumento do parâmetro a da $\bigvee_{R}$, durante o tratamento térmico de $A T$, dão suporte a esta hipótese. Foi verificado também, na segunda série de experimentos, que a partição de $\mathrm{C}$ é contínua durante o tratamento térmico de revenimento. Isto, devido ao fato da $Y_{R}$ residual apresentar maior parâmetro a após dois revenimentos a $520^{\circ} \mathrm{C} / 2 \mathrm{~h}$ cada. Mesmo após o AT, a martensita virgem foi mais envelhecida com o TC do que com a permanência à temperatura ambiente. $O$ que explica a maior fração volumétrica de carbonetos de revenido na amostra com AT+TC quando comparada com a amostra com AT sem TC, na segunda série de experimentos, mesmo sem o TC ter eliminado a austenita retida nas amostras submetidas a AT. Na terceira série de experimentos não há amostra com AT sem TC.

$\mathrm{Na}$ terceira série de experimentos, a amostra com AT+TC partiu de uma condição inicial bem diferente das demais: com maior fração volumétrica de $Y_{R} e$ com a mesma estabilizada. Isto desencadeou uma evolução mais lenta nos estágios 1, 2 e 3 nas curvas de $\triangle$ TEP. Havendo, portanto, menor segregação de átomos de carbono para os defeitos do reticulado da $\alpha$ '. O envelhecimento da a' no TC ocorreu em uma $\alpha$ ' já empobrecida em carbono (menor parâmetro c/a, segunda série de experimentos). Indicando, assim, haver menor número de locais para a nucleação devido à menor fração volumétrica de a' e menor teor de carbono em solução sólida na mesma.

No estágio 4 a amostra com AT+TC acelera o aumento do $\Delta$ TEP, aproximando-se dos valores de $\Delta$ TEP das demais amostras. $E$ no estágio 5 , verifica-se que as amostras sem TC (com e sem AT) passam a apresentar valores de $\triangle$ TEP superiores aos das amostras com TC. Embasando assim a teoria de que no estágio 5 está sendo detectado o crescimento dos carbonetos, pois, na segunda série de experimentos estas amostras apresentam carbonetos mais grosseiros. 
Note que para um revenimento duplo a $520^{\circ} \mathrm{C} / 2 \mathrm{~h}$ cada, o valor do parâmetro de Hollomon-Jaffe é de 17.750. Para este valor, o $\triangle$ TEP da amostra sem AT e sem TC é o mais alto. Assim, os carbonetos da amostra sem AT e sem TC deveriam ser mais grosseiros do que os da amostra com AT+TC. No entanto, o TEP foi realizado de forma cumulativa (tratamento isotérmico + resfriamento em água + medição do valor de TEP + tratamento isotérmico + etc...). Ou seja, provavelmente houve uma desestabilização da $Y_{R}$ com os sucessivos aquecimentos e resfriamentos. Diferentemente do apresentado por Perez et al. ${ }^{[50]}$, não houve estabilização do valor de $\triangle$ TEP, indicando que os carbonetos continuaram crescendo. Para haver estabilização do valor de $\Delta$ TEP deveria ter sido feito um tratamento isotérmico com temperatura superior às utilizadas ou tempos muito longo, ou seja, não foi atingida a saturação, que corresponderia a um super-revenimento

Quanto à temperatura de tratamento criogênico, há uma forte indicação de que haja uma curva com cinética em $C$ para a transformação martensítica. Isto devido ao fato de haver menor fração volumétrica de $\gamma_{R}$ para as amostras tratadas a $-80^{\circ} \mathrm{C}$ quando comparadas às amostras tratadas a $-196^{\circ} \mathrm{C}$. No entanto, não há indicação de diminuição da fração volumétrica de $\bigvee_{R}$ com o aumento do tempo de permanência à estas temperaturas. Isto reforça o que diversos autores afirmaram: de que há outros fenômenos ocorrendo no TC que não somente a transformação $Y_{R} \rightarrow \alpha^{,[6,10,11,12]}$. Sendo que neste trabalho, foi atribuído ao TC a formação de uma estrutura modulada devido ao envelhecimento da $\alpha$ ' virgem, como apresentado por Meng et al. ${ }^{[6]}$.

Desta forma, a soma das três séries de experimentos mostrou-se bastante eficaz para a determinação dos fenômenos e mecanismos envolvidos nas etapas de alívio de tensões, tratamento criogênico e revenimento. Clareando e desmistificando o tratamento criogênico dos aços ferramenta AISI D2. 


\section{CONCLUSÕES}

As conclusões, para o aço ferramenta para trabalho a frio AISI D2 estudado, podem ser divididas em 3 grupos: i) transformação martensítica; ii) estabilização da austenita; e iii) precipitação de carbonetos secundários de revenido.

i) Transformação martensítica

1. Há maior transformação da austenita retida em martensita no tratamento térmico subzero $\left(-80^{\circ} \mathrm{C}\right)$ quando comparado ao tratamento térmico criogênico $\left(-196^{\circ} \mathrm{C}\right)$.

2. Para tempos crescentes de permanência às temperaturas subzero e criogênica (3, 10 e 30 horas) a fração volumétrica de austenita retida manteve-se constante.

ii) Estabilização da austenita

3. O tratamento térmico de alívio de tensões estabiliza a austenita retida devido à partição de carbono da martensita supersaturada para a austenita. Há uma redução do parâmetro c/a do reticulado da martensita e aumento no parâmetro a do reticulado da austenita.

4. A estabilização da austenita retida devida ao tratamento térmico de alívio de tensões impede que a mesma se transforme em martensita em temperaturas criogênicas.

5. Com a inserção do tratamento térmico de alívio de tensões há menor fração volumétrica de martensita para participar do processo de envelhecimento.

6. A partição de carbono da martensita supersaturada para a austenita continua durante todo 0 processo de revenimento. A austenita retida presente após o tratamento térmico de duplo revenimento apresenta um parâmetro a do reticulado maior, mostrando que foi enriquecida em carbono.

iii) Precipitação de carbonetos de revenido

7. Não há precipitação de carbonetos secundários micrométricos devido à inserção da etapa de tratamento criogênico no ciclo térmico.

8. Há maior fração volumétrica de carbonetos de revenido $\left(M_{7} C_{3}\right.$ e $\left.M_{2} C\right)$ e os mesmos encontram-se mais homogeneamente distribuídos quando há a inserção do tratamento criogênico entre a têmpera e o revenimento.

9. A fração volumétrica de carbonetos de revenido $\left(\mathrm{M}_{7} \mathrm{C}_{3}\right.$ e $\left.\mathrm{M}_{2} \mathrm{C}\right)$ é maior quando não há a inserção da etapa de alívio de tensões entre a têmpera e o tratamento criogênico. 
10. O refinamento e maior fração volumétrica dos carbonetos de revenido devido à inserção do tratamento criogênico (logo após a tempera) é atribuído ao envelhecimento da martensita que ocorre em temperaturas criogênicas, produzindo uma estrutura modulada com regiões enriquecidas e empobrecidas em carbono. A precipitação de carbonetos é facilitada no primeiro estágio do revenimento, aumentando assim o número de carbonetos.

11. Devido ao maior número de carbonetos precipitados no primeiro estágio do revenimento os mesmos crescerão menos.

12. O refinamento e a maior fração volumétrica de carbonetos de revenido com a inserção da etapa de tratamento criogênico podem ser explicados pela facilitação na precipitação de carbonetos no primeiro estágio do revenimento seguida de uma precipitação in situ de carbonetos de revenido: $n \rightarrow \theta \rightarrow M_{7} C_{3}$ ou $M_{2} C$. 


\section{TRABALHOS FUTUROS}

1. Caracterização por metalografia eletrônica de transmissão das amostras para: i) verificar a estrutura martensítica com e sem tratamento criogênico; ii) identificar os carbonetos precipitados com especial atenção aos carbonetos precipitados no primeiro estágio do revenimento.

2. Comparação das propriedades mecânicas e tribológicas de amostras: i) com e sem o tratamento criogênico; ii) com tratamento criogênico e subzero; iii) com e sem a etapa de alívio de tensões.

3. Estudo do envelhecimento da martensita virgem e da partição de carbono em uma liga com a composição da matriz do aço AISI D2 (sem a presença de carbonetos eutéticos e secundários micrométricos).

4. Estudo dilatométrico e calorimétrico (DSC) das reações que ocorrem durante tratamentos criogênicos e de revenimento. 
APÊNDICE A - TRABALHOS PUBLICADOS 


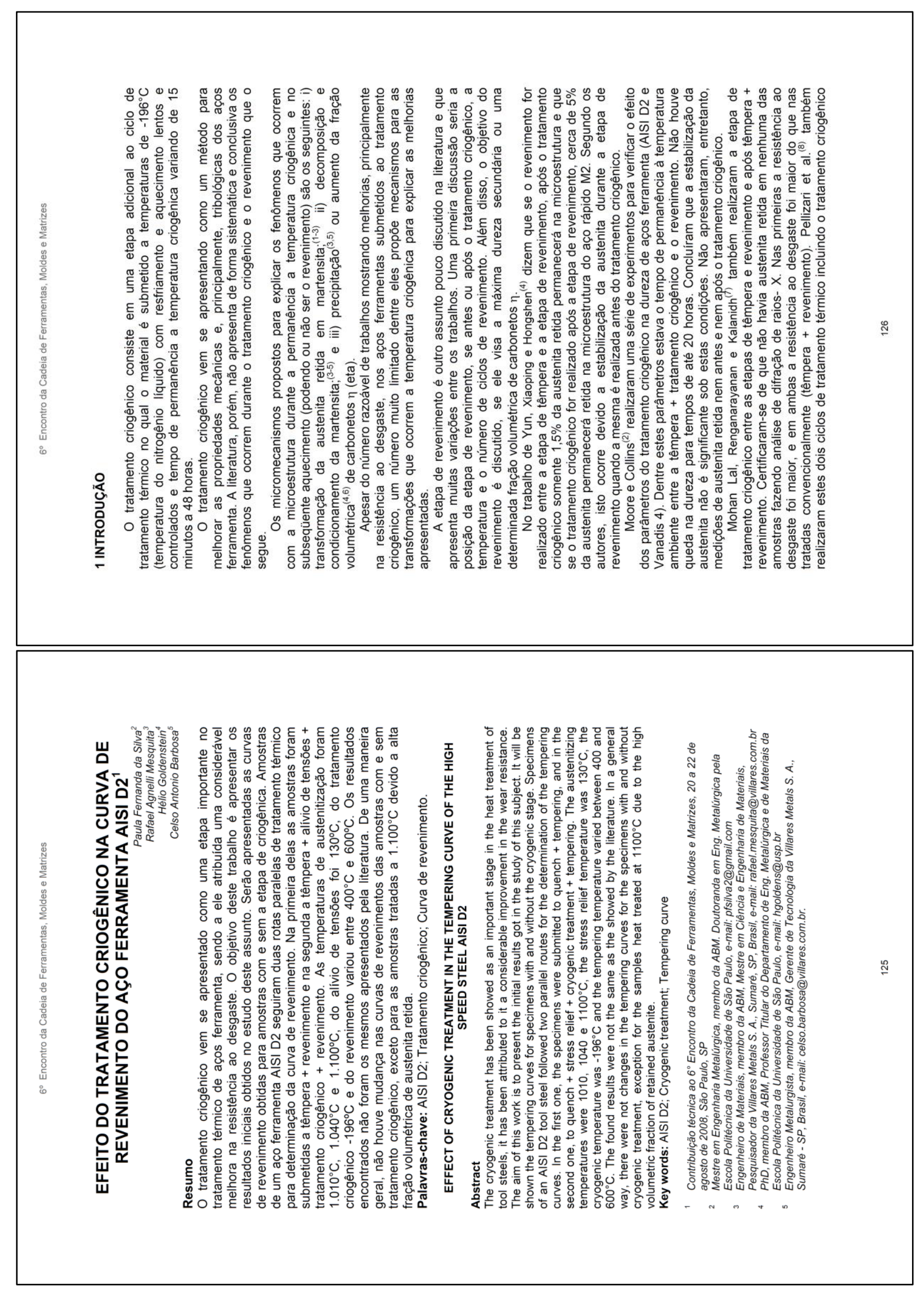




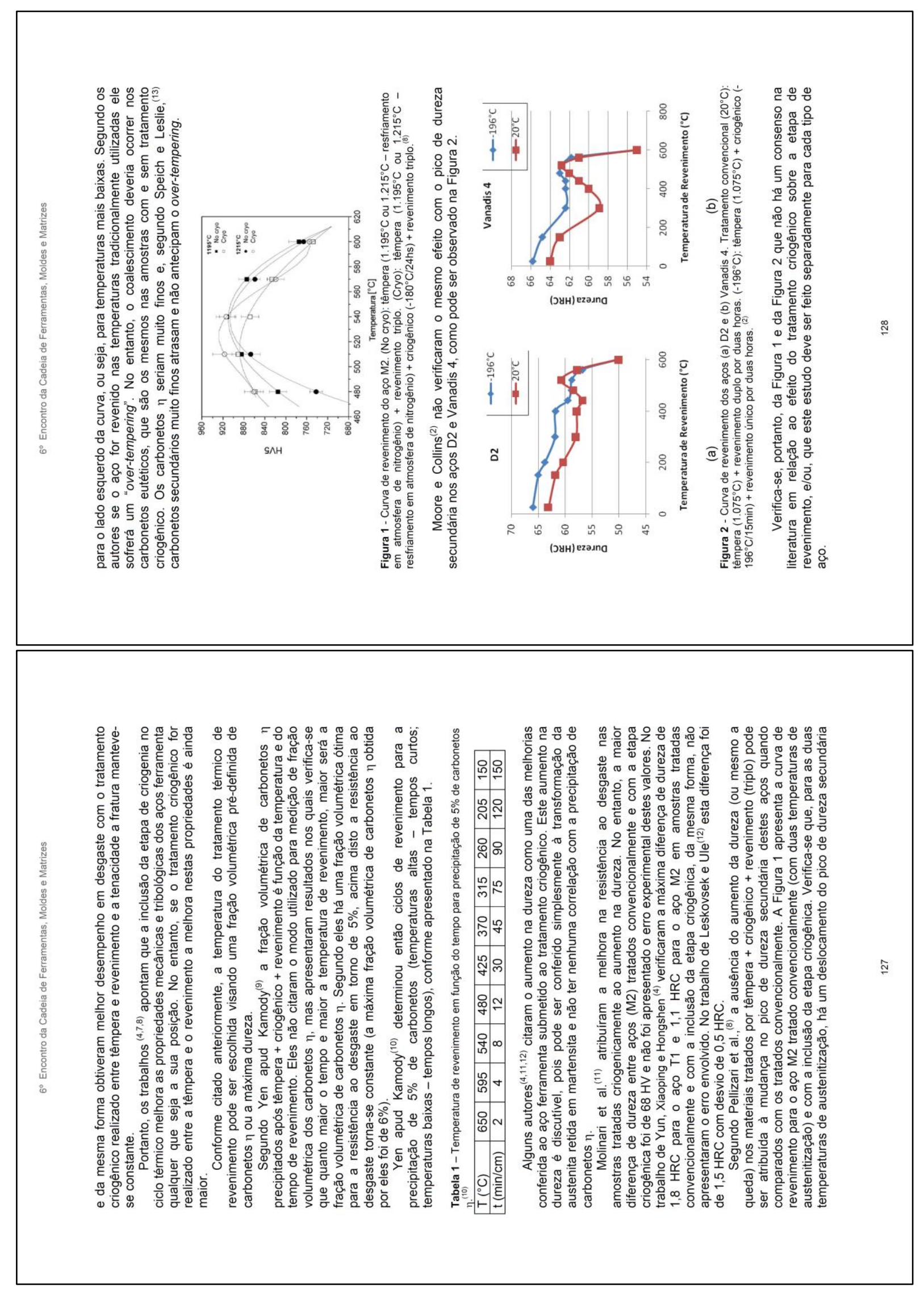




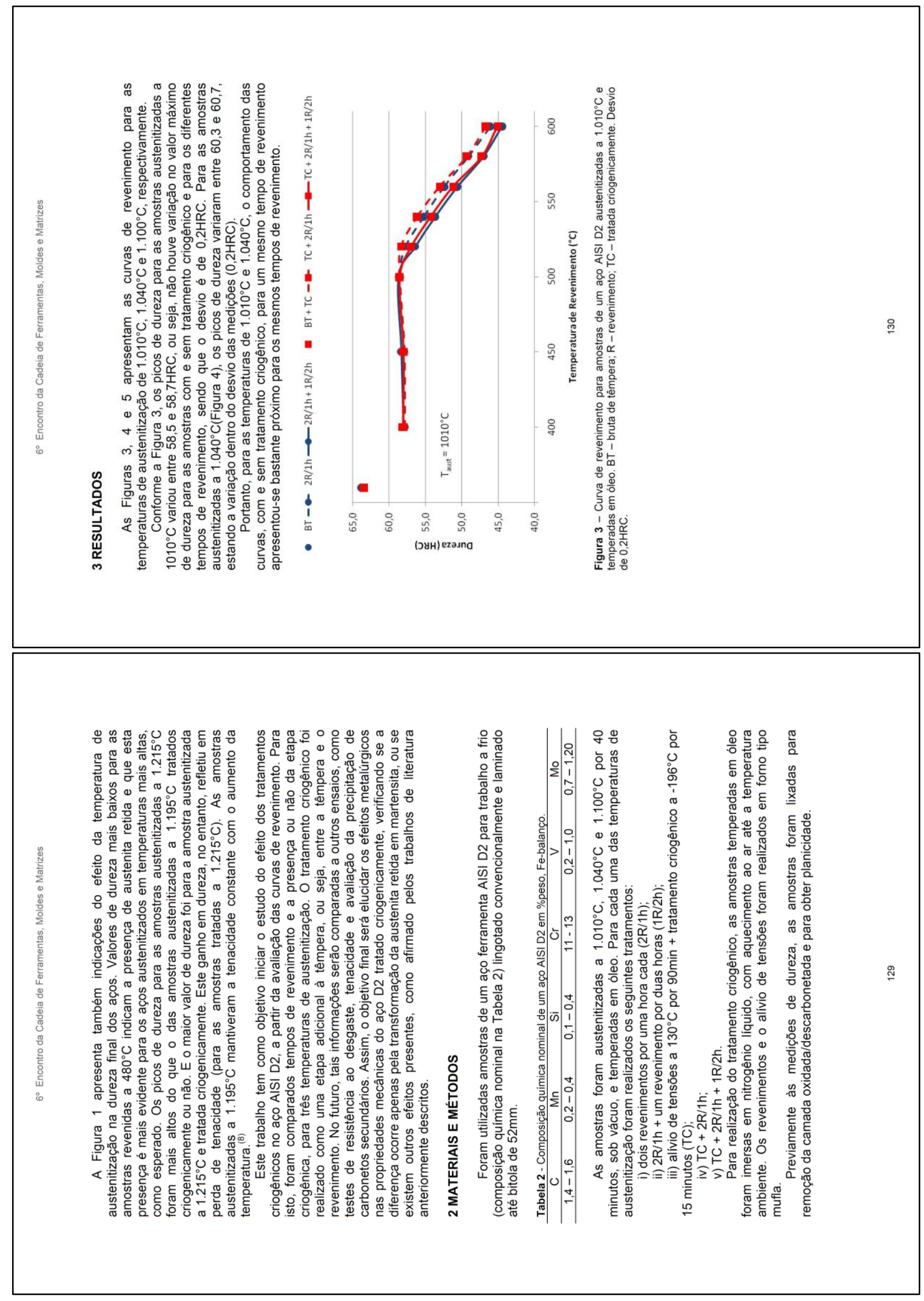




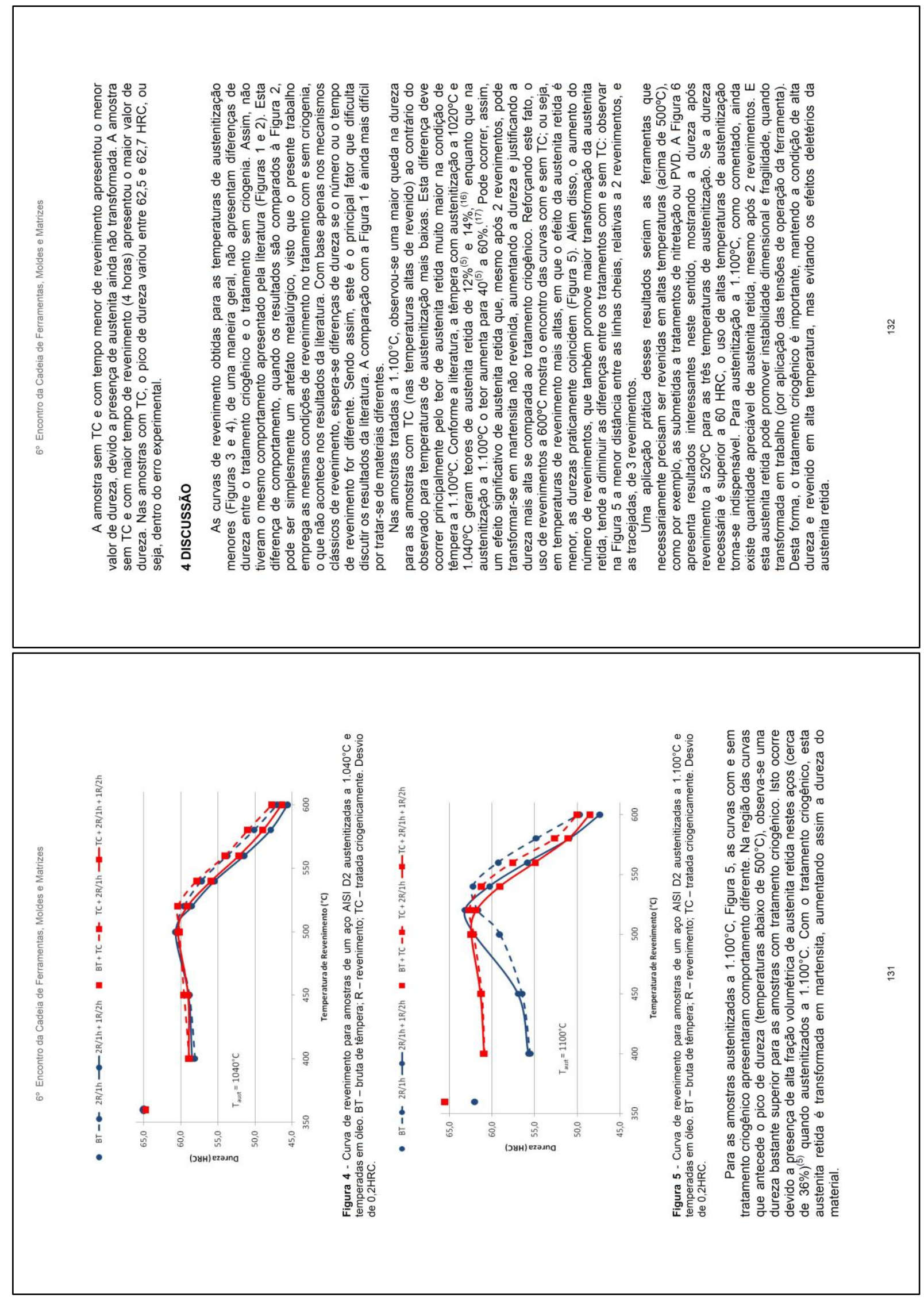




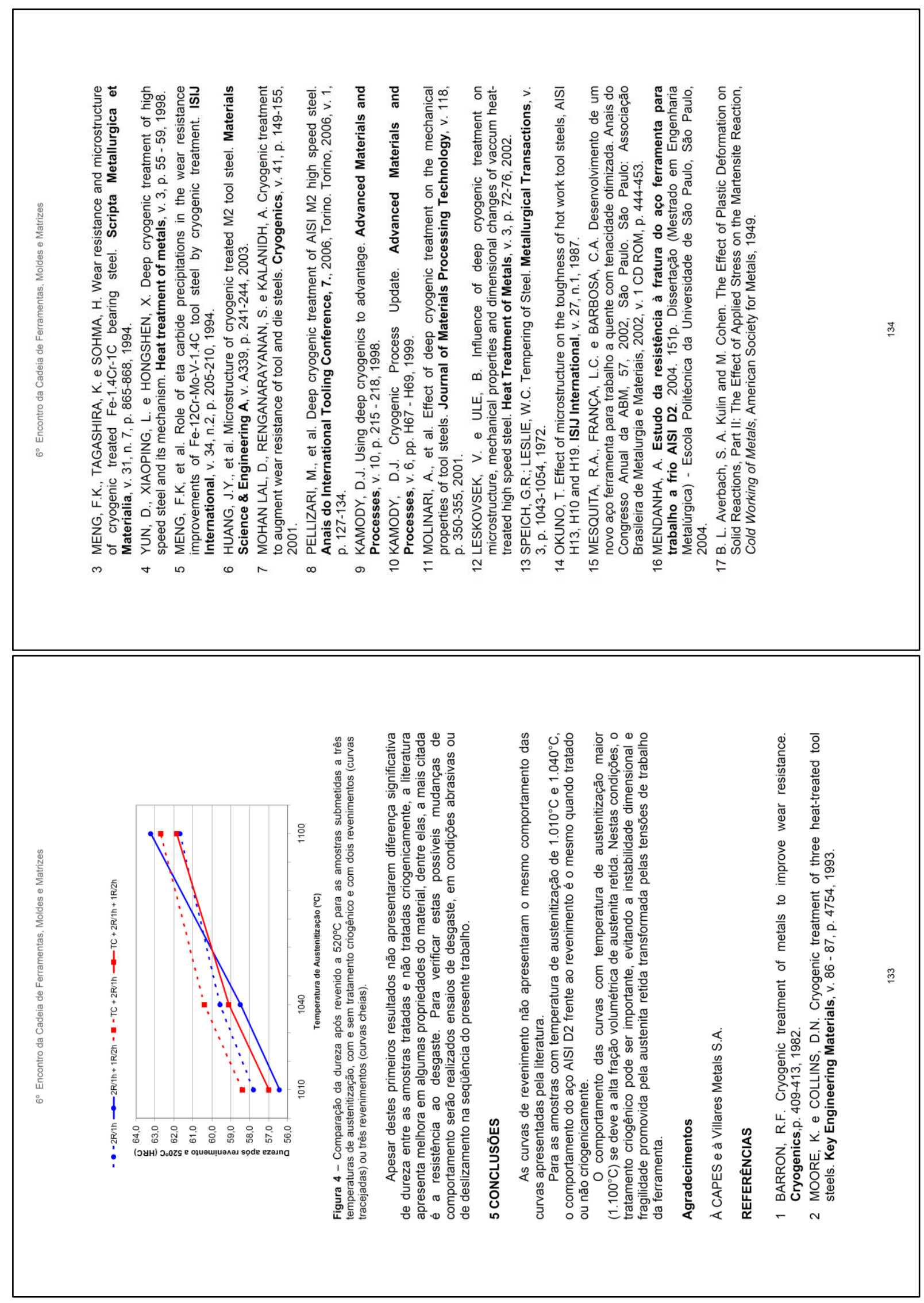




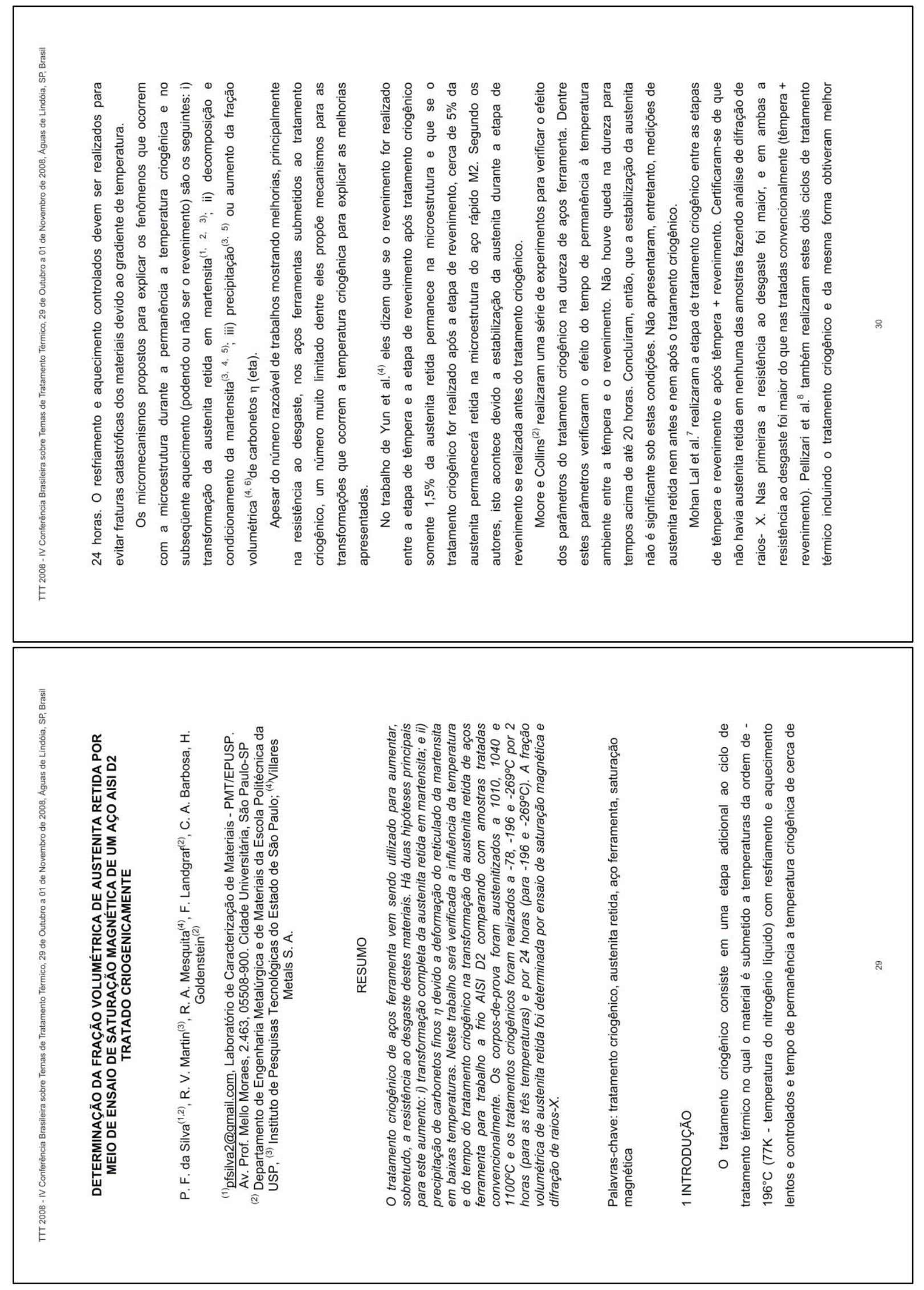




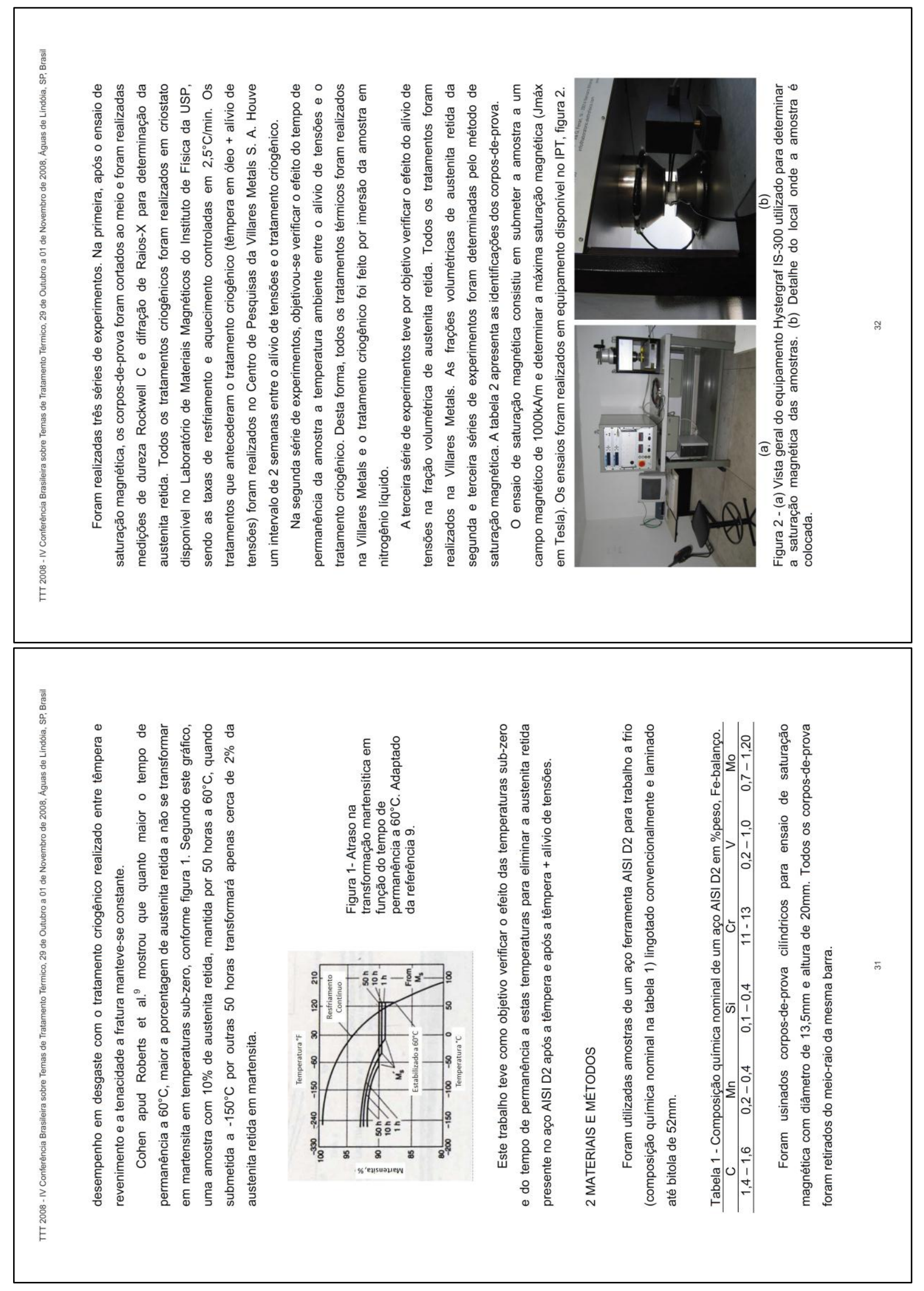




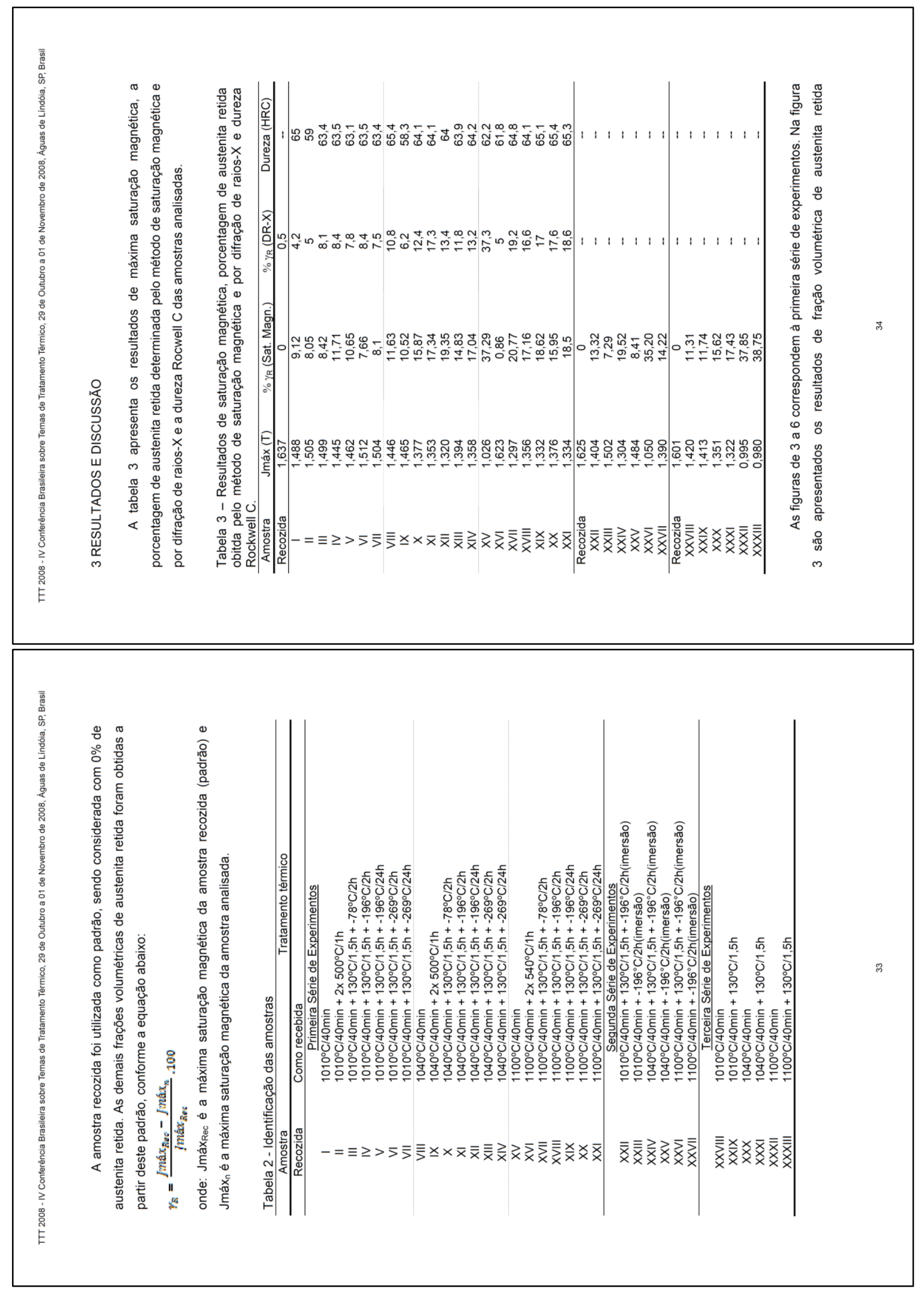




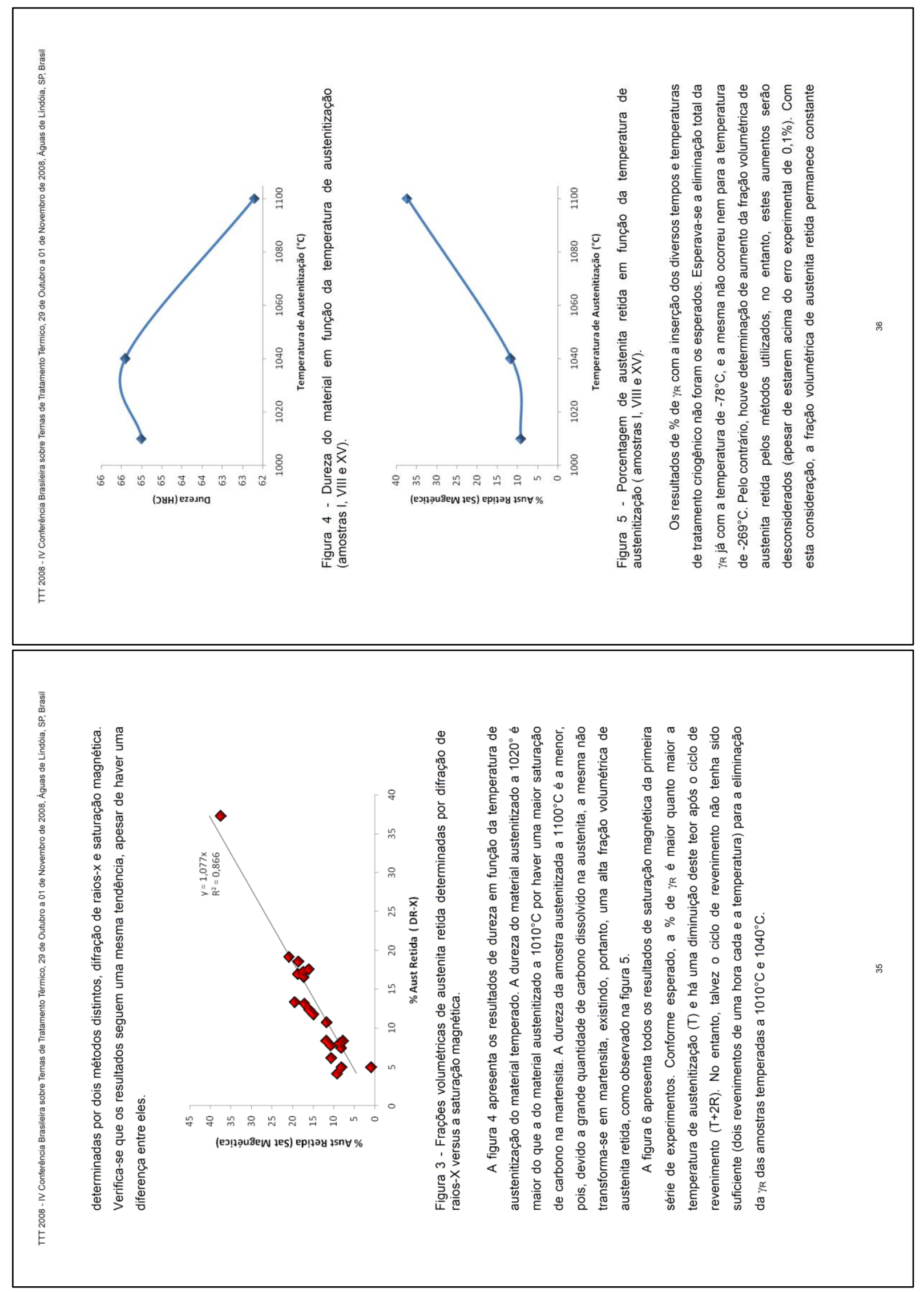




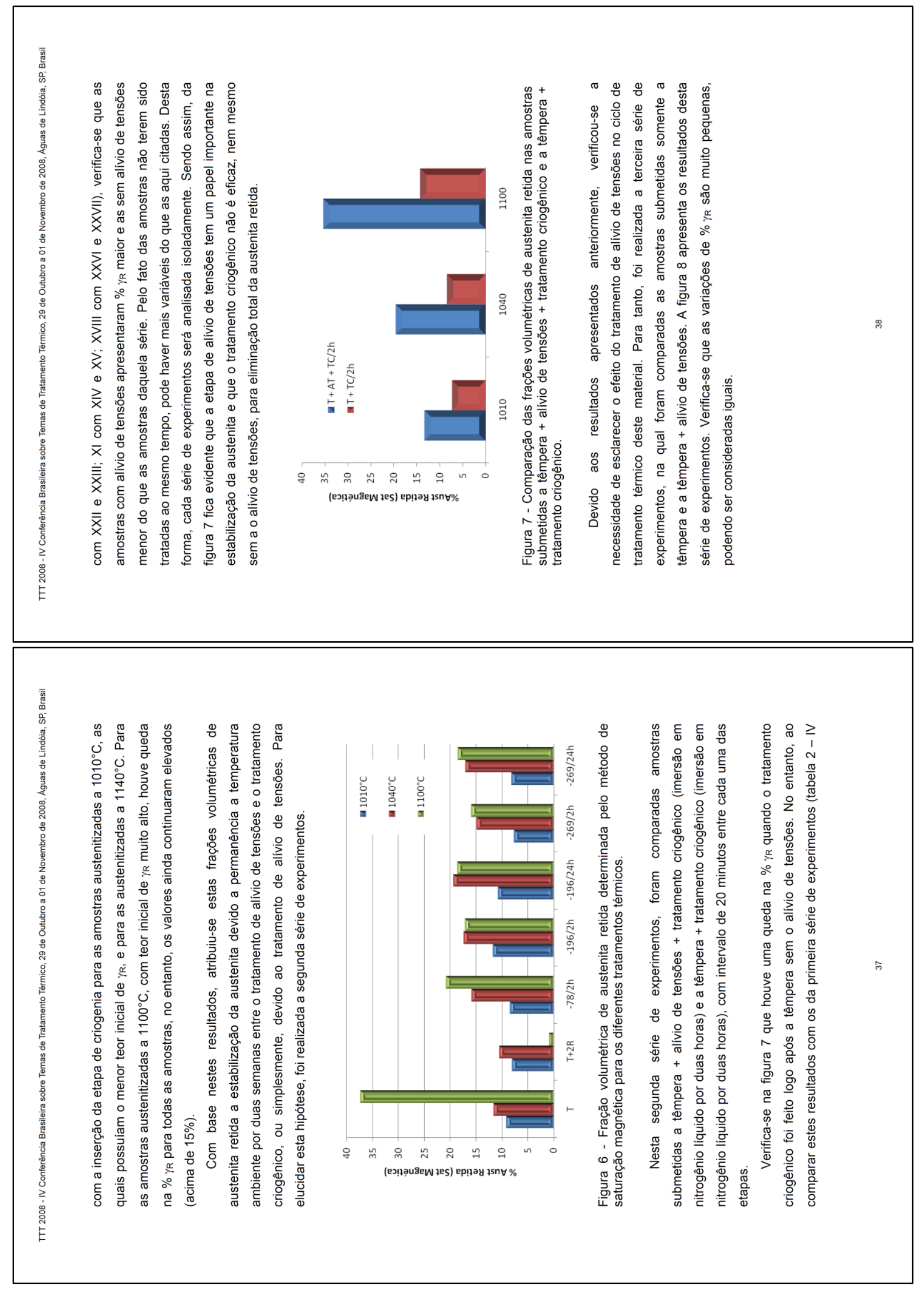




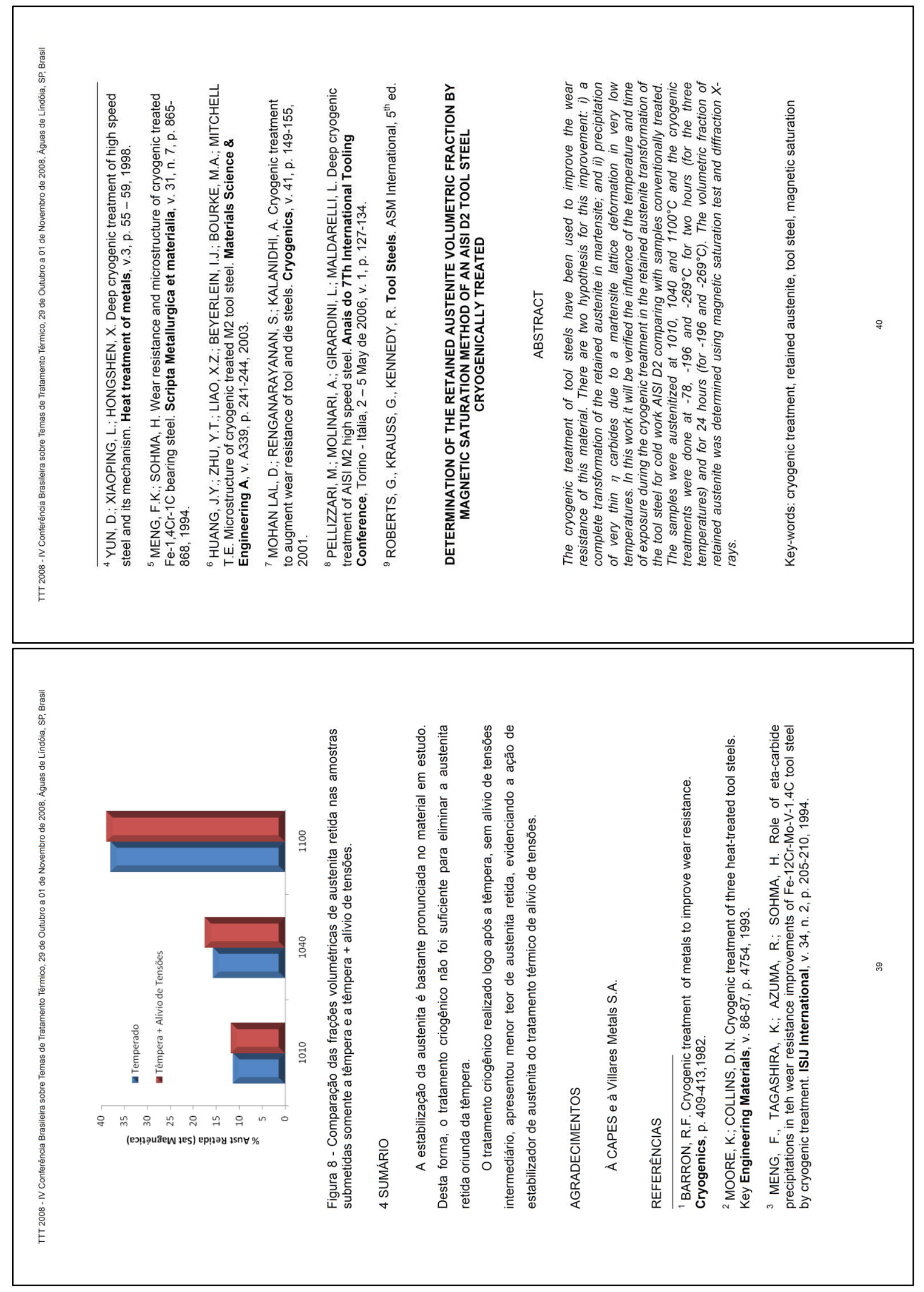




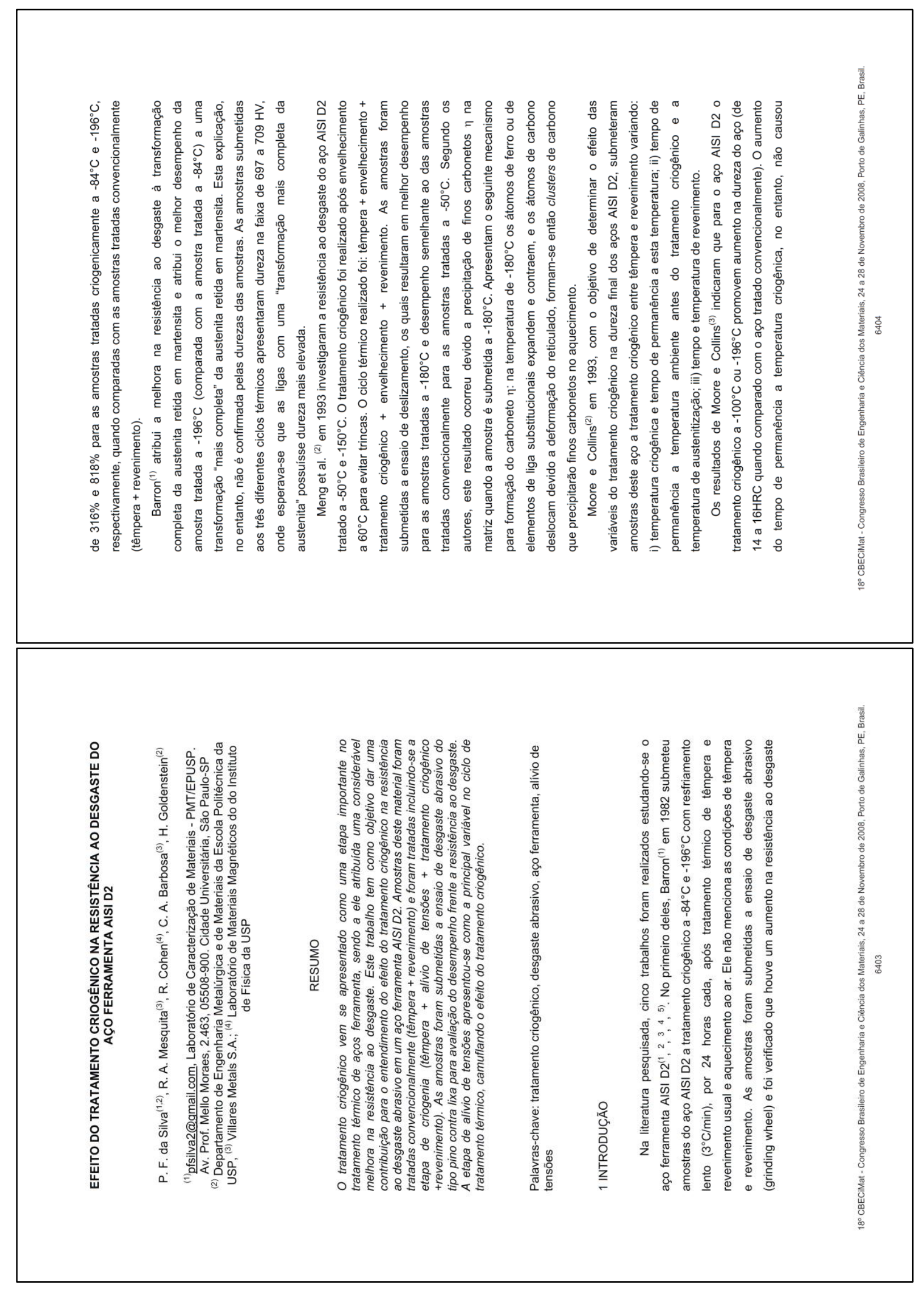



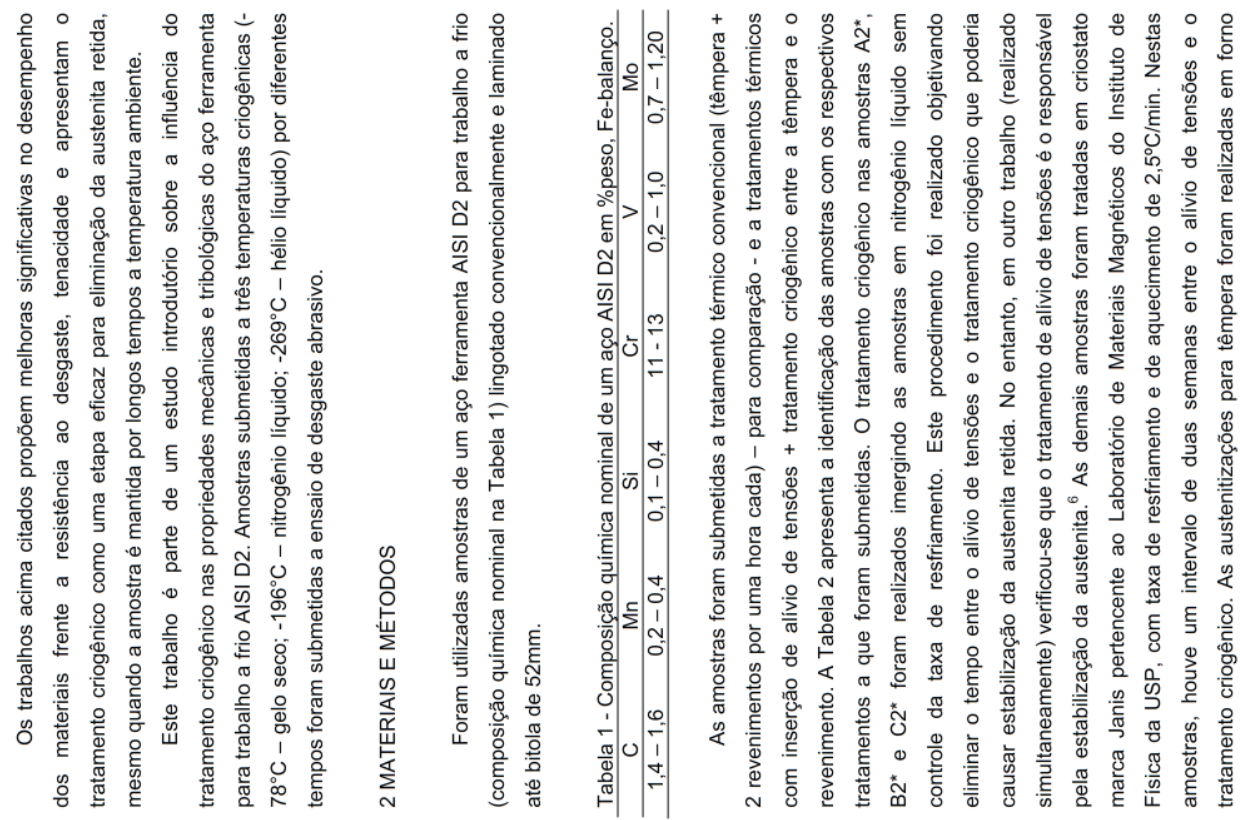

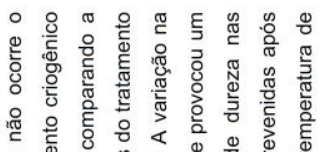

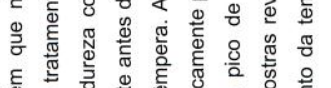

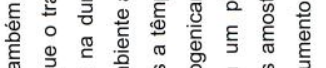

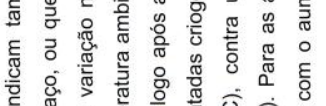

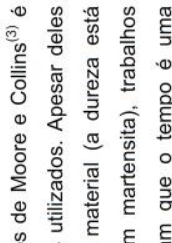

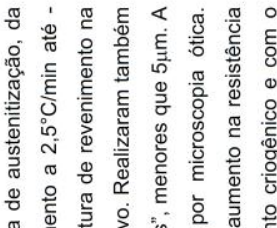

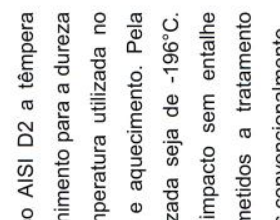

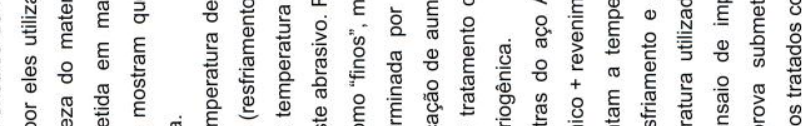

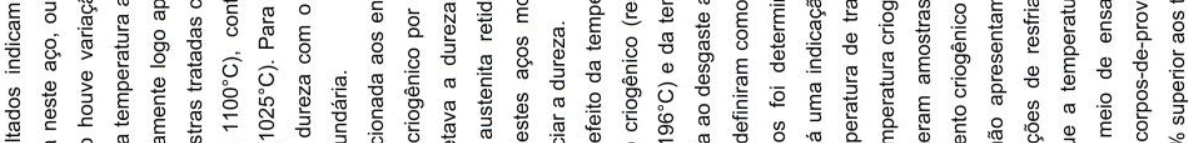

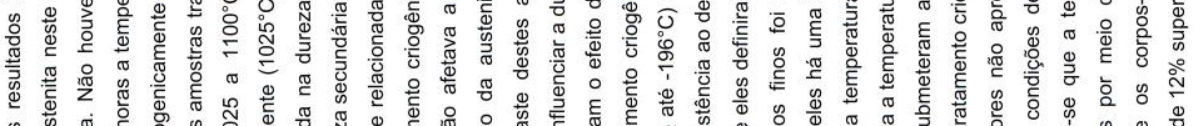

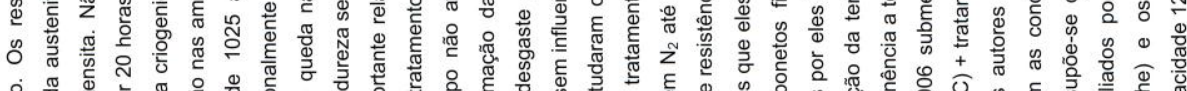

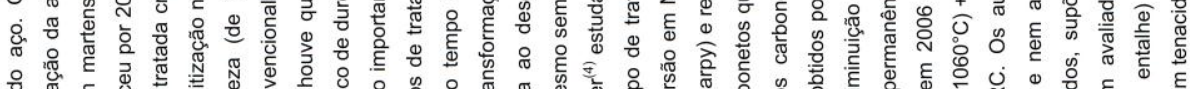

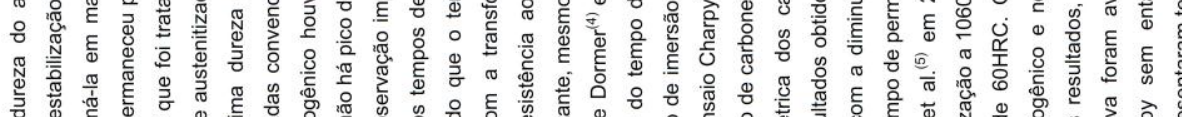

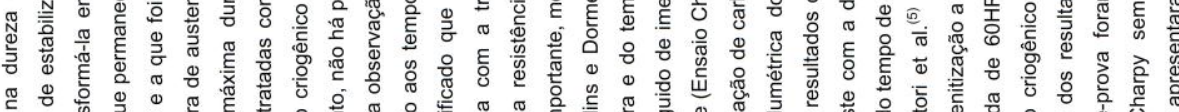

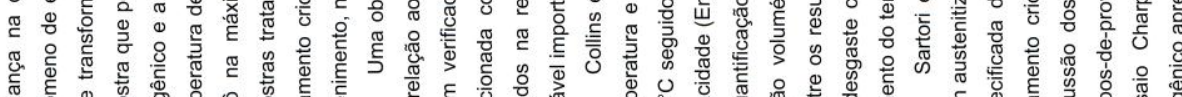

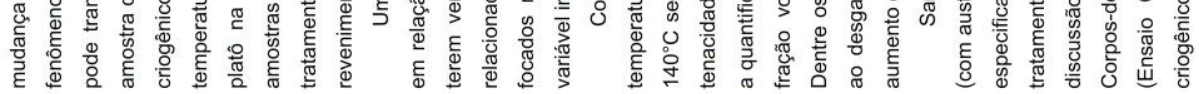



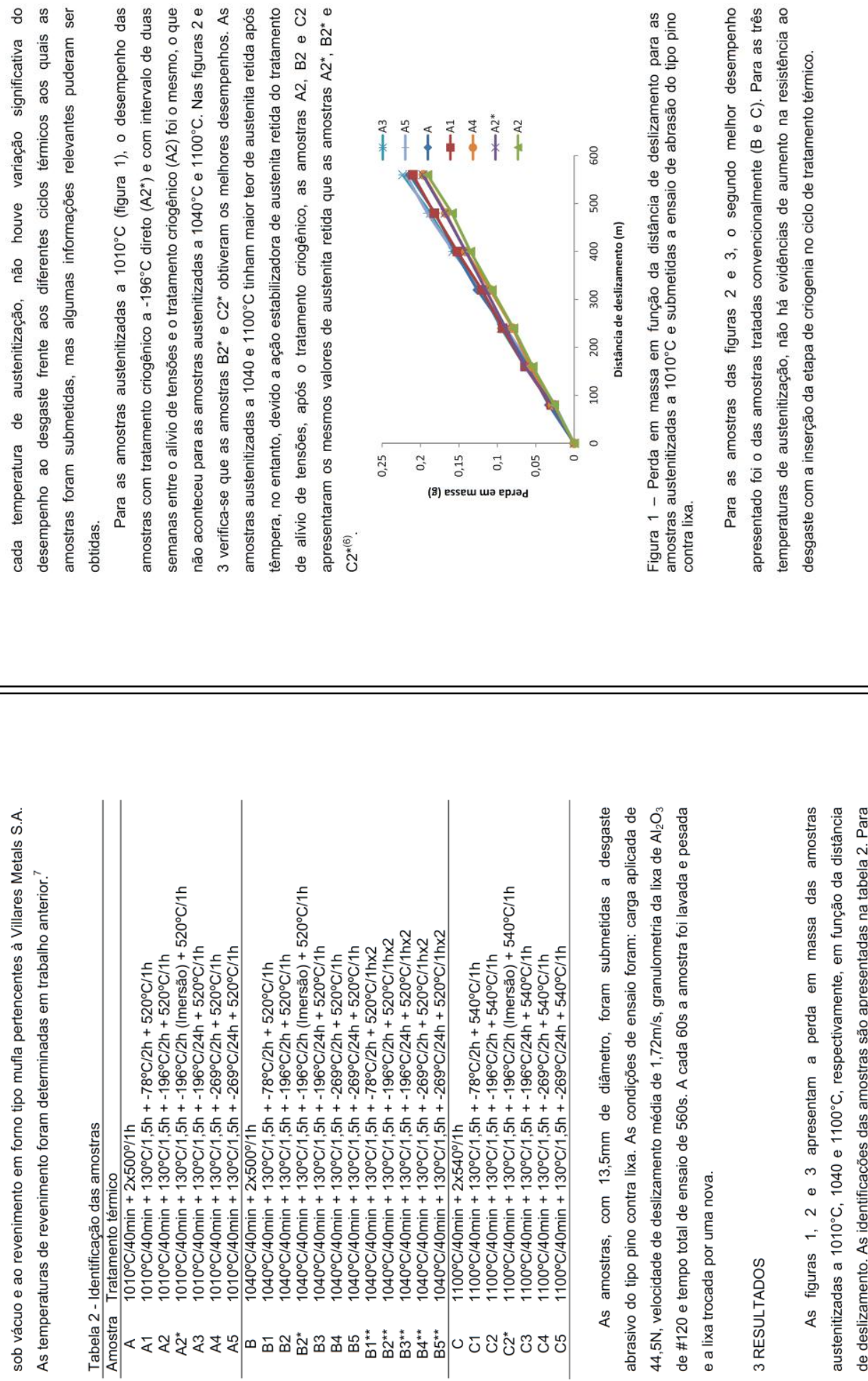


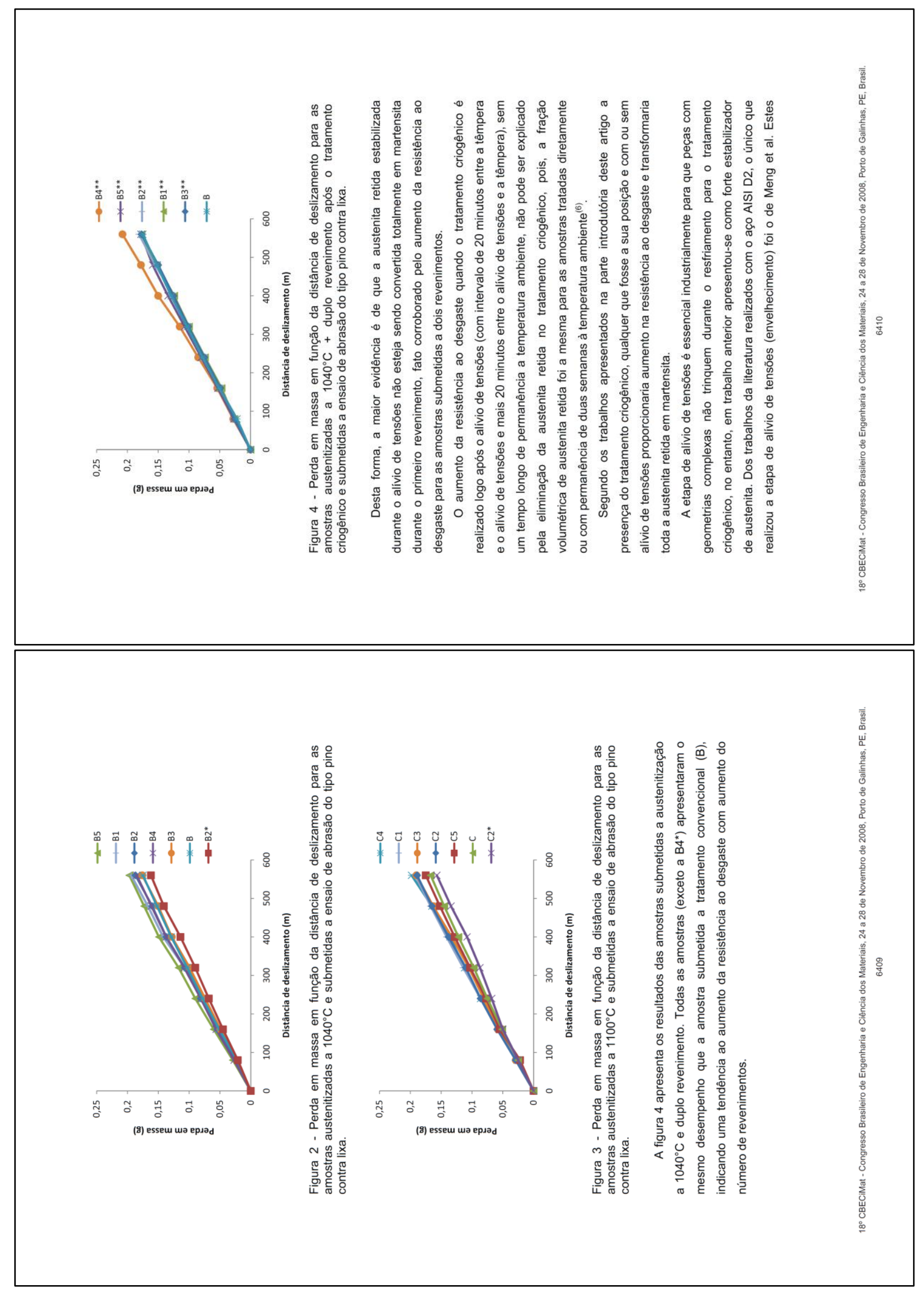



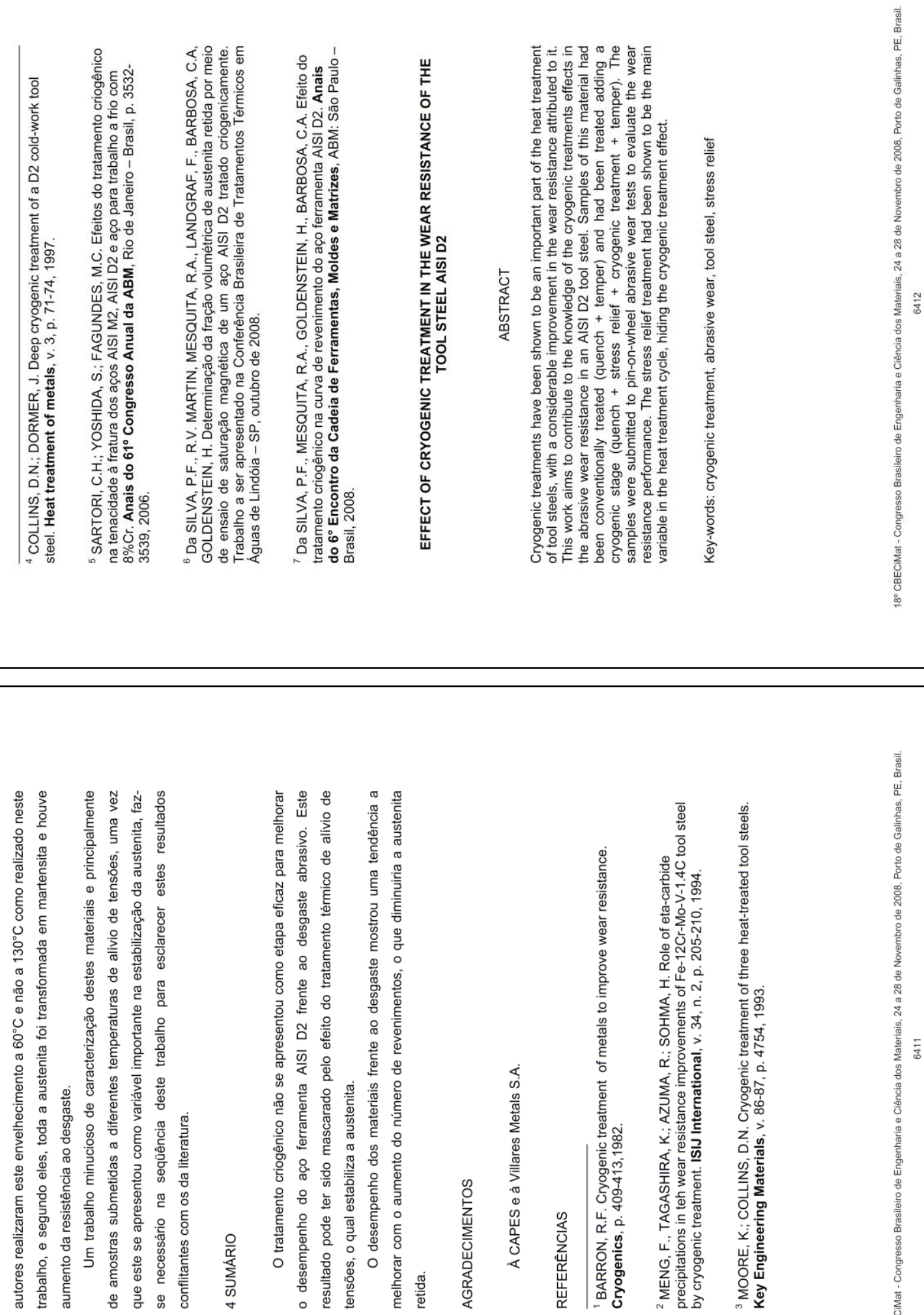

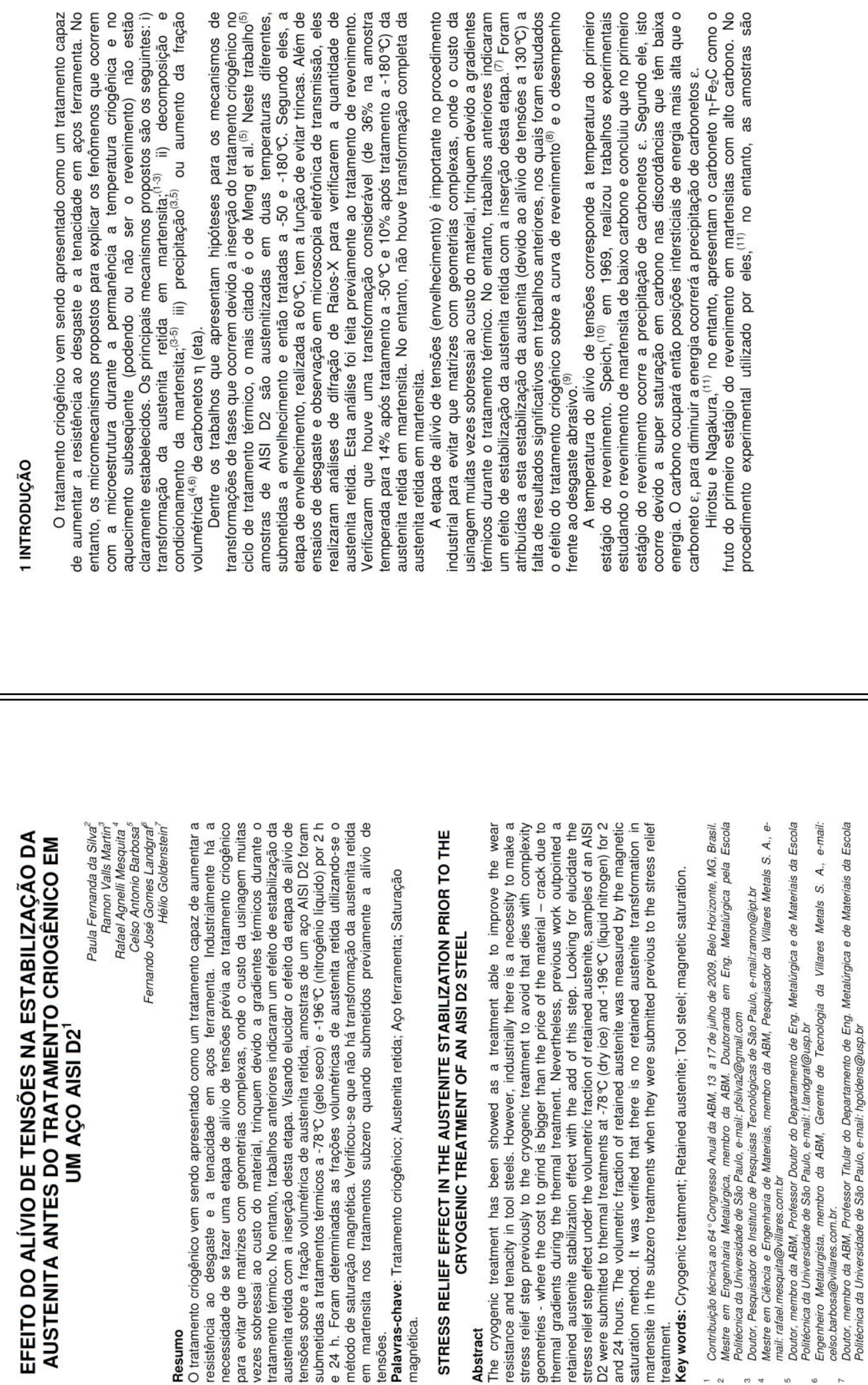

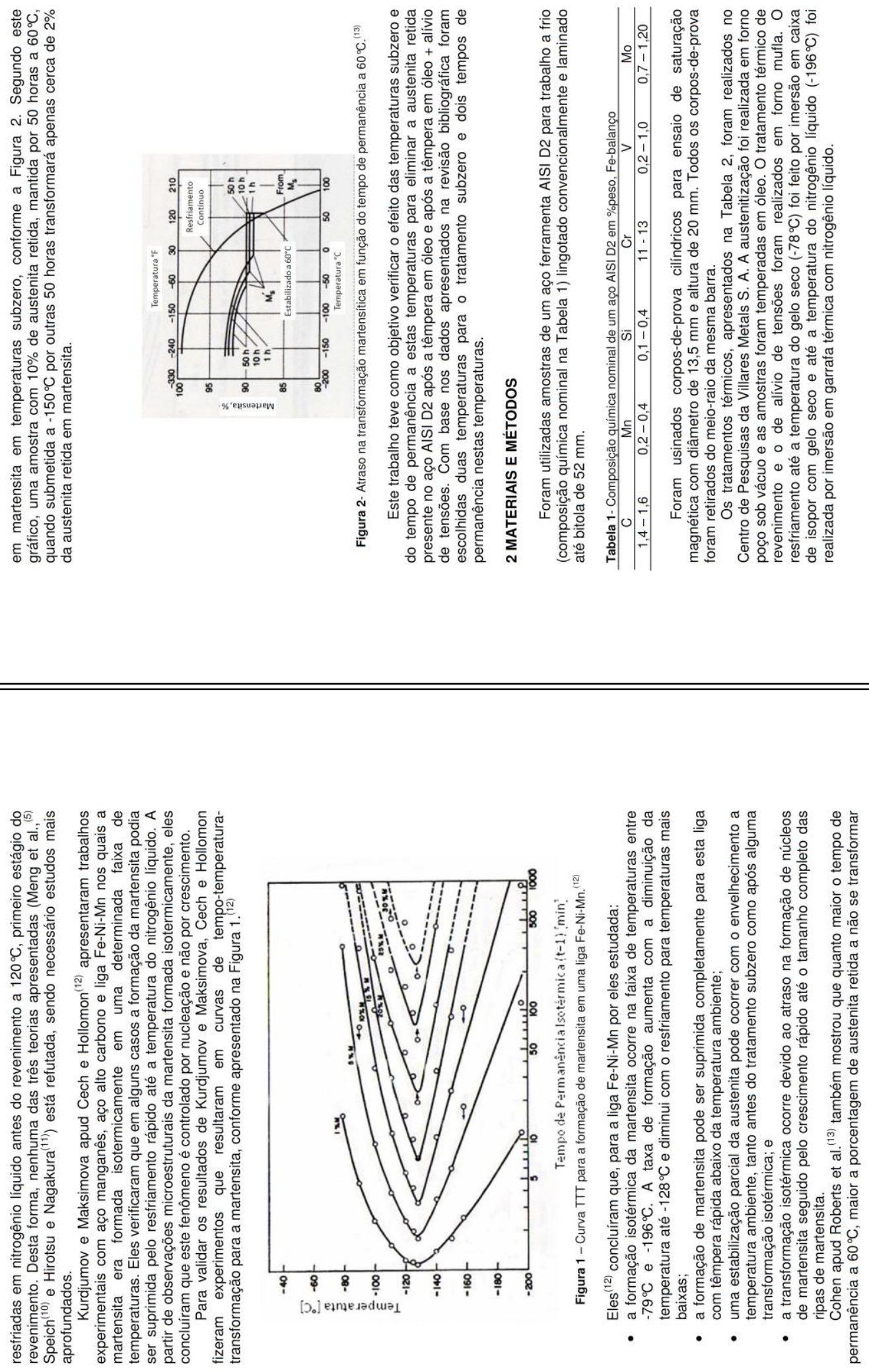

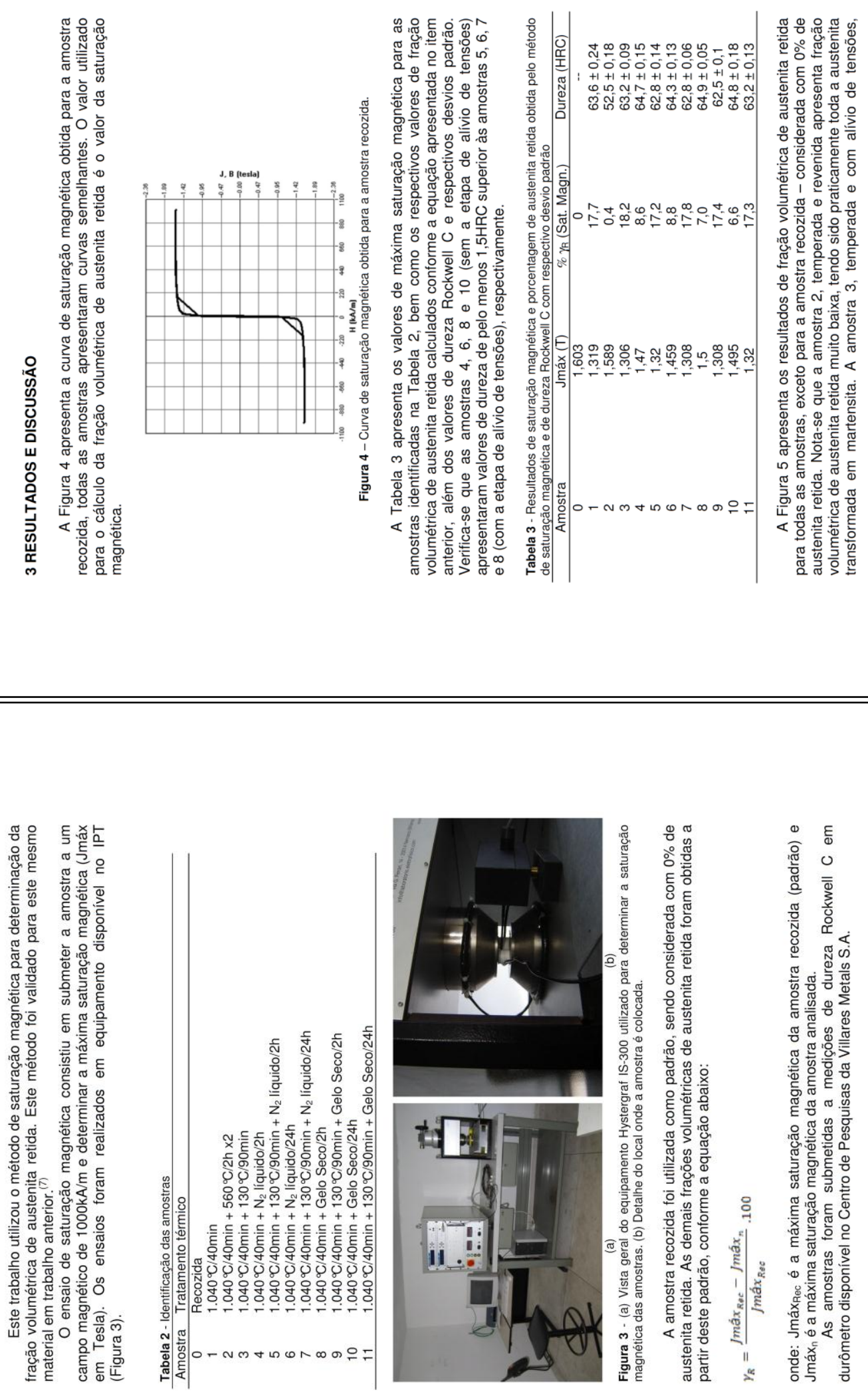

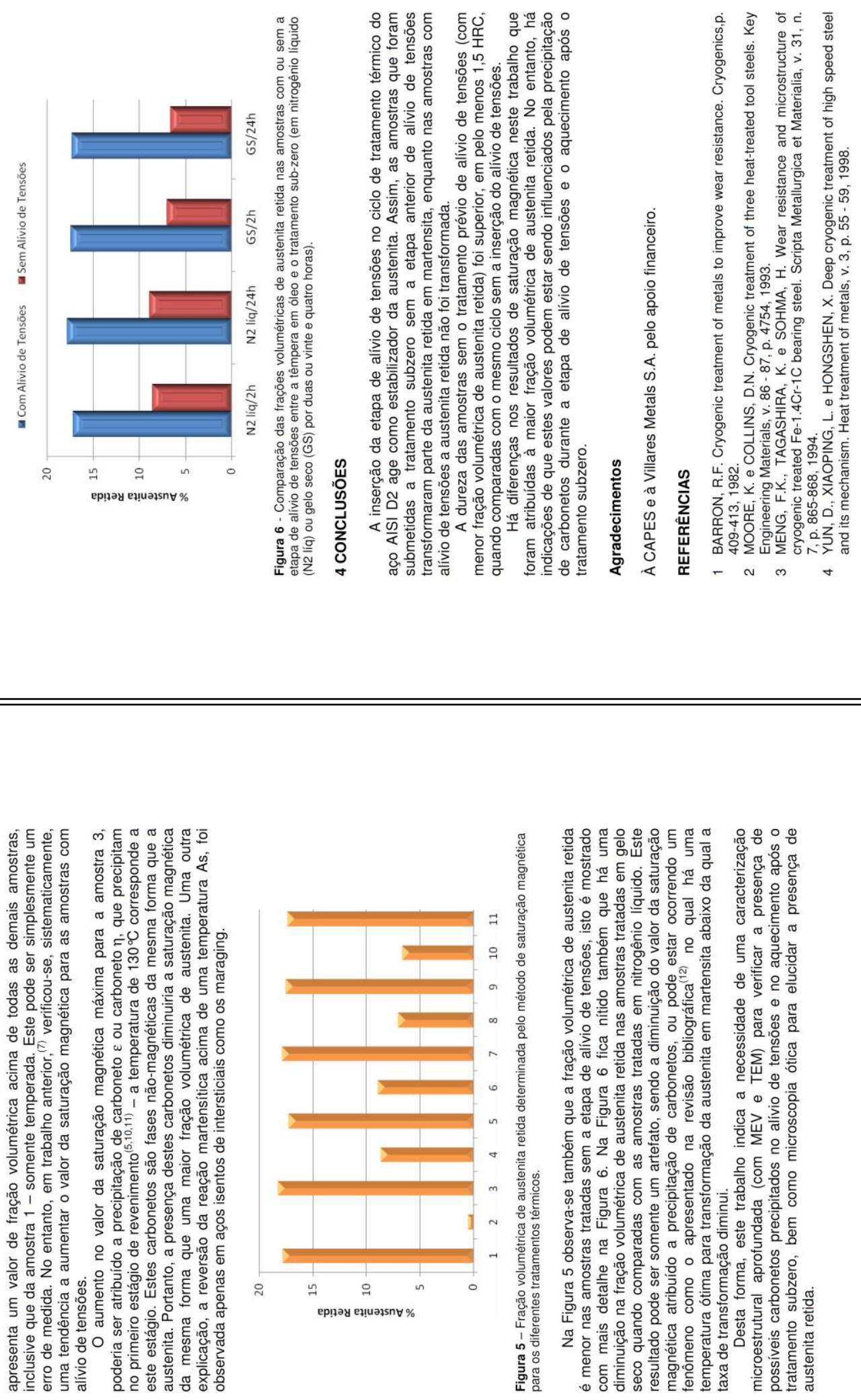


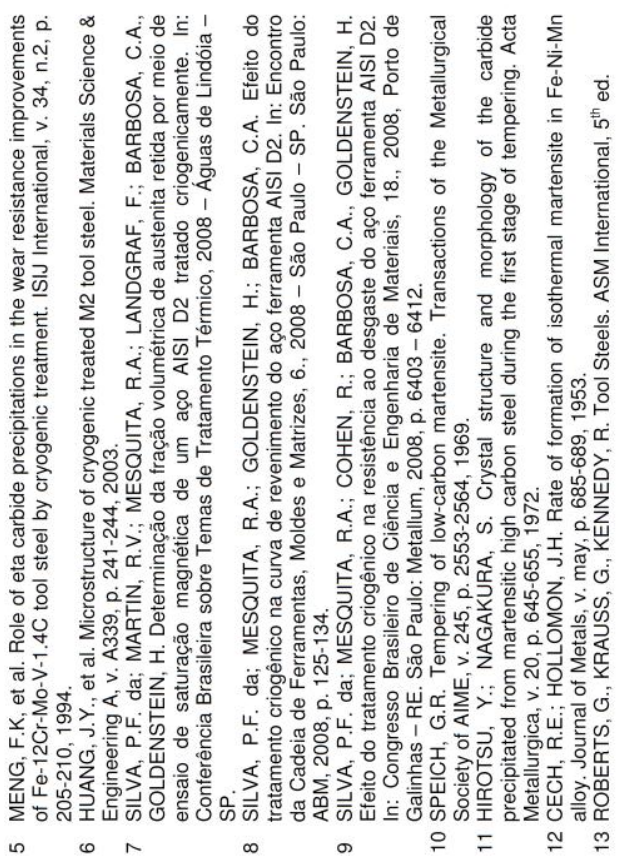


$11^{\text {th }}$ International Conference

on Advanced Materials

ICAM2009 $\begin{aligned} & \text { Rio de Janeiro Brazil } \\ & \text { September } 20.25\end{aligned}$

Effect of Stress Relief on the Amount of Retained Austenite After Cryogenic Treatment and on the Wear Resistance of a Tool Steel

P. F. S. Farina ${ }^{(1)^{*}}$, R. A. Mesquita ${ }^{(2)}$, C. A. Barbosa ${ }^{(2)}$ and H. Goldenstein ${ }^{(1)}$

(1) Laboratório de Transformações de Fases, Departamento de Eng. Metalúrgica e de Materiais, EPUSP, e-mail: pfsilva2@gmail.com

(2) Villares Metals S. A.

* Corresponding author.

Abstract - The practice of tempering for stress relief before cryogenic thermal treatment in an AISI D2 tool steel has been shown to stabilize the retained austenite, nullifying the effect of cryogenic treatment The practice simultaneously enhances the wear resistance of the steel after complete thermal cycling (quench + stress relief + cryogenic treatment + double temper).

Cryogenic treatment has been shown to have a large effect on the properties of heat treated steels, especially tool steels. Nevertheless, due to the complexity of some parts it is necessary to do a prior stress relief heat treatment to avoid cracks and catastrophic failures. In previous work [1] it was verified that the stress relief treatment stabilizes the austenite even when the sample is submerged in liquid nitrogen. The literature [2] suggests that there is a C-curve kinetic behavior for the austenite to martensite transformation at temperatures lower than Ms.

In order to confirm those previous work results[1] and test the hypothesis of a C-curve behavior, samples from an AISI D2 tool steel bar were austenitized at $1040^{\circ} \mathrm{C}$ for 40 minutes and then quenched in oil. Half of the samples were submitted to a stress relief treatment at $130^{\circ} \mathrm{C}$ for 90 minutes in order to enable comparison between samples with and without stress relief. Afterwards, some samples were submitted to a deep cryogenic treatment (DCT - immersion in liquid nitrogen) and others to a shallow cryogenic treatment (SCT -immersion in dry ice), for 2 and 24 hours.

After cryogenic treatment the volumetric fraction of retained austenite was determined using a magnetic saturation test, which was validated in a previous work [1]. This test consists of introducing the samples into a magnetic field (Hystergraf IS-300) of $1000 \mathrm{kA} / \mathrm{m}$ and determining the maximum magnetic saturation. After that, the values obtained are compared to the value characteristic of an annealed sample, which is considered to have zero percent retained austenite.

Figure 1 shows that all the samples submitted to stress relief before the cryogenic treatment have the same volumetric fraction of austenite as the samples just quenched. These results confirm that the prior stress relief stabilizes the austenite, and even with a DCT for $24 \mathrm{~h}$ no austenite is transformed into martensite. In addition it shows that the samples without stress relief submitted to SCT have less retained austenite than the ones submitted to DCT, and the amount of austenite diminishes with increasing time at SCT temperatures suggesting that the martensitic transformation show indeed a C-curve kinetic behavior.

The samples were double tempered and submitted to a wear test (described in detail in reference [3]). Figure 2 shows that, for this particular wear test, samples submitted to a stress relief heat treatment before cryogenic cooling showed a better behavior than the ones without this treatment.

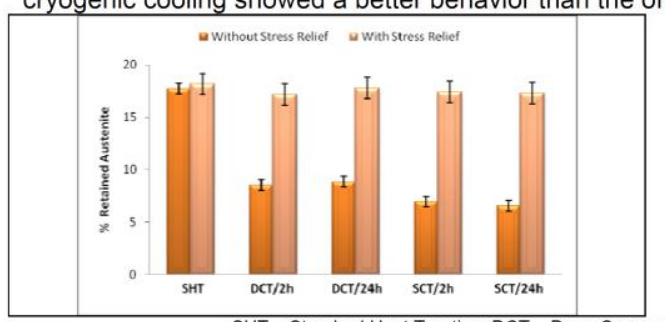

Figure 1 - Percentage of retained austenite with and without stress relief previous to the cryogenic treatment.

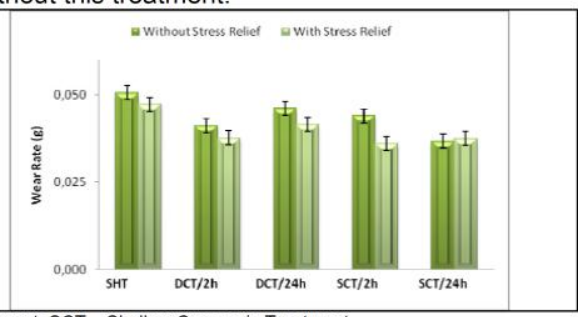

Treatment; SCT - Shallow Cryogenic Treatment.
Figure $\mathbf{2}-$ Wear rate of the samples with and without stress relief previous to the cryogenic treatment.

\section{References}

[1] P. F. da Silva, R. V. Martin, R. A. Mesquita, F. Landgraf, C. A. Barbosa, H. Goldenstein. Determinação da fração volumétrica de austenita retida por meio de ensaio de saturação magnética de um aço AISI D2 tratado criogenicamente. TTT 2008, Águas de Lindóia SP, Out 2008.

[2] J-C Zhao and M. R. Notis. Materials Science and Engineering, R15 (1995), p. 135-208.

[3] P. F. da Silva, R. A. Mesquita, R. Cohen, C. A. Barbosa, H. Goldenstein. Efeito do tratamento criogênico na resistência ao desgaste do aço ferramenta AISI D2. CBECIMAT 2008, Porto de Galinhas - PE, Nov. 2008. 


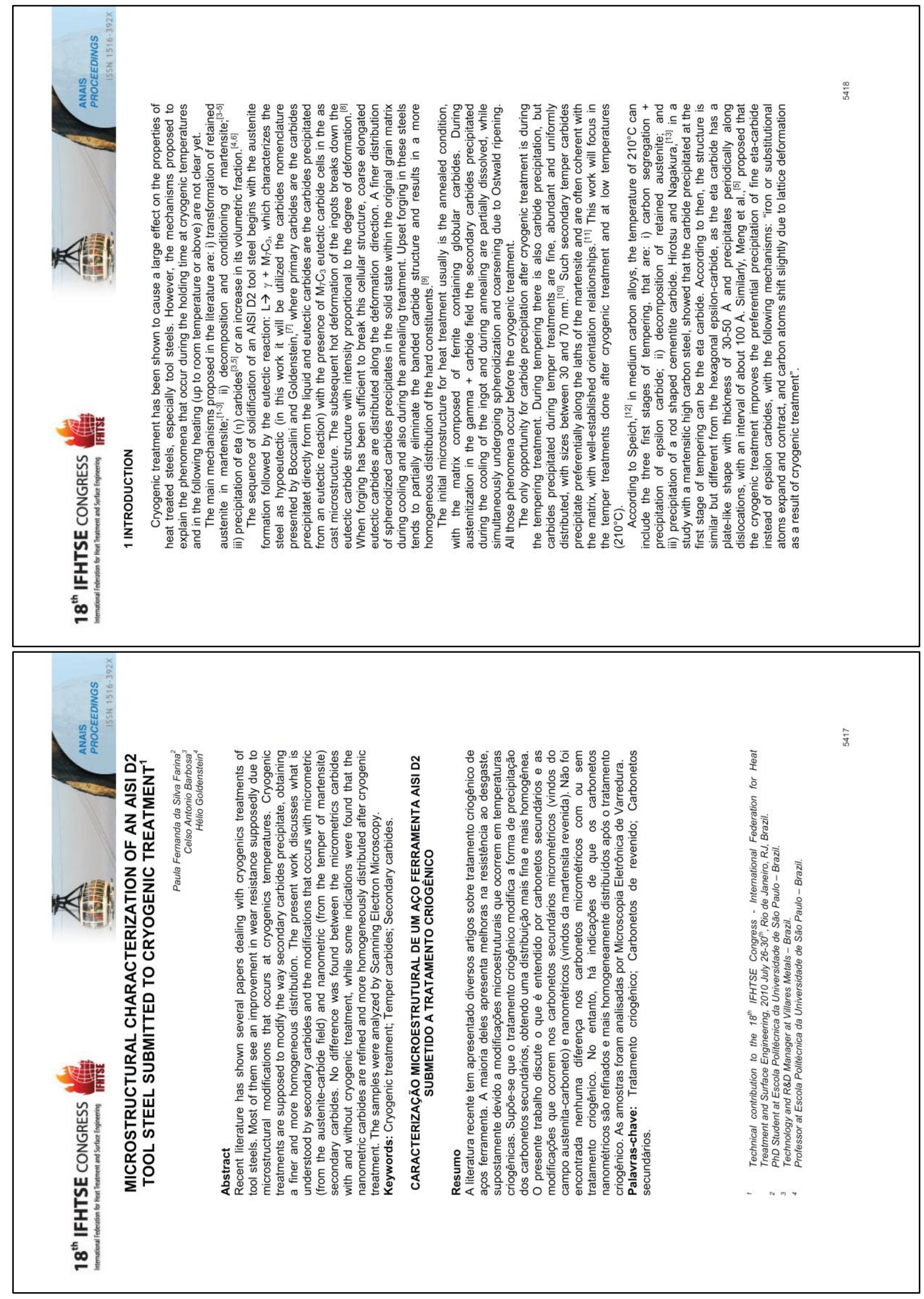




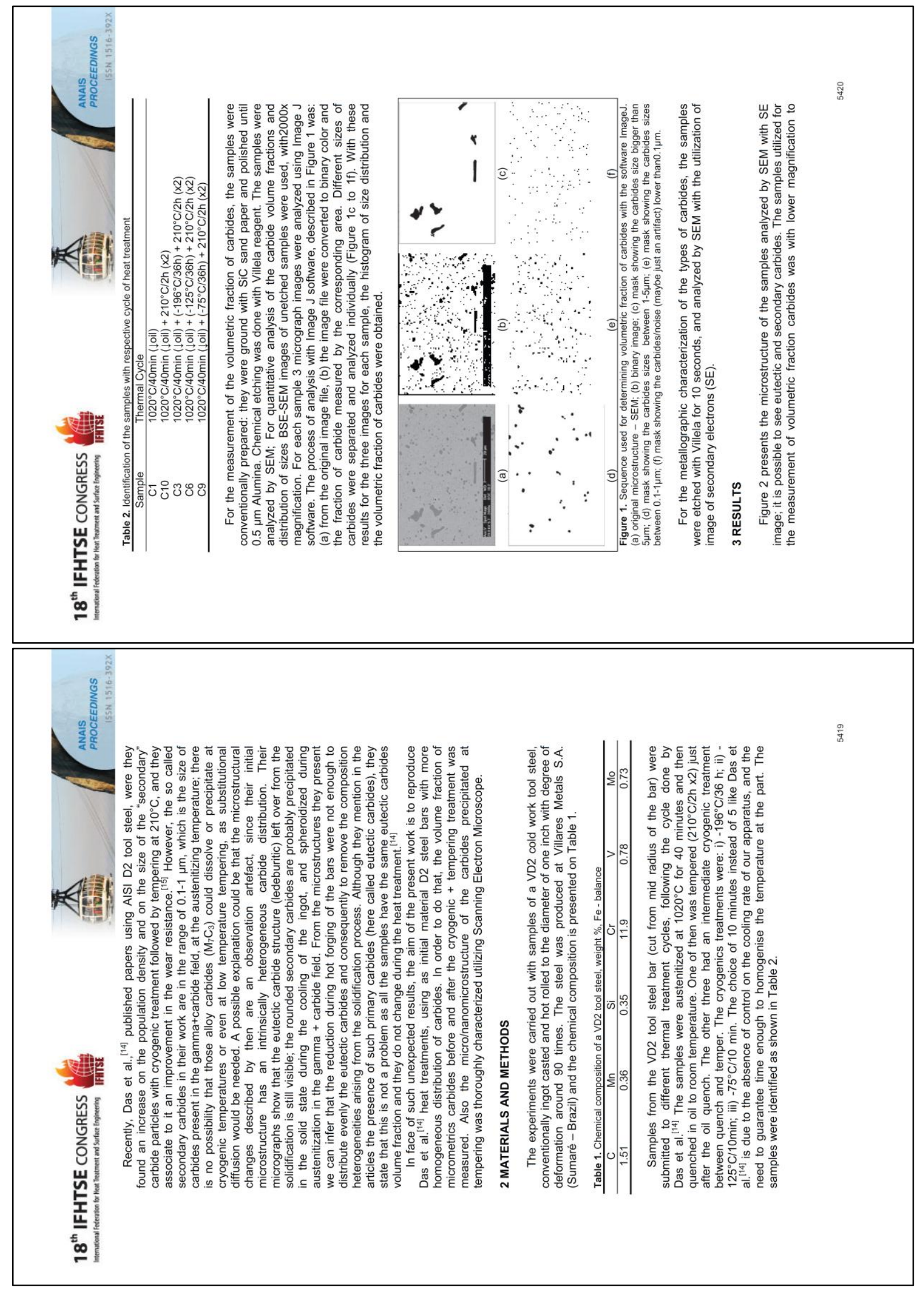




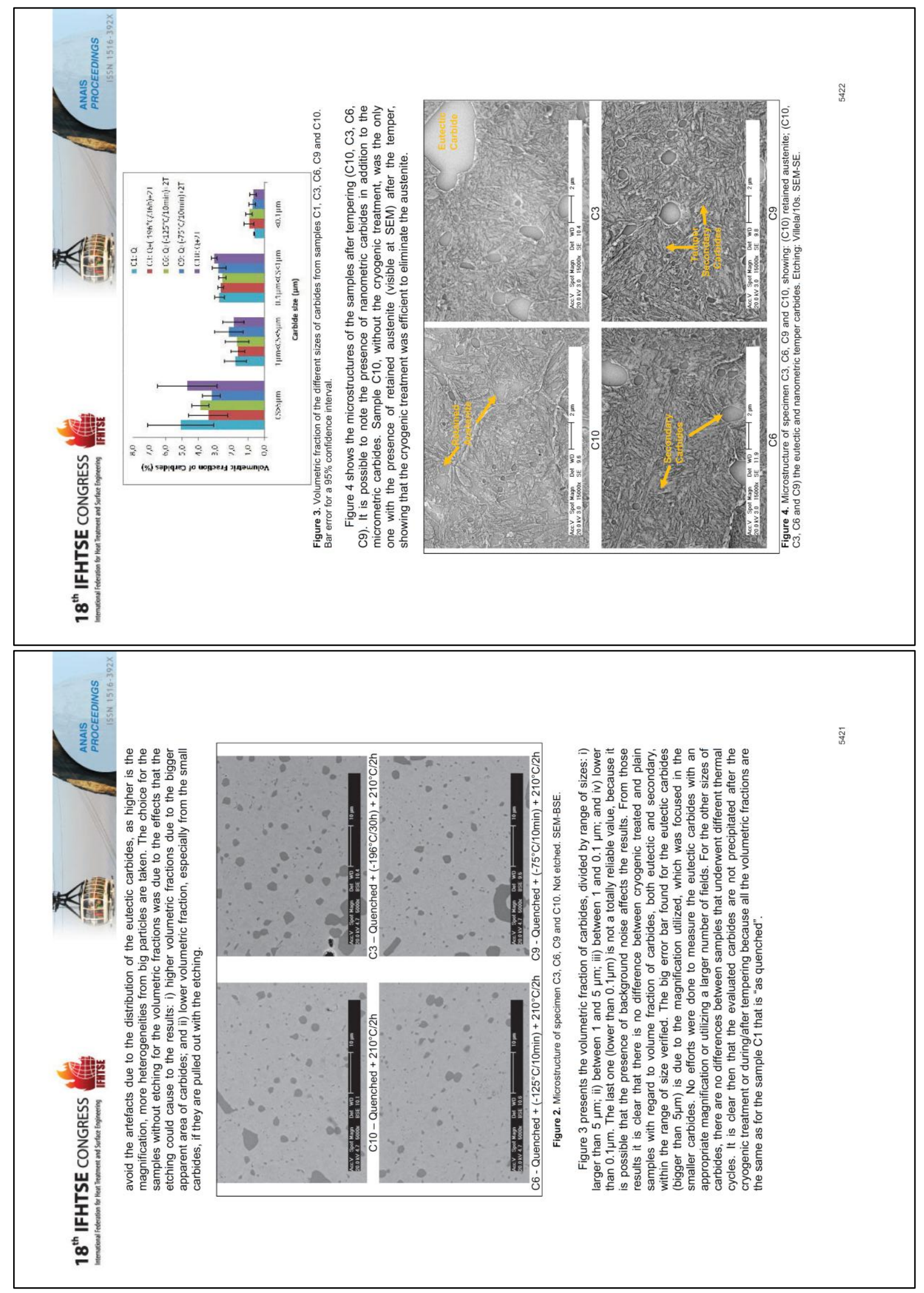




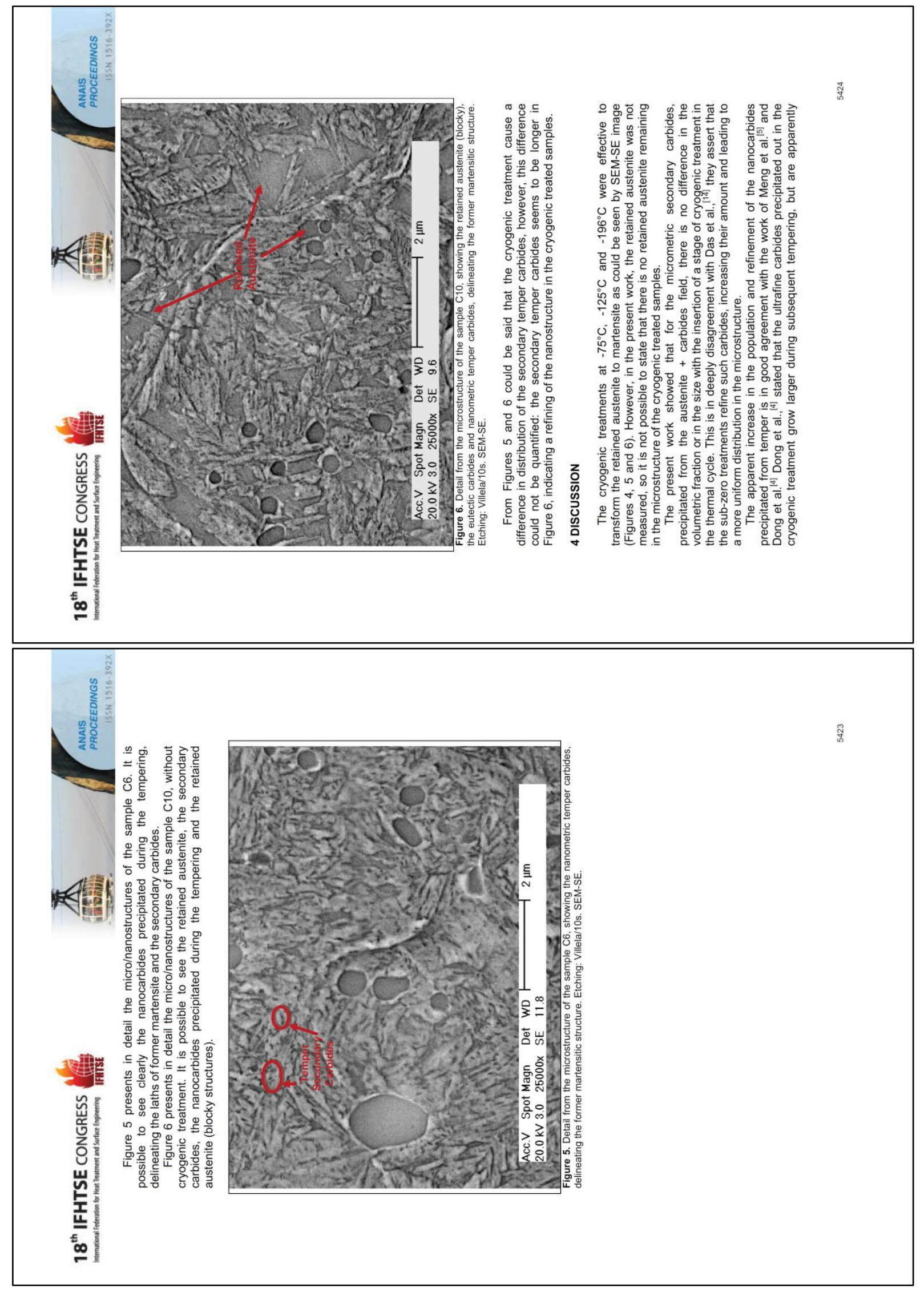




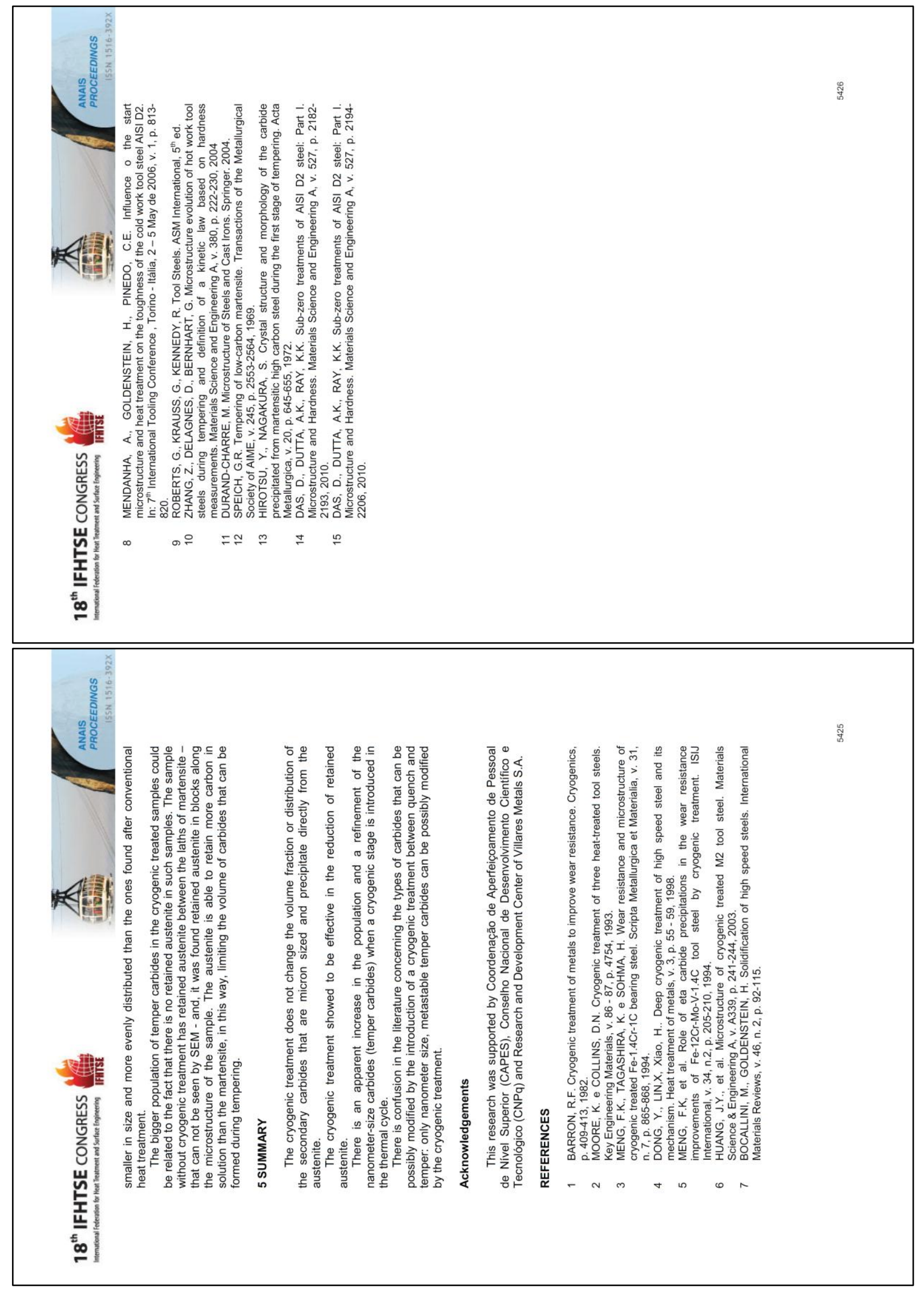



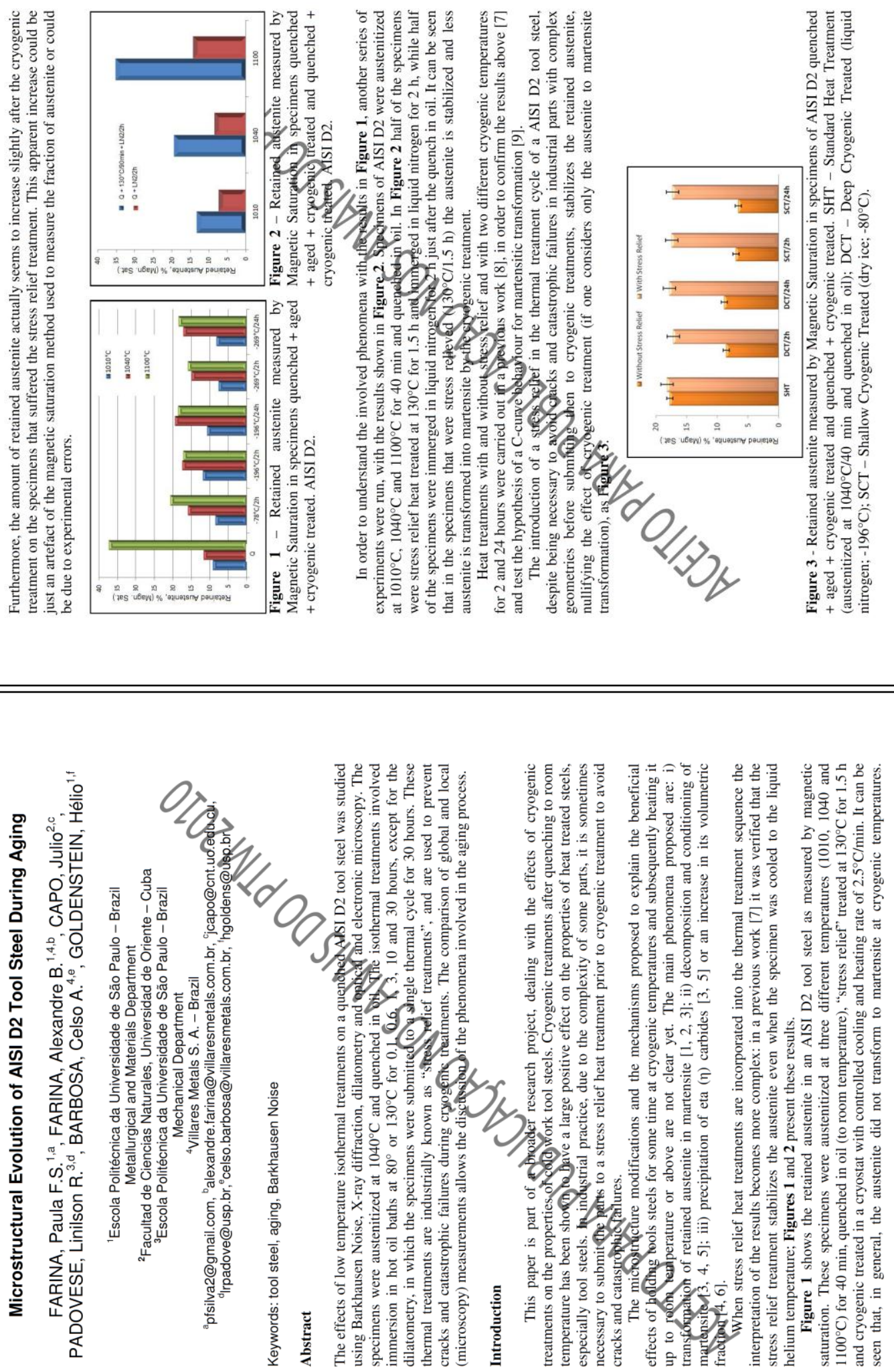

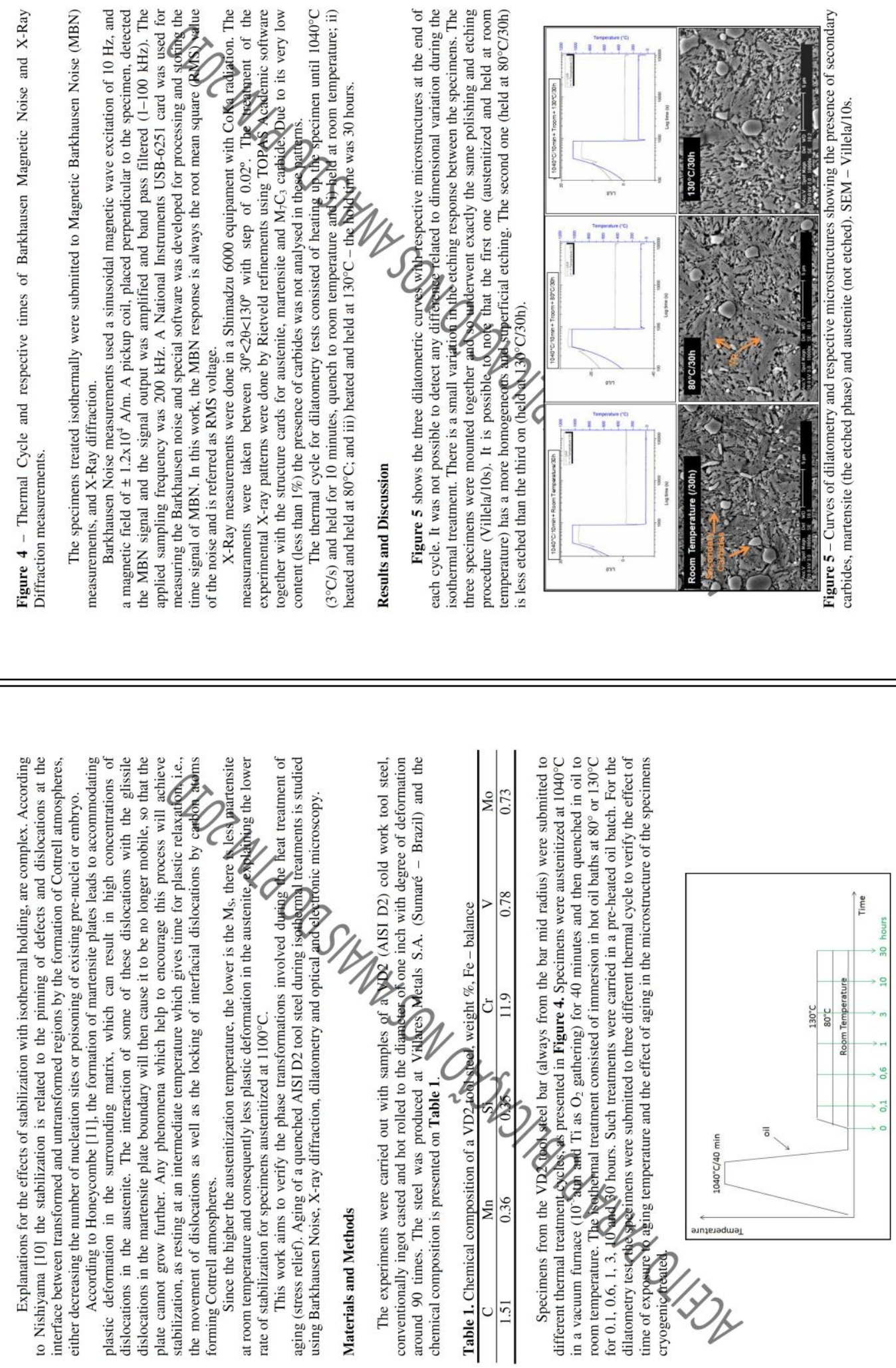

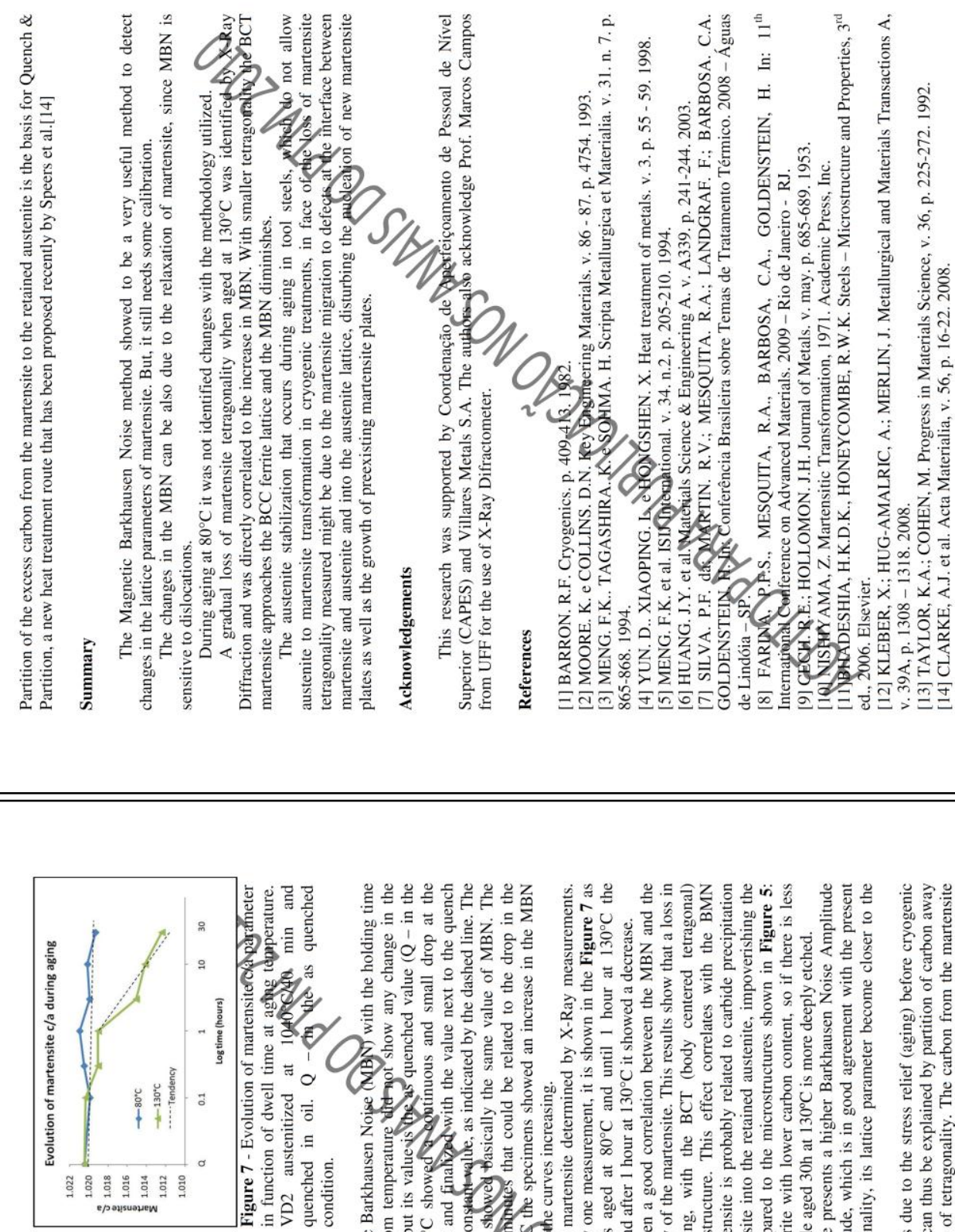

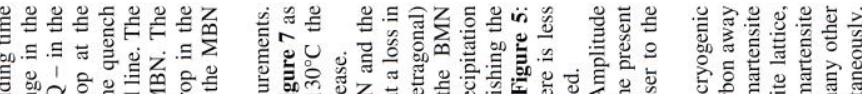
$\begin{array}{lll} & \\ 0\end{array}$

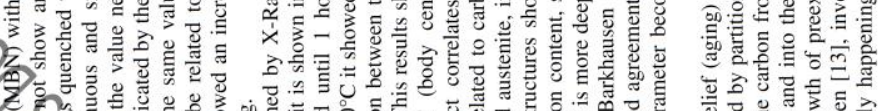

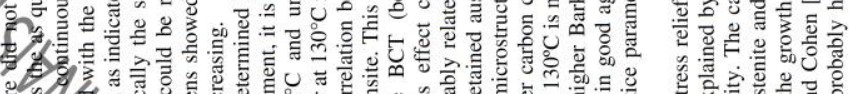

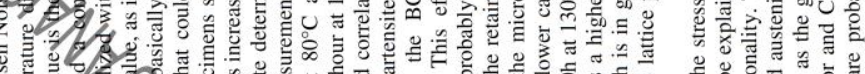

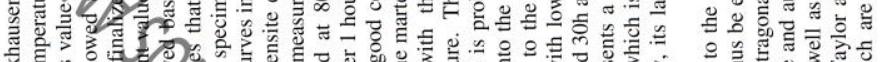

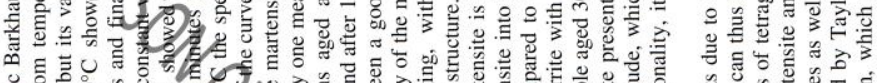

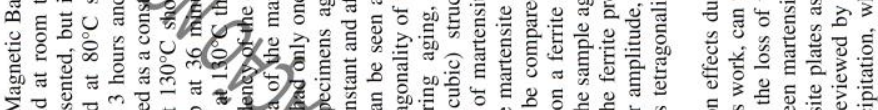

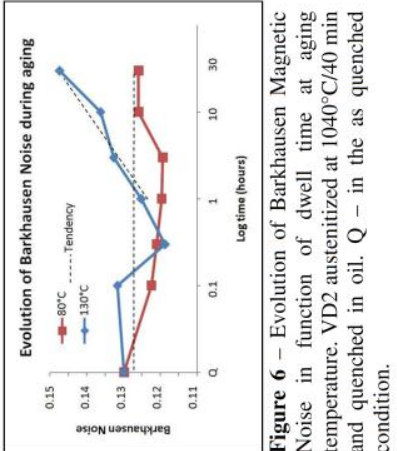

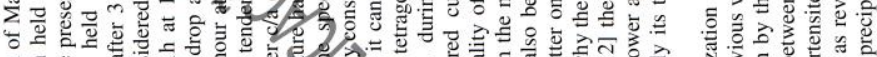

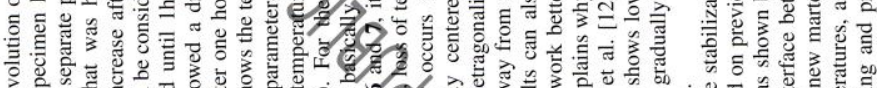

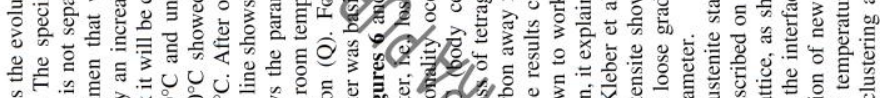

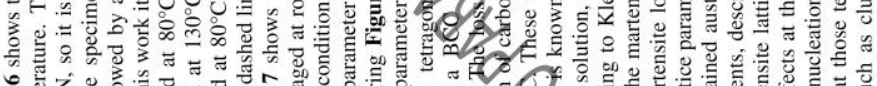

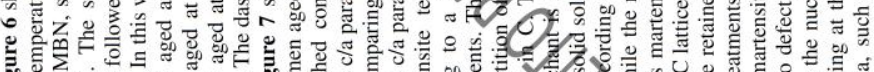

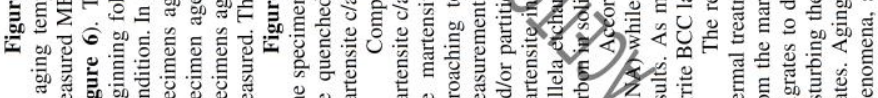

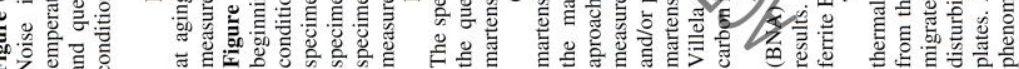




\section{REFERÊNCIAS}

1. ROBERTS, G. A.; CARY, A. R. Tool Steels. 4a. ed. [S.I.]: American Society for Metals, 1980.

2. BOCCALINI, M.; GOLDENSTEIN, H. Solidification of high speed steels. International Materials Reviews, v. 46, n.2, 2001.

3. MENDANHA, A.; GOLDENSTEIN, H.; PINEDO, C. E. Influence o the start microstructure and heat treatment on the toughness of the cold work tool steel AISI D2. 7th International Tooling Conference. Torino- Itália: [s.n.]. 2-5 de Maio de 2006. p. 813-820.

4. BHADESHIA, H. K. D. K.; HONEYCOMBE, R. W. K. Steels - Microstructure and Properties. 3a. ed. [S.I.]: Elsevier, 2006.

5. BRANCO, J. R. T.; KRAUSS, G. Heat treatment and microstructure of tool steels for molds and dies. In: KRAUSS, G.; NORDBERG, H. Tool Materials for Molds and Dies - Applications and Performance. Colorado: CSM Press, 1987.

6. MENG, F. et al. Role of eta carbide precipitations in the wear resistance improvements of $\mathrm{Fe}-12 \mathrm{Cr}-\mathrm{Mo}-\mathrm{V}-1.4 \mathrm{C}$ tool steel by cryogenic treatment. ISIJ International, v. 34, n.2, p. 205-210, 1994.

7. OPPENKOWSKI, A.; WEBER, S.; THEISEN, W. Evaluation of factors influencing deep cryogenic treatment that affect the properties of tool steels. Journal of Materials Processing Technology, v. 210, p. 1949 - 1955, 2010.

8. BARRON, R. F. Cryogenic treatment of metals to improve wear resistance. Cryogenics, p. 409-413, Agosto 1982.

9. MOORE, K.; COLLINS, D. N. Cryogenic treatment of three heat-treated tool steels. Key Engineering Materials, v. 86-87, p. 47-54, 1993.

10. MENG, F.; TAGASHIRA, K.; SOHMA, H. Wear resistance and microstructure of cryogenic treated Fe-1.4Cr-1C bearing steel. Scripta Metallurgica e Materialia, v. 31, n.7, p. $865-868,1994$.

11. YUN, D.; XIAOPING, L.; HONGSHEN, X. Deep cryogenic treatment of high speed steel and its mechanism. Heat treatment of metals, v. 3, p. 55-59, 1998.

12. HUANG, J. Y. et al. Microstructure of cryogenic treated M2 tool steel. Materials Science and Engineering A, v. 339, p. p. 241-244, 2003.

13. LARROUSSE ilustrado da língua portuguesa. 1a. ed. São Paulo: Larrousse do Brasil, 2004. 
14. COLLINS, D. N. Cryogenic treatment of tool steels. Advanced Materials \& Processes, v. 12, p. H23-H29, 1998.

15. RHYIM, Y.-M. et al. Effect of deep cryogenic treatment on carbide precipitation and mechanical properties of tool steel. Solid State Phenomena, v. 118, p. 9-14, 2006.

16. BENSELY, A. et al. Enhancing the wear resistance of case carburized steel (En 353) by cryogenic treatment. Cryogenics, v. 45, p. 747-754, 2006.

17. PELLIZARI, M.; MOLINARI; A. Deep Cryogenic Treatment of Cold Work Tool Steel. 6th International Tooling Conference. Karlstad - Suécia: [s.n.]. 2002. p. p. 657-669.

18. YUGANDHAR, T.; KRISHNAN, P. K. Cryogenic Treatment and it's effect on tool steel. 6th International Tooling Conference. Karlstad, Suécia: [s.n.]. 10-13 Setembro, 2002. p. 671-684.

19. GOBBI, S. J. et al. Efeito do tratamento criogênico profundo no desgaste microabrasivo do aço AISI D2. 18ํㅡㄹ CBECiMat - Congresso Brasileiro de Engenharia e Ciência dos Materiais. Porto de Galinhas - PE - Brasil: [s.n.]. 2008. p. 6711-6722.

20. COLLINS, D. N.; DORMER, J. Deep cryogenic treatment of a D2 cold-work tool steel. Heat Treatment of Metals, v. 3, p. 71-74, 1997.

21. SARTORI, C. H.; YOSHIDA, S.; FAGUNDES, M. G. Efeitos do tratamento criogênico na tenacidade à fratura dos aços AISI M2, AISI D2 e aço para trabalho a frio com $8 \%$ de Cr. $61^{\circ}$ Congresso Anual da ABM. Rio de Janeiro: ABM - São Paulo. 2006. p. 3532-3539.

22. DAS, S.; DUTTA, A. K.; RAY, K. K. Effect of deep cryogenic treatment on the carbide precipitation and tribological properties behavior of D2 steel. Materials and Manufactuting Processes, v. 22, p. 474-480, 2007.

23. WIERSZYLLOWSKI, I.; NIEMCZYK, W. The influence of deep cryogenic treatment on precipitation phenomena during tempering and ageing. Defect and Diffusion Forum, v. 283-286, p. 65-73, 2009.

24. DAS, D.; DUTTA, A. K.; RAY, K. K. On the refinement of carbide precipitates by cryotreatment in AISI D2 steel. Phylosophical Magazine, v. 89, p. p. 55-76, 2010.

25. DAS, D.; DUTTA, A. K.; RAY, K. K. Sub-zero treatments of AISI D2 steel: Part I Microstructure and Hardness. Materials Science and Engineering A, v. 527, p. 2182-2193, 2010. 
26. UNTERWEISER, P. M.; BOYER, H. E.; KUBBS, J. (Eds.). Heat treater's guide standard practices and procedures for steel. [S.I.]: Metals Park, Ohio American Society for Metals, 1982.

27. SILVA, P. F. et al. Efeito do tratamento criogênico na curva de revenimento do aço ferramenta AISI D2. 6 Encontro da Cadeia de Ferramentas, Moldes e Matrizes. São Paulo - SP: ABM. 20 a 22 de agosto de 2008. p. 125-134.

28. MENDANHA, A. Estudo da resistência à fratura do aço ferramenta para trabalho a frio AISI D2. 2004. 151p. Dissertação (Mestrado). Escola Politécnica, Universidade de São Paulo, São Paulo, 2004.

29. MOHAN LAL, D.; RENGANARAYANAN, S.; KALANIDH, A. Cryogenic treatment to augment wear resistance of tool and die steels. Cryogenics, v. 41, p. 149-155, 2001.

30. KAMODY, D. J. Using deep cryogenics to advantage. Advanced Materials and Processes, v. 10, p. 215-218, 1998.

31. KAMODY, D. J. Cryogenic Process Update. Advanced Materials and Processes, v. 6, p. h67-h69, 1999.

32. ZHANG, Z.; DELAGNES, D.; BERNHART, G. Microstructure evolution of hot work tool steels during tempering and definition of a kinetic law based on hardness measurements. Materials Science and Engineering A, v. 380, p. 222230, 2004.

33. DURAND-CHARRE, M. Microstructure of Steels and Cast Irons. [S.I.]: Springer, 2004.

34. NISHIYAMA, Z. Martensitic Transformation. [S.I.]: Academic Press, Inc., 1971.

35. CECH, R. E.; HOLLOMON, J. H. Rate of formation of isothermal martensite in Fe-Ni-Mn alloy. Journal of Metals, v. may, p. 685-689, 1953.

36. TAYLOR, K. A.; COHEN, M. Aging of ferrous martensite. Progress in Materials Science, v. 36, p. 225-272, 1992.

37. PORTER, D. A.; EASTERLING, K. E.; SHERIF, A. M. Phase Transformations in Metals and Alloys. 3a edição. ed. Boca Raton: CRC Press, 2009.

38. SILVA, P. F. et al. Determinação da fração volumétrica de austenita retida por meio de ensaio de saturação magnética de um aço AISI D2 tratado criogenicamente. Apresentado na IV Conferência Brasileira sobre Temas de Tratamento Térmico. Águas de Lindóia - SP: [s.n.]. 25 a 28 de abril de 2008. 
39. SILVA, P. F. et al. Efeito do alívio de tensões na estabilização da austenita antes do tratamento criogênico em um aço AISI D2. $64^{\circ}$ Congresso Anual da ABM. Belo Horizonte, MG: ABM. 13 a 17 de julho de 2009.

40. FARINA, P. F. S. et al. Effect of stress relief on the amount of retained austenite after cryogenic treatment and on the wear resistance of a tool steel. 11th International Conference on Advanced Materials. Rio de Janeiro: [s.n.]. 2009.

41. ROBERTS, G.; KRAUSS, G.; KENNEDY, R. Tool Steels. 5th ed. ed. [S.I.]: ASM International.

42. FARINA, P. F. S. et al. Microstructural Evolution of AISI D2 Tool Steel During Aging. Solid-Solid Phase Transformations in Inorganic Materials (PTM). Avignon - França: [s.n.]. 6 a 11 de junho - 2010.

43. SPEER, J. et al. Carbon partitioning into austenite after martensite transformation. Acta Materialia, v. 51, p. 2611-2622, 2003.

44. DE MOOR, E. et al. Dilatometric studyof the quench and partitioning process. The 3rd Internartional Conference on Advanced Structural Steels. Gyeongju, Korea: [s.n.]. August 22-24, 2006.

45. SPEICH, G. R.; LESLIE, W. C. Tempering of Steel. Metallurgical Transactions, v. 3, p. 1043-1054, 1972.

46. HIROTSU, Y.; NAGAKURA, S. Crystal structure and morphology of the carbide precipitated from martensitic high carbon steel during the first stage of temoering. Acta Metallurgica, v. 20, p. 645-655, 1972.

47. SPEICH, G. R. Tempering of low-carbon martensite. Transactions of the Metallurgical Society of AIME, v. 245, p. 2553-2564, 1969.

48. THOMSON, R. C.; MILLER, M. K. Carbide precipitation in martensite during the early stages of tempering $\mathrm{Cr}$ - and Mo-containing low alloy steels. Acta Materialia, v. 46, p. 2203-2213, n. 61998.

49. HAYAKAWA, M.; TANIGAMI, M.; OKA, M. Low temperature aging of the freshly formed martensite in an Fe-Ni-C alloy. Metallurgical Transactions A, v. 16A, p. p. 1745-1750, 1985.

50. PEREZ, M.; MASSARDIER, V.; KLEBER, X. Thermoeletric power appied to metallurgy: principle and recent applications. International Journal of Materials Research, v. 100, p. 1461-1466, out. 2009.

51. DONG, Y.; XIAOPING, L.; HONGSHEN, X. Deep cryogenic treatment of highspeed steel and its mechanisms. Heat Treatment of Metals, v. 3, p. 55-59, 1998. 
52. SILVA, P. F. et al. Efeito do alívio de tensões na estabilização da austenita antes do tratamento criogênico em um aço AISI D2. $64^{\circ}$ Congresso Anual da ABM. Belo Horizonte: ABM. 13 a 17 de julho de 2009.

53. RIDLEY, N.; STUART, H.; ZWELL, L. Lattice parameters of Fe-C austenites at room temperature. Transactions of the Metallurgical Society of AIME, v. 245, p. 1834-1836, agosto 1969.

54. FARINA, A. B. Modelagem termodinâmica de tratamentos térmicos. V Conferência Brasileira sobre Temas de Tratamento Térmico. Atibaia: [s.n.]. 25-28 de abril de 2010. Não publicado.

55. GORNI, A. G.; MEI, P. R. Equivalência entre tempo e temperatura durante o envelhecimento de aços HSLA e ULCB. $62^{\circ}$ Congresso Anual da ABM. Vitória - ES: ABM. 23-27 de julho de 2007. p. 3273-3279.

56. CANALE, L. C. F. et al. A historical overview of steel tempering parameters. Int.J. Microstructure and Materials Properties, v. 3, p. 474-525, 2008. 